\title{
Uruguayos mirando Chile: el problema de la unidad de la izquierda y el acceso al poder por la vía electoral (1956-1971)
}

\section{Lic. Jimena Alonso}

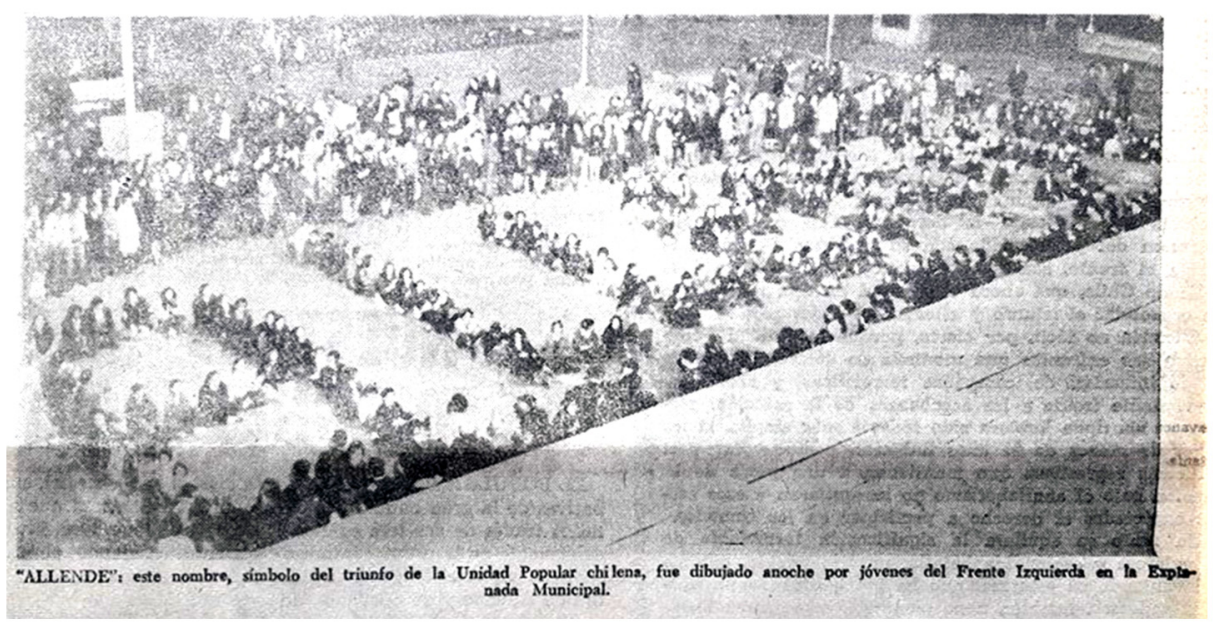

Tesis para optar por el título de Magíster en Historia y Memoria FaHCE - UNLP

Director: Dr. Aldo Marchesi, Udelar. Co- Directora: Prof. Ana Julia Ramírez, UNLP 
Contra los militantes del olvido, los traficantes de documentos, los asesinos de la memoria, contra los revisores de enciclopedia y los conspiradores del silencio (...), el historiador, el historiador solo, animado por la austera pasión de los hechos, de las pruebas, de los testimonios, que son los alimentos de su oficio, puede velar y montar guardia. (Yerushalmi, 1988, p. 25) 


\section{RESUMEN}

Los análisis referidos al proceso que culminó con la fundación del Frente Amplio, el 5 de febrero de 1971 en Uruguay, muestran una ausencia en la historiografía.

Por otro lado, de las pocas excepciones que encontramos, la mayoría se centra en un análisis de la coyuntura nacional, enmarcando el nacimiento de dicha coalición como producto de la necesidad de una alianza política común que sirviera de real oposición a las políticas represivas desplegadas por el gobierno de Jorge Pacheco Areco (1967-1972). Partiendo de tal análisis, el objetivo principal de este proyecto, se centra en aportar elementos para la comprensión del proceso que culminó con la unidad de la izquierda en Uruguay y la consiguiente fundación del Frente Amplio, pero que -sin desconocer las variables nacionalesaporte una mirada regional, que ilumine en la recepción que la experiencia del proceso de unificación de la izquierda chilena y fundamentalmente el triunfo electoral de la Unidad Popular, imprimieron en el recorrido de sus pares uruguayos. La propuesta, se enmarca entonces, dentro de los estudios basados en la transnacionalización de la política y las posibles zonas de contacto, que puedan detectarse entre procesos con características similares que se produjeron en la región.

Se parte de la premisa de que a partir del triunfo de la revolución cubana en 1959, diversos sectores de la izquierda latinoamericana, comenzaron a discutir la posibilidad de reeditar este modelo en sus diversos países. A partir de 1970, con el triunfo de Salvador Allende, aparece en la escena pública, otro camino para la revolución. Podríamos decir entonces, que, a partir de allí, se instalan en América Latina, dos caminos de acceso al poder, uno armado guiado por el camino de la revolución cubana y uno electoral, cuyo camino marcaba Chile. De esta manera, nos proponemos indagar en el proceso que llevó a la unidad de la izquierda en Uruguay, analizando cuál fue la influencia que el camino recorrido por la izquierda chilena, generó en dicho proceso, a partir de tres partidos claves y su vinculación con su par trasandino: el Partido Comunista, el Socialista y el Demócrata Cristiano.

Palabras clave: unidad de la izquierda, vía pacífica, Uruguay, Chile. 


\section{AGRADECIMIENTOS}

Esta tesis es el producto de un largo recorrido. En ese camino, conté con el apoyo de varias personas, sin las cuáles la tarea hubiera sido bastante más difícil.

En primer lugar, agradecer entonces, a mis directores -Aldo Marchesi y Ana Julia Ramírez- que orientaron, sugirieron y respetaron mis tiempos e idas y vueltas con este proyecto. Sin su apoyo y buena disposición, este trabajo no habría sido posible.

En segundo lugar, agradezco a la Maestría, no sólo por el enriquecimiento de sus seminarios, sino por la orientación, respuesta a miles de preguntas, y la buena disposición siempre. En su representación: Ana Barletta, Laura Lenci, Andrés Bisso, Fernanda Tocho, Belén Castro, Javier Guiamet, Emanuel Correa y Laura Codaro.

Al Programa de Pasantías en el Exterior, de la Comisión Sectorial de Investigación Científica de la Universidad de la República, que financió los pasajes, cuándo yo todavía vivía en Uruguay y viajaba semanalmente a cursar los seminarios.

A quienes en ese primer momento, eran mis compañeros de trabajo diario y apoyaron mis ausencias, en Decanato de la Facultad de Humanidades y Ciencias de la Educación: Álvaro Rico, Piero Bernasconi, Carolina Olhaberry, Fernanda Diab, Santiago Alzugaray, Pablo Ferreira, Lucas D'Avenia, Irene Taño y Andrea Carriquiry; y en la Secretaría de Derechos Humanos para el Pasado Reciente: Carla Larrobla, Fabiana Larrobla, Magdalena Figueredo y Mara Martínez.

Producto de una beca de la Agencia Nacional para la Investigación y la Innovación, pude realizar una estancia de investigación de poco más de dos meses en la ciudad de Santiago de Chile, clave para el relevamiento documental en dicho país. A ellos también mi agradecimiento. En Santiago, al Instituto de Estudios Avanzados de la Universidad de Santiago de Chile, quienes aceptaron recibirme y evacuar cientos de dudas durante mi estancia.

También a Alfredo Riquelme, de la Universidad Católica de Chile que mostró entusiasmo por mi incipiente proyecto y me brindó generosamente varios documentos clave. Esa generosidad lamentablemente no siempre existe en la academia.

A Carmen Norambuena y María Eugenia Horvitz, de la Universidad de Santiago de Chile y Universidad de Chile respectivamente, quienes también además de orientarme y responder dudas, me enseñaron que más allá de jerarquías académicas hay valores éticos que no se cruzan. Son ellas también faros guía. 
A los funcionarios del Archivo General Histórico del Ministerio de Relaciones Exteriores de Chile, que mostraron una disposición y paciencia asombrosa durante las horas que estuve consultando su repositorio.

A Viviana Corvalán y Juan Pablo Fuentealba, que me abrieron sin conocerme una buena parte de su historia familiar.

A Carla Peñaloza, colega y amiga, quién hizo que mi estadía en Santiago fuera tremendamente más sencilla. No sólo me orientó en lo que a la tesis se refiere, sino que también me abrió las puertas de su casa y de su familia, haciendo que mi extrañamiento uruguayo desapareciera. Segura de que este es el comienzo de varios proyectos en común, mi agradecimiento infinito.

En Uruguay también, a los miembros del Grupo de Estudios Interdisciplinarios sobre el Pasado Reciente y del Departamento de Historia Americana, con quienes tuve la oportunidad de discutir el proyecto y algunos avances del mismo. Sus aportes y guías, enriquecieron sin duda, este texto.

A Mariela Cornes y Álvaro Corbacho, del Archivo Histórico- Diplomático del Ministerio de Relaciones Exteriores uruguayo, con los que también compartí horas de trabajo. Sin su orientación, posiblemente seguiría sumergida en papeles.

A Alexandra Novóa y los demás miembros del Centro de Fotografía que buscaron aunque sin éxito- el original de la foto de tapa.

También a Raquel Sierra, de la Fundación Vivían Trías, que me acercó datos de contacto de varios de los entrevistados y me orientó sobre la documentación existente allí.

A Pablo Martínez Bengochea del Instituto Humanista Cristiano Juan Pablo Terra, por la importante labor de preservación documental, la apertura y el asesoramiento sobre la historia del Partido Demócrata Cristiano en Uruguay. Allí también a Chiara, que me abrió las puertas un verano y me envió cientos de documentos digitalizados. Su colaboración fue fundamental para que pudiera acceder a los mismos.

Gabriel Bucheli, Marisa Silva, Silvia Dutrenit y Martín Puchet, han evacuado consultas, sugerido lecturas y materiales en varias oportunidades. Al igual que Susana Dominzaín, que me contagió la pasión por Chile durante mi carrera de grado.

Particularmente a Olga Fernández y Jaime Secco, que me contactaron y me sugirieron varios datos de las personas que entrevisté. También allí, sin la enorme generosidad de ambos, varios de las historias personales que aquí se relatan estarían en el debe. 
A todos aquellos que me contaron sus historias, sus experiencias, sus emociones: Juan Trímboli, Guaraní Pereda, Carlos Baráibar, Carlos Pérez, Carlos Riverós, Eduardo Aparicio, Héctor Lescano, Jorge Mazzarovich, Jorge Rodríguez, José Díaz, José Luis Veiga, José Pereira, Julio Louis, María Elena Martínez, Mauricio Langón, Miguel Millán, Miguel Vasallo, Moriana Hernández, Luis Senatore, Roberto Markarián, y particularmente a Raúl Legnani, con quién lamentablemente no podré compartir los resultados.

Muchos amigos han soportado en todos estos años, mi obsesión por Chile. Con ellos intercambié miradas, lecturas y viajes: Javier Correa, Carla Larrobla, Magdalena Figueredo, Adriana Alfonso, Mariana Risso, Manuela Abrahan, Olga Fernández, Julia Córdoba, Soledad Iglesias y Virginia Faruelo. A ellos mis gracias infinitas.

En La Plata, a mis compañeros de Aletheia, con quienes compartí varias de las indagaciones de la tesis. También a Patricia Flier y los integrantes del proyecto "La historia reciente y los usos públicos del pasado: militancias, etnicidad y políticas de memoria desde/en América Latina", cuyos comentarios sin duda enriquecieron mis miradas.

En el último período a los compañeros del Centro de Investigaciones Socio Históricas (CISH), con quienes comparto horas de trabajo, discusiones varias y litros de mate. Desde el primer día, me sentí en casa.

En último lugar aquí, pero sin duda en el primero, a mis compañeros de cohorte, a quienes les agradezco: la enseñanza de aprender a transitar por las diagonales sin perderme, el aviso de los feriados para que no sacara pasajes, el envío de materiales por mail, la ayuda para poder hacer muchos trámites a la distancia, pero sobre todo por los mates (argentinos y uruguayos), los cafés (argentinos, colombianos y guatemaltecos), los almuerzos, las meriendas, las lecturas, los intercambios, las discusiones, las picadas, las cervezas, los viajes, los partidos de fútbol y los recibimientos en muchas casas... Allí a Lucía Abbattista, Florencia Basso, Elías Sánchez, Andrea Raina, Brenda Oliva, Vanesa Olmos, Virginia Sampietro. Y en los últimos años: Javiera Robles, Victoria Álvarez, René Hernández, Mariana Vila, Melina Jean Jean y Federico Brugaletta.

A mi familia, Beatriz, Alfredo, Horacio, Helena y Guillermo, quienes están siempre para alentar todos los caminos. 


\section{SIGLAS}

API: Acción Popular Independiente

CENCADEC: Centro de Capacitación de la Democracia Cristiana

CNT: Convención Nacional de Trabajadores

CUT: Central Única de Trabajadores

DC: Democracia Cristiana

FA: Frente Amplio

FAU: Federación Anarquista Uruguaya

FECH: Federación de Estudiantes de Chile

FEUU: Federación de Estudiantes Universitarios del Uruguay

FIdeL: Frente Izquierda de Liberación

FRAP: Frente de Acción Popular

FRENAP: Frente Nacional del Pueblo

GAP: Grupo de Amigos del Presidente

IC: Izquierda Cristiana

ILAES: Instituto Latinoamericano de Estudios Sociales

INDAP: Instituto Nacional de Desarrollo Agropecuario

IS: Internacional Socialista

JDC: Juventud Demócrata Cristiana

JJCC: Juventudes Comunistas de Chile

JUDCA: Juventud Demócrata Cristiana de América

MAC: Movimiento de Apoyo al Campesino

MAPU: Movimiento de Acción Popular Uruguaya / Movimiento de Acción Popular Unitario (en Chile)

MIR: Movimiento de Izquierda Revolucionaria

MLN-T: Movimiento de Liberación Nacional- Tupamaros

MPS: Medidas Prontas de Seguridad

MPU: Movimiento Popular Unitario

MRO: Movimiento Revolucionario Oriental

MUSP: Movimiento de Unificación Socialista Proletario

ODCA: Organización Demócrata Cristiana de América

OLAS: Organización Latinoamericana de Solidaridad

PCCh: Partido Comunista de Chile

PCU: Partido Comunista del Uruguay

PCUS: Partido Comunista de la Unión Soviética 
PDC: Partido Demócrata Cristiano

POS: Partido Obrero Socialista

PR: Partido Radical

PS: Partido Socialista

PSCh: Partido Socialista de Chile

PSP: Partido Socialista Popular

UJC: Unión de la Juventud Comunista

UP: Unión Popular (en Uruguay) / Unidad Popular (en Chile)

USOPO: Unión Socialista Popular

UTAA: Unión de Trabajadores Azucareros de Artigas

VRM: Vanguardia Revolucionaria Marxista 


\section{INDICE}

Resumen

p. 1

Agradecimientos

p. 2

Siglas

p. 5

Índice

p. 7

\section{Introducción}

$\begin{array}{ll}\text { 1.1. Presentación del tema } & \text { p. } 9\end{array}$

$\begin{array}{ll}\text { 1.2. Metodología y corpus documental p. } 13 & \text { p. }\end{array}$

1.2.1. La perspectiva transnacional p. 14

$\begin{array}{ll}\text { 1.2.2. Corpus documental p. } 19 & \text { p. }\end{array}$

1.3. Marco teórico p. 22

$\begin{array}{ll}\text { 1.4. Estado de la cuestión } & \text { p. } 26\end{array}$

$\begin{array}{ll}\text { 1.5. Los capítulos } & \text { p. } 31\end{array}$

2. Crece desde el pie: la recepción del comunismo chileno en su par uruguayo (1956-1967)

2.1. Uruguayos en Chile y chilenos en Uruguay: los momentos

de encuentro

p. 37

2.2. El carácter de la revolución: de la etapa "democrático burguesa"

a la "democrática nacional"

p. 41

2.3. Construyendo alianzas amplias

p. 44

2.3.1. Del "Frente de Liberación Nacional" al "Frente Democrático de Liberación Nacional": la alianza con la burguesía nacional

p. 44

2.3.2. El primer paso: la alianza socialista- comunista. Las enseñanzas del FRAP en Chile

p. 47

2.3.3. "Señores: jesto que iniciamos es una revolución!”: el

nacimiento del Frente Izquierda de Liberación (FIdeL)

p. 56

2.4. El camino: lucha de masas

p. 62

2.5. El problema de las vías: "el camino menos doloroso de transición al socialismo"

p. 66

2.5.1. "Prepararse para cualquier forma de lucha": la necesidad de un aparato armado

p. 74

2.6. Algunas apreciaciones finales

p. 77

\section{Socialismo o Miseria: la recepción del socialismo chileno en su par uruguayo}

3.1. Socialistas en Chile y Uruguay: los puntos de encuentro

3.1.1. Una experiencia de trabajo conjunto: El Secretariado

Latinoamericano de la Internacional Socialista

p. 90

3.2. El carácter de la revolución: de la "Revolución Democrática de

Trabajadores" a la "Revolución Nacional y Popular".

p. 93

3.3. Disyuntivas en torno a la unidad

3.3.1. Del "Frente de Trabajadores" al "Frente Nacional y

Popular.: el problema de la alianza con la burguesía nacional

p. 98

3.3.2. La alianza con el comunismo y las enseñanzas del FRAP

en Chile

3.3.2.1 El rechazo a la alianza con el comunismo en Uruguay

p. 100

p. 102

3.3.3. La Unión Nacional y Popular

p. 105

p. 107

3.4. El camino: entre el respeto a la legalidad y la vía armada

3.4.1. La santa violencia de los de abajo: de la derrota electoral 
3.4.2.1. Militantes socialistas en acciones armadas. De

"El Coordinador" al "Congreso de Chillán"

p. 118

3.4.2.2. Socialistas uruguayos y chilenos en la OLAS

p. 125

3.5. Algunas apreciaciones finales

4. Como en Chile, Democracia Cristiana: la recepción de la democracia cristiana chilena en su par uruguayo (1958-1967)

p. 130

4.1. Cristianos en Chile y Uruguay: puntos de encuentro

p. 137

4.1.1. La Organización Demócrata Cristiana de América

p. 141

4.2. El carácter de la revolución: cristiana, democrática y en libertad

p. 143

4.3. Las alianzas: el "camino propio" y las dificultades de un acuerdo con la izquierda

4.3.1. El "camino propio" en Uruguay: ni liberalismo, ni marxismo (1962)

4.3.2. La recepción de la campaña electoral de Frei en Uruguay (1963-64)

4.4. "América del mañana, Democracia Cristiana": los primeros años de

4.5. El camino: la vía no capitalista de desarrollo y el socialismo comunitario

5.1.1. Los últimos años del gobierno de Frei: la Democracia

5.2. El avance del autoritarismo en Uruguay y la recepción de los sucesos chilenos (1968-1970)

5.2.1. "Habia llegado la revolución": la recepción en

Uruguay del triunfo de Allende

5.3. Hermano no te vayas, ha nacido una esperanza: la fundación del Frente Amplio

5.5. Algunas apreciaciones finales 


\section{Introducción}

\subsection{Presentación del tema}

La noche del 4 de setiembre de 1970, los jóvenes comunistas, socialistas y democratacristianos uruguayos, se reunieron en la Explanada de la Intendencia de la ciudad de Montevideo, por la principal avenida de la ciudad y uniformados con sus camisas rojas, verdes y naranjas respectivamente formaron la palabra "Allende". Festejaron la derrota de la derecha chilena, y el triunfo de una coalición electoral de izquierdas, que por la vía pacífica mostraba que la revolución tenía otros caminos. Entre octubre y diciembre de ese mismo año, se aceleran las negociaciones y los pronunciamientos de los diversos sectores de la izquierda, que el 5 de febrero de 1971 darán nacimiento en Uruguay al Frente Amplio (FA) ${ }^{1}$.

Mi interés por el proceso político chileno surgió en los últimos años de mi carrera de grado en Uruguay, cuándo realicé una pequeña investigación sobre el exilio tupamaro durante el gobierno de Salvador Allende (1970- 1973). El proceso de avance del autoritarismo en Uruguay comenzó varios años antes de consumado el golpe de Estado del 27 de junio de 1973. La presidencia de Jorge Pacheco Areco (1968-1972) y luego la de Juan María Bordaberry (1972-1973), se caracterizaron por la instalación de las Medidas Prontas de Seguridad $^{2}$ y por la pérdida de las libertades individuales. El aumento de detenidos por razones políticas se acrecienta considerablemente en este período; razón por las cual varios de los militantes que se encontraban requeridos optan por salir del país. Sumado a estos, llegan varios detenidos que haciendo uso de la opción constitucional ${ }^{3}$, eligen Chile como lugar de destino, fundamentalmente luego de la asunción de la Unidad Popular el 3 de noviembre de 1970. Desde fines de ese año y hasta el golpe de Estado de setiembre de 1973, Chile se convirtió en el lugar de privilegio del exilio uruguayo.

\footnotetext{
${ }^{1}$ Ver foto de tapa y relato de Jorge Mazzarovich en p. 208. La fotografía es de Aurelio González, publicada en el diario comunista El Popular el 06.09.1970.

${ }^{2}$ La disposición constitucional, habilitaba la instalación de Medidas Prontas de Seguridad (MPS) en: "casos graves e imprevistos de ataque exterior o conmoción interior, dando cuenta dentro de las 24 horas a la Asamblea General (...) o en su caso, a la Comisión Permanente, de lo ejecutado y sus motivos, estándose a lo que estas últimas resuelvan". (Nahum y otros, 1990, p. 60). Entre el 13 de junio de 1968 y 1971, se vivió bajo el régimen permanente de MPS, con excepción de solo tres meses, entre el 15 de marzo y el 24 de junio de 1969. En ese período, la Asamblea General fue citada 83 veces para suspender las MPS, no logrando en todas esas ocasiones el quórum mínimo de funcionamiento.

${ }^{3}$ El inciso 17, del artículo 168 de la Constitución uruguaya permite a los detenidos bajo el régimen de Medidas Prontas de Seguridad, la opción de optar por salir del país.
} 
Finalizada dicha investigación, mantuve la inquietud de saber qué había sucedido en este período con el resto de la izquierda uruguaya, fundamentalmente la no armada, y cómo habían vivido esa experiencia. Con esa primera curiosidad ingresé a la Maestría. Realizando las primeras lecturas y con el aporte de varios de los seminarios cursados, detecté una primera información evidente: si bien la izquierda legal fue reprimida ya desde 1968, con detenciones a sus militantes, allanamientos de sus locales, y el asesinato de varios de ellos en manifestaciones callejeras, la salida del país de estas organizaciones no comenzó hasta luego de consumado el golpe de Estado.

Sin embargo, de la lectura de la prensa partidaria, se podía detectar claramente que el seguimiento de los sucesos políticos chilenos tenía radical importancia para la izquierda uruguaya. Y fundamentalmente, a partir de 1970 con el triunfo de Salvador Allende, cuándo se concretó la posibilidad de que la izquierda unificada en una alianza -por lo menos únicamente electoral- pudiera acceder al gobierno.

Y ahí se sumó otro de los focos de interés, la fundación del Frente Amplio en febrero de 1971. Me resultó llamativo, por ejemplo, que el llamado para la constitución de dicha colectividad política fuera un mes después del triunfo electoral de Allende y en medio de las discusiones entre la Unidad Popular (UP) y la Democracia Cristiana (DC) para su apoyo en el Congreso Nacional chileno ${ }^{4}$. Si tomamos en cuenta que los intentos de unidad de la izquierda en Uruguay venían planteándose desde mediados de la década del 50' aunque sin logros, podríamos pensar que el triunfo de la UP en Chile constituyó un incentivo para la consolidación de la fundación de una fuerza de izquierda común en Uruguay.

Realizando las tareas mismas de investigación, se me fue ampliando el marco cronológico con el que debía trabajar. Si bien el punto de partida fue 1970, a medida que me iba acercando al tema la necesidad de ir para atrás y ver en ambos casos cómo se había llegado a ese contexto fue inevitable. Es decir, ¿cómo había logrado la izquierda chilena unificarse y ganar las elecciones? Claramente, no era un acontecimiento que se hubiera producido mágicamente en 1970; pero también qué había sucedido con la izquierda uruguaya para que finalmente accediera a aliarse pocos meses después.

De esta manera, establecimos como marco temporal el período 1956-1971, partiendo de dos acontecimientos claves: la fundación del Frente de Acción Popular (FRAP) en Chile, constituyendo una importante alianza entre socialistas y comunistas, que por poco margen casi acceden al gobierno en las elecciones nacionales de 1958 y en ese mismo año se produce

\footnotetext{
${ }^{4}$ Como veremos, la Constitución chilena de la época establecía que, si un candidato no lograba la mayoría absoluta, en lugar de realizar un balotaje, el ganador lo elegía el Congreso entre las dos primeras minorías.
} 
en Uruguay, la primera convocatoria del Partido Comunista del Uruguay (PCU) a formar una alianza con el Partido Socialista (PS). El final del período está marcado por el triunfo de Salvador Allende el 4 de setiembre de 1970, su repercusión en Uruguay y la fundación del Frente Amplio el 5 de febrero de 1971.

El objetivo entonces de este trabajo es aportar elementos para la comprensión del proceso que culminó con la unidad de la izquierda en Uruguay y la consiguiente fundación del FA. Pero que, sin desconocer las variables nacionales, aporte una mirada regional que ilumine la influencia que la experiencia del proceso de unificación de la izquierda chilena y fundamentalmente el triunfo electoral de la Unidad Popular, imprimieron en el recorrido de sus pares uruguayos.

Para ello veremos, la manera en que los acontecimientos políticos y los desarrollos teóricos realizados por la izquierda en Chile fueron recepcionados en Uruguay, tomando como eje central los tres partidos de la izquierda articuladores de la coalición: el Partido Comunista, el Partido Socialista, y el Demócrata Cristiano y los vínculos con sus pares chilenos.

No debemos dejar de señalar que el objetivo central no es la realización de un estudio comparativo que de cuenta de elementos comunes o diversos de los procesos de unificación en ambos países. Sino que, partiendo de la experiencia chilena y de su recepción en Uruguay, nos proponemos aportar en el proceso que culminó con la fundación del Frente Amplio. Es decir, reflexionar si el triunfo de Salvador Allende, un candidato socialista, con un claro perfil marxista, que logra el acceso al gobierno a través de las elecciones, constituyó un impulso final que mostró que ese camino también era posible.

Desde este punto de vista, nos propusimos indagar en las siguientes líneas:

1. Las crónicas en la prensa uruguaya de izquierda acerca de la posible victoria del FRAP. Elecciones de 1958 y 1964.

2. El proceso de fundación de la UP en la prensa uruguaya de izquierda.

3. El impacto del proceso político chileno en los diversos sectores de la izquierda uruguaya.

3.1. Los comunistas y la transición pacífica al socialismo.

3.2. Los socialistas debaten sobre las vías en ambos países.

3.3. La democracia cristiana: el viraje hacia la derecha en Chile y el viraje hacia la izquierda en Uruguay. El problema de la coalición con partidos marxistas.

4. El triunfo de Allende y los quiebres en la DC chilena. 


\subsection{Sus repercusiones en la fundación del Frente Amplio.}

4.2. Las elecciones de 1971 en Uruguay.

La idea que guía la investigación es que, así como la revolución cubana en 1959 mostró la posibilidad del triunfo revolucionario a través de la guerrilla o la vía armada; el triunfo de Allende en 1970 constituyó un nuevo camino revolucionario. Los frentes electorales, fueron para varios grupos que no compartían la estrategia del uso de las armas, otra vía para por otros medios, lograr los mismos objetivos ${ }^{5}$. El triunfo chileno, concretará entonces esta posibilidad y será ejemplo para el resto de la izquierda latinoamericana.

El mismo 5 de setiembre, -al día siguiente del triunfo de Allende- Edward Korry (Embajador norteamericano en Chile desde 1967), remite un informe a la Casa Blanca, en la que señala que "Chile votó con calma para tener un estado marxista-leninista, la primera nación del mundo en hacer esa elección libremente (...). Tendrá un efecto muy profundo en América Latina y el resto del mundo, hemos sufrido una grave derrota (...)" (Amorós, 2013, p. 288). En diciembre de 1970, el New York Times, analizaba las elecciones chilenas y auguraba "consolidando el acceso del marxismo al gobierno de Chile, sólo resta adivinar en cuál de los países vecinos intentarán las fuerzas de izquierda, repetir la experiencia." (Rodríguez, 2016, p. 236)

Jorge Lanzaro, señala que

de hecho, se abre aquí un contrapunto, entre las tesituras que se acercan más al modelo de la Revolución Cubana y las que se asemejan al modelo chileno, a través de una vía alternativa que plasma allí en la formación de la Unidad Popular y que en nuestras tierras viene a encarnar el FA. (2004, p. 36).

En este mismo sentido, Arturo Valenzuela señala que

el triunfo de Allende captó la atención internacional, (...) porque el nuevo gobierno prometía realizar sus transformaciones revolucionarias dentro del marco constitucional y legal chileno. (...). En un contexto histórico diferente, Chile sería el pionero en establecer un segundo modelo para la construcción de una sociedad socialista, un modelo basado no en la destrucción violenta del orden antiguo, sino en su reemplazo pacífico de acuerdo con su tradición democrática, pluralista y libertaria. (1989, p. 127)

\footnotetext{
${ }^{5}$ Dedicatoria de Ernesto Guevara a Salvador Allende, cuándo luego de un encuentro le regala su libro Guerra de guerrillas, a comienzos de 1960.
} 
Las preguntas que guiaron la investigación fueron: ¿Cuál fue la recepción de la experiencia chilena de unificación de las izquierdas en Uruguay? ¿Qué elementos del proceso chileno fueron tomados en Uruguay como modelo a seguir?; ¿Cómo impactó en la izquierda uruguaya la construcción del FRAP? ¿Qué valoración se hizo de las elecciones de 1958 y 1964, dónde casi se vislumbra el triunfo electoral de este sector?; ¿Cuál fue la recepción del gobierno de Eduardo Frei en la izquierda uruguaya?; ¿Cómo se vio el triunfo de la UP en la prensa uruguaya de izquierda?; ¿Cuáles fueron los debates a la interna de los tres partidos (socialistas, comunistas y demócratas cristianos) en Uruguay? ¿Cuáles fueron los intercambios con su par chileno?; ¿Qué elementos se incorporaron para el proceso uruguayo? ¿Y cuáles no?

\subsection{Metodología y corpus documental}

Las particularidades del objeto de investigación requieren del auxilio de recursos metodológicos amplios y la combinación de fuentes variadas. En este sentido se considera fundamental tomar aportes de diversas corrientes emanadas tanto de las ciencias políticas como de los diversos trabajos historiográficos, que den cuenta en primer lugar de las características principales del sistema de partidos en Uruguay, así como del contexto de crisis en el que se produjo la unificación de las fuerzas de izquierda.

Para el desarrollo de la investigación se recurrió a una estrategia metodológica múltiple, que reuniera los modos de trabajo de archivo habituales en el campo historiográfico con el trabajo de campo propio de la investigación social cualitativa, a partir de la realización de entrevistas a los participantes de dichos procesos. En este sentido, creemos que los aportes de la historia oral son fundamentales para poder integrar insumos, que de otra forma no podríamos acceder, como la subjetividad del protagonista o el recuerdo de determinados acontecimientos que no fueron registrados por los documentos escritos.

Se aplicó una metodología cualitativa que permitió el abordaje de conjuntos documentales variados, considerando las entrevistas orales pero a la vez, vinculando su análisis con distintos materiales presentes en los diversos archivos documentales. Se trata de una metodología que permita acceder tanto a la información sobre los acontecimientos como a las interpretaciones que los actores tienen de los mismos. En este sentido se combinarán tres áreas fundamentales: la historia oral junto con la observación documental y la perspectiva transnacional. 


\subsubsection{La perspectiva transnacional}

(...) la historiografía uruguaya (...) ha estado muy anclada a su realidad local y eso no le ha permitido mirar a su alrededor para ver cuánto de sus procesos políticos han estado relacionados a procesos de circulación de ideas y personas más allá de las fronteras nacionales. (Marchesi y Yaffé, 2010, p.109)

América Latina, se presta quizás como ningún otro espacio geográfico, para desarrollar un enfoque analítico que aborde las interacciones e intercambios, desde una mirada que se replantee las fronteras y la nación. Siendo un espacio tradicional, de recepción de sujetos, proyectos e ideas, esta perspectiva beneficia sin duda, los enfoques que trascienden la concepción de la región como un "punto de llegada" o simplemente como la "periferia".

No se trata de poner en duda el interés de estudiar los espacios estatales o nacionales, sino que se trata de entender fenómenos que parten de la interacción o el intercambio de varios grupos nacionales o naciones. En este mismo sentido, podemos tomar los fundamentos del historiador chileno Fernando Purcell cuando señala que

se hace necesario hoy superar lo que el historiador francés Gérard Noiriel ha denominado "la tiranía de lo nacional". Esta tiranía ha acercado a la mayoría de los historiadores en el mundo a un trabajo basado en marcos de análisis sumamente estrechos que han llevado a la construcción de murallas imaginarias que han separado las historias nacionales en vez de vincularlas. (Purcell y Riquelme, 2009, p. 9)

Bárbara Weinsten, señala que podríamos establecer como un buen comienzo para las investigaciones basadas en esta perspectiva, la publicación en 1998 de dos libros coordinados por latinoamericanistas, que adoptaron un enfoque transnacional. El primero de ellos, “Activist beyond borders: advocacy networks in international politics"-, escritos por Margaret Keck y Kathryn Sikkink, es un estudio de los movimientos sociales transnacionales (fundamentalmente los vinculados a la protección del medio ambiente y los derechos humanos). A partir de estos movimientos, las autoras, lograron identificar un largo recorrido común de intercambio y colaboración entre ellos, antes pensados como limitados a su acción nacional. El segundo libro, "Close encounters of Empire: writing the Cultural History of USLatin American relations", editado por Gilbert Joseph, Catherine LeGrand y Ricardo Salvatore, si bien no está identificado como una obra claramente transnacional, las preocupaciones del mismo se combinaron para realizar un programa de renovación de la 
historia de las relaciones internacionales a través de esta perspectiva. De hecho, uno de los principales aportes lo constituye la propuesta de cambiar la mirada de las relaciones internacionales de la esfera puramente política o diplomática, e incorporar los intercambios cotidianos fundamentalmente en el campo cultural. La segunda propuesta realizada por estos autores es que los investigadores deben buscar en las "zonas de contacto", que no son necesariamente físicos o geográficos (aunque pueden serlo), sino que también incluye a las "comunidades de conocimiento", a los encuentros a nivel cultural y político. Por último, señalan que las relaciones interamericanas no pueden ser pensadas en un sentido único, es decir, que rechazan la visión que identifica un único punto de origen de una idea y un proceso de “irradiación" a partir del cual comenzará a penetrar en nuevas zonas y se resaltan justamente los contextos de circulación.

No es menor subrayar, que, si bien el impulso de los estudios basados en la perspectiva transnacional surgió de los cuestionamientos intelectuales de los latinoamericanistas norteamericanos, rápidamente se difundió más allá de las fronteras de la región y más allá de los estudios históricos, siendo tomado por investigadores de muchas otras áreas. De hecho, tanto los que señalan los orígenes de esta perspectiva en 1990, como aquellos que enfatizan su consolidación hacia finales de la década, coinciden en la vinculación entre el desarrollo de la perspectiva transnacional y los estudios sobre la globalización y los análisis comparativos.

Si de los primeros la perspectiva transnacional ha cuestionado la noción de modernización, el carácter unidireccional de las transformaciones y el efecto homogeneizador de los procesos globalizadores, frente a los segundos ha dejado en evidencia un tratamiento de la nación como fenómenos homogéneos y a-históricos. (Abbattista y Starcenbaum, 2013, p. $1-2)$.

Por otro lado, es necesario señalar, que el grupo conocido como Subaltern Studies, integrado por investigadores hindúes, ya venía proponiendo este tipo de análisis. El historiador, Dipesh Chakrabarty planteaba que la mirada del historiador no debía restringirse el espacio nacional, ya que existen contactos constantes entre culturas y sociedades.

En este sentido, María Ligia Coelho Prado, señala que la historia transnacional no está cerrada a ningún área de investigación en particular, sino que puede aplicarse a la historia política, a la cultural, la intelectual o la empresarial. Para Isabel Hofmeyr,

la clave para entender el enfoque de la Historia Transnacional la constituye la preocupación central por movimientos y circulaciones. El método transnacional debe construirse en el 
movimiento entre lugares y regiones, y no únicamente en el estudio de los procesos históricos que tienen lugar en diferentes lugares. (Coelho Prado, 2011-2012, p.19).

Si bien, las investigaciones basadas en esta perspectiva son relativamente recientes, en la actualidad se están desarrollando una multiplicidad de trabajos que incorporan esta mirada. Se hace imposible referir a todos ellos, como ejemplos o antecedentes historiográficos de investigaciones constituidas a la luz de este enfoque. Igualmente, daremos cuenta de algunas de las investigaciones que se han desarrollado en los últimos años, que han contribuido a pensar en diversas problemáticas que trascienden un enfoque exclusivamente nacional. Así podemos tomar los trabajos de: Ariel C. Armony (2004), Fernando Purcell y Alfredo Riquelme (2009), Patrick Barr-Melej (2009), Raffaele Nocera (2009), Fernando Pedroza (2011), Alessandro Santoni (2011) y con un enfoque más centrado en lo latinoamericano podemos ubicar los trabajos de Aldo Marchesi (2009 y 2012), Leandro Sessa (2013) y Roberto Pittaluga (2015).

El capítulo de Ariel Armony, "Transnacionalizando la guerra sucia: Argentina en Centroamérica", forma parte de un estudio más amplio sobre la Guerra Fría y su proyección en México, América Central y el Caribe. Esta obra, dedica su última parte a presentar dos casos de la transnacionalización de la Guerra Fría a partir de la proyección de la Unión Soviética en América Latina y de Argentina en Centroamérica, fundamentalmente la acción de las fuerzas represivas argentinas en la acción contrainsurgente aplicadas en un primer momento en Nicaragua, y luego en El Salvador, Guatemala y Honduras. Elegimos este último, justamente para visualizar los contactos o la influencia de dos procesos ocurridos ambos en regiones latinoamericanas. De esta manera, lo que el autor denomina como la cruzada anticomunista argentina, fue un paso fundamental, en la creación de zonas de colaboración y contacto con distintos tipos de formalización. Estas zonas de contacto no están ubicadas en un territorio específico, sino que constituyen espacios de intercambio y circulación tanto de ideas como de recursos y vínculos.

Fernando Purcell y Alfredo Riquelme son los editores de una investigación, que incluye los trabajos de Raffaele Nocera y Patrick Barr-Melej, cuyo objetivo es "potenciar en forma colectiva la multiplicidad de miradas con las que podemos observar la historia de Chile en su intersección con lo regional y lo global” (2009, p.13). En su Introducción, enmarcan el trabajo dentro de las corrientes que intentan romper con las historias nacionales y levantar la mirada a una investigación que ubique a Chile en un marco global. En el artículo de Raffaele Nocera, "Italia y América Latina: una relación de bajo perfil, 1945-1965. El caso Chile”, el 
autor indaga en los vínculos políticos para intentar ubicar el papel del país andino en el marco de la Guerra Fría. Si bien señala, que América Latina no fue un asunto de máximo interés para la política exterior italiana, las relaciones político-partidarias se vieron fortalecidas en la década de 1960, sobre todo para los sectores vinculados a las Democracias Cristianas. Nocera, explica que esta cercanía tendrá su eco luego tanto bajo el gobierno de Salvador Allende, como luego de su derrocamiento y durante la instauración de la dictadura militar de Augusto Pinochet.

El artículo de Patrick Barr-Melej, centra su atención en el fenómeno del hippismo chileno, ubicándolo dentro de un contexto de conexiones y corrientes culturales más amplias, de carácter transnacional. A partir del caso del festival de Piedra Roja realizado en 1970, inspirado en el recital de Woodstock en 1969, el autor analiza varios de los temas asociados con la contracultura, el pelo largo, la liberación sexual, el consumo de drogas y como estos ingresaron al debate chileno, mostrando -justamente- el poder de las tendencias culturales transnacionales.

El trabajo de Fernando Pedroza, "La otra izquierda. Las estrategias de la socialdemocracia europea en América Latina, 1951-1971”, tiene como objetivo mostrar los diversos planes utilizados por la Internacional Socialista para aumentar su influencia en la región (cuyo predominio estaba dado tanto por la URSS como por Cuba) durante el período señalado. El trabajo se centra en demostrar que la historia de la izquierda en América Latina debe incorporar a la socialdemocracia europea como un actor relevante fundamentalmente en los años 1950-1960. Tal como su autor señala, "se buscó aportar otra visión sobre la cuestión, mostrando la actividad llevada adelante por las organizaciones y líderes socialdemócratas europeos (...) y las consecuencias que estas relaciones transnacionales han tenido en los procesos políticos de la región" (2011, p.135).

La investigación de Alessandro Santoni, "El comunismo italiano y la vía chilena", es quizás la referencia clave para la tesis que nos proponemos. Allí, el autor analiza justamente la recepción que el Partido Comunista Italiano (PCI) realiza de los acontecimientos sucedidos en Chile: las tensiones a la interna del Partido Comunista y su repercusión en Italia, la Unidad Popular como ejemplo exitoso para la alternativa de gobierno, las tensiones durante el gobierno de Allende, las discusiones que estos procesos van generando en el PCI (y su distanciamiento con la política chilena), y luego del golpe militar finalmente el apoyo a la causa de los exiliados.

Los dos trabajos de Aldo Marchesi: "Geografías de la protesta armada: nueva izquierda y latinoamericanismo en el cono sur. El ejemplo de la Junta de Coordinación 
Revolucionaria" del año 2009 y "La partida decisiva de la revolución en América Latina. Militantes bolivianos, chilenos y uruguayos en la Argentina peronista. Buenos Aires, 19731976" del año 2012. En el primero de los trabajos, el autor selecciona el recorrido de un militante del MLN-T -Enrique Lucas López- para mostrar los intercambios y las relaciones que se daban entre los diferentes grupos armados que actuaban en el cono sur a fines de los años $60^{\prime}$ y principios de los 70' (que finaliza en la concreción de la Junta de Coordinación Revolucionaria), así como ilumina sobre el carácter regional que las luchas de estos movimientos adquirieron. El autor muestra los diversos intercambios y relaciones que se dieron entre estos grupos más allá de los diferentes contextos nacionales y que hace posible estudiar estos vínculos como un objeto de estudio en sí mismo. Claramente Marchesi señala "que el presente artículo busca contribuir a pensar el fenómeno de la izquierda armada más allá de fronteras nacionales". (2009, p. 43). En el segundo trabajo, se dedica especialmente a analizar el recorrido de estos militantes y sus vinculaciones en Argentina entre 1973-1976, único gobierno democrático de la región, luego de ocurridos los golpes de Estado en Uruguay y Chile. El artículo se centrará en analizar por un lado, las visiones de estos militantes acerca del proceso político que se estaba desarrollando en Argentina, y a la vez, las discusiones internas que se generaron en estos grupos (MLN- T uruguayo, MIR chileno, ELN boliviano y PRT argentino) a partir de lo ocurrido en Chile y las estrategias a seguir en América Latina. Es inevitable señalar, como estos acontecimientos externos ocurridos a nivel regional, finalmente determinan o influencian las diversas estrategias de las luchas locales. Este análisis se perdería, si el autor, se hubiese centrado exclusivamente en el estudio de los casos nacionales sin tomar en cuenta estas interacciones.

La tesis doctoral de Leandro Sessa, "Aprismo y apristas en la Argentina. Derivas de una experiencia antiimperialista en la "encrucijada" ideológica y política de los años treinta", analiza la recepción de la experiencia peruana de la Alianza Popular Revolucionaria Americana (APRA) en la Argentina de los años 30'. Siendo este país, uno de los escenarios del exilio aprista en esos años, el autor se propone reconstruir sus redes e indagar en quienes mostraron interés en conformar un frente político para enfrentar al imperialismo, "como una forma de acercarse a definir el lugar del antiimperialismo latinoamericano" (2013, p. 14). De esta manera, el aporte más relevante de la investigación es la vinculación entre esta experiencia exiliar y la reconstrucción de iniciativas políticas inspiradas en el aprismo, pero llevadas adelante por militantes argentinos.

En el año 2015, Roberto Pittaluga ha publicado una profunda investigación -producto también de su tesis doctoral- titulada: "Soviets en Buenos Aires: la izquierda de la Argentina 
ante la revolución en Rusia", en la cuál reconstruye las transformaciones que dicho acontecimiento provocó en la izquierda argentina: sus tramas conceptuales, su identidad, sus imaginarios y sus representaciones. El objetivo entonces fue reconstruir como los sucesos ocurridos en Moscú en 1917, y su recepción en Argentina, provocaron un giro identitario en varias de las organizaciones de izquierda; pero además dar cuenta, de la dimensión transnacional de dichas representaciones sobre la Revolución Rusa y cómo estas fueron leídas en Buenos Aires.

Si bien la mayoría de estas investigaciones en sentido estricto, no tienen que ver con el análisis aquí propuesto, revisarlas fue un aporte necesario tanto desde el punto de vista metodológico como de escritura de la tesis. Vincular los tres partidos con su correlato chileno en un período medianamente extenso de tiempo, no fue tarea sencilla para plasmar en papel.

\subsubsection{Corpus documental}

Las fuentes utilizadas en esta investigación son variadas, debido principalmente a que el Frente Amplio no cuenta con un archivo propio que rescate la historia del mismo durante este período. Sí contamos con repositorios propios de cada uno de los partidos integrantes de la coalición que fueron analizados. En los tres casos el corpus documental central fue la prensa partidaria de la época.

Debido fundamentalmente al avance represivo, en varios casos, los diarios y semanarios de la izquierda transitaron por diversos períodos de censura. Algunos de días otros por fases más largas, esto provocó que debieran emitirse con otros nombres y otras autoridades y sin vinculación orgánica y explícita con el partido de origen. En este sentido, analizamos: El Popular (1956-1971), vinculado al Partido Comunista; El Sol (1956-1967), Izquierda (19681969) y El Oriental (1969-1973), para el Partido Socialista y El Ciudadano (1962-1964), De Frente (1965-1967), Flecha (1968-1973), para el Partido Demócrata Cristiano. En este último caso, las transformaciones en su prensa, no se debieron únicamente a censuras del gobierno, sino que también fueron producto de los giros de su política interna, tal como veremos en el capítulo respectivo.

Por otro lado, incluimos la Revista Estudios, del PCU, que estaba dedicada exclusivamente a la formación teórica de los militantes. Sus artículos son densos, escritos por los principales teóricos del comunismo, tanto a nivel nacional como internacional. El seguimiento a los sucesos soviéticos, fundamentalmente a partir de la "desestalinización" de 
1956, y durante todo el período, resulta casi agobiante. Y también la Revista Encuentro, publicada por la Juventud Demócrata Cristiana (JDC), entre 1969 y 1973.

La prensa escogida como corpus clave para la tesis, fue seleccionada con el criterio de utilizar aquella exclusivamente partidaria, con información orgánica y para la formación de sus militantes. Quedaron por ello excluidas tanto Marcha como Época, ya que ambas respondían a colectivos más heterogéneos de la izquierda.

Lamentablemente a la Fundación Rodney Arismendi, que tiene en su custodia varios documentos del PCU de utilidad para esta investigación, fue imposible acceder luego de realizar varias gestiones sin ninguna respuesta. En la Fundación Vivían Trías no existe archivo propiamente dicho, sí pudimos acceder a algunos números de la prensa socialista que no se encuentran en los repositorios estatales, así como el vínculo con varios militantes de la época.

La Democracia Cristiana uruguaya cuenta con una joya casi desconocida. El Instituto Humanista Cristiano Juan Pablo Terra, posee una profusa biblioteca sobre los desarrollos teóricos de la Democracia Cristiana, tanto uruguaya como chilena, y está en proceso de ordenamiento y digitalización de los documentos del archivo privado de Juan Pablo Terra al que pudimos acceder. Varios de esos documentos se encuentran además publicados en cinco tomos sobre la historia de la DC uruguaya, desde varias perspectivas de análisis. Para este caso, contamos además con acceso al archivo privado del ex Senador, Carlos Baráibar, joven militante demócrata cristiano en la etapa analizada.

También consultamos en la Facultad de Humanidades y Ciencias de la Educación en Uruguay el Archivo de Propaganda Política, dónde pudimos ubicar algunos de los elementos de las campañas electorales desarrolladas por la izquierda uruguaya, fundamentalmente en los comicios de 1966 y 1971.

En Buenos Aires, en el Centro de Documentación e Investigación de la Cultura de Izquierdas (CeDInCI) ubicamos los Boletines del Secretariado Latinoamericano de la Internacional Socialista, que durante el período analizado tuvo sede en Montevideo. Su ubicación -que no encontramos en Uruguay- fue clave para rastrear esta experiencia conjunta del socialismo latinoamericano.

Por otro lado, examinamos los documentos diplomáticos existentes tanto de la Embajada de Uruguay en Chile, como de Chile en Uruguay, a partir del cual pudimos reconstruir los distintos viajes e intercambios de información entre los tres partidos 
seleccionados. Como veremos, el rol de la embajada y de los embajadores, será distinto en cada etapa y también marcará sus diferencias con el partido del cuál informan.

También, accedí a una pasantía de investigación durante dos meses en la ciudad de Santiago de Chile, donde pude realizar relevamiento documental de algunos de los archivos allí existentes. En primer lugar, el archivo del Congreso Nacional cuenta con documentos partidarios en los tres casos que son únicos, no encontrándose en otro acervo documental. Así, por ejemplo, hemos podido contar con algunos de los documentos emanados de los Congresos partidarios del Partido Comunista de Chile (PCCh), del Partido Socialista (PS) y de la DC. Varios de ellos se encuentran digitalizados y puestos a disposición en su sitio web.

En segundo lugar, la Biblioteca Nacional donde pude analizar la prensa partidaria del Partido Comunista de Chile, fundamentalmente El Siglo y la revista Principios. Al igual que en el caso uruguayo, esta última se centró en difundir documentos teóricos, así como la línea política acordada en cada etapa para la formación interna de sus militantes.

Desde el punto de vista partidario, pudimos acceder al archivo del Partido Socialista de Chile, que salvaguarda enorme cantidad de documentación, entre los que se encuentran: la revista Arauco, medio de prensa orgánico del socialismo chileno, discursos y escritos de varios de sus principales dirigentes, entre los que podemos nombrar a Salvador Allende, Carlos Altamirano, Raúl Ampuero o Clodomiro Almeyda, entre otros; así como los documentos emanados de sus congresos.

También, pudimos acceder con varias dificultades y poca voluntad por parte de los administradores al archivo existente en la Casa Museo Eduardo Frei Montalva. Las trabas para poder acceder a los documentos fueron varias, por lo que pude relevar brevemente algunos de los documentos internos de la DC chilena durante su estancia en el gobierno.

Por otro lado, realizamos 21 entrevistas a militantes uruguayos de las tres fuerzas políticas analizadas, que desde diversas experiencias transitaron por estos intercambios. Como el período investigado es amplio, son escasas las personas que pueden relatar lo ocurrido a lo largo de esos quince años, la mayoría vivió algunos de esos años, entrando a militar fundamentalmente a mediados de los años $60^{\prime}$. Poder contar con experiencias que de alguna manera abarquen todo el período, fue lo que provocó la necesidad de ampliar el número de las personas entrevistadas. En todos los casos las entrevistas fueron realizadas únicamente por la autora de la tesis y específicamente para la misma, por lo que no referiré a ellas cada vez. Al final se encuentran las referencias de cada una. 
En último lugar, contamos con memorias o escritos teóricos de algunos de los principales dirigentes de las izquierdas de ambos países ${ }^{6}$.

\subsection{Marco teórico}

En los últimos años diversos investigadores han abordado diferentes estudios orientados a profundizar el período de la historia reciente, tanto de Uruguay, como de otros países de la región. Sin embargo, la historia del proceso que llevó a la unidad de la izquierda y a la fundación del Frente Amplio en Uruguay, no ha sido hasta el momento objeto de análisis, ni por parte de la academia, ni por parte de los actores involucrados. Por ello, es llamativa la escasa atención sobre la historia del Frente Amplio, que, con un creciente aumento electoral desde la salida de la dictadura, es hoy la coalición de izquierda más importante de Uruguay y ocupa el gobierno nacional desde el año 2005.

La mayoría de los estudios actuales, que investigan a este sector político, provienen de la Ciencia Política, y se centran fundamentalmente en el avance electoral y en sus actuales propuestas de gobierno. Un elemento no menor y que va en este mismo sentido, es el hecho de que el Frente Amplio no tiene archivo propio, ni siquiera ha escrito como colectivo su "historia oficial".

Por otro lado, las investigaciones existentes dan cuenta de su fundación, a partir de un análisis de las distintas variables del contexto nacional. En este sentido, se sostiene que

la crisis nacional y su derivación autoritaria coadyuvaron fuertemente para que esa unidad se concretara, constituyéndose en el efectivo catalizador que no había llegado a generar, por ejemplo, los efectos locales de la crisis capitalista de 1929 y la posterior dictadura terrista. (Caetano, Rilla, Gallardo, 1995, p. 48).

Javier Gallardo también ubica al nacimiento del Frente Amplio como producto, en parte, de la necesidad de respuesta al autoritarismo de Pacheco, aunque afirma que esas explicaciones contextuales resultan insuficientes para dar cuenta de la constitución de esta nueva fuerza política. Y agrega:

\footnotetext{
${ }^{6}$ Para el caso uruguayo, ubicamos: Arismendi (1999 y 2013), Barros Lemez (1987), Díaz (1995), Pérez (1996), Plá (1959), Seregni (1971 y 1985), Terra (1971 y 2014) y Trías (1965). Para el caso chileno: Allende (1973), Almeyda (1967), Altamirano (1968), Ampuero (1964), Corvalán (1971 y 2010), Debray (1973), Gazmuri y Martínez (2000), Gumucio y otros (1966), Marambio (2009), Marín (2002), Neruda (2013), Rodríguez (1995) y Waiss (1961 y 1962).
} 
su concreción cabe imputarla más específicamente a la opción y el propósito -proveniente desde diversas trayectorias y desde un amplio abanico de orígenes partidarios- de una acción de ruptura y de alternativa respecto al bipartidismo tradicional (...) y a la combinación de estrategias partidarias y de referentes políticos y normativos de "orden" general conjugados en una coyuntura específica. (1995, p. 112-113).

Si bien le aporta al origen del Frente Amplio una nueva orientación, vista no sólo como una reacción ante la política autoritaria, sino como parte también de una combinación de estrategias partidarias las causas de su nacimiento sigue analizándolas dentro del marco de lo nacional.

Aunque se produjeron intentos anteriores de construcción de un frente común, es durante la presidencia de Jorge Pacheco Areco (1967-1972) que la izquierda comienza a visualizar la necesidad de construir un frente unificado, que sirviera de oposición a las políticas que venían desarrollándose desde el gobierno. La profundización de las políticas represivas, sumado a los efectos generales de la crisis, contribuyó al fortalecimiento de la oposición, siendo muestra de ello las posiciones comunes que legisladores de varios partidos comenzaron a profesar en el Parlamento ${ }^{7}$. Esta actuación conjunta no implicó necesariamente vincularse luego con la izquierda, podemos decir que este trabajo previo fue fundamental en la alianza contra el régimen de Pacheco. Al decir de Miguel Aguirre Bayley "aun sin autoridades, ni programas comunes, el Frente Amplio ya existía en el Parlamento como única oposición real al pachecato" (1985, p. 17). Como antecedente relevante no podemos dejar de señalar la realización del Congreso del Pueblo en 1965 y el Congreso de Unificación Sindical en octubre de 1966. Ambas experiencias de trabajo conjunto de varios sectores de la izquierda serán claves para comprender el proceso que culminará con la fundación del Frente Amplio, pero también constituyen una clara señal del grado de movilización de la sociedad ${ }^{8}$.

\footnotetext{
${ }^{7}$ Fundamentalmente se había intentado impedir la utilización de las Medidas Prontas de Seguridad, denunciando torturas a varios presos políticos y oponiéndose a la censura de la prensa. En esta postura encontramos entre otros a: Zelmar Michelini, Amilcar Vasconcellos, Alba Roballo, Hugo Batalla, Francisco Rodríguez Camusso, Enrique Rodríguez, Rodney Arismendi, Ariel Collazo, Juan Pablo Terra, José Luis Massera y Gerardo Cuesta, entre otros. Con la excepción de Vasconcellos, el resto de los legisladores que mantuvieron estas posturas, fueron de los primeros integrantes del Frente Amplio.

${ }^{8}$ Otros antecedentes de trabajo conjunto a tener en cuenta, fue la creación del Movimiento Nacional para la Defensa de las Libertades Democráticas y la Soberanía (1968). Todas experiencias de acción conjunta, que fueron demostrando que el trabajo a partir de un acuerdo básico común era posible.
} 
Finalmente, y luego de varios intercambios y movimientos a la interna de los diversos partidos, el 5 de febrero de 1971 en la reunión celebrada en la antesala del Senado en el Palacio Legislativo, quedó formalmente constituido el Frente Amplio 9 .

Tal como señalan, varios autores "la construcción del Frente Amplio, (...) significó otra opción por los caminos democráticos para la superación de la crisis del país. Su existencia, además, alteró la composición del sistema político nacional y contribuyó a cuestionar el bipartidismo tradicional”. (Nahum y otros, 1998, p. 74).

Sin embargo, no hay hasta el momento investigaciones que analicen dicho proceso, partiendo de un análisis transnacional que pueda iluminar en clave regional los recorridos de los diversos sectores políticos que culminaron en su unificación.

De las pocas investigaciones realizadas podemos ubicar algunas referencias que sostienen la idea de una cierta influencia regional a los acontecimientos que se estaban desarrollando en Uruguay. Miguel Aguirre Bayley, por ejemplo, afirma que, sumado a la crisis política, ciertos sucesos en el contexto internacional crearon las condiciones para la cristalización del Frente Amplio. Allí señala

a la gravísima crisis institucional interna, puede agregarse otro importante factor externo: la victoria de la Unidad Popular en Chile. Ese hecho se convirtió en un argumento capitalizador de voluntades para la izquierda y otros sectores progresistas de los partidos tradicionales. En efecto, el triunfo de Salvador Allende (...) alentó nuevos esfuerzos para crear un Frente Popular sin exclusiones. (1985, p. 17).

El mismo planteo realiza desde la Ciencia Política el investigador Luis Costa Bonino cuando señala que

el triunfo en setiembre de 1970, de Salvador Allende y de la Unidad Popular chilena, proporcionó el empujón de optimismo que ésta vapuleada oposición necesitaba, y un modelo político a imitar, en ausencia de una tradición común a la cual referirse. El triunfo de la Unidad Popular y la proximidad de las elecciones aceleró el trámite de las alianzas políticas (...). (1995, p. 228).

Más recientemente, la historiadora Vania Markarián, ilumina sobre este mismo aspecto al afirmar que además de la crisis institucional que vivía el país, jugó un papel

\footnotetext{
${ }^{9}$ Integrado por el Frente Izquierda de Liberación, Grupos de Acción Unificadora, Movimiento Blanco Popular y Progresista, Movimiento Herrerista, Movimiento por el Gobierno del Pueblo, Partido Comunista, Partido Demócrata Cristiano, Partido Socialista (Sector Izquierda Nacional), Partido Socialista (Sector Movimiento Socialista), Partido Obrero Revolucionario y el Comité Ejecutivo Provisorio que formuló el llamamiento del 7 de octubre de 1970. El 10 de febrero de 1971, adhirió la Unión Popular y en marzo el Movimiento Pregón "Julio César Grauert" y el Partido Revolucionario de los Trabajadores.
} 
importante en la fundación del Frente Amplio el nacimiento y el triunfo de la Unidad Popular en Chile, y que incluso existe un encuentro entre las Primeras 40 Medidas del Gobierno de la Unidad Popular y las Primeras 30 Medidas de Gobierno propuestas por el Frente Amplio,

entre la lucha a largo plazo de la izquierda por la hegemonía de los trabajadores y la necesidad a corto plazo de forjar una alianza con los sectores medios, similar a la Unidad Popular en Chile, pero con una agenda de contenido menos claramente socialista. (2006, p. 20-27).

\section{Contrariamente Gerardo Caetano y José Rilla afirmaron en 1995 que}

la creación del Frente Amplio, en cambio, no parece haber estado tan vinculada a condicionamientos externos favorables. Eventos como la invasión a Checoslovaquia o la expansión de experiencias foquistas en América Latina, por cierto, que no facilitaban consensos en el debate de la izquierda vernácula, aunque también es verdad que por entonces hacían sentir su influjo algunos ensayos frentistas en el continente y en Europa. De todos modos, la unidad de la izquierda en 1971 parece haber sido más hija de una larga acumulación política local que de un condicionamiento externo favorable. (1995, p. 49).

Sin embargo, varios años después en la biografía sobre Líber Seregni, Gerardo Caetano junto a Salvador Neves, afirmarán que "la victoria de Salvador Allende en Chile como candidato presidencial de la Unidad Popular, una alianza que, aunque distinta tenía similitudes con el frente que se proponía en Uruguay, alentó a sus constructores”. (2016, p. 140)

Incluso Mauricio Rodríguez en la investigación sobre Zelmar Michelini, también acuerda en pensar que el triunfo de Salvador Allende en Chile "daría un empujón anímico a aquellos que, como Zelmar, creían en que los distintos grupos progresistas vinculados a la izquierda podían confiar, con posibilidades serias de victoria, en construir un tercer espacio político, la alternativa a los partidos tradicionales". (2016, p. 227)

Jaime Yaffé en su tesis doctoral afirma que Chile representaba el primer caso en la historia contemporánea en que la izquierda revolucionaria alcanzaba el gobierno mediante una elección democrática.

Sobre todo, para los uruguayos, ya que en circunstancias en que el desafío guerrillero impugnaba fuertemente la estrategia del PC, lo que estaba sucediendo en Chile ofrecía la posibilidad de ejemplificar en términos históricos concretos la factibilidad de la apuesta al "camino menos doloroso", al menos como "vía de aproximación" a la revolución. Arismendi constataba en el período histórico que va de la revolución cubana al triunfo 
electoral de la izquierda chilena, la configuración de una situación revolucionaria a escala continental y una ampliación de las "vías de acceso" a la revolución nacional-democrática en América Latina. (2016, p. 204)

Las elecciones de 1971 marcaron un punto fundamental en lo que tiene que ver con el avance de la derecha en la política uruguaya. Juan María Bordaberry, candidato de los sectores más conservadores del Partido Colorado, gana las elecciones, luego de unos comicios duramente criticados, que finalizan con la denuncia de fraude realizada por el Partido Nacional ${ }^{10}$. El Frente Amplio obtenía en sus primeras elecciones un $18 \%$ del total de los votos a nivel nacional y un significativo 30\% en Montevideo, duplicando la cantidad de adhesiones que en elecciones anteriores habían obtenido cada uno de los grupos integrantes de la nueva coalición de izquierda (5 bancas en el Senado de 30 y 18 diputados de 99). Igualmente, "las reacciones de los dirigentes, militantes y partidarios del FA fueron ambiguas, principalmente porque la mayoría había sido optimista sobre el resultado electoral de la nueva coalición con el ejemplo chileno en mente.” (Markarián, 2006, p. 31).

\subsection{Estado de la cuestión}

Como señalábamos anteriormente, las investigaciones con respecto a la fundación o la historia del Frente Amplio son escasas, así como también hay una gran ausencia historiográfica referente a los partidos de la izquierda uruguaya.

En el caso del Partido Comunista contamos únicamente con tres trabajos específicos que dan cuenta de los virajes ideológicos de este sector. En primer lugar, Marisa Silva (2009) analiza desde el punto de vista cultural qué implicaba ser comunista en los $60^{\prime}$, los rituales, el papel de los dirigentes, la formación política, el rol de la URSS, etc., siendo más una pesquisa centrada en las mentalidades. Dos años más tarde, Ana Laura De Giorgi (2011) suma una mirada cultural sobre los militantes comunistas, socialistas y tupamaros, aportando códigos compartidos, su visión sobre lo cultural, la injerencia de la organización en la vida privada de los militantes, etc.

\footnotetext{
${ }^{10}$ La candidatura individualmente más votada, fue la de Wilson Ferreira Aldunate, obteniendo un $26,5 \%$ del electorado, aunque no logró el triunfo por efecto del doble voto simultáneo. En total, el Partido Nacional había obtenido 12.802 votos menos que el Partido Colorado. En los días siguientes, el dicho Partido denunció (antes de conocerse los resultados definitivos), una serie de hechos fraudulentos (robo de hojas y sobres de votación, puertas sin lacrar en el lugar dónde se custodiaban las urnas, entre otras). El 2 de enero de 1972, Wilson denunció que existían más votos que votantes y el Directorio del Partido pidió la anulación del acto eleccionario. Finalmente, en febrero la Corte Electoral no hizo lugar a su pedido, y proclamó oficialmente el triunfo de la fórmula colorada Bordaberry- Sapelli.
} 
Gerardo Leibner (2011) realiza una extensa investigación sobre el PCU desde 1941 hasta el golpe de Estado de 1973. Desde un punto de vista más centrado en los debates ideológicos internos, el autor analiza el viraje interno de 1955, los reacomodos ideológicos de los años posteriores -y sus implicancias prácticas en la vida del Partido-, las estrategias políticas: la importancia de la unidad sindical y de la alianza obrero-estudiantil, la polémica chino-soviética y la constitución del Frente Izquierda de Liberación (FIdeL) en 1962. Si bien el autor se centra en una perspectiva exclusivamente nacional, la aguda mirada sobre este partido la transforma en una obra clave para comprender los debates, las tensiones y la línea política del comunismo uruguayo en un período clave.

En un segundo nivel, podríamos ubicar el trabajo de Miguel Aguirre Bayley (2012) sobre la experiencia del FIdeL, primera experiencia de amplitud de una alianza política propuesta por el Partido Comunista. El trabajo es valioso, en primer lugar, porque es el único que rescata la historia política de este sector, pero que además incluye un largo anexo con varias fuentes documentales sobre su origen. El trabajo es breve y no aparecen discusiones, ni tensiones que den cuenta de su proceso político.

La historia del aparato armado del PCU está tapada bajo un largo manto de silencio. Les cuesta a ellos mismos dar cuenta de su existencia, de quiénes lo integraron, etc. Quizás ese silencio es lo que provoca que desde la academia tampoco se visualice la posibilidad de investigar al respecto. Con lo que contamos es apenas una entrevista realizada a Ricardo Calzada por Jaime Yaffé y Gabriel Buchelli (2007) y un artículo de Adolfo Garcé (2014) donde dan cuenta de las tensiones internas que este proceso generó. Por su parte, Leibner le dedica a este asunto escasas páginas.

En último lugar, contamos con la reciente tesis doctoral, inédita aún, de Jaime Yaffé (2016), que, si bien se centra en analizar el vínculo de estos partidos con la lealtad democrática, su análisis nos permite mirar el giro ideológico y las estrategias políticas de estos partidos desde mediados de la década del 50'.

En el caso del Partido Socialista la situación historiográfica es crítica. En primer lugar, no existe una investigación que dé cuenta de la historia de este sector político, con la exclusión del aporte realizado por Fernando López D`Alessandro (1988), pero que se centra en su fundación y la polémica con el comunismo en los primeros años de la década del $20^{\prime}$.

Por otro lado, contamos con algunos trabajos que, sin dar cuenta de la historia global del socialismo uruguayo, si aportan miradas que fueron de utilidad para el desarrollo de esta tesis. 
En primer lugar, el trabajo de Nicolás Duffau (2008) analiza la participación de militantes socialistas en la fundación de El Coordinador, germen de lo que fue luego el Movimiento de Liberación Nacional- Tupamaros (MLN-T). Los vínculos entre ambos sectores, los debates internos del socialismo sobre las vías de la revolución son abordados por Duffau, así como las tensiones finales cuándo el sector que luego fundará el MLN-T rompe finalmente con el PS.

En una línea más específica, contamos también con el artículo de Fernando Pedroza (2013) que analiza el rol del PS uruguayo en el Secretariado Latinoamericano de la Internacional Socialista. Clave para entender este trabajo de experiencia conjunta y dar cuenta de la dimensión de los vínculos y los contactos personales entre los dirigentes del PS uruguayo con los demás socialismos de la región, especialmente el chileno.

En último lugar, tenemos la tesis de Gustavo Trullen (2014) -también inédita- sobre la experiencia de la Unión Popular (UP). Al igual que el trabajo de Aguirre Bayley para el caso del FIdeL, Trullen se dedica extensamente a analizar la creación en 1962 de la Unión Popular -alianza del socialismo con algunos sectores provenientes del Partido Nacional-, su marco en una estrategia más amplia de horadar el capital electoral de los partidos tradicionales, su pésimo resultado en las elecciones de ese mismo año y la crisis interna que este hecho provocó en los años siguientes.

Tal como señalamos anteriormente, los trabajos de De Giorgi (2011) y Yaffé (2016), realizan -al igual que para el comunismo- aportes también para el socialismo uruguayo, desde sus respectivas perspectivas.

El Partido Demócrata Cristiano (PDC) uruguayo contó hasta hace pocos años también con escasas investigaciones sobre su origen, desarrollo y propuestas políticas. Fueron claves en su momento los aportes realizados por Carlos Real de Azúa (1972) y Romeo Pérez (1984; 1987), ambos dedicados a analizar la matriz ideológica a partir de la cual se fundó el PDC y las transformaciones internas que esto provocó en la ex Unión Cívica ${ }^{11}$. En los últimos tres años, a iniciativa del Instituto Humanista Cristiano Juan Pablo Terra, se ha publicado una colección que lleva seis tomos sobre la historia de este sector. El primero, a cargo de Mario Cayota (2014), se centra en analizar las raíces de la Democracia Cristiana uruguaya, la influencia del socialcristianismo europeo, su experiencia en el mundo sindical y sus primeras

\footnotetext{
${ }^{11}$ Cómo veremos en el capítulo dedicado a la Democracia Cristiana, en Uruguay se funda en 1962 producto de una importante transformación interna de la Unión Cívica que en febrero de ese año resuelve -no sin tensionescambiar entre otras cosas su denominación a PDC.
} 
acciones políticas entre fines del siglo XIX y principios del XX. El segundo tomo, a cargo de Julio Ilha López (2014), analiza el rol desempeñado por el PDC en la fundación del Frente Amplio. Papel relevante, si tomamos en cuenta que es la única experiencia en que cristianos y marxistas aprueban unirse en una alianza común. Siguiendo con esta línea, se ubica el tercer tomo a cargo de Rodrigo Rampoldi (2014), que analiza el rol del PDC en su lucha contra el avance autoritario del gobierno de Jorge Pacheco Areco y Juan María Bordaberry, hasta consumar finalmente el golpe de Estado. Estos tres tomos son claves para el desarrollo de esta tesis, ya que, si bien también se centran en un análisis exclusivamente nacional, dan numerosas pistas que dan cuenta del desarrollo ideológico y estrategia de este sector político. El cuarto tomo, realizado por César Failache (2014), analiza las propuestas programáticas entre 1966 y 1984, tomando como punto de partida los planes de gobierno de esas tres elecciones nacionales: 1966, 1970 y 1984. El quinto tomo, también a cargo de Julio Ilha López (2016), analiza la construcción ideológica de la izquierda cristiana en Uruguay entre 1911 y 1984. El sexto -realizado por Esteban Köster (2016), analiza el rol de la democracia cristiana, sus luchas y resistencias contra la dictadura militar, excediendo los límites temporales de esta tesis

Más allá de los importantes aportes realizados por los autores de cada una de las investigaciones, las mismas se enriquecen porque contienen un importante anexo documental donde se incluyen casi en totalidad los documentos publicados por este sector político en cada uno de los períodos. Fuentes que en varios casos son únicas.

Como señalamos al comienzo, específicamente sobre el Frente Amplio, son pocas las investigaciones realizadas hasta el momento. Un trabajo clásico es el de Miguel Aguirre Bayley, publicado originalmente en 1985 y con una actualización en el año 2005, justamente cuando dicha coalición accede al gobierno. Aguirre Bayley analiza concretamente los pasos que dan cada uno de los sectores que luego integrarán la alianza y también aporta un anexo documental con las principales declaraciones de ese momento, así como los primeros documentos fundantes de la coalición de izquierda.

En la década de los 90'surgieron algunas primeras pesquisas sobre la izquierda en Uruguay, que, si bien no son estudios exclusivos sobre el Frente Amplio, aportan en cuanto a su relevancia para el sistema de partidos y la crisis del tradicional bipartidismo en Uruguay. Allí podemos ubicar los trabajos de Carlos Zubillaga (1991), Gerardo Caetano y José Rilla (1995) y Javier Gallardo (1995). En una misma línea, aunque proveniente de las Ciencias Políticas, tenemos los trabajos realizados por Jorge Lanzaro (2004; 2005), que también 
iluminaron el camino sobre el nacimiento de este sector y su importancia para el sistema de partidos uruguayo.

El trabajo de Carlos Demasi (2006), publicación de una exposición pública, da cuenta del proceso de ruptura de los sectores del Partido Nacional y del Partido Colorado, que separándose de sus tradicionales aliados, jugarán también un rol clave en la fundación del Frente Amplio.

En el mismo año, se publican otras dos obras. En primer lugar, el trabajo de Vania Markarián (2006), producto de su tesis doctoral que tiene por objeto el análisis del exilio de la izquierda uruguaya y las redes transnacionales de Derechos Humanos, le dedica un capítulo, al análisis de los cambios ideológicos de la izquierda en los 60’y la fundación de esta nueva fuerza política en 1971.

En Buenos Aires, María Celeste Ratto (2006) dedica un capítulo en una obra más amplia a analizar desde la Ciencia Política la génesis de este sector y su importancia en el sistema de partidos uruguayo.

Jaime Yaffé y Adolfo Garcé (2006) analizan los giros y los cambios en la estrategia y el programa político de este sector desde su fundación en 1971 hasta el 2004 cuando finalmente ganan las elecciones. Si bien el período es amplio con respecto al desarrollo de esta tesis, en su comienzo nos aportó algunas pistas sobre los primeros sucesos que dieron lugar al nacimiento de esta fuerza política.

Debemos también sumar el trabajo realizado por Clara Aldrighi y Guillermo Waksman (2015), que si bien analizan el exilio tupamaro en el Chile de la Unidad Popular, fueron quienes nos aportaron los principales datos para rastrear la creación del primer comité de base del Frente Amplio en el exterior, fundado en la ciudad de Santiago.

No es menor señalar, que varios de estos investigadores estuvieron (o están) vinculados a los sectores políticos que investigan: Silva y Leibner con el PCU, Aguirre Bayley con el FIdeL, Zubillaga y Romeo Pérez con la Democracia Cristiana y Aldrighi con el MLN-T. Para nada queremos decir con esto que hay un sesgo en sus investigaciones, sino simplemente reflexionar cómo esta ausencia en la historiografía se traduce en aportes vinculados con trayectorias personales.

En otro nivel, contamos con trabajos biográficos sobre las principales figuras de la izquierda uruguaya. Cómo trabajos más vinculados a la memoria, en ellos se pueden registrar algunos de los recorridos individuales que dan cuenta de este proceso. Allí ubicamos los trabajos de Álvaro Barros Lémez (1987 y 1989), sobre Rodney Arismendi y Líber Seregni, 
respectivamente; Nelson Caula (1990), sobre la figura de Enrique Erro; Samuel Blixen (1997) Seregni. La mañana siguiente; Fernando Butazzoni (2002) registra un interesante diálogo entre Líber Seregni y Mauricio Rosencof; Alberto Silva (2004) sobre la figura de Juan José Crottogini; Jorge Chagas y Gustavo Trullen (2011) ilustran sobre la vida de Guillermo Chifflet hasta el momento del golpe de Estado. Más recientemente, contamos con los aportes de Mauricio Rodríguez (2016) sobre la vida de Zelmar Michelini; y Gerardo Caetano y Salvador Neves realizan una reactualización de su biografía de Líber Seregni, al cumplirse el centenario de su nacimiento.

Como hemos señalado anteriormente, si bien la mayoría de estos trabajos se centran en análisis nacional, algunos nos brindan ciertas pistas sobre una posible influencia del proceso chileno en el caso uruguayo. Sin embargo, esa constatación no pasa de una enunciación, sin analizar realmente en qué medida la recepción de los sucesos chilenos tuvo impacto en las decisiones de la izquierda uruguaya sobre sus estrategias políticas. Con esa motivación nos propusimos estas tesis.

\subsection{Los capítulos}

La presente tesis se compone de cuatro capítulos de análisis, a los que se le suman la introducción y las conclusiones.

Los tres primeros capítulos comparten una lógica de análisis temporal y por partido. El primero dedicado a los partidos comunistas, el segundo a los partidos socialistas y el tercero a las democracias cristianas. En los tres se intentó mantener una estructura similar que permitiera dar cuenta de algunas de las líneas de análisis. En primer lugar, se analizan en los tres casos los puntos de encuentro, es decir los contactos personales y orgánicos que se dieron en los partidos en este período: viajes, asistencias a congresos, o en el caso más concreto del socialismo y la democracia cristiana, la realización conjunta de experiencias de coordinación como el Secretariado Latinoamericano de la Internacional Socialista o la Organización Demócrata Cristiana de América. En segundo lugar, analizamos las definiciones sobre el carácter de la revolución y la discusión sobre las etapas de la misma, revolución socialista o revolución democrático- burguesa. En tercer lugar, las distintas políticas de alianzas, los conflictos tanto del socialismo como de la democracia cristiana para aliarse con el comunismo en Uruguay, la necesidad de aliarse o no con los sectores de la burguesía nacional, las enseñanzas de la experiencia del FRAP en Chile y las elecciones de 1958, las experiencias del FIdeL y la Unión Popular y la derrota del FRAP en 1964 y la estrategia triunfante del "camino 
propio" realizado por la DC chilena. En cuarto lugar, los caminos o las vías, es decir, las discusiones sobre cómo llegar al socialismo, la apuesta por la vía pacífica, la discusión sobre la posibilidad real de la izquierda acceda al gobierno mediante elecciones, la necesidad de constituir o no aparatos armados, la participación en la Organización Latinoamericana de la Solidaridad (OLAS) realizada La Habana en 1967.

El cuarto capítulo está dedicado a analizar como una unidad el período 1968-1971. En ambos países es una etapa clave e intensa en cuanto al desarrollo político y, por lo tanto, merecedora de un análisis conjunto. La fundación de la Unidad Popular en 1969, el triunfo de Allende al año siguiente, las discusiones a la interna de la DC que provocaron finalmente su quiebre, fueron recepcionadas en un Uruguay también en conflicto. La muerte del Presidente Óscar Gestido y la asunción de Jorge Pacheco Areco, el avance del autoritarismo, los llamados para la conformación de una alianza amplia ya desde 1968, las discusiones internas en cada uno de los partidos, que finalmente se unificaron en 1971, y la primera campaña electoral del Frente Amplio, a la luz de lo que iba ocurriendo en Chile es el objeto de análisis de este capítulo.

Por último, realizamos algunas apreciaciones finales con respecto a los temas más destacados de la tesis, las dificultades con las que nos hemos encontrado en el recorrido, los temas pendientes y las posibilidades que se abren para investigaciones futuras. 


\title{
2. Crece desde el pie ${ }^{12}$ : la recepción del comunismo chileno en su par uruguayo (1956-1967)
}

\author{
Nuestro camino es ancho. \\ Hay sitio a nuestro lado para todos \\ (Pablo Neruda. "Al Partido Comunista de Chile". Revista \\ Principios. Nro. 82. Enero-Febrero 1962)
}

En el presente capítulo, nos dedicaremos a analizar el recorrido ideológico que realizaron los Partidos Comunistas tanto en Chile como en Uruguay desde 1956 hasta 1967, con el fin de poder analizar la influencia que el comunismo chileno desarrolló sobre el uruguayo, intentando rastrear momentos de contacto y zonas de influencia.

A mediados de la década del 50' se produjeron en ambas colectividades procesos internos y externos, que los llevaron a transformar su accionar político. En el caso uruguayo, como veremos, el cambio de Eugenio Gómez por Rodney Arismendi ${ }^{13}$ en la Secretaría General, provocará -lo que se conoce como "viraje"- en su línea política, una amplitud en el sector que lo alejará de las críticas sectarias que lo caracterizaban hasta el momento ${ }^{14}$. El viraje, que comenzó en julio de 1955, se consolidó dos meses después con la realización del XVI Congreso del Partido Comunista del Uruguay (PCU) y hasta 1958 fue el período de formulación de las bases de su estrategia política que -aunque con pequeños matices producto de los cambios en la coyuntura local e internacional- sostendrán el accionar comunista hasta el golpe de Estado del 27 junio de 1973.

\footnotetext{
${ }^{12}$ Título de la canción de Alfredo Zitarrosa. Crece desde el pie.

${ }^{13}$ Rodney Arismendi (1913-1989), ingresa a militar en el PCU en 1930, siendo su Secretario General entre 1955 y 1987. Fue electo diputado en 1946 y mantuvo hasta el golpe de Estado de 1973, 27 años de actividad parlamentaria ininterrumpida. Fue detenido el 8 de mayo de 1974 y expulsado del país el 4 de enero siguiente rumbo a la Unión Soviética donde permaneció hasta su regreso a Uruguay en 1985. Teórico fundamental del comunismo uruguayo, entre sus obras se encuentran: La filosofía del marxismo y el señor Haya de la Torre (1946); Para un prontuario del dólar (al margen del Plan Truman) (1947); Problemas de la revolución continental (1962); Lenin, la revolución y América Latina (1970); Insurgencia juvenil (1972); Ocho corazones latiendo (1987).

${ }^{14}$ No viene a la cuestión aquí referir a la crisis del PCU anterior a 1955 y los motivos que impulsaron el viraje. Es clave para ello, referir al documento "Acerca de los problemas del Partido", redactado por Arismendi en julio de 1955, en el que partiendo de una dura critica a la línea impartida anteriormente (se acusaba de carencias ideológicas, políticas y organizativas) que -producto de una desviación ideológica- alejaron a la colectividad de las "masas", proponía algunas de las correcciones necesarias (incluso de actitudes y conductas individuales que debían desarrollar los comunistas) que demostró que el nuevo Secretario General (a tan sólo dos días después de ser electo) tenía bastante clara la línea estratégica alternativa. Lo que si es interesante señalar, es que a diferencia del PS que también transitaba por modificaciones en esos mismos años, en el caso de los comunistas los que dieron "el golpe" contra Eugenio Gómez, eran los mismos que lo acompañaban en sus tareas, por lo que no implicó un cambio de renovación ni directriz ni generacional. Sin embargo, el cambio en su estrategia y su accionar político si implicó un giro profundo (Leibner, 2011; Yaffé 2016)
} 
En Chile, poco tiempo después, se producen dos acontecimientos que también marcarán el accionar político de esta colectividad. En abril de 1958, muere Galo González ${ }^{15}$, hasta ese entonces Secretario General del Partido desde 1949. Si bien, la asunción de Luis Corvalán ${ }^{16}$ en su lugar no implicó un cambio de línea política tan profundo como en el caso de Uruguay, el desarrollo teórico que emprendió el Partido fue notable en este período. Por otro lado, el 6 de agosto de 1958 el Partido Comunista de Chile (PCCh) recupera la legalidad luego de la derogación de la llamada "Ley Maldita", lo que -como veremos- lo hará resurgir nuevamente a la arena política pública.

En ambos casos, desde comienzos de la década del 60' los comunistas, tuvieron un importante crecimiento tanto a nivel militante como de caudal electoral, asumieron un rol clave en las unificaciones sindicales de ambos países (alcanzando una cierta hegemonía en las direcciones de las centrales sindicales), incidieron fuertemente en el movimiento estudiantil, lograron importantes apoyos en sectores culturales y de la intelectualidad, y cumplieron un papel relevante en los procesos de unificación de la izquierda a nivel político partidario.

Ambos partidos fueron también profundamente internacionalistas y pro-soviéticos, provocándoles en varios momentos tensiones con el resto de la izquierda e incluso con varias organizaciones sociales producto de su defensa irrestricta a la política emanada desde Moscú. De hecho, el comunismo latinoamericano no tuvo un espacio de coordinación propia, más allá del Movimiento Comunista Internacional, como si crearon los socialistas y los democratacristianos.

La unidad de las izquierdas fue una consigna clara, profunda y coherente, de ambos Partidos Comunistas durante todo el período, aunque con diferentes derivas, como veremos a lo largo del texto.

Organizamos el capítulo, de la siguiente manera: en el primer apartado, intentamos dar cuenta sucintamente de los puntos de contactos individuales u orgánicos entre ambos sectores

\footnotetext{
${ }^{15}$ Galo González (1894-1958), comienza su militancia en el PCCh en 1927, siendo electo miembro de su Comité Central tres años más tarde. Como trabajador de las minas del cobre y luego del puerto de Valparaíso, estuvo vinculado al sector sindical del Partido. Entre 1949 y 1958 fue designado Secretario General del PCCh.

${ }^{16}$ Luis Corvalán (1916-2010), ingresa al PCCh en 1932. Trabajó como periodista en los periódicos comunistas Frente Popular y El Siglo. En 1947, luego de la ilegalización del Partido, fue detenido en las cárceles de Pitrufquén y Pisagua. En 1950 es nombrado miembro del Comité Central y en 1958 electo Secretario General, cargo que ejercería hasta 1990. Fue electo Senador desde 1961 y hasta el golpe de Estado de 1973. Instalada la dictadura militar, fue detenido y encarcelado en la Escuela Militar, trasladado luego a Isla Dawson (junto con el resto de los miembros del gobierno de la Unidad Popular), Ritoque y Tres Álamos. A fines de 1976, luego de una intensa campaña internacional, Corvalán es liberado y recibió asilo en la Unión Soviética. Regresa legalmente a Chile en 1988.
} 
(visitas de chilenos a Uruguay y viceversa, asistencia a los Congresos partidarios, actividades conjuntas, declaraciones en la prensa, etc.).

En el segundo apartado, damos cuenta de los debates ideológicos entorno al carácter de la revolución: la necesidad de la etapa democrático-burguesa, y su implicancia en ambos contextos nacionales.

En el tercer apartado, abordamos un tema clave: las alianzas con otros sectores. En este sentido, analizamos la fundamentación ideológica de la necesidad de una alianza con la burguesía nacional en ambos casos; la alianza socialista-comunista, y en este sentido, como fue recepcionada en Uruguay la experiencia del FRAP (elecciones de 1958 y 1964); las dificultades del trabajo conjunto entre socialistas y comunistas en Uruguay, y, por último, la fundación del FIdeL, primera propuesta de amplitud electoral realizada por el PCU.

En el cuarto y quinto apartado, analizamos la estrategia política, es decir el camino para llegar el socialismo: lucha de masas y vía pacífica. En el quinto, analizamos las discusiones sobre las vías, la necesidad de constituir un aparato armado y los matices desarrollados por el comunismo uruguayo.

Finalmente, cerramos el capítulo con algunas apreciaciones finales.

Los orígenes del Partido Comunista de Chile se remontan al año 1922, cuando el entonces Partido Obrero Socialista (POS), fundado en 1912 se adhiere a la III Internacional y oficializa de este modo su orientación hacia el comunismo. Ya desde su nacimiento, el PCCh, marca una característica diferencial con la mayoría de sus pares latinoamericanos, ya que no surge de una ruptura con los clásicos Partidos Socialistas, si no en la transformación total de éste. Esta característica, es lo que permite visualizar una continuidad claramente obrera entre el POS, liderado por Luis Emilio Recabarren y el nuevo Partido Comunista de Chile.

El Partido Comunista del Uruguay, por el contrario, nace en 1921 como producto efectivamente de una transformación del Partido Socialista. En su VI Congreso Extraordinario el PS, aprobó las "21 condiciones” exigidas por la III Internacional para incorporarse a la misma y, por lo tanto, cambiar la denominación por Partido Comunista. Como veremos en el próximo capítulo, el sector minoritario -encabezados por el histórico dirigente socialista Emilio Frugoni-, en desacuerdo con estas formulaciones, rompe y refunda el Partido Socialista.

Ya en la década del 30'y alineados con el VII Congreso del Komintern en 1935, ambos partidos comunistas abrazaron con fuerza la propuesta de creación de Frentes 
Populares como respuesta al avance autoritario ${ }^{17}$. Estos Frentes tendrían dos características claves que marcarían la línea política comunista en todo el período: su carácter democrático y su integración amplia (no solo por los diversos sectores de izquierda, sino también por socialdemócratas o partidos de centro). Sin embargo, el desarrollo de esta estrategia en ambos países fue bien disímil.

En Chile en junio de 1936 se constituyó el Frente Popular integrado por socialistas, comunistas y radicales; quienes triunfaron en las elecciones de 1938. Los comunistas participan activamente en este gobierno, llegando incluso a ocupar carteras ministeriales. Como veremos en el capítulo siguiente, en 1943 los socialistas rompen con el Frente Popular y se alejan del gobierno. En las elecciones a realizarse en 1946, los comunistas apoyaron al radical González Videla, mientras que los socialistas fueron con candidato propio. El triunfo del candidato radical, permitió por un breve período a los comunistas mantenerse en el gobierno y ocupar tres ministerios. Pero al año siguiente, en el marco de un fuerte anticomunismo internacional, el Presidente expulsó al PCCh del gobierno y promulgó la Ley Permanente de Defensa de la Democracia -conocida como "Ley Maldita"- que ilegalizó a los comunistas.

En Uruguay, si bien la idea de crear un Frente Popular amplio, que incorporara a todos los sectores antifascistas no prosperó, los comunistas apoyaron al candidato presidencial socialista -Emilio Frugoni- para las elecciones de 1938. Como veremos más adelante, este acercamiento no volverá a producirse hasta la conformación del Frente Amplio en 1971, una alianza profundamente más amplia que la suma del socialismo y el comunismo uruguayo, aunque la insistencia del PCU se mantendrá durante todo el período.

En el caso chileno, es en este contexto de ilegalidad, que comienzan a desarrollarse a la interna del Partido, corrientes rupturistas, que abandonaron la idea del triunfo siguiendo los caminos institucionales, llegando a actuar de manera armada y directa ${ }^{18}$. Mientras tanto, la

\footnotetext{
${ }^{17}$ La ponencia de Jorge Dimitrov en el VII Congreso del Komintern, establecía claramente la necesidad de crear "sobre la base de un "Frente Único Proletario" un amplio "Frente Popular Antifascista" que aunque no siendo todavía gobierno de la dictadura proletaria, sea capaz de aplicar medidas enérgicas contra el fascismo y la reacción" (Casals, 2010, p. 23).

${ }^{18}$ Encabezada por el entonces Secretario de Organización, Luis Reinoso (lo que les costó el nombre de "reinosistas"), esta corriente propuso un cambio fundamental en la interna del Partido: caracterizando al gobierno de González Videla como de "dictadura", plantearon la necesidad de organizar la resistencia contra el gobierno autoritario, basándose en la organización de las masas y en el abandono a las prácticas institucionales del sistema "burgués". El X Congreso de 1956 informó al respecto:

El Partido tuvo que afrontar... a un agente del enemigo que se introdujo en nuestras filas, el traidor Luis Reinoso, que formó una fracción dentro del Partido con el propósito de dividirlo... Reinoso
} 
línea oficial del Partido apuntó a reconquistar la legalidad, reinsertándose en el sistema institucional, a partir de una política de alianzas amplia. El triunfo de esta postura y la expulsión de la línea disidente, permitieron que los comunistas tuvieran una activa participación en la conformación del Frente Nacional del Pueblo en 1951 (FRENAP) y al acercamiento con el Partido Socialista de Chile (PSCh) liderados en ese entonces por Salvador Allende ${ }^{19}$.

En ambos casos también, se produjo una clara influencia de las resoluciones del XX Congreso del Partido Comunista de la Unión Soviética (PCUS), referentes no solamente al proceso de desestalinización, sino también a las posibilidades de crear alianzas amplias, de elaborar estrategias políticas acordes a las condiciones internas de cada país y promovió el camino pacífico como vía de acceso al socialismo ${ }^{20}$. A la vez, tres acontecimientos vinculados a la política soviética fueron motivo de tensiones con sus pares socialistas: la crisis de Polonia en 1956, la invasión a Hungría el mismo año, y la intervención en Checoslovaquia en 1968. Las declaraciones condenatorias de varios movimientos sociales tanto en Chile como en Uruguay, y las argumentaciones justificatorias de los comunistas de ambos países, provocaron distancias, que debieron remediarse en los años subsiguientes. Tal como señala Rolando Álvarez, para el caso chileno, pero que puede perfectamente aplicarse para el uruguayo, "la necesidad política de defender el socialismo real era tan importante como para justificar todas y cada una de las acciones de la Unión Soviética" (2014, p. 72).

\subsection{Uruguayos en Chile y chilenos en Uruguay: los momentos de encuentro}

Los contactos entre los militantes del PCU y PCCh en este período fueron continuos y profundos. La atención que los uruguayos le prestaban al proceso transitado por su par chileno, podemos rastrearlo por ejemplo, en la cantidad de noticias que tanto desde $E l$ Popular como desde Estudios se publicaron referente a varios sucesos ocurridos en el vecino país. No es posible, reproducir aquí cada uno de esos puntos de encuentro, pero si podemos

pretendió arrastrarnos a una política aventurera, de acción directa, para aislarnos de las masas (Venegas, 2003, p. 50)

${ }^{19}$ En 1951 el Partido Socialista de Chile y el Partido Comunista de Chile, se unen en el Frente Nacional del Pueblo. En 1953 se incorporó el Partido Democrático; en 1954 el Partido del Trabajo; y en 1956 los partidos Democrático del Pueblo y Socialista Popular, transformándose en el Frente de Acción Popular (FRAP).

${ }^{20} \mathrm{Si}$ bien como veremos, el llamado a la vía pacífica tuvo una enorme aprobación en los Partidos Comunistas de Uruguay y de Chile, en ese contexto, era la respuesta al reclamo que venían realizando tanto el Partido Comunista italiano como el francés, que preveían la posibilidad de generar alianzas con otras fuerzas de izquierda que les permitiera el triunfo en elecciones democráticas. 
señalar, que de sus páginas se desprende: la solidaridad y la denuncia ocurrida durante la ilegalización de esta colectividad en Chile, los buenos augurios por la fundación del FRAP, el seguimiento de las elecciones tanto en 1958 como en 1964, así como la denuncia de los diversos acontecimientos represivos que ocurrieron en Chile, durante el gobierno de Eduardo Frei Montalva (1964-1970) ${ }^{21}$.

Otra de las formas habituales de contacto, fueron las visitas de delegaciones de uno $\mathrm{u}$ otro país a Congresos o actividades organizadas por su partido hermano. Jorge Mazzarovich, fue desde muy joven militante primero de la Juventud y luego del Partido Comunista del Uruguay. Recuerda que:

teníamos un intercambio bastante fuerte, constante, se expresaba de muchas formas: dirigentes políticos y sindicales que viajaban a Chile, compañeros chilenos que llegaban al Uruguay, por las más diversas vías, encuentros, congresos, intercambios de experiencias, solidaridad con luchas concretas que en uno u otro país se desarrollaran. $(. . .)^{22}$

\section{En 1958, Julieta Campusano ${ }^{23}$ participa como delegada del PCCh al XVII Congreso} Nacional del $\mathrm{PCU}^{24}$. Las palabras de la dirigente comunista fueron publicadas por la revista Estudios y la selección refiere justamente al tema de la unidad de la izquierda y la importancia de la alianza comunista-socialista:

Factores decisivos en las victorias del pueblo chileno y en el avance de la lucha político electoral, han sido el que hayamos agregado a la unidad sindical, (...) la unidad política de la clase obrera, al hacerse realidad la unidad y entendimiento entre el Partido Socialista y el Partido Comunista. Durante muchos años, alentado por los agentes de la reacción y del imperialismo, habían logrado mantener una guerra civil entre comunistas y socialistas que trajo como consecuencia, la división del movimiento obrero y la ruptura política, comenzada con tan buenos auspicios con el triunfo del Frente Popular. Con todo, la unidad

\footnotetext{
${ }^{21}$ Por citar algunos ejemplos, en 1965 se produce una importante huelga en la mina de El Teniente que durará tres meses, y origina un paro solidario de la Confederación de Trabajadores del Cobre; el 11 de marzo de ese mismo año, con el objetivo de disolver una reunión sindical en la mina El Salvador, los militares disparan y dan muerte a seis obreros y dos mujeres, y provocan más de treinta heridos.

${ }^{22}$ Jorge Mazzarovich comienza a militar desde muy joven en la Unión de la Juventud Comunista a fines de los años 50' en su sector sindical. En el año 1963 se integra a la Dirección de la Juventud y poco tiempo después pasa a militar directamente en el Partido Comunista. Participa en la fundación de la Convención Nacional de Trabajadores (CNT), el Frente Izquierda de Liberación (FIdeL) y luego en el Frente Amplio. Viaja a Chile numerosas veces entre 1967 y 1973. Detenido en mayo de 1975, permaneció recluido hasta 1985. Durante el primer gobierno frenteamplista (2005-2010) fue designado Embajador en Cuba.

${ }^{23}$ Julieta Campusano (1918-1991), ingreso al PCCh en su temprana juventud, siendo miembro de su Comité Central ya en 1944. En las elecciones de 1947 fue electa regidora por Santiago. Durante el gobierno de González Videla fue encarcelada hasta 1958. Diputada entre 1961-1965 y Senadora por el período 1965-1973, siendo reelecta ese último año por el período 1973-1981 período interrumpido por el golpe militar. Luego del 11 de setiembre, se asiló en la Embajada de Holanda, regresando al país clandestinamente en 1987.

${ }^{24}$ Ministerio de Relaciones Exteriores de Chile. Archivo General Histórico. Embajada de Chile en Uruguay. Fondo Histórico. Año 1958.
} 
socialista- comunista, es la base en que se afirma el Frente de Acción Popular (...). Este movimiento significa para nosotros el núcleo inicial del movimiento de liberación nacional ${ }^{25}$.

Resultan interesantes los documentos de la Embajada de Chile en Uruguay, que nos muestran no solamente los diversos intercambios, pedidos de visa, etc., de los dirigentes comunistas que viajaban de un país a otro, sino también las preocupaciones gubernamentales por estos intercambios. Por ejemplo, en octubre de 1959, con motivo de la realización en Santiago del "Congreso Juvenil Latinoamericano", el Ministro de Relaciones Exteriores de Chile informa al Consulado General que "deberá negarse la visación de pasaportes de personas que aparezcan vinculadas a dicho Congreso (...)"26.

El 4 de agosto de 1959, El Popular informa de la visita de Arismendi a Chile invitado por el FRAP. En el contexto de la Conferencia de Cancilleres realizada el 12 de agosto siguiente en esa misma ciudad, los diversos partidos de la izquierda chilena organizaron la realización de una asamblea pública integrada por las diversas fuerzas de la izquierda latinoamericana, y un gran contra-acto central en el que Fidel Castro sería el orador principal. Tres días después, el 7 de agosto, la Embajada de Chile en Uruguay informa de la inhabilitación para viajar a Chile -entre otros latinoamericanos- de Rodney Arismendi. El documento dice simplemente:

absténgase Ud. de visar (...) Rodney Arismendi, comunista uruguayo (...). Sin embargo, si alguno exhibiera prueba fehaciente de situación oficial que hiciera imposible negar visación, autorizase concederla demorándola lo más posible con pedido de antecedentes, etc., $\mathrm{y}$ avisando de inmediato fecha y medios viaje ${ }^{27}$

Los intercambios entre los comunistas de ambos países, así como el avance de las fuerzas de izquierda en Chile, fueron también motivo de preocupación para las autoridades uruguayas. Con motivo de la realización del XIX Congreso del PCU en julio de 1966, "el Presidente del Consejo, señor Alberto Heber, comunicó que el Gobierno impedirá que penetren al país delegaciones extranjeras, diciendo: “aquí no entran más que uruguayos. (...)

\footnotetext{
${ }^{25}$ Revista Estudios. $\quad \mathrm{N}^{\circ} 10$. Setiembre 1958. Fragmentos de la intervención de la delegación del Partido Comunista de Chile (Julieta Campusano), p. 134.

${ }^{26}$ Ministerio de Relaciones Exteriores de Chile. Archivo General Histórico. Embajada de Chile en Uruguay. Fondo Histórico. Año 1959. Volumen 5386.

${ }^{27}$ Ministerio de Relaciones Exteriores de Chile. Archivo General Histórico. Embajada de Chile en Uruguay. Fondo Histórico. Año 1959. Volumen 5385 A.
} 
el mecanismo a utilizarse sería el de la negación de visas a dichos extranjeros "28. Finalmente, esta resolución no pudo aprobarse, y las delegaciones extranjeras pudieron participar del Congreso sin inconvenientes.

Sin embargo, al año siguiente, las comunicaciones entre ambos partidos comenzaron a ser motivo de ciertos acontecimientos no menores. El 28 de setiembre de 1967, El Popular denuncia que al dirigente comunista Leopoldo Bruera, "le fue impedido en el día de ayer desembarcar del avión en que se había trasladado a Santiago, debiendo regresar a Uruguay $(\ldots){ }^{\prime 2}{ }^{29}$ Si bien son anécdotas, en el sentido de que no fue masivo el impedimento de viajes de dirigentes comunistas hacia ambos países, las tensiones, controles y vigilancia nos muestran que los intercambios eran continuos y que estaban generando por lo menos preocupación en los ámbitos gubernamentales.

Otro de los puntos de acercamiento, se dio en el terreno cultural. Varios son los documentos que muestran al igual que los militantes, no solamente los viajes de actuaciones de varios de los músicos - por ejemplo- del canto popular, sino la presencia de su música en las actividades cotidianas de los partidos. Jorge Mazzarovich recuerda

un camino de excepcional importancia, para consolidar esta unidad, para sentir que de verdad éramos parte de una misma lucha en el continente se jugó a nivel cultural. Porque para nosotras todas las expresiones, excepcionales, por cierto, del arte y la cultura de Chile eran nuestras como la cosa más natural del mundo. Como era lo más natural del mundo que nos llegaran los discos de Víctor Jara antes de que se editaran en Chile. Yo lamento haber perdido aquellas cubiertas de los discos grandes que él me dedicaba con tanto cariño. (...).

Moriana Hernández, recuerda al detalle los vínculos que tenían con su par chileno. Si bien la cita es un poco extensa, nos permite ver con claridad la presencia -aunque sea simbólica de los chilenos- en su actividad militante cotidiana.

(...) nosotros como Juventud Comunista teníamos mucha admiración y copiamos una cosa de los chilenos. (...) Como copiamos las camisas rojas, porque las camisas rojas eran chilenas. En el caso de ellos no eran rojas eran bourdeaux, nosotros las enrojecimos un poquito más, pero el hecho de uniformar a la juventud con una camisa es una copia de Chile. (...). Y otra cosa (...), que también de alguna manera copiamos a los chilenos fue en la cosa del canto. Acá tuvieron un éxito loco los Quilapayún cuando vinieron y (...) un coro grande que se llamaba La Brigada, que cantaba mucha gente y la dirigió Federico García Vigil (...). Era un modelo moderno de propaganda (...) la versión chilena era un

\footnotetext{
${ }^{28}$ Ministerio de Relaciones Exteriores de Chile. Archivo General Histórico. Embajada de Chile en Uruguay. Fondo Países. Año 1966. Departamento de Asuntos Americanos. Sin Volumen. Confidencial Nro. 617/61.

${ }^{29}$ El Popular. 28.09.1967. Reproducido también en Ministerio de Relaciones Exteriores de Chile. Archivo General Histórico. Embajada de Chile en Uruguay. Fondo Países. Año 1967. Volumen 3. Ofício Nro. 969/564.
} 
poquito más creativa, ahí hubo una influencia clarísima. Por supuesto que no hubo reunión que se preciara de tal, que no se cantaran las cosas de Violeta Parra, que no cantáramos la Cantata de Iquique, la música chilena fue la música de la época. $(\ldots)^{30}$.

Los problemas financieros también eran motivo de intercambio entre las diversas colectividades de la izquierda. En el caso que nos ocupa, Mazzarovich recuerda que era común "ayudarlos o llamarlos cuando estábamos en una situación muy difícil. La situación financiera para variar era difícil aquí en la izquierda, entonces, los llamábamos (...). Recorrimos con ellos el país entero [Uruguay] en algún momento”. El poder logístico del PCCh estaba más consolidado que el de Uruguay, sobre todo desde mediados de la década del $60^{\prime}$ que se produjo un importante crecimiento de su caudal militante y electoral. A esas ayudas refiere Mazzarovich, que se intensificaron luego del acceso al gobierno del PCCh con la Unidad Popular en 1970.

\subsection{El carácter de la revolución: de la etapa "democrático burguesa" a la "democrática nacional"}

La caracterización de la revolución que ambos partidos comunistas realizaron estaba basada en las etapas consideradas por la teoría marxista. Sin embargo, a lo largo del período, realizaron transformaciones con el fin de adaptar este mapa doctrinario a las diversas realidades nacionales.

En el caso chileno, en primer lugar, señalaban la necesidad de cumplir con la etapa democrático-burguesa de la revolución, a la que denominaban democrático-popular, en la que se llevarían a cabo los objetivos antifeudales, antiimperialistas y antioligárquicos, a la vez que se enfatizaba en la necesidad de una dirección proletaria del proceso. En esta estrategia, el PCCh no se adjudicaba un rol pasivo, sino que buscaba conducirlo, acompañado de todos aquellos sectores que compartieran los objetivos del cambio revolucionario. En el desarrollo de este camino, "habrá pluralidad de partidos en el país, compartiendo el ejercicio de poder (...) [promoviendo] que, junto al Parlamento, vayan creciendo formas de democracia directa susceptibles de asegurar en el futuro el desarrollo hacia el socialismo" ${ }^{31}$. El diagnostico establecía que la revolución democrático-burguesa era una tarea aún pendiente en Chile y que ella se podría llevar a cabo a partir de una amplia alianza con los sectores burgueses no

\footnotetext{
${ }^{30}$ Proveniente de una familia comunista, ingresa a su Juventud a los 11 años en 1961, sumándose a las actividades de apoyo a la revolución cubana. Durante el golpe militar parte a su exilio en México, donde regresa en los comienzos de la transición democrática. Hoy se mantiene alejada del PCU.

${ }^{31}$ Revista Principios, $\mathrm{N}^{\circ} 43$, julio-agosto de 1957. Edmundo Pérez. La vía pacífica, p. 8.
} 
monopólicos, pero bajo la conducción de la clase obrera. Por lo tanto, como veremos, uno de los objetivos principales era la búsqueda de la alianza con los sectores de centro.

El objetivo final, era obviamente, la construcción de una sociedad sin clases, pero sin desarrollar en profundidad como era ese imaginario. En 1962, definían

\begin{abstract}
los comunistas, luchamos, claro está por el socialismo y el comunismo. El socialismo es un régimen que históricamente sucede al capitalismo, que termina con la explotación del hombre por el hombre, que socializa todos los medios de producción y se basa en el principio de que cada cual aporta según su capacidad y recibe según su trabajo. Como se dice en el Programa del PCUS, el comunismo es un sistema aún más avanzado, un régimen social sin clases, con una forma única de propiedad sobre los medios de producción (...) y con una plena igualdad social de todos los miembros de la sociedad (...) y será realizado el gran principio de cada cual, según su capacidad, a cada cual, según sus necesidades ${ }^{32}$.
\end{abstract}

Como vemos, la referencia a las resoluciones del PCUS seguía siendo permanente. El PCCh establecía el antiimperialismo y el socialismo, como dos etapas de un proceso continuo y único, que se correspondía con el proceso revolucionario mundial, que había comenzado en octubre de 1917 en Moscú. La base de la tesis establecía claramente la inserción de la revolución chilena en el proceso revolucionario mundial de transición del capitalismo al socialismo encabezado por la URSS. Es decir, que la revolución nacional, pacífica y democrática que los comunistas impulsaban en Chile, estaba subordinada a un proceso global encabezado por los soviéticos. Si bien el proceso revolucionario mundial había comenzado en 1917, la revolución estaba planteada siempre en términos primero nacionales, continentales y luego internacionales. En 1965, afirmaban

la lucha por nuestra liberación tiene un doble carácter nacional e internacional al mismo tiempo. La experiencia de la revolución cubana, de Guinea, de Ghana y de otras naciones, demuestra palmariamente que los países pequeños pueden enfrentar con éxito al imperialismo y consolidar y desarrollar sus avances si se apoyan en el mundo socialista y en la solidaridad de todos los pueblos ${ }^{33}$.

Dos años después, continuaban con esta misma línea

la política del imperialismo hace más obligatoria la acción conjunta de los pueblos latinoamericanos y realza el carácter continental de su lucha y le confiere a ésta una mayor trascendencia mundial. En la medida que el imperialismo (...) hace caso omiso de la

\footnotetext{
${ }^{32}$ Partido Comunista de Chile. Informe de Luis Corvalán. Hacia la conquista de un Gobierno Popular. XII Congreso Nacional del Partido Comunista de Chile. 1962, p.41.

${ }^{33}$ Ídem., p.15.
} 
soberanía de cada país, no respeta las fronteras geográficas (...) los revolucionarios se ven obligados a llevar su solidaridad a nueva altura, incluso participando directamente en las luchas liberadoras de otros pueblos hermanos, siempre, claro está, que así lo requiera el movimiento revolucionario de esos pueblos y se coloquen a su servicio y actúen bajo su dirección $(\ldots)^{34}$.

El objetivo de la clase obrera era entonces, dar la lucha por la liberación en su propio país y sobre esa base, entregar la mayor solidaridad posible a las luchas revolucionarias de otras naciones.

Luego del triunfo de la Unidad Popular, los comunistas chilenos declararán iniciada la revolución, ya que el desarrollo de los objetivos antiimperialistas, antifeudales y antioligárquicos así lo demostraban (Álvarez, 2014, p. 68).

Los comunistas uruguayos, también identificaron en 1955 que era necesaria una etapa previa a la revolución directamente socialista. El XVI Congreso del PCU, afirmó la estrategia política a desarrollar luego del viraje, que giraría en torno

al objetivo de la revolución democrática y nacional-liberadora, que implicaba la necesidad de construir al Partido Comunista como el partido de la clase obrera y la unificación sindical de esta, para convertirla en la conductora del proceso histórico, y a la vez, la elaboración de alianzas con otras clases sociales (...) y con sus representantes políticos interesados en la transformación sustancial, en el marco de un Frente Democrático de Liberación Nacional. (Leibner, 2011, p. 267).

La segunda etapa, sería la fase propiamente socialista. En 1958 denominaron la etapa democrático nacional de la revolución, que se caracterizaría por ser agraria y antiimperialista. "Los objetivos antimperialistas (nacionales) de la revolución, se entrelazan con sus objetivos agrarios y antifeudales (democráticos).” (Arismendi, 1999, p. 38)

El documento programático aprobado en el XVII Congreso en agosto de 1958, definiría en lo esencial el accionar del comunismo hasta el golpe de Estado de 1973. Allí se afirma que esta primera etapa, no se trataba de la revolución socialista propiamente dicha sino de una revolución que "removería los obstáculos para la posterior instauración del régimen socialista." (Yaffé, 2016, p. 192). Pero a la vez, se aclaraba que tampoco se trataba de una revolución burguesa, ya que su triunfo implicaría un "gobierno del pueblo, encabezado por el

\footnotetext{
${ }^{34}$ Corvalán, Luis (1967) Unión de las fuerzas revolucionarias y antiimperialistas de América Latina, Santiago, s/e, p. 6-7.
} 
proletariado y dirigido por el Partido Comunista ${ }^{\circledR 3}$. Según la caracterización de la revolución, señalada en este mismo documento, la misma sería agraria, democrática y nacional.

Otro de los principales aportes teóricos de Arismendi y que quedó aprobado también en el XVII Congreso, fue justamente enmarcar el desarrollo de la revolución uruguaya en el contexto latinoamericano. Teniendo como punto de partida la realidad latinoamericana, y considerando a la vez los aspectos excepcionales del Uruguay dentro de ese contexto general. La revolución democrática nacional debía desarrollarse en cada país del continente, para ser de esta forma un eslabón de la revolución antiimperialista latinoamericana. Tal como se señala en 1958, "la revolución nacional liberadora en nuestro país es una porción de la revolución antimperialista de toda América Latina, en particular de los países del sur, la que se integra a su vez, en la revolución anticolonialista mundial." (Arismendi, 1999, p. 39) Si bien, esto fue aprobado incluso antes del triunfo de la revolución cubana, luego de 1959 esta tesis sería confirmada y desarrollada con mayor profundidad.

\subsection{Construyendo alianzas amplias}

Como veremos a lo largo del capítulo, el tema de la "unidad" fue el asunto clave de la estrategia sostenida por ambos Partidos Comunistas a lo largo de todo el período. Esto los llevó a ser impulsores de amplias alianzas a nivel de las izquierdas partidarias, pero también motores de la unidad -por ejemplo- del movimiento sindical. La unidad total de la clase obrera, de las fuerzas de izquierda, del pueblo, a nivel nacional; así como la unidad del movimiento comunista y de la unidad de acción para resistir al imperialismo a nivel internacional, fueron casi obsesiones que marcaron la política comunista.

\subsubsection{Del "Frente de Liberación Nacional" al "Frente Democrático de Liberación}

\section{Nacional": la alianza con la burguesía nacional}

Inaugurada recién la década del 50', el entonces Secretario General del PCCh Galo González, proclama la necesidad de desarrollar lo que denomina "Frente de Liberación Nacional", en el contexto de lucha contra las visiones rupturistas encabezadas por Luis Reinoso, señaladas anteriormente. Lo que el historiador Tomás Moulián, denomina

\footnotetext{
${ }^{35}$ Revista Estudios, Nro. 10, Setiembre de 1958, José Luis Massera. Por la revolución agraria antimperialista, primer tramo en el camino hacia el establecimiento del régimen socialista en Uruguay. Informe del Comité Central, p. 51.
} 
llamativamente "frente amplio" (2006, p.176) y que se confirmó oficialmente en la IX Conferencia Nacional de 1952. Coherentes con los postulados que se venían desarrollando desde las décadas anteriores y más allá de la negativa evaluación de la experiencia del Frente Popular, los comunistas mantendrán durante todo el período la estrategia de ampliar el marco de alianzas.

La clave estaba en lograr una alianza con la burguesía nacional progresista, antioligárquica, antiimperialista y antifeudal, es decir con todos aquellos sectores que entraran en contradicción con el imperialismo, la burguesía monopólica y la oligarquía terrateniente, considerados el enemigo principal. Más allá de las críticas que cayeron sobre el Frente Popular, su experiencia dejó una marca insuperable en el comunismo chileno: la confirmación de que era posible una alianza entre comunistas y socialistas y que ésta podía acceder al gobierno a través de un triunfo electoral. Como veremos, para los socialistas, esta experiencia dejó la enseñanza contraria. Es decir, que aliarse con sectores moderados -lo que incluía tanto al Partido Radical (PR) como a la DC -diluía el carácter verdaderamente clasista de la revolución. Esta evaluación fue la que impulsó: a los comunistas por un lado, a promover la conformación del FRENAP en 1951, y a los socialistas a asegurar que su integración fuese únicamente por organizaciones "claramente de izquierda".

En el viraje de 1955, Arismendi sostenía que además de estudiar los clásicos del marxismo, era necesario iniciar un proceso de estudio concreto y profundo de la realidad uruguaya, con el fin de elaborar una línea estratégica que fuera acorde. Ya en el primer informe, presentado, señalaba

la realidad objetiva del país, en sus relaciones de producción, y en el alineamiento en consecuencia de las clases sociales sobre el escenario nacional, los caminos de la unidad de todo el pueblo para poner en marcha el movimiento democrático popular de liberación nacional. (citado en Leibner, 2011, p. 238).

La estrategia, era constituir en Uruguay un "Frente Democrático de Liberación Nacional", que implicara la alianza entre clases y

la unión de los obreros y los campesinos, a los que sumarán los intelectuales y estudiantes, artesanos, empleados públicos y privados; la magnitud y la fuerza de ese movimiento, determinará que adhiera a él la burguesía nacional. El Frente es el agrupamiento combativo de todos los sectores cuyos intereses están en abierta pugna con los imperialistas y con el actual régimen de feudales y grandes burgueses (...). Naturalmente, como lo enseña la 
experiencia internacional, la clase obrera será la dirigente del Frente; su alianza de lucha con los campesinos, la fuerza motriz de ese movimiento revolucionario ${ }^{36}$.

Pero la innovación del planteo estaba dada en que la toma del poder no implicaba solamente propiciar alianzas con las clases burguesas nacionales, para luego imprimir en ellos un giro en su política; sino que el desafío debía de ser ofensivo, es decir crear una fuerza política independiente, que representase a una alianza obrero-campesina, incluyendo a los sectores medios, con el fin de desplazar a las clases dominantes y establecer un poder alternativo democrático-popular. La denominación del Frente, no era una innovación del PCU post viraje de 1955, sino que ya venía desarrollándose en algunos documentos internos desde comienzos de la década de 1950.

La vanguardia de esta alianza debía estar asegurada en la clase obrera. Para ello era necesario, asegurar la alianza socialista-comunista, y por otro lado, dedicar esfuerzos en consolidar una alianza desde abajo, desde la acción común de los militantes de base (barriales, sindicales, estudiantiles, etc), miembros de todas las fuerzas sociales y políticas, alrededor de los objetivos revolucionarios de cada etapa. La clave estaba, entonces, en lograr no un acuerdo de cúpulas dirigentes, sino en promover con amplitud el desarrollo conjunto de acciones de base con miembros de otras tendencias, promoviendo las condiciones que posibilitaran luego un acuerdo de los dirigentes políticos. Funcionaría- fundamentalmentepara generar presión a la interna de los partidos que no eran afines a crear acuerdos con los comunistas.

Las resoluciones del XVII Congreso del PCU, realizado en 1958 se plantearon tres objetivos estratégicos en los que debía centrarse el accionar partidario: la unidad del movimiento sindical, la unidad de la izquierda punto de partida para la conformación del Frente Democrático de Liberación Nacional y la construcción de un gran partido. Tal como señala Marisa Silva, esta estrategia fue profundamente innovadora, "en la medida en que se proponía saltar las tradicionales barreras de un partido de ideas para convertirse en un partido de masas de carácter nacional.” (2009, p. 112)

Pocos meses después, en enero de 1959, Arismendi publica Acerca del papel de la burguesía nacional en la lucha antiimperialista. Estudio de los problemas del movimiento liberador de América Latina ${ }^{37}$, donde presenta las contradicciones de la burguesía nacional

\footnotetext{
${ }^{36}$ Revista Estudios, Nro. 1, febrero-marzo de 1956, Alberto Suárez, El carácter antimperialista y antifeudal de la revolución uruguaya, p. 30-31.

${ }^{37}$ Publicado primero en la revista Por la paz y el socialismo, Praga, Nro 5 y 6, es reeditado en setiembre del mismo año en el Nro. 9 de la Revista Estudios.
} 
latinoamericana, sus tendencias ambivalentes y sus expresiones políticas contradictorias. Aquí vemos un cierto matiz, con los planteos de su par chileno. Arismendi consideraba que el eje de la alianza antiimperialista, era la obrero-campesina, y luego recién algunos sectores de la burguesía nacional. El proletariado, claramente tenía el papel conductor, pero guiado por esas contradicciones era necesario ganar los sectores de la burguesía proclives a acompañar una revolución agraria y antiimperialista. Según Arismendi, la revolución cubana demostró, que se podía pasar rápidamente a una fase socialista en el proceso revolucionario, con lo cual acelerados los tiempos- el enfrentamiento con la burguesía nacional era inevitable.

\subsubsection{El primer paso: la alianza socialista- comunista. Las enseñanzas del FRAP en Chile}

El primer paso para la consolidación de esa amplia alianza era asegurar un acuerdo socialista-comunista, que aseguraría dos elementos indispensables: un predominio de las clases proletarias, que permitieran a su vez conducir el proceso. Este primer acuerdo, era el que iba a impedir la "traición de la burguesía", tal como había sido catalogado el fracaso del Frente Popular, porque la clase obrera estaría en la vanguardia de los cambios. En este sentido, evaluaban que el fracaso del Frente Popular, no se debía a la alianza con el centro identificado con el PR- sino a "que socialistas y comunistas marchamos muy dispersos y a veces en verdadera guerra fratricida." (Casals, 2010, p. 53). Para Galo González, esta alianza sumada a un importante movimiento de masas, serán las variables que impedirán esa "traición burguesa", tal como había sucedido en las décadas anteriores.

El discurso mayoritario en el PCCh fue siempre entonces, de acercamiento con los socialistas. Galo González, lo afirma claramente,

nuestro Partido tiene el vehemente deseo de estrechar de más en más su amistad con los Partidos Socialistas. No queremos rivalizar con ellos, disputarnos los sindicatos ni nada parecido. Deseamos un gran Partido Comunista, luchamos por nuestros puntos de vista. Pero deseamos también un gran Partido Socialista y nos parece saludable que ellos luchen como nosotros por sus puntos de vista. (...) Somos partidarios de todo esto en el bien entendido, claro está, que de la otra parte haya sentimientos recíprocos y de que todos juntos, comunistas y socialistas, lucharemos por el socialismo y hoy día por la liberación nacional $^{38}$.

\footnotetext{
${ }^{38}$ Revista Principios, N 36, setiembre de 1956, p. 57.
} 
Este objetivo, llevó incluso a que el PCCh propusiera la fusión de ambos partidos socialista y comunista- en la constitución de un partido único de los trabajadores, "que solo será posible cuando él se base en una sola ideología, la marxista-leninista, con una línea consecuentemente revolucionaria e impregnada de un inconmovible internacionalismo proletario"39. Esta propuesta, se realizó formalmente en octubre de 1959, mientras se desarrollaba el XVIII Congreso Ordinario del Partido Socialista, quien la rechaza señalando que las profundas discrepancias ideológicas sumadas al alineamiento internacional comunista hacen imposible la fusión. No es menor señalar, que a la interna del socialismo se expresaron voces favorables a esta propuesta, entre las que se destaca la de Allende, como veremos en el capítulo siguiente.

Luego de la derrota en las elecciones de 1964, el PCCh envía al conflictivo Congreso de Linares del PS a mediados del año siguiente, un saludo en el que explicitarán

creemos que une a los dos partidos la concepción de que en Chile es indispensable una revolución antiimperialista y antioligárquica de verdad y la marcha común hacia el socialismo. Nos unen además incontables luchas de la clase obrera, la clase fundamental de la sociedad contemporánea, de las masas trabajadoras, luchas en las cuales nuestros militantes han combatido y siguen combatiendo hombro con hombro. (...) Nos une también, por supuesto, una convicción común en cuanto a la necesidad de alcanzar el poder político para el pueblo y los trabajadores (...), que abra a su vez camino a las impostergables transformaciones revolucionarias que el desarrollo del país plantea ${ }^{40}$.

A finales de ese mismo año, desde Principios, se confirmaba esta idea: "hoy en la oposición, mañana en el Gobierno del Pueblo, comunistas y socialistas somos y debemos seguir siendo el eje de todo el proceso revolucionario chileno" 41 .

La posibilidad de ampliar la alianza hacia otros sectores -cuyo núcleo central era la unidad socialista-comunista- fue la disputa histórica entre el PCCh y el PS en todo este período. Poco antes de fundado el FRAP, los comunistas ya insistían en que

el nuevo programa considera también a los industriales, profesionales, comerciantes y agricultores ricos como integrantes del futuro gran frente democrático de liberación nacional. (...) Hay que hacer que las organizaciones obreras conversen con las organizaciones capitalistas sobre los problemas comunes y les ayuden a resolverlos. (...) Unos y otros tienen intereses que los llevarán a sumarse al Frente de Liberación Nacional. Lo importante es descubrir esos intereses ${ }^{42}$.

\footnotetext{
${ }^{39}$ Revista Principios, $\mathrm{N}^{\circ}$ 52, diciembre de 1958, p. 79.

40 Revista Principios, N 108 , agosto de 1965, p.127-128.

41 Revista Principios, $N^{\circ} 110$, noviembre- diciembre de 1965, p.5.

42 Revista Principios, №33, enero-febrero de 1956, p. 13-14.
} 
En este sentido, el FRAP, respondía también a la estrategia planteada por los comunistas de avanzar en una alianza lo más amplia posible, hacia la etapa denominada democrático-burguesa, del camino hacia el socialismo. Esto es lo que explica, que si bien para las elecciones de 1958, son un claro referente de la campaña allendista, en las primeras reuniones de la Convención del Pueblo apoyan a Guillermo del Pedregal, un ex ibañista, y claro exponente de la burguesía nacional. Una vez más, intentaban ampliar la política de alianzas.

Incluso, luego de la derrota electoral de 1964, a diferencia del PS (que declara su oposición intransigente al gobierno de Frei), el PCCh se declara en la oposición al gobierno, pero anunciando que apoyarán todas las medidas que sean de carácter popular. El Partido Comunista ha asumido, que la lección a obtener de la derrota en las elecciones es la necesidad de ampliar el FRAP.

La idea es que el carácter contradictorio del gobierno de Frei, por el pluriclasismo de las fuerzas que lo integran, exige preservar la independencia de clase del proletariado, impidiendo las ilusiones que pueda despertar el reformismo burgués de la DC, pero también rechazar el sectarismo y la oposición ciega. (Arrate y Rojas, 2003, tomo I, p.383).

La consigna es clara y expresa la esperanza de poder lograr un acuerdo con el PDC. Al decir de Luis Corvalán: "nuestra oposición será firme, activa, pero no ciega.” (Arrate y Rojas, 2003, tomo I, p.392). Como veremos, en los próximos capítulos, serán los comunistas, quienes celebrarán el desarrollo de una izquierda cristiana a la interna de la DC. Sabiendo de las diversas tensiones a la interna del partido de gobierno, le prestarán particular atención a los sectores disidentes. En este sentido, afirmarán que lo importante era identificar a los verdaderos enemigos, y estos eran la oligarquía y el imperialismo, y por lo tanto, dentro de la DC existían sectores con algún grado de contradicción con estos enemigos principales. El quiebre de lo que se conocerá como Movimiento de Acción Popular Unitario (MAPU), y su acercamiento a la izquierda irá de la mano con esta consigna:

(...) no podemos adoptar el criterio de meter en un mismo saco a todos los democratacristianos, inclusive a los obreros, campesinos, dueñas de casa, pobladores, a gente modesta. Si actuáramos de este modo, lo único que conseguiríamos sería aislarnos de ellos y facilitar la obra del reformismo democratacristiano (...). Se trata, justamente, de no 
entregar la dirección del movimiento popular y parte apreciable del pueblo a los partidos de la burguesía ${ }^{43}$.

En el caso uruguayo, desde el viraje de 1955, los comunistas intentan acuerdos con su par socialista. En el Informe aprobado por el Comité Central del PCU para ser presentado en el XVI Congreso de setiembre de 1955, ya se afirmaba que era una tarea del Partido,

proponer al Partido Socialista la acción en común en defensa de la paz, contra la colonización yanqui, en salvaguarda de las libertades democráticas y derechos sindicales, por las reivindicaciones económicas, y sociales de los trabajadores y de las masas populares. Debemos proponerle, en particular, tener una preocupación común de ambos Partidos por la unidad de la clase obrera y el reforzamiento de los sindicatos. (Arismendi, 1999, p. 19)

Pocos meses después, el 25 de abril de 1956, Rodney Arismendi envía la primera carta al Comité Ejecutivo del Partido Socialista con un "fraternal llamado a la unidad (...)". La crisis económica, que trae consigo desocupación obrera, cierres de empresas, reducción de horas de trabajo, bajos salarios, encarecimiento del costo de vida, se traduce en las luchas que a lo largo del país llevan adelante los obreros organizados, "la experiencia histórica enseña que el poder de la clase obrera es mayor cuanto más poderosa y fuerte es la unidad del proletariado, la unidad sindical y la acción común de los Partidos Socialista y Comunista." (Arismendi, 1999, p. 22). Asumen, asimismo, que ambos partidos tienen diferentes concepciones de llegar al socialismo, pero eso no puede jamás desviarlos de que todo triunfo de la clase obrera, los acerca a ese objetivo común ${ }^{44}$.

Los superiores intereses de la defensa del bienestar y la libertad del proletariado hacen indispensable hacer a un lado todo cuanto divide, para colocar en primer plano todo cuanto pueda contribuir a la unión. Nadie puede pensar que ello suponga para ninguno la renuncia de sus principios. (Arismendi, 1999, p. 24).

\footnotetext{
${ }^{43}$ Partido Comunista de Chile. Adelante por el camino del XIII Congreso. Documentos del XIII Congreso Nacional del Partido Comunista de Chile. 1965, p. 36.

${ }^{44}$ Durante todo el período, varios son los artículos que enfatizan en la necesidad de la unidad: César Reyes Daglio en la Revista Estudios. Nro. 2, abril-mayo de 1956. Algunas consideraciones respecto a la proposición al Partido Socialista; Juan Francisco Pazos, Nro. 5 y 6, mayo-junio de 1957. La unidad se necesita ahora; Enrique Rodríguez, Nro. 7, noviembre de 1957, Algunos aspectos de la situación política y las próximas elecciones; César Reyes Daglio, Nro. 8, marzo de 1958, Los problemas de la unidad y el Congreso socialista; Jaime Pérez, Nro. 31, setiembre-octubre de 1964, Avanzar en la creación de la fuerza social de la revolución uruguaya; Jaime Pérez, Nro. 32, noviembre-diciembre de 1964, El porqué de la coincidencia de nuestros dos partidos; Carlos Arizaga, Nro. 36, julio-agosto de 1965, La urgencia de ampliar la unidad de la izquierda; Rodney Arismendi, Nro. 44, 1967, Unidad en la lucha por la liberación; Nro. 45, noviembre de 1967, Enrique Rodríguez, Ante el agravado panorama nacional, ampliar la unidad popular; entre otros.
} 
La propuesta concreta, no era solamente una alianza a nivel electoral por ahora, sino la acción coordinada de sus parlamentarios, ediles, militantes obreros, así como la acción conjunta de los partidos, en hechos que mejoren las condiciones de vida de los sectores populares $^{45}$. Como ya hemos señalado, la respuesta socialista es negativa en todas estas oportunidades.

Seis meses después, en octubre de 1956, realizaran un segundo intento. En la carta enviada directamente al Dr. Emilio Frugoni, Secretario General del Partido Socialista-, asumen que

la senda de la unidad no se recorre en un día, pero estamos seguros que si comenzamos a actuar en las fábricas, campos y universidades, en el Parlamento, en la Junta Departamental $\mathrm{y}$ en otros terrenos, en torno a un núcleo de aspiraciones obreras, y populares acerca de las cuales coincidimos, el entendimiento entre nuestros partidos será una segura y auspiciosa realidad. (Arismendi, 1999, p. 26)

Al igual que lo planteado, por su par chileno, la unidad socialista comunista era considerada el primer paso necesario para poder ampliar el camino de las alianzas con miembros de otras clases sociales y constituye

una premisa de la unidad total de la clase obrera y de su desempeño como dirigente del movimiento democrático de liberación nacional. A su vez, la realidad internacional reclama poner fin a la escisión del movimiento obrero (...). En esta nueva realidad mundial la unidad de comunistas y socialistas es decisiva para preservar la paz y para acelerar nuevas e históricas victorias en escala internacional. (...) Muy cerca de nuestro país, los socialistas de Chile (...) actúan conjuntamente con el Partido Comunista (Arismendi, 1999, p. 28).

La propuesta del PCU, estaba un paso atrás que la de su par chileno. Obviamente, desde 1956 con la fundación del FRAP la acción coordinada de socialistas y comunistas, ya era un hecho. En Uruguay, se estaba lejos de poder proponer la refundación de ambos partidos en uno sólo, la propuesta - como quedaba señalado en ambas cartas- era la unidad de acción. Los comunistas uruguayos, lo explicitan claramente en su segunda carta,

\footnotetext{
${ }^{45}$ En la misma carta, se ponen como ejemplos: lucha común por los aumentos de salarios para los trabajadores, aumentos de sueldos para los funcionarios públicos y municipales y de las jubilaciones y pensiones para las clases pasivas, por una política impositiva que no recaiga sobre los sectores populares sino sobre el gran latifundio, las grandes empresas y los monopolios extranjeros; en defensa de las libertades sindicales; por una política exterior independiente que contribuya al triunfo de las propuestas de desarme y propender a que la gravitación conjunta de socialistas y comunistas determine un clima favorable a la unidad de la clase obrera en beneficio de sus intereses y libertades. (Arismendi, 1999, p. 25)
} 
nuestra proposición no pretende (...) que cada Partido deba abandonar sus particulares concepciones acerca de las vías hacia el Socialismo, y que de ello deba surgir una artificial refundición. Nuestra carta insistía precisamente en lo contrario: las diferentes concepciones acerca de las rutas para llegar al socialismo no deben ser obstáculo de la unidad de acción. (Arismendi, 1999, p. 31)

Para Arismendi, el PS al sostener su negativa, cargaría con la grave responsabilidad de impedir la acción conjunta de los dos partidos obreros que debían ser el núcleo central de una alianza más amplia que los lleve a construir un frente "antimperialista, democrático y avanzado" (Yaffé, 2016, p. 235)

El nacimiento del FRAP en Chile, no pasó desapercibido por sus pares uruguayos, la posibilidad de constituir una alianza comunista-socialista, fue el objetivo central del comunismo uruguayo en el período. Si además, tenemos en cuenta que en 1958 esta coalición casi logra la asunción de Allende a la Presidencia del país, la confirmación de ese modelo era inequívoca $^{46}$.

El 16 de noviembre de 1960, César Godoy Urrutia $^{47}$ viaja a Montevideo a la celebración del 40 Aniversario del $\mathrm{PCU}^{48}$. En el informe enviado por el Embajador en Uruguay, Sr. Ricardo Latchman, al Ministro de Relaciones Exteriores de Chile, se transcriben íntegramente sus palabras en el acto mencionado (publicadas originalmente en El Popular). En diciembre los comunistas uruguayos, visualizaban "la (...) urgencia de la formación de un frente político de las fuerzas de izquierda antimperialistas"49 y Jaime Pérez, agregaba "hemos vuelto a dirigirnos a las fuerzas de izquierda, y particularmente al Partido Socialista, para plantearles la necesidad de la unidad, con un agregado si se quiere dramático, decimos unidad ahora" $" 50$.

El 7 de marzo de 1961, el Embajador Latchman informa:

\footnotetext{
${ }^{46}$ En setiembre de 1958, FRAP pierde las elecciones por una escasa diferencia de votos. Alessandri es el triunfador, con 390 mil votos; seguido por Allende con 356 mil; luego le sigue Frei con 256 mil; Bossay cuarto con 192 mil y por último el "cura de Catapilco" con 41 mil. El resultado era claramente alentador, de la elección anterior, Allende había pasado del 5,4 al 28,5\% del caudal electoral.

${ }^{47}$ César Godoy Urrutia (1901-1985), fue uno de los fundadores del Partido Socialista de Chile en 1933. Luego del triunfo del Frente Popular y la asunción de Pedro Aguirre Cerda se retira del PSCh y se suma al Partido Socialista de los Trabajadores. En 1944, ingresa al PCCh, siendo electo diputado en 1945 y miembro de su Comité Central en 1956. Perseguido por la Ley de Defensa de la Democracia se exilia en México. A su regreso es electo diputado nuevamente. Luego del golpe militar es detenido y logra finalmente exiliarse en México en el año 1975. Regresa a Chile en 1984.

${ }^{48}$ Ministerio de Relaciones Exteriores de Chile. Archivo General Histórico. Embajada de Chile en Uruguay. Fondo Histórico. Año 1960. Volumen 5740. El informe se acompaña con una caracterización histórica del PCU.

${ }^{49}$ Revista Estudios. Nro. 18, diciembre de 1960, Enrique Rodríguez. Llamado a todas las fuerzas antimperialistas, democráticas y avanzadas del país, p. 9.

${ }^{50}$ Revista Estudios, Nro. 18, diciembre de 1960, Jaime Pérez. Ha llegado a la hora de formar el frente de las izquierdas, p. 13.
} 
Partido Comunista uruguayo ha invitado al Secretario General Partido Comunista Chile Luis Corvalán para que participe en un acto público se efectuará 21 del corriente en Montevideo, como objeto de que exponga "la rica y ejemplarizante experiencia" de los comunistas chilenos, según reza texto carta enviado por Diputado Rodney Arismendi (...). El acto que organizan comunistas, tendría por objeto impulsar su campaña unidad fuerzas izquierdistas uruguayas y reunirlas en una entidad política similar al FRAP de Chile ${ }^{51}$.

Una semana después, se informa que Corvalán habría aceptado viajar a Montevideo, para participar de un acto el 21 de ese mismo mes. El aerograma enviado por el Embajador Latchman, concluye "agradeceré a Us. confirmarme cablegráficamente esta información que interesa a la policía uruguaya ${ }^{, 52}$.

En este contexto, llegaron a Montevideo, Luis Corvalán y Orlando Millas ${ }^{53}$. Al día siguiente, El Popular, afirma:

Nuevos vientos soplan en nuestra América Latina (...). En Chile, las elecciones nacionales consagraron un avance de tal magnitud del Partido Comunista y de las fuerzas de la izquierda unidas en el FRAP que se situarán en condiciones de disputar de igual a igual el poder político a las fuerzas de la derecha. El trabajador, el hombre de nuestro pueblo se pregunta: ¿Cómo avanzar también en el Uruguay? $(\ldots)^{54}$.

En el informe enviado por el Embajador de Chile da cuenta que

el mencionado acto político tuvo por finalidad promover un acercamiento con los demás partidos de izquierda de este país para formar un frente unido, similar al Frente de Acción Popular de nuestro país (...). En cuanto se publiquen las versiones taquigráficas de los discursos pronunciados (...), especialmente del dirigente chileno, los enviaré a Ud. $(\ldots)^{55}$.

Dichas palabras son efectivamente enviadas el 8 de abril siguiente, donde se rescata que

\footnotetext{
${ }^{51}$ Ministerio de Relaciones Exteriores de Chile. Archivo General Histórico. Embajada de Chile en Uruguay. Fondo Países. Año 1961. Volumen 4. Aerograma No.39.

${ }^{52}$ Ministerio de Relaciones Exteriores de Chile. Archivo General Histórico. Embajada de Chile en Uruguay. Fondo Países. Año 1961. Volumen 4. Aerograma Confidencial Nro. 41.

${ }^{53}$ Orlando Millas (1918-1991), comienza su carrera política en la Federación Juvenil Socialista, integrándose al PCCh en los primeros años de la década del 40'. Director del diario comunista El Siglo entre 1942 y 1945. Detenido en Putre durante el gobierno de González Videla, luego de la legalización del PCCh fue miembro de la Cámara de Diputados entre 1961 y 1972. El 17 de junio de ese año, Salvador Allende lo nombra Ministro de Hacienda. Luego del golpe de Estado parte al exilio. Muere en Rotterdam el 26 de diciembre de 1991.

${ }_{55}^{54}$ El Popular. 15.03.1961.

${ }^{55}$ Ministerio de Relaciones Exteriores de Chile. Archivo General Histórico. Embajada de Chile en Uruguay. Fondo Países. Año 1961. Volumen 2. Nro. 80/57.
} 
el senador chileno se refirió, especialmente, a la necesidad de alcanzar en todos los países la unidad socialista-comunista. Dio una amplia información sobre el proceso unitario realizado en Chile por los partidos populares a través del FRAP, y de la Central Única de Trabajadores y que ha tenido, según su opinión, como resultado inmediato, el amplio triunfo de los partidos de izquierda en las últimas elecciones parlamentarias de Chile. $(\ldots)^{56}$.

La idea de formar un frente unido similar al FRAP, será notorio en los documentos producidos por la Embajada. El 28 de junio de 1961, el Embajador de Chile en Uruguay, informaba a su Ministro de Relaciones Exteriores, que

los comunistas uruguayos están dedicados a formar un Frente Patriótico Nacional, en el que tendrán cabida los sectores autodefinidos como "izquierdistas, antiyanquis y antiimperialistas" (...). Dijo al respecto, el Secretario General del Partido Comunista Uruguayo y diputado, Rodney Arismendi, en uno de sus últimos informes: “(...). En el fondo lo que persiguen los comunistas de este país, es constituir una réplica de lo organizado en Chile bajo el nombre de FRAP y cuyos principales dirigentes ya han viajado a este país, en distintas y recientes oportunidades, para "explicar" a sus "camaradas uruguayos", las tácticas empleadas por ellos frente al Partido Socialista y otros sectores de izquierdistas chilenos. ${ }^{57}$

Incluso, el tema de la unidad de acción con los socialistas volverá a estar presente en el XVIII Congreso de 1962. La sostenida negativa del conglomerado socialista, los llevará a plantear nuevas alianzas, que se materializarán en la conformación del FIdeL. Tal como se señala en las resoluciones del Congreso

desgraciadamente, la resolución del Partido Socialista, negándose a un frente sin exclusiones, obliga a nuestro pueblo a dar la batalla electoral en otras condiciones. El Partido Socialista tomó sobre sí, la pesada responsabilidad de dividir la izquierda, ya unida prácticamente en la actividad gremial, en la solidaridad con Cuba y en el corazón de los grandes sectores populares. (Arismendi, 1999, p. 70).

Gerardo Leibner, afirma que la negativa les valió a los socialistas una continua pérdida del caudal militante, que fue traspasándose hacia filas comunistas, y en la definición luego de las elecciones de 1962, de nuevas incorporaciones a la izquierda de militantes a favor de una alianza mas inclusiva como la postulada por los comunistas (2011, p. 243).

\footnotetext{
${ }^{56}$ Ministerio de Relaciones Exteriores de Chile. Archivo General Histórico. Embajada de Chile en Uruguay. Fondo Países. Año 1961. Volumen 2. Oficio No. 85/59.

${ }^{57}$ Ministerio de Relaciones Exteriores de Chile. Archivo General Histórico. Embajada de Chile en Uruguay. Fondo Países. Año 1961. Volumen 1. Confidencial No. 200/16.
} 
En abril de 1963 -ya creado el Frente Izquierda de Liberación-, luego de las elecciones municipales en Chile donde el FRAP alcanza un 29,5\% del caudal electoral, El Popular titula La mano tendida al Partido Socialista, con una clara alusión en la nota interna de lo acertado de la alianza:

\begin{abstract}
A menudo hemos resaltado la significación ejemplar del FRAP como núcleo de unión de las fuerzas de izquierda, y en particular, de la alianza de los partidos de raíz marxista, comunistas y socialistas. Ello, desde luego con vistas no solamente a las justas electorales sino para reforzar, alentar, unir, organizar las batallas generales de nuestro pueblo por su bienestar (...). Desde la primera hora, hemos propuesto la unidad al Partido Socialista, sosteniendo que ella debía constituir el núcleo central de la unidad de las izquierdas. (...) En el acto realizado en la sede central del Partido Comunista (...), el compañero Arsimendi, volvió a dirigir un llamado a los compañeros del Partido Socialista, tendiéndoles la mano fraternalmente $(\ldots)^{58}$
\end{abstract}

Luego de la realización del Congreso del Pueblo y de finalizado el proceso de unificación sindical en la Convención Nacional de Trabajadores (CNT), donde trabajaron juntos socialistas y comunistas, junto a militantes de otras tendencias políticas, la negativa socialista era evaluada como el elemento que impediría traducir los avances en la conciencia de los trabajadores en una expresión política a nivel partidario. En julio de ese mismo año, realizarán dos nuevas propuestas al respecto ${ }^{59}$, obteniendo la misma respuesta negativa.

La campaña del FRAP para las elecciones de 1964, también fue seguida con atención por sus pares uruguayos. La posibilidad de que en Chile, una alianza amplia de izquierdas triunfara en las elecciones, daba aire a los debates que se estaban desarrollando en varios países. Pocos meses antes de las elecciones, Estudios publicaba un profundo análisis de la situación chilena, tomando en cuenta no solamente las posibilidades de triunfo, sino también la reacción de la derecha, la polarización de la sociedad, la posición de Frei, las posibilidades de Allende de llevar adelante sus medias en caso de ganar, los vínculos con la revolución cubana, entre otros ${ }^{60}$.

\footnotetext{
${ }_{58}^{58}$ El Popular. 14.04.1963.

${ }^{59}$ El Popular: La unidad es necesaria ya ahora, compañeros de EL SOL (03.07.1963); La hora de la unidad ha sonado ya (09.07.1963).

${ }^{60}$ Revista Estudios. Nro. 30, julio-agosto de 1956. R. Mauri, El pueblo chileno se prepara a gobernar con Allende, p. 9-16.
} 


\subsection{3. "Señores: jesto que iniciamos es una revolución!" $" 61$ el nacimiento del Frente Izquierda de Liberación (FIdeL)}

La conquista de la unidad no puede ser el fruto de un efecto mágico. (...) La unidad no viene por si misma hay que forjarla. No es de revolucionarios - se ha repetido en esta tribuna-sentarse a esperar el paso del cadáver del imperialismo. La unidad en nuestro país es decisiva, no es una menuda tarea electoral, es una gran tarea revolucionaria.

(Arismendi ante el XVIII Congreso del PCU, 1962. Citado en Arismendi, 1999, p. 72)

El año 1962, fue un año clave para la izquierda uruguaya. Además del contexto nacional, marcado por diversas movilizaciones obreras y actividades de solidaridad con Cuba, por primera vez los dos partidos tradicionales de la izquierda uruguaya -socialistas y comunistas- se presentaron en el marco de frentes, en alianzas con otros agrupamientos. Uno de ellos, -el FIdeL-, tuvo como eje articulador central al Partido Comunista y el otro frente -la Unión Popular- al Partido Socialista. Como veremos en el capítulo siguiente, mientras que el PCU seguía manteniendo el postulado de la unidad sin exclusiones, los socialistas prefirieron aliarse con el hasta entonces diputado por el Partido Nacional, Enrique Erro.

El 9 de julio de 1962, el Embajador de Chile en Uruguay, -Ricardo Lachtman- informa al Ministro de Relaciones Exteriores, que

simultáneamente se reunieron, en días pasados, los órganos máximos de cinco grupos de izquierda para discutir la estrategia política con vistas a las elecciones generales (...). Comunismo: frente sin exclusiones.

El XVIII Congreso del Partido Comunista Uruguayo, realizado en estos días, según sus dirigentes, tuvo singular importancia, por la trascendencia de los temas tratados, la participación de delegaciones del extranjero y la numerosa concurrencia que asistió a sus deliberaciones.

El Partido Comunista chileno estuvo representado por Manuel Cantero, miembro de la Comisión Política del Comité Central. Intervino en el debate general e hizo un bosquejo de la unidad de las izquierdas en Chile, reunidas en el FRAP; analizó las distintas etapas de dicho proceso, su crecimiento electoral y auguró el triunfo del FRAP en $1964(\ldots)^{62}$

\footnotetext{
${ }^{61}$ Inicio del discurso de Luis Pedro Bonavita, primer Presidente del FIdeL, en el acto realizado el $1^{\circ}$ de setiembre de 1962. (Aguirre Bayley, 2012, p. 123)

${ }^{62}$ Ministerio de Relaciones Exteriores de Chile. Archivo General Histórico. Embajada de Chile en Uruguay. Fondo Países. Año 1962. Volumen 7. Ofício Nro. 179/111.
} 
El FIdeL, se crea el 15 de julio de 1962, será presidido por Luis Pedro Bonavita ${ }^{63}$ y lo integrarán el Partido Comunista, Agrupación Batllista "Avanzar", Movimiento Batllista "26 de octubre", Movimiento Revolucionario Oriental (MRO) ${ }^{64}$, Comité Universitario, Movimiento Nacional de los Trabajadores de la Cultura, Comité Central Obrero, Comité por la Unidad de la Izquierda de Paysandú, Comité Unidad de Izquierdas de Salto, Grupo de Izquierda de Maldonado y varios independientes. Cuatro años después se incorporará el Movimiento Popular Unitario (MPU) fundado el 2 de julio de $1966^{65}$.

Al día siguiente de su fundación, el diario comunista El Popular, relataba lo sucedido con detalle. La declaración fundacional de la nueva organización señalaba

partidos y grupos políticos, que hemos venido luchando por la unidad de izquierdas sin exclusiones, resolvemos dar por constituido un frente de acción política, integrado por los participantes, que deje abierto el camino para la incorporación de todas las fuerzas de izquierda objetivo por el que luchamos y seguiremos luchando (...). Esta acción para lograr la unidad política de todos los sectores populares seguirá siendo el centro de nuestra lucha, pues entendemos que sólo así abriremos el cauce para que la fuerza liberadora del pueblo pueda expresarse antes, en, y después de las próximas elecciones (...) Aquí en la Unidad de las Izquierdas, el pueblo encontrará el camino que nos conducirá a la liberación nacional ${ }^{66}$.

Además del acta fundacional, en el nacimiento mismo de la organización, se acordaban dos documentos básicos, el denominado Manifiesto (donde se desarrollaron los principios de la alianza y sus concepciones estratégicas básicas) y la Plataforma de lucha inmediata (que incluía las bases programáticas). En el primero de estos documentos, se afirma

la realización de estos objetivos, sólo se podrá alcanzar por la lucha del pueblo, que lleve al poder a los auténticos representantes de las clases trabajadoras. El Frente Izquierda de Liberación aspira a que ello pueda lograrse, en nuestro país, por vías pacíficas. El imperialismo yanqui y los reaccionarios nativos son quienes conducen a la violencia, al pretender desconocer la voluntad de las masas populares (...) (citado por Aguirre Bayley, 2012, p. 34)

\footnotetext{
${ }^{63}$ Luis Pedro Bonavita (1903-1971), ingreso a la política a fines de los años 20' vinculándose a sectores del Partido Nacional. Luego del golpe de Estado de Gabriel Terra en 1933, enfrentó a la dictadura junto a Carlos Quijano, Lorenzo Carnelli y Justino Zabala Muniz, quienes acompañaron la revolución de enero de 1935 encabezado por Basilio Muñoz. Sub secretario del Ministerio de Ganadería y Agricultura a partir de 1943. En 1959 fue miembro del directorio del Frigorífico Nacional, en representación de los productores. En 1961 renuncia al cargo en solidaridad con los obreros del ente que habían iniciado una huelga ante la represión impuesta por el gobierno del Partido Nacional. Al año siguiente, se suma al FIdeL, sector por que el fue electo diputado en 1962 y reelecto en 1966.

${ }^{64}$ Se retirará luego de la reunión de la Organización Latinoamericana de Solidaridad (OLAS) en 1967, sumándose a quienes proclamaban la vía armada como único camino posible de llegar al socialismo.

${ }^{65}$ Revista Estudios, Nro. 25, setiembre de 1962. Niko Schvarz, Un hecho augural: la creación del Frente Izquierda de Liberación, p. 2.

${ }^{66}$ El Popular. 16.07.1962.
} 
De esta manera, parecería que las elecciones se convirtieron además en una especie de plebiscito de la izquierda uruguaya, dividida entre dos estrategias políticas. Visto desde esta perspectiva, la victoria de la estrategia comunista queda legitimada, por lo menos desde el apoyo electoral, que se verá reforzada luego de las elecciones de 1966.

Juan Trímboli, era por ese entonces militante del MRO y representante de dicho sector en el FIdeL por lo que participaba regularmente de sus ámbitos de dirección. Recuerda que

el camino del Frente de Izquierda y el de la Unión Popular, que era la otra fuerza encabezada por el PS tuvo caminos muy distintos (...). Si bien el FIdeL no había tenido la enjundia electoral que tuvo después el Frente Amplio, frente a la Unión Popular la barrió. Yo creo que hubo una demostración allí de que lo que el PC planteaba (...), era la búsqueda de una unidad mucho más amplia y quienes se cerraban a esa unidad era la gente del PS, con distintos argumentos ${ }^{67}$.

La valoración positiva de las elecciones realizada por el FIdeL ${ }^{68}$, no puede sintetizarse exclusivamente a la apertura o a la alianza con otras fuerzas, durante toda la década del 60 'producto de un intenso trabajo en lo que consideraban "línea de masas", tuvo como consecuencia un aumento en el caudal militante comunista, así como el desarrollo de sus medios de prensa, propaganda, etc. Como veremos, en los capítulos siguientes, el triunfo del FIdeL, se da un contexto dónde la izquierda aparece disgregada, no solamente por el nacimiento de la Unión Popular, sino también por el surgimiento del PDC y de la Lista 99 que contenía dentro del Partido Colorado a una buena parte de la izquierda batllista.

La coherencia de la alianza sin exclusiones será una constante en la estrategia comunista del período, al punto de lanzar el FIdeL luego de constituida y presentada públicamente la Unión Popular. La esperanza de poder formar una alianza socialistacomunista seguía estando presente.

\footnotetext{
${ }^{67}$ Juan Trímboli, se vincula al MRO en 1961. Al año siguiente, será su representante en el FIdeL, siendo el suplente de Ariel Collazo en la Cámara de Diputados. Participa de la delegación uruguaya en la OLAS en 1967. Cae detenido en octubre de 1970, y sale para Chile a comienzos de 1971 haciendo uso de la opción constitucional para salir del país. Allí se vincula al MAPU chileno hasta su exilio en la RDA luego del golpe de Estado del 11 de setiembre de 1973. Durante su exilio se vincula al PCU. Radicado desde el retorno de la democracia en la ciudad de Santiago.

${ }^{68}$ Con respecto a las elecciones anteriores, y en comparación con el caudal electoral exclusivo del PCU, el FIdeL había logrado un crecimiento en casi todos los departamentos, llegando incluso a duplicar su votación en varios de ellos. En Montevideo, se había llegado a un aumento electoral de más de 12.000 votos. Esto le proporcionó no solamente una profunda victoria sobre la Unión Popular, sino también poder posicionarse como la tercera lista más votada en varias zonas obreras de la capital, como el Cerro, La Teja, Paso Molino o Belvedere. De hecho, a partir del FIdeL el PCU logró superar el punto máximo de votación que había sido en 1946, con 32.000 votos. Si bien en porcentaje, no era más que el 3,5\% del total electoral, lo significativo era la ampliación de la barrera comunista hacia determinados sectores, que de hecho, les había permitido el crecimiento.
} 
Ahora bien, más allá de que la constitución del FIdeL iba en sintonía con los postulados comunistas, no se creyó que éste era el logro del tan pensado Frente Democrático de Liberación Nacional, sino más bien que era el punto de partida, dejando las puertas abiertas a la incorporación de nuevos grupos, incluso insistiendo con la posibilidad de un frente más abarcador que incluyera definitivamente a los socialistas y sus aliados.

En 1966, señalaban

¿Quiénes pueden estar con el FIdeL? Todos aquellos que compartían su programa de soluciones. Todos aquellos que viven de su trabajo, sean colorados, blancos, comunistas, hombres de otras ideologías, católicos, protestantes, ateos. Pueden estar en él los obreros, empleados, estudiantes, amas de casa, campesinos, jubilados, comerciantes. Si se pertenece al pueblo y se sufre con él se puede estar con el Frente. Y quedaban excluidos: los latifundistas, los grandes capitalistas, los representantes criollos de los monopolios extranjeros, los especuladores, los grandes banqueros, los oligarcas. Si se explota al pueblo no se puede estar con el Frente (citado por Leibner, 2011, p. 436).

La forma organizativa del Frente, también favoreció la incorporación de varios independientes, que vieron la apertura con buenos ojos. La afiliación de Luis Pedro Bonavita o de Luis Gil Salguero, constatan esta teoría. De la misma manera, la creación de ámbitos plurales de participación también permitió la incorporación de militantes de base que no encontraban un lugar en los ámbitos más estrictamente partidarios, así la conformación del Comité de Trabajadores de la Cultura, el Comité Universitario, el Comité Obrero, etc., sumaron un lugar de militancia plural. Con esta estrategia, según El Popular, se juntaron más de mil firmas - casi todas de profesores y maestros- de adhesiones en los días previos a las elecciones de $1962^{69}$. Esta búsqueda de acercamiento con la intelectualidad, era también parte de la estrategia de llegar a las capas medias, fundamentalmente haciendo hincapié en aquellas profesiones que tenían relación con los problemas sociales: la educación, la salud, la vivienda, etc.

De hecho, si bien el PCU fue el eje alrededor del cual se movía el Frente, para la confección de las listas electorales de 1962, fueron bastante abiertos. Ariel Collazo ${ }^{70}$ dirigente del MRO- encabezó la lista a la Cámara de Diputados, y representantes destacados tuvieron lugares en casi todos los departamentos. De la misma manera, Luis Pedro Bonavita,

\footnotetext{
${ }^{69}$ El Popular. 16.11.1962.

${ }^{70}$ Ariel Collazo (1929-2014), se vincula a la política en los años 50' en el Partido Nacional, dentro de la lista 51 de Daniel Fernández Crespo. Es electo diputado por primera vez para el período 1959-1963. En 1960, visita Cuba e imbuido de las ideas de la Cuba revolucionaria y luego de varias desavenencias con el Partido Nacional, abandona el sector y funda el MRO. Es detenido en 1972 y a fines de ese año deportado a España. Regresa a Uruguay en 1994.
} 
fue el segundo candidato a la Cámara de Senadores y Luis Gil Salguero era el candidato al Consejo Nacional de Gobierno ${ }^{71}$.

El triunfo electoral, profundizó de hecho, la estrategia de las alianzas amplias como camino hacia el socialismo y le aseguró a este sector de la izquierda una muy buena representación parlamentaria: Enrique Rodríguez ${ }^{72}$ (PCU) en el Senado, y Ariel Collazo (MRO), Rodney Arismendi y José Luis Massera ${ }^{73}$ (ambos comunistas) en la Cámara de Diputados. A fines de noviembre, El Popular tituló: Victoria unitaria. Avance del FIdeL o Triunfo del FIdeL: derrota del anticomunismo, plebiscito por la unidad sin exclusiones ${ }^{74}$ por citar alguno de los claros ejemplos que encontramos en la prensa partidaria de la época. A la vez que se festejaba el triunfo, se podría ver claramente la confirmación de la estrategia, que implicaba "la más amplia unión del pueblo uruguayo" "75. Dos días después Arsimendi, recalcó "no tenemos ninguna política exclusivista, sino que nuestra política es de puertas abiertas de par en par (...). Todas las puertas están abiertas, para vigorizar la lucha reivindicativa y antiimperialista del pueblo uruguayo" ${ }^{76}$. Las referencias a Chile, en este contexto siguen siendo claras. El editorial del diario comunista, del $1^{\circ}$ de diciembre, señalaba

en lo que al FIdeL respecta, por su programa -destinado a transformar las estructuras caducas- y por su integración social -clase obrera y sectores sociales avanzados- es una fuerza enfilada hacia la revolución. Otro problema son los caminos peculiares de la revolución uruguaya. No despreciamos la lucha electoral. Sabemos que, en Chile, por ejemplo, el FRAP pasó de una elección a otra, de 50.000 a 350.000 sufragios. Pero lo fundamental es constituir la gran fuerza social que lleva a cabo la transformación revolucionaria de la sociedad. Y esta tarea no terminó con la elección: recién empieza $(\ldots)^{77}$

\footnotetext{
${ }^{71}$ Igualmente, varios militantes del PCU, mantuvieron su identidad reservada "para pasar como independientes". Este fue el caso de Luis Echave o de Jorge Martínez. Esta actitud, le costó al Partido cargar con la mochila durante varios años de intentar manipular sus organizaciones aliadas. (Leibner, 2011, p. 429)

${ }^{72}$ Enrique Rodríguez (1910-1990). Obrero del calzado desde los 14 años, se vincula al Partido Comunista desde su sector sindical en 1931. En 1936 ingresa al Comité Central del PCU. En la década del 40'fue elegido Secretario General de la Unión General de Trabajadores (UGT). Electo diputado por primera vez, para el período 1947-1951. Intervino en el viraje del PCU, liderado por Arismendi. En 1957 es el codirector del diario El Popular. En 1959 vuelve al Parlamento hasta 1963, que es electo Senador. Luego del golpe de Estado, se exilia en Praga entre 1974-1984, cuando regresa a Montevideo.

${ }^{73}$ José Luis Massera (1915-2002). Ingeniero y matemático, ingresa a la actividad política en asambleas estudiantiles y como dirigente del Movimiento de Partidarios de la Paz, durante la II Guerra Mundial. Al finalizar la Guerra se afilia al PCU. Fue electo diputado en 1962 y reelecto en 1966. Durante la dictadura, pasó a la clandestinidad y ejerció la dirección del Partido. Fue detenido el 22 de octubre de 1975. Una importante campaña desde el exterior exigió su liberación, que logró en 1984.

${ }^{74}$ El Popular. 29.11.1962.

${ }^{75}$ Ídem.

${ }^{76}$ El Popular. 01.12.1962.

77 Ídem.
} 
En el mismo sentido, Ruben Yacovski, señaló en El Popular, que la clave del crecimiento era la unidad, por lo que la izquierda unida debía mostrar la "necesidad de un polo de atracción que multiplique posibilidades" ${ }^{\text {78. }}$.

Los contactos con los comunistas chilenos prosiguieron también en el entorno del FIdeL. Con motivo de la realización de su Primer Congreso, fueron invitados los parlamentarios Baltasar Castro (Senador) y Jorge Montes (Diputado). César Reyes Daglio, relata que

trayendo la expectativa y el fraterno saludo del poderoso FRAP chileno, dos de sus representantes (...) enriquecieron el contenido del Congreso y galvanizaron el entusiasmo y la fe de quienes participaron en él y de las masas que siguieron su desarrollo ${ }^{79}$.

Siguiendo con esta misma línea, es que el FIdeL es uno de los principales impulsores de la formación en setiembre de 1965 de la Mesa por la Unidad del Pueblo, integrada también por el Partido Socialista, dirigentes sindicales, universitarios, y militantes independientes. Fue presidida por el dirigente socialista José Pedro Cardozo, Luis Pedro Bonavita, el dirigente sindical Héctor Rodríguez y el maestro Julio Castro.

Igualmente, más allá del avance de poder coordinar en un movimiento las acciones de los dos partidos marxistas con el fin de discutir un posible acuerdo programático, la experiencia no prosperó. Dos acontecimientos -uno nacional y otro internacional- provocaron una serie de discusiones que frustraron cualquier posibilidad unitaria. El primero de los acontecimientos fue la exclusividad comunista en la delegación uruguaya a la Conferencia Tricontinental que se realizó en La Habana en 1966 (conflicto que volverá a reeditarse en ocasión de la reunión de la OLAS en $1967^{80}$ ) y la segunda la reforma constitucional denominada "popular"- impulsada por el PCU a través de algunos sindicatos como alternativa a la que promovían los partidos tradicionales. Podríamos agregar como tercer elemento, el problema del lema a utilizar en caso de un eventual acuerdo electoral. El PCU puso el lema del FIdeL a disposición, cuestión que era muy difícil de aceptar por los socialistas, que como

\footnotetext{
${ }^{78}$ El Popular. 06.12.1962.

${ }^{79}$ Revista Estudios, Nro. 26, octubre de 1963. César Reyes Daglio, El Congreso del FIdeL y los caminos de unidad de las izquierdas, p. 63.

${ }^{80}$ Los cubanos organizadores de la OLAS, habían depositado en el FIdeL la responsabilidad de organizar la delegación uruguaya que participaría de la misma. Por lo tanto, en un primer momento, y haciendo un uso bastante exclusivo de su responsabilidad, habían integrado la delegación estrictamente con miembros de los grupos integrantes del FIdeL. Esto provocó nuevamente un duro debate con el resto de la izquierda uruguaya que pretendían participar. Como veremos en el capítulo siguiente, los socialistas uruguayos lograron participar en calidad de "observadores" de la Conferencia, gracias a la gestión personal que realizó Salvador Allende -por entonces senador socialista-. Mientras tanto, los comunistas siguieron encabezando la delegación, Arismendi la presidía y además fue designado por los cubanos como uno de los cuatro vicepresidentes de la conferencia.
} 
veremos en el capítulo siguiente, por varias divisiones internas necesitaban utilizar su propio lema.

Para las siguientes elecciones, en 1966, los intentos de alianza con el Partido Socialista seguían siendo infructuosos. La campaña electoral, entonces, se centró en intentar consolidarse como algo más que una mera alianza para los comicios. En un boletín propagandístico del Comité de Enseñanza Secundaria, puede leerse, por ejemplo, que "el FIdeL es mucho más que un frente electoral. Como dijera su Presidente, Luis Pedro Bonavita, lo que ha iniciado es una revolución que terminará con el pueblo en el poder" (citado por Leibner, 2011, p. 436). El apoyo electoral en 1966, fue nuevamente un triunfo de la línea comunista, logrando casi el doble de votos que en la elección anterior (76.750). La integración parlamentaria de la izquierda, quedó esta vez representada exclusivamente por los miembros del FIdeL (dada la pésima votación de la Unión Popular), siendo reelecto Enrique Rodríguez en el Senado y en Diputados: nuevamente Ariel Collazo y Rodney Arismendi, a los que se sumaron: Luis Pedro Bonavita, José Luis Massera y Gerardo Cuesta.

\subsection{El camino: lucha de masas}

La revolución no puede ser nunca el producto -como se piensa en algunos sectores de las capas medias- de un impacto genial que despierte súbitamente la emoción del pueblo (...). Comprenderá siempre y antes que nada (...) la capacidad de movilizar, organizar y conducir a la lucha a las multitudes populares (PCU, XVIII Congreso, 1962. Citado en Arismendi, 1999, p. 64)

El camino privilegiado de los comunistas de ambos países, más allá de la discusión sobre la vía pacífica o armada, que veremos más adelante, es el de la lucha de masas. Entendiéndola, como la movilización de los sectores sociales (ya sean obreros, estudiantes, pobladores, etc.) en función de lograr reivindicaciones concretas que mejoren su calidad de vida (mejoras salariales, acceso a la vivienda, etc.), que sirvieran de base para la construcción de un nuevo modelo social. Partiendo de este entendido, la lucha de masas podía materializarse de diversos modos: en una toma de tierra con el fin de profundizar la reforma agraria (en el caso chileno), en el apoyo a una huelga obrera por mejoras salariales, en un paro estudiantil, etc.

En 1965 el PCCh afirmaba: 
hemos aprendido que la unidad no se forja en frío, sino al calor de la movilización de las masas. Un obrero católico aprende más en una huelga, en la toma de los terrenos para levantar una población, en las manifestaciones callejeras y en general en las batallas de clases, que escuchando mil conferencias ${ }^{81}$.

Siempre que la acción fuera de masas, de apoyo a un sujeto colectivo, no se tomaba en cuenta la legalidad o no de la acción. "Si eran miles los partidarios de una acción radical, los comunistas debían estar conduciendo dicho movimiento" (Álvarez, 2014, p. 37). El vínculo entre estos sectores y sus movilizaciones, con la práctica parlamentaria, denominada comúnmente reformista era una constante en la visión política de los comunistas. Por ello era clave, que el militante comunista estuviera siempre vinculado con su entorno de base. No se entendía la militancia comunista, sin una práctica concreta, sin un hacer vinculado con las reivindicaciones del pueblo. Siguiendo al historiador Rolando Álvarez, era entonces, un claro llamado a la acción.

Un comunista podía estar hoy resistiendo el desalojo de carabineros en una toma de terrenos, mañana hacer un "casa a casa" por su candidato a diputado, más tarde ir a la reunión del sindicato y el fin de semana participar en las actividades de la junta de vecinos. (2014, p. 38).

Todas estas actividades, no eran visualizadas como contradictorias, sino más bien todas ellas aportaban para el objetivo final revolucionario. Entendido éste como

el movimiento de la clase obrera y del pueblo organizado, que mediante la lucha de masas, desplaza del poder a las actuales clases gobernantes, elimina el viejo aparato del Estado, las relaciones de producción que frenan el desarrollo de las fuerzas productivas e introduce transformaciones de fondo en la estructura económica, social y política del país, abriendo camino al socialismo. ${ }^{82}$

Lo revolucionario entonces no estaba determinado exclusivamente por el uso de armas, sino por el respaldo masivo y popular hacia los sectores revolucionarios. El uso de la violencia era evitable, siempre y cuando, las clases dominantes no hagan uso de ella. Como veremos en el apartado siguiente, para los comunistas chilenos las armas, aparecen con una

${ }^{81}$ Partido Comunista de Chile. Adelante por el camino del XIII Congreso. Documentos del XIII Congreso Nacional del Partido Comunista de Chile. 1965, p. 28.

${ }^{82}$ El Siglo. "Proyecto de una nueva redacción del Programa del Partido Comunista de Chile". 24.08.1969. 
utilidad defensiva y no como parte del desarrollo de una guerrilla urbana, y eran la base de discrepancia con el Movimiento de Izquierda Revolucionaria (MIR) ${ }^{83}$.

En este contexto, la participación en las elecciones, iba también de la mano de la acción de masas. Las elecciones, eran percibidas como una herramienta más de lucha, y un instrumento de liberación, que sería capaz -junto a la movilización- de crear las condiciones para la realización de cambios estructurales en el país. Son los parlamentarios comunistas, por ejemplo, los que impulsan la aprobación de leyes sociales que mejoren la vida de los sectores populares, los que acompañan un conflicto obrero, etc. Tanto Orlando Millas, como Luis Corvalán realizaron argumentaciones teóricas sobre la participación en el Parlamento de los comunistas. Él último de ellos, dirá:

nuestros diputados y senadores combinan su labor parlamentaria con la extraparlamentaria. Se les ve tanto en el Parlamento, como en la población, el Sindicato, el desfile callejero. Son profesionales de la revolución. No tienen otra actividad que la que exige su cargo. Y son asalariados del Partido. Su dieta la entregan al Partido y éste es quien les fija sus salarios. (...). Asegurar en el Parlamento un buen numero de comunistas va, pues, en beneficio de los trabajadores y del pueblo ${ }^{84}$.

La "línea de masas", fue también la línea política fundamental del Partido Comunista del Uruguay, entre 1955 y 1973. Arismendi, dirá justamente que la acción comunista debía ser pedagógica con las masas ${ }^{85}$, generadora de experiencia, desde las reivindicaciones más genuinas del movimiento popular (económicas, de mejoras de las condiciones de trabajo, etc) se irían incorporando reivindicaciones más elevadas que llevarían a cumplir con los objetivos programáticos. Al igual que su par chileno, consideraban que, desde la inserción en los ámbitos de masas, apoyando las reivindicaciones obreras, es que se pretendía elevar la conciencia de clase de los trabajadores, sobre la base de su propia experiencia cotidiana. La clave del proceso de concientización no estaba dado -entonces- solamente en el conocimiento de la doctrina teórica sino fundamentalmente en la experiencia, en la práctica cotidiana.

\footnotetext{
${ }^{83}$ Para ver las discrepancias sobre el uso de la violencia (fundamentalmente con el MIR), se pueden ver los dos artículos de Jorge Texier, en la Revista "Principios": El izquierdismo sólo favorece a la derecha, $\mathrm{N}^{\mathrm{0}} 122$, noviembre-diciembre 1967, y La herencia de Lenin en la lucha contra el ultraizquierdismo, $\mathrm{N}^{\circ}$ 134, abril-mayo 1970.

${ }^{84}$ Revista "Principios", N 104, noviembre-diciembre de 1964, p.10-20.

${ }^{85}$ Leibner sostiene que en el fondo había una concepción pedagógica, didáctica, muy sofisticada. Para concientizar al proletariado, no bastaban las prédicas, la agitación y la propaganda, ni la educación teórica en general, era necesaria la acumulación práctica de experiencias propias, de conflicto y de lucha, por parte de los trabajadores. Tampoco estas experiencias de por si elevarían espontáneamente la conciencia. Los comunistas, los elementos conscientes, los educadores si se quiere, tenían que apoyar, acompañando el proceso, participar, orientar sin imponer y sin forzar el movimiento más allá del grado de conciencia alcanzado, e ir significando la experiencia realizada $(2011$, p. 343)
} 
En este contexto, queda formalmente constituida la Unión de la Juventud Comunista (UJC), el 24 de agosto de 1955, con el claro objetivo de ser la puerta de ingreso y a la vez un ámbito de formación política de los nuevos militantes comunistas. En este mismo sentido, se celebraron varios activos de intelectuales denominados trabajadores de la cultura, con el fin de ampliar los márgenes del Partido también a esos sectores ${ }^{86}$. José Luis Massera, lo dejaba muy claro al señalar "la intelectualidad avanzada, constituye la vanguardia de la pequeña burguesía. Después del campesinado, constituye el aliado más importante del proletariado en la revolución nacional liberadora" (citado por Leibner, 2011, p. 256).

La concepción táctica, implicaba que la acción de los militantes comunistas, debía estar guiada por el apoyo a cualquier lucha reivindicativa, y en la organización de los trabajadores y los sectores populares: crear organización dónde la hubiera, fortalecerla donde fuera necesario, concientizar militantes para que se sumaran al proceso, eran las tareas básicas de un militante comunista. José Luis Massera, afirmará en 1966 que "los revolucionarios solo pueden llegar a ser efectivamente revolucionarios si actúan con las masas populares, si se funden con las masas populares, si nadan en el seno de las masas populares" ${ }^{\$ 7}$. De la misma manera, los parlamentarios comunistas debían llevar adelante las reivindicaciones de las clases populares. Se concebían, entonces, como la vanguardia revolucionaria del movimiento obrero.

Esta estrategia fue la que llevó al PCU a acompañar las huelgas de $1958^{88}$, entre ellas la de la Ley Orgánica de la Universidad, que imprimió para siempre la unidad entre el movimiento obrero y estudiantil; pero también la huelga de los frigoríficos, de los textiles, e incluso de jubilados, que entre otros conflictos se produjeron ese año. Obviamente la profunda implicancia de los comunistas uruguayos en el desarrollo del Congreso del Pueblo en 1965 y del proceso de unidad del movimiento sindical, va también en clara concordancia con esta línea.

\footnotetext{
${ }^{86}$ En este mismo momento, el PCU define comenzar a publicar la denominada "Gaceta de Cultura", una revista editada por un grupo de intelectuales comunistas, entre los que se encontraban: Juan Cunha, Atahualpa del Cioppo, Alfredo Gravina, Bernabé Michelena, entre otros, financiada exclusivamente por el Partido. Si bien, no cumplió el objetivo de ser un referente cultural, si fue importante para analizar las implicancias del Partido en poder ampliar su llegada a otros sectores, no exclusivamente obreros. Por otro lado, lo que se proponían era crear un espacio que fuera compatible entre la labor intelectual y la militancia partidaria. A la publicación de esta revista, le siguieron a partir de 1956, un espacio para reseñas bibliográficas, artísticas y culturales en la revista "Estudios", y a comienzos de los años 60'la publicación de los "Cuadernos de Cultura" y el suplemento cultural en "El Popular".

${ }^{87}$ El Popular. 20.05.1966.

${ }^{88}$ Según el dirigente, Félix Díaz, el crecimiento de afiliados en este proceso fue importante, detallando que más del $60 \%$ de los afiliados eran militantes sindicales o miembros de comités de base de empresas. El Popular. 09.08.1958.
} 


\subsection{El problema de las vías: "el camino menos doloroso de transición al socialismo"}

El problema de las vías de la revolución fue uno de los temas más debatidos en el movimiento comunista internacional a lo largo de todo el siglo XX. Como ya hemos señalado en 1956, en la Unión Soviética se producía el histórico XX Congreso del PCUS, en dónde además de las críticas al estalinismo, se reconocía la necesidad de la coexistencia pacífica entre el bloque socialista y los países occidentales, y se aceptaba -por primera vez- la pluralidad de vías al socialismo, es decir la legitimación de una vía pacífica. A grandes rasgos, podríamos decir que desde la segunda mitad de la década del 50', se fueron conformando dos grandes alternativas: quienes abrazaron fervientemente el camino del tránsito pacífico al socialismo, donde claramente se ubicó el PCCh, y quienes defendieron la teoría de la inevitabilidad de la lucha armada para lograr un cambio revolucionario.

En abril de 1956, el PCCh aun en la clandestinidad, celebra su X Congreso ${ }^{89}$, en el que define su programa político, en base a dos claros lineamientos: la revolución democráticoburguesa y la vía pacífica al socialismo ${ }^{90}$. Ya desde la declaración del "Frente de Liberación Nacional”, se venía discutiendo a la interna del partido, el tema de las vías de la revolución. Y si bien, desde su fundación se valoró el camino de la vía pacífica, se la declara como línea oficial en este Congreso.

El antecedente de lo ocurrido con el Frente Popular, confirmaba para los comunistas, la posibilidad de este camino. En un artículo de la Revista Principios de 1956, se afirma claramente que

esta cuestión ha sido planteada desde la alta tribuna del XX Congreso del Partido Comunista de la Unión Soviética. Pero, en verdad ya había sido planteada por la vida (...). En Chile se había demostrado la posibilidad de utilizar la vía parlamentaria para el ascenso al poder de las fuerzas populares. ${ }^{91}$

Si bien, como hemos visto, en la discusión sobre las vías de la revolución, la opción por este camino estaba acordado desde mediados de la década del $50^{\prime}$, no fue hasta comienzos

\footnotetext{
${ }^{89}$ Entre sus resoluciones, este Congreso, reemplaza el 4 de junio de 1912 (fecha de fundación del Partido Obrero Socialista) por el 2 de enero de 1922 (fecha de fundación del Partido Comunista) y por ende borra los 4 Congresos Nacionales que realiza el POS. Esto implica que el Congreso comenzara como el XIV y terminara como el X.

${ }^{90}$ Durante este período, numerosos artículos en la Revista Principios, compartían los argumentos del camino pacífico. Como ejemplo, pueden citarse: Luis Corvalán, Aseguremos el camino pacifico, en Principios, $\mathrm{N}^{\circ} 101$, mayo-junio de 1964; Orlando Millas, La lucha por la aplicación de la línea politica, en Principios, $\mathrm{N}^{\circ} 110$, noviembre-diciembre de 1965, y Luis Guastavino, Nuestra línea revolucionaria, en Principios, $\mathrm{N}^{\mathrm{o}} 116$, noviembre-diciembre, 1966.

${ }^{91}$ Revista Principios, $\mathrm{N}^{\circ} 35$, julio-agosto de 1956, p.34.
} 
de los años 60 'cuando comenzaron a realizarse esfuerzos teóricos para definir que implicaba la vía pacífica. En 1958, en la revista del Partido, se establece un primer acercamiento:

el Vigésimo Congreso del Partido Comunista de la Unión Soviética nos señaló diversos caminos hacia el socialismo. Planteó la obligatoriedad de tener en cuenta las particularidades nacionales en la lucha por el socialismo y la posibilidad de llegar a él por una de estas dos vías, la pacífica o la violenta; pero indicando que el camino es uno solo, el de la lucha de la clase obrera, el de la alianza obrero campesina, el de la conquista de la hegemonía por el proletariado, el de la solidaridad internacional y el de la estrecha alianza entre los países socialistas y los trabajadores de los países capitalistas en la lucha por la paz, la democracia, la independencia nacional y el socialismo. Las formas pueden cambiar, pero el contenido señalado no tiene modificación posible ${ }^{92}$.

Será nuevamente Luis Corvalán, en 1961, el que realice el esfuerzo teórico por definir lo que se entendía por vía pacífica. En su informe al Pleno Nacional del PCCh, afirma que

en las nuevas condiciones internacionales, luchando tesoneramente por la paz, por las libertades democráticas, contra los monopolios y por transformaciones de fondo, se acrecientan las posibilidades de la clase obrera de marchar hacia el socialismo por una vía pacífica, agrupando a su alrededor a la mayoría del pueblo ${ }^{93}$.

Sostuvo -además- que era necesario precisar vía violenta y vía revolucionaria, dado que, según su concepción, el camino pacífico era también revolucionario, en la medida en que se trataba de alcanzar por diferentes medios los mismos objetivos. A su vez, diferenció también el concepto de vía pacífica del uso de la legalidad, ya que el objetivo final, planteado por los comunistas era que "el movimiento obrero y popular rompa con el lastre de legalismo y se guíe, antes que por las leyes y la Constitución dictadas por la burguesía, por sus propios intereses de clase". En una breve definición, señalaba entonces que la vía pacifica "presupone lucha de clases y no colaboración de clases, no una coexistencia amigable entre explotadores y explotados, ni la renuncia al derecho a tomar las armas si ello fuera necesario" ${ }^{24}$. Para ello era clave democratizar el sistema político, condición necesaria para la aplicación de la vía pacifica y primer objetivo de la acción comunista ${ }^{95}$.

92 Revista Principios, N 52, diciembre de 1958, p. 7.

93 Partido Comunista de Chile. Informe de Luis Corvalán. Derrotemos al Imperialismo y los gerentes. Pleno Nacional del Partido Comunista de Chile. 1961, p 23.

94 Revista Principios, No 77, enero de 1961, p. 7-13.

${ }^{95}$ Esto implicaba: reformas tendientes a la ampliación del sufragio, a derogar leyes que restrinjan la pluralidad de partidos, entre ellas claramente la "Ley Maldita" y acciones tendientes a mejorar el sistema electoral, evitar fraudes, etc. Tal como afirma Marcelo Casals, el caso del PCCh es paradigmático. "Durante gran parte de su historia tendió a la participación institucional mediante todo tipo de elecciones. (...). Incluso cuando el sistema mismo le cerró las puertas a la institucionalidad, éste siguió propiciando la participación electoral”. (2010, p. 36) 
En 1963, en medio de las definiciones para la campaña electoral del año siguiente, Luis Corvalán publicará el trabajo titulado La vía pacífica es una forma de revolución, en el que parte del supuesto de que en ciertas circunstancias, el sistema burgués, puede dejar de responder a los intereses de la clase dominante (Corvalán, 1971, p. 50-68). Para ello es necesario, que los partidos representativos de las clases populares generasen un proyecto de liberación nacional, que reúna a la mayoría de la sociedad, logrando una victoria electoral. En el contexto de la campaña de 1964, Luis Corvalán publica el artículo Aseguremos el camino pacífico, en donde a partir del análisis de una posible victoria del FRAP en los comicios de setiembre, la acción de la izquierda debería estar en proteger la institucionalidad de las fuerzas rupturistas tanto de izquierda como de derecha, ya que la clave de la vía pacífica se ubicaba en la posibilidad de contar con elecciones libres, cuestión que solo podía asegurarse con un gobierno democrático estable.

Ahora bien, la derrota en las elecciones de 1964 (con el antecedente vivido en 1958) puso en debate nuevamente el tema de la amplitud de la alianza, así como puso en tela de juicio en varios colectivos de la izquierda chilena, la posibilidad real de poder acceder al gobierno por elecciones democráticas. En este contexto se producirán dos escisiones, que darán nacimiento a nuevos colectivos: la Vanguardia Revolucionaria Marxista (VRM) ${ }^{96}$ y el

\footnotetext{
${ }^{96}$ Dicha agrupación nació de la conjunción de la Vanguardia Nacional Marxista y el Partido Revolucionario Trotskista, ambas pequeñas colectividades integradas por militantes del PCCh que se habían escindido durante el período de clandestinidad, como los que apoyaron a Luis Reinoso o los fundadores del "Movimiento 2 de abril" creado en 1957 luego de los sucesos que le dieron nombre. Su principal medio de prensa, fue el periódico $E l$ Rebelde, que, aunque no desarrolló un gran aporte teórico, sus páginas si estuvieron dedicadas mayormente a la crítica por la opción sistémica de buena parte de la izquierda. Concretamente, analizaban como inviable la posibilidad de llegar al poder por la "vía pacífica", fundamentando su teoría en la inexistencia de ejemplos históricos. Tanto la Unión Soviética, como China y Cuba, habían logrado el triunfo revolucionario a partir de una opción violenta. Para ello, entonces, la institucionalización de la izquierda chilena más que sumar, era un obstáculo para la evolución del cambio revolucionario. Incluso, criticaron la opción de la lucha de masas propugnada por los comunistas, no desde el punto de vista teórico, sino por el uso que el PCCh le daba. La práctica comunista de ampliar su alianza política y sus bases sociales, también irían en el camino de colaboración con las clases opresoras. Este debate se enmarca en medio del conflicto chino-soviético, en relación a las diferentes estrategias propuestas y a los afanes hegemónicos de ambas potencias. La VRM defendió claramente los postulados del PC chino. En mayo de 1964, realizan su Primer Congreso, ya con la participación de Miguel Enríquez (que como veremos en el capítulo siguiente, había roto con la Juventud Socialista). Este será el escenario de división de la organización, entre el sector pro chino liderado por Benjamín Cares (que luego se unirá al Partido Comunista Revolucionario) y el sector conocido como "VRM- Rebelde" (integrada entre otros por Miguel Enríquez), quienes entorno al periódico promovieron un programa de corte socialista. Fue este último grupo, el que encabezó una crítica a las estrategias sistémicas desarrolladas por la izquierda tradicional. Igualmente, en junio, llamaron "al pueblo a levantar una vigorosa movilización a través de huelgas, de mitines, de ocupaciones de fäbricas, minas, tierras y sitios para vivir, que preparen y organicen la conquista del poder por los trabajadores, y la transformación socialista de Chile. Llamamos al pueblo entero a apoyar la candidatura presidencial de Salvador Allende" (Amorós, 2015, p. 124) Ya desde 1964, diversas figuras políticas afines a las posturas rupturistas, comenzaron a trabajar con el fin de unificar a estos pequeños grupos. Las reuniones, se realizaron en el local de la VRM-Rebelde en Santiago, y fueron dirigidas entre otros por Clotario Blest, Enrique Sepúlveda, y Oscar Waiss. El resultado fue la organización del Congreso de la Unidad Revolucionaria, realizado en agosto de 1965 realizado en el local de la Federación del Cuero y Calzado de la ciudad de Santiago. El nuevo colectivo funcionaría en base a cuatro pilares básicos: la independencia política, la fijación de objetivos
} 
grupo conocido como Espartaco ${ }^{97}$. El PCCh en ese contexto, había rechazado enérgicamente la tesis de las "dos piernas", que proponía el simultáneo desarrollo de la integración al juego electoral con una política militar con miras a organizar un movimiento insurreccional.

De hecho, la expulsión de estos colectivos fue funcional a la interna del Partido para el mantenimiento de la línea, ya que implicó la reafirmación de la opción sistémica a la interna. Pocos días luego de realizado el acto electoral, el Partido afirmará:

nuestra línea política ha demostrado ser justa. Lo que se plantea ahora no es cambiarla sino enriquecerla para actuar de acuerdo a la nueva realidad. Nuestra vía pasa por las elecciones, pero no es una vía electorera, y no nos cruzamos de brazos en el período que media entre una y otra elección. Nuestra vía es ante todo, la vía de las masas, de lucha, de combate; es la vía del movimiento multitudinario de masas y nos exige consolidar y ensanchar los progresos e impulsar los combates de la clase obrera y del pueblo por sus objetivos sociales, económicos, y políticos $(\ldots)^{98}$.

El PCCh, reafirmó su línea política basada en la vía chilena al socialismo. "Ni la frustración por la derrota, ni las tensiones internas, ni la radicalización de su principal aliado, sacaron al PC de su camino de construir el socialismo, sin un baño de sangre (...).” (Álvarez, 2014, p. 30). Gladys Marín reafirma esta idea al señalar que,

después de la derrota del 64 no nos desanimamos. Había un movimiento que tenía un propósito, que tenía un destino. (...) Por eso no recuerdo haber sentido para nada como una derrota los resultados de la elección del 64 (...) porque uno sentía que había un movimiento que iba creciendo. (2002, p. 73).

revolucionarios socialistas inmediatos, la restauración del camino revolucionario que había marcado Recabarren y la defensa de una amplia democracia interna que permita un permanente y profundo debate político. Del Congreso participaron unos 60 delegados, que representaban a una serie de pequeñas organizaciones rupturistas como: el grupo anarquista "Libertario", el cristiano Clotario Blest acompañado de un sector sindical clasista, el Partido Socialista Revolucionario, el trotskista Partido Socialista Popular, un grupo de las Juventudes Comunistas dirigido por Luciano Cruz y la VRM- Rebelde. Como veremos con más detenimiento en el capítulo siguiente, fue en base a este amplio espectro político que nació el MIR.

${ }^{97}$ El grupo de orientación pro-china, se originará al comienzo a la interna del PCCh, liderados por el entonces Senador Jaime Barrios. Al igual que otras tendencias rupturistas, basarán su planteo en que la derrota de 1964, mostró la necesidad de modificar la estrategia y volcar la organización hacia la vía armada. Luego de afirmar que "sólo la acción directa, a través de la insurrección armada, puede implementar el proceso revolucionario que llevará al pueblo al poder", fueron inmediatamente expulsados del Partido. (Arrate y Rojas, 2003, tomo I, p.382). Fundan lo que se conocerá como "Espartaco", quienes en 1966 (unificándose con otros grupos) darán nacimiento al Partido Comunista Revolucionario (PCR), de orientación maoísta. Coherentes con su línea ideológica, no se integrarán ni al FRAP, ni a la UP, y serán duramente críticos con ambos procesos.

98 Revista Principios, $N^{\circ} 103$, setiembre- octubre de 1964, p.129. 
El triunfo de Frei no implicaba entonces el fin de su línea estratégica, sino simplemente la postergación del momento histórico para su aplicación. Ni el diagnóstico, ni la estrategia, ni -por supuesto- la unidad de la izquierda fueron puestos en cuestión.

Es en 1965, que el Partido produce un viraje en su línea política, implantando lo que denominó como vía no armada, lo que significaba un claro reconocimiento de que el camino hacia el socialismo no sería necesariamente pacifico, sino que serían inevitables diversos grados de violencia social. Es decir, que si bien se privilegiaba el camino de la acción parlamentaria por sobre el camino armado, este no descartaba la posibilidad de la lucha armada, siempre y cuándo fuese inevitable. En realidad, lo que se discutía no era el uso de la violencia en términos generales, sino la negación de la estrategia de la insurgencia general.

En el XII Congreso de 1962, se afirmó:

el pueblo no busca la violencia. Una vez más dejamos claramente establecido que los comunistas estamos por que el país decida su futuro sin guerra civil. Pero que el enemigo no piense que la clase obrera y las masas populares chilenas no le van a hacer la cruza en cualquier terreno. La decisión del pueblo chileno es irrevocable: conquistar su derecho a gobernarse por sí mismo (...). Y que sepa el enemigo que si desata la violencia, la peor parte la sacara é $1^{99}$.

Estas definiciones serán claves en la estrategia a tomar durante el gobierno de la Unidad Popular y centro de debate con un importante sector del PS, y obviamente del MIR. Tal como señala Luis Corvalán,

la vía pacífica no está obligatoriamente vinculada a las elecciones, que en ella lo fundamental es la lucha de masas, que se puede llegar pacíficamente al poder de distintas maneras y que, en el caso chileno, considerábamos más probable acceder a él -y en este sentido nos orientábamos- a partir de la conquista del Gobierno en una elección de Presidente de la República. Sostuvimos además, que esta vía no desaloja acciones de fuerza, violentas, como la toma de terreno por los pobladores sin casa y que, por esto mismo, para ser rigurosos debíamos llamarla vía no armada en vez de pacífica. (2010, p. 100)

El giro estuvo marcado no solamente por las críticas de otros sectores de izquierda, sino por el aprendizaje recorrido luego de las represiones sufridas durante el gobierno de Frei Montalva. La diferencia sustancial con otros sectores, se encontraba en la creencia de que no era necesaria una ruptura institucional o la toma del poder por una vía violenta, sino que la

\footnotetext{
${ }^{99}$ Partido Comunista de Chile. Informe de Luis Corvalán. Hacia la conquista de un Gobierno Popular. XII Congreso Nacional del Partido Comunista de Chile. 1962, p.39.
} 
estrategia era la de fundar una nueva sociedad a partir de la construcción de una fuerza política y social hegemónica, a partir del desarrollo de la lucha de masas, donde el juego electoral tenía un rol preponderante pero no excluyente de otros caminos. Volodia Teitelboim ${ }^{100}$, lo explicita claramente en su intervención en el XIII Congreso del PCCh: "lo electoral no es la llave inevitable del poder y por eso el Partido ha llamado a dominar todas las formas de lucha"101.

En el caso uruguayo, que como vimos se encontraba en el medio del debate luego de 1955, las resoluciones del XX Congreso del PCUS con respecto a la posibilidad de la vía pacífica, les permitía desarrollar una estrategia política de acuerdo a las tradiciones democráticas imperantes en el país. Guiados por los aportes teóricos de Arismendi, podríamos decir que con respecto a este debate el PCU se ubicó en un camino intermedio. Si bien mantuvo una profunda defensa del trabajo de masas en barrios, sindicatos, gremios, etc., y la apuesta por el camino electoral, a la vez sostenían que el camino más probable para la revolución latinoamericana era el armado, fundamentalmente luego del triunfo de la revolución cubana.

El PCU pensaba que valía la pena avanzar hacia sus objetivos estratégicos dentro de la legalidad "burguesa" tanto como fuera posible. Sin embargo, no se hacía ilusiones acerca de poder recorrer la vía pacífica hasta el final. De hecho, como veremos en el apartado siguiente, el camino intermedio los llevó a profundizar entre el "frente de masas", fundamentalmente en el movimiento sindical y estudiantil y a la creación de un frente político encaminado a promover la unidad de las fuerzas de izquierda, a la vez que resolvieron la creación de un aparato armado que mantuviera a los militantes preparados para el desarrollo de cualquier forma de lucha.

En su informe sobre el XVII Congreso que Arismendi elevó al Comité Nacional del PCU, señaló que

en las nuevas condiciones mundiales, no es obligatorio que la revolución socialista sea siempre acompañada por la guerra civil, es decir por la insurrección y la lucha armada

\footnotetext{
${ }^{100}$ Volodia Teitelboim (1916-2008), empezó a militar en las Juventudes Comunistas (JJCC) en 1932. Poco tiempo después, ingresó a estudiar Derecho e la Universidad de Chile. Luego de dictada la Ley de Defensa de la Democracia, fue detenido y trasladado a Pisagua. Entre 1961-1965 fue electo diputado y al terminar su mandato electo Senador, cargo que ejerció hasta el golpe de Estado del 11 de setiembre de 1973. Durante la dictadura militar se exilió en Moscú. Regresó clandestinamente a Chile en 1988. Al año siguiente fue electo Secretario General del PCCh, cargo que ejerció hasta 1994. Desarrolló a la vez, una importante carrera literaria, recibiendo el Premio Nacional de Literatura de Chile en el año 2002.

${ }^{101}$ El Siglo. "Intervención de Volodia Teitelboim en el transcurso del XIII Congreso del PC". 15.10.1965.
} 
subsiguiente. En algunos países, dentro de determinadas circunstancias, es posible la transición pacífica e inclusive, la utilización del Parlamento ${ }^{102}$.

Sin embargo, agregaba que, si bien el camino pacífico no debía descartarse para el caso uruguayo, tampoco debía considerarse único, ni siquiera el más probable. Consciente de las críticas que podrían desarrollarse, a partir de esta interpretación, Arismendi fue bastante cauteloso en abrazar dicha estrategia, estableciéndola como una posibilidad. Si bien parece un matiz, o el uso de un término, la variable estaba no en concebirla directamente como una alternativa a la vía armada o insurreccional, sino como una posibilidad más. Es decir, que ninguno de los caminos quedaba descartado.

Arismendi recordó que en esa misma reunión del Comité Nacional del Partido un participante habría planteado que dadas las características del Uruguay se podía proclamar la inevitabilidad del desarrollo pacífico de la revolución. El planteo fue rechazado (Yaffé, 2016, p. 191). Con el antecedente de lo ocurrido en Guatemala en 1954, luego del derrocamiento del presidente constitucional Jacobo Arbenz, las posibilidades del tránsito pacífico al socialismo en América Latina tenían limitaciones que no dependían solamente de la voluntad de los revolucionarios. El avance del anticomunismo, sumado a la evolución de las acciones autoritarias por parte de los gobiernos uruguayos de las décadas del 60'y los primeros años del 70', hacían que se visualizara el uso de la violencia como el más probable para el avance de un proceso revolucionario.

La posición matizada de Arismendi será la que se impondría como oficial del PCU, y permitirá coexistir en la interna a quienes acordaron con esta posibilidad, junto a los marxistas más ortodoxos, que imaginaban a la revolución como la insurrección armada conducida por la clase obrera, inspirados en los relatos soviéticos.

La vía pacífica, con la posibilidad de aumentar la representación comunista en el Parlamento, y acumular hasta lograr el acceso al Poder Ejecutivo, de cierta manera, se había respaldado con el triunfo electoral de las elecciones de 1962 y fundamentalmente de 1966. Sumado a un aumento del caudal militante, del fortalecimiento de la clase obrera (luego de la realización del Congreso del Pueblo y de finalizado su proceso de unificación en la Convención Nacional de Trabajadores), y del aumento de los jóvenes que se iban acercando a la UJC.

Sin embargo, es en este contexto, que comienzan a gestarse también opciones rupturistas - no solo dentro del Partido Socialista- sino también dentro del PCU. Al igual que

${ }^{102}$ Revista Estudios, Nro. 2, abril-mayo de 1956, pp. 33. 
su par chileno, el conflicto chino-soviético que se estaba produciendo en el campo socialista, también tuvo algunas consecuencias en la interna uruguaya. Un grupo de jóvenes militantes de la UJC, mayoritariamente universitarios, adhirieron con las tesis maoístas. Al Partido continuar sosteniendo su fidelidad a la Unión Soviética y no permitir una expresión contraria a su interna, este colectivo se alejó y en 1963 fundaron una nueva organización, denominada Movimiento de Izquierda Revolucionaria (MIR) ${ }^{103}$.

Lo interesante de este conflicto, - más allá de las discusiones a nivel ideológico sobre el campo socialista y las estrategias a nivel internacional-, fue que si bien se les criticaba por su pretensión de generar una vanguardia revolucionaria sin anclaje en la clase obrera y sin vínculos con el Partido Comunista, Arismendi dejó en claro que no quedaban excluidos dentro de lo que él consideraba "aliados". De hecho, deja en claro "que sectores radicalizados del estudiantado provenientes de "capas sociales intermedias" iban a cumplir importantes funciones en la lucha por la revolución agraria y la liberación nacional". (Leibner, 2011, p. 472-473) El ejemplo claro, de revolucionarios provenientes de los sectores intermedios que habían logrado superar ideológicamente su origen de clase, estaba encarnado claramente en Fidel Castro.

Ahora bien, el matiz de Arismendi, no era solamente por el cálculo de mantener unido internamente al Partido, sino por la profunda convicción de que la vía pacífica podía desarrollarse en Uruguay, dependiente de algunas condiciones: primero de la necesidad de que la clase obrera, sea la conductora del proceso revolucionario; en segundo lugar, la materialización de esa posibilidad, dependía además no solamente de las condiciones subjetivas, sino también de las objetivas: correlación de fuerzas, y dinámicas políticas, tanto a nivel nacional, como latinoamericano y mundial.

Arismendi argumentaba que el PCU se pronunciaba "por el camino menos doloroso de transición al socialismo". (Leibner, 2011, p. 284). Es decir, que se prefería la vía democrática, pacifica, como primera opción, pero se reconocía la existencia de que las clases dominantes (externas, encarnada en el imperialismo norteamericano e internas) evitarían la realización de dicha posibilidad. Es decir, que el uso de la violencia, no dependía únicamente de las acciones de las clases populares, sino de la reacción de las fuerzas del orden vigente, que iba a

\footnotetext{
${ }^{103}$ Un dato no menor, es que el quiebre de esta nueva organización, no se produjo de la forma de una ruptura tradicional. El nuevo colectivo, no rompió unificadamente, sino que se produjeron distanciamientos individuales y el MIR se conformó como tal con militantes ya alejados de la UJC. De todas maneras, luego de constituida la nueva organización, si tuvieron una cierta influencia sobre los jóvenes militantes comunistas y una actitud abiertamente hostil hacia las definiciones del PCU.
} 
agudizarse con las contradicciones de clase y con el avance político de la izquierda. Por lo tanto, ninguna vía podía quedar descartada de antemano. La vía pacífica aparecía entonces, como una posibilidad no exclusiva, ni siquiera necesariamente predominante e incluso no necesariamente la más probable.

El objetivo de Arismendi, por otro lado, era desbaratar los argumentos de la izquierda rupturista, y brindar argumentos teóricos sobre las perspectivas revolucionarias, la táctica a desarrollar por el movimiento obrero, con el fin de preparar a las masas hacia las formas superiores de la lucha, que no iban en consonancia -necesariamente- con querer "cortar camino" 104 .

La precaución - de no abrazarse completamente hacia el camino pacífico- sumado al triunfo de la revolución cubana en 1959 que confirmó la tesis del uso inevitable de la lucha armada, le permitió celebrar el triunfo revolucionario de la isla sin necesidad de contradecirse ni justificarse. Por otro lado, ya en Problemas de una revolución continental ${ }^{105}$, Arismendi había dejado en claro que la revolución uruguaya no se podía separar del contexto del continente, y que la posibilidad del triunfo revolucionario iba a estar marcado por el proceso de la revolución continental. Esto llevaba necesariamente, a la conclusión de que la vía armada era la menos deseada pero la más probable; pero también a que era necesaria la defensa de las libertades democráticas -que por lo menos en un período- se vivían en Uruguay.

\subsection{1. "Prepararse para cualquier forma de lucha": la necesidad de un aparato armado}

La concepción de que las clases dominantes iban a defender "con uñas y dientes" sus privilegios, sumado a los avances autoritarios que comenzaban a visualizarse en América Latina, provocaron que ambos Partidos Comunistas - con mayor o menor desarrollovisualizaran la necesidad de crear un aparato armado y preparar a sus militantes para cualquier forma de lucha -tal como ellos mismos señalaban- o para defender las conquistas del pueblo luego del posible triunfo del gobierno popular.

El PCCh, desarrolló en los primeros años de la década del 60' un aparato militar, que denominaron como "comités de vigilancia" y "grupos chicos" que recibieron instrucción

\footnotetext{
${ }^{104}$ Para poder entender el desarrollo teórico de Arismendi, en este terreno, son fundamentales tres artículos de la revista Estudios de 1964 que van en sintonía: Cinco anotaciones acerca de la situación política nacional y la táctica del movimiento obrero y popular (Nro. 28 de marzo-abril); Anotaciones acerca de la táctica del movimiento obrero y popular. Después del golpe en Brasil (Nro. 29 de mayo-junio) y Anotaciones acerca de la táctica del movimiento obrero y popular (Nro. 30 julio-agosto)

105 Revista "Estudios", Nro. 19-20, mayo de 1961.
} 
militar en la Unión Soviética primero y en Cuba luego, como parte de su formación como cuadros políticos. Luis Corvalán, recordará más adelante que

nosotros, desde 1963, habíamos empezado a formar militarmente a miembros del Partido con miras a defender las conquistas del pueblo chileno cuando este alcanzara el poder, de lo que estábamos absolutamente seguros. Constituimos los llamados Grupos Chicos compuesto cada uno de éstos por no más de cinco compañeros. (...). Constituimos también las Comisiones de Vigilancia (...) y se prepararon para la defensa personal y la lucha callejera y la custodia de locales y dirigentes (...). (2010, p. 163).

En Uruguay, la intensificación de la vida política, luego del golpe de Estado en Brasil en abril de 1964, la crisis económica por la que se encontraba atravesando América Latina en general, y la ruptura de relaciones con Cuba van a provocar que -según Jaime Pérez-

nosotros decidamos que es necesario crear una estructura armada del Partido. Ahí estábamos Arismendi, Suárez, yo y Aurelio Pérez González, una persona que en su juventud había hecho el servicio militar y que había sido empleado de un frigorífico. ¿Cuáles eran las razones que nos llevaron a eso? Primero, que estaba en el aire la posibilidad de un golpe militar. Es decir que arrancamos pensando que a un golpe militar había que enfrentarlo, naturalmente con las masas (...). (1996, p. 27).

Es interesante señalar, que es el golpe de Estado en Brasil y no la revolución cubana, lo que alerta al PCU de la necesidad de desarrollar un aparato armado, que este a la orden del acontecer de los sucesos políticos.

Arismendi, señalaba "en estas circunstancias, el movimiento obrero y popular uruguayo debe procurar estar en condiciones de actuar en todos los terrenos en que se promueva la lucha. Lo hemos dicho y repetido cien veces" ${ }^{\text {106 }}$. Y tan solo dos meses después, agregaba

la clase obrera y el pueblo del Uruguay se plantea el problema que tantas veces han debido afrontar dramáticamente tantos países de América Latina (...) la capacidad de pasar rápidamente de una a otra forma de lucha, tanto en lo referente a la preservación de un movimiento popular que puede verse obligado a pasar a la clandestinidad como a la posibilidad de enfrentar al enemigo con las armas en la mano" ${ }^{107}$.

\footnotetext{
${ }^{106}$ Revista Estudios Nro. 29, mayo-junio de 1964. Rodney Arismendi, Anotaciones acerca de la táctica del movimiento obrero y popular. Después del golpe en Brasil, p. 6.

${ }^{107}$ Revista Estudios Nro. 30, julio-agosto de 1964. Rodney Arismendi, Anotaciones acerca de la táctica del movimiento obrero y popular, p. 7.
} 
Siguiendo con la idea de que la clave de la estrategia era la lucha de masas, la elección de los métodos de lucha, dependían del "estado de ánimo" de las masas, por lo que seguía siendo necesario cooptar la simpatía de la clase obrera y los sectores populares ${ }^{108}$. Por otro lado, se asumía que para poder tener las condiciones para el pasaje de un método a otro de lucha, era necesaria la preparación de los militantes. La existencia del aparato armado, quedaba entonces justificada por la necesidad de tener militantes preparados para la lucha antigolpista.

Jaime Pérez ${ }^{109}$, presenta además otro motivo, para la creación de un aparato armado a la interna del PCU.

En el 64'el maoísmo por un lado, la experiencia guerrillerista por otro, la agudización de la crisis en el país, generaron en la juventud, principalmente en la estudiantil, lo que podríamos llamar "cortoplacismo", es decir, la idea de que alcanzaba con tirar unos tiros y se lograba el triunfo revolucionario. (...). En tanto partido, nosotros habíamos tenido prácticamente de siempre la autodefensa. Esa autodefensa fue el núcleo de la estructura armada. Justo es decir que nunca matamos ni herimos a nadie. Justo es decir, también, que si no hubiéramos hecho eso el propio MLN podía haberse transformado en una organización de miles y miles de jóvenes y haberse generado una autentica tragedia nacional. El hecho de haber creado ese aparato militar nuestro, le dio escape a una cantidad de jóvenes comunistas para no trasladarse al $\mathrm{MLN}^{110}$. (1996, p. 28).

Podemos pensar entonces, que fue con un objetivo preparativo, pero también para retener a una cierta militancia, que ya desde 1964 (y en los años siguientes) algunos jóvenes comunistas realizaron pequeños atentados, por ejemplo en el marco de la ruptura de

\footnotetext{
${ }^{108}$ Arismendi, reafirmaba que aún en esas condiciones [de intentos golpistas] la iniciativa de la violencia por la reacción, la elección de los métodos de lucha siguen estando subordinados a la situación política, en particular al estado de ánimo de las masas. La práctica de tales métodos pasa, pues, a depender en gran medida de la existencia previa de una preparación adecuada, de la existencia de cuadros y de la aptitud combativa de la vanguardia revolucionaria capaz de arrastrar tras de sí a la mayoría de la clase obrera y del pueblo.
}

(Revista Estudios Nro. 30, julio-agosto de 1964. Rodney Arismendi, Anotaciones acerca de la táctica del movimiento obrero y popular, p. 7).

109 Jaime Gerschuni Pérez (1928-2015) Hijo de una familia judía de Europa oriental, se vincula desde muy joven al PCU. Integró durante muchos años la Junta Departamental de Montevideo, hasta 1971 que fue electo diputado. Durante la dictadura militar, estuvo detenido entre 1974 y 1984. En 1988, sustituyó a Rodney Arismendi en la Secretaría General del PCU y un año después, fue electo Senador. Producto de la crisis de la Unión Soviética y su repercusión en el comunismo internacional, renuncia a la Secretaría General y al Partido en 1992.

${ }^{110}$ Tal como plantea Leibner, justificar el desarrollo de un aparato armado, con el fin de mantener dentro del Partido a los jóvenes "radicalizados" entra en franca contradicción con los mínimos criterios de seguridad que cualquier organización armada (con más o menos desarrollo) cuida. En este sentido, el conocimiento de estos jóvenes de la existencia de dicho aparato parece ser, por lo menos reducida. (...) "saber en el sentido de tener la certeza y alguna información concreta que se estaba preparando un aparato armado al interior del Partido no era algo que "miles de miembros de la Juventud Comunista" lo supieran." (Leibner, 2011, p. 483). 
relaciones con $\mathrm{Cuba}^{111}$, o cuando la invasión norteamericana en República Dominicana (mayo de 1965$)^{112}$ e incluso cuando la visita del Presidente norteamericano Lyndon Jhonson en $1967^{113}$, con el fin de "tan solo elevar en dos grados la temperatura" (testimonio anónimo, citado por Leibner, 2011, p. 493).

El latinoamericanismo de las acciones de solidaridad, era considerado una especie de aporte nacional, al camino de la revolución latinoamericana, a la vez que iba preparando a los militantes para el momento del desarrollo de la revolución uruguaya. No es menor señalar, que en las tres actividades reseñadas, fueron acompañadas de acciones de masas: la marcha hacia el aeropuerto para despedir a los diplomáticos cubanos, la jornada en la principal avenida de la capital para denunciar la intervención en Santo Domingo y la marcha de jóvenes hacia Punta del Este por la visita de Jhonson en 1967. Tal como señala Leibner, haciendo referencia a los militantes entrevistados para su investigación, todos se manifestaron más o menos en estos términos "que la vanguardia actúe como tal, arrastrando al movimiento popular en su conjunto, pero solo un paso adelante, sin desprenderse de él y sin aislarse." (2011, p. 496).

\subsection{Algunas apreciaciones finales}

Como hemos visto a lo largo del capítulo, el desarrollo estratégico de ambos partidos comunistas, tuvo escasas variaciones en el período 1956-1967. La profunda raigambre en el Movimiento Comunista Internacional, y fundamentalmente la clara dirigencia en éste, del PCUS, ha producido que ambos partidos en contextos políticos -internos y externosclaramente diferentes, enuncien una estrategia política muy similar. No es menor señalar, que el comunismo latinoamericano no construyó un organismo coordinador a nivel continental, como si lo hicieron otros sectores de la izquierda. Pareciera que los lineamientos emanados desde Moscú, fueran suficientes para construir sus tácticas políticas a nivel local. Justamente,

\footnotetext{
${ }^{111}$ El 08.09.1964 Uruguay rompe relaciones con Cuba siguiendo las recomendaciones de la Asamblea General de la OEA realizada en Punta del Este, pese a que se abstuvo de votar la resolución. En este contexto, la revista Estudios por ejemplo registra: pintadas, manifestaciones relámpago, estallidos de bombas frente al National City Bank, la Embajada de Estados Unidos, la fábrica de la Coca- Cola y el incendio de autos de diplomáticos norteamericanos. Al día siguiente, bombas contra la empresa McCormick, contra el local de la Alianza Cultural Uruguay- Estados Unidos, frente a la Embajada de Brasil, Radio Carve y frente a los domicilios de Luis Giannattasio (Presidente del Consejo Nacional de Gobierno) y otros tres Consejeros. (Nro. 31, setiembreoctubre de 1964. Cronología de una gran batalla popular, p. 8-20.)

${ }^{112}$ El Popular. "Enérgicas demostraciones de repudio por la agresión yanqui en Santo Domingo". 04.05.1965. La nota iba acompañada de una página entera de fotografías que registraban las manifestaciones del día anterior, una de ellas de dos jóvenes apedreando el local del Pan American, con el agregado a pie de foto que "la empresa yanqui concita el odio de los jóvenes".

${ }_{113}$ Estudios Nro 43, 1967, Cronología. Memorables jornadas antiimperialistas, p. 17-22.
} 
el aporte teórico fundamental de Arismendi, fue elaborar para América Latina y para Uruguay, un análisis de la realidad del continente que fuera afín con los lineamientos generales.

Hemos analizado, como la unidad de las fuerzas de izquierda -a nivel político partidario y a nivel social (sindical, estudiantil, etc.)- fue el motor de la acción de los comunistas en estos once años. La unidad del pueblo -en sentido amplio-, la alianza con la burguesía nacional pero manteniendo en la clase obrera la vanguardia del proceso, el desarrollo de la lucha de masas (acompañado de su apuesta en las diferentes instancias electorales) y la vía pacífica como camino prioritario (aún con el matiz planteado por el PCU) para alcanzar el socialismo, fue común y permanente en ambos sectores hasta ocurridos los golpes de Estado en ambos países en 1973.

Lo que más apreciaban los comunistas uruguayos de los chilenos, era su claro raigambre obrero y popular y la posibilidad de haber concretado la alianza con los socialistas. Hemos analizado, como la experiencia del FRAP -fundamentalmente a partir de las elecciones de 1958, pero también de 1964- fue un ejemplo claro para el comunismo uruguayo, que la estrategia de la alianza con el socialismo era acertada, y que podía de hecho, llevarlos a un triunfo electoral. La afirmación en varios documentos, de conformar una alianza similar, son muestras de ello, así como el permanente contacto entre ambos partidos y la asistencia del comunismo chileno en actos en Uruguay, con el fin de mostrar justamente como ese camino iba dando sus frutos en el país trasandino.

Los matices planteados por ambos sectores, se desarrollaron entonces fundamentalmente por la diferencia en los contextos nacionales en los que se movían. En el caso de los comunistas chilenos, adhirieron a la vía pacífica, con mayor entusiasmo que su par uruguayo. El triunfo electoral del Frente Popular en los 30', así como una unidad mayor de la izquierda (que permitió acercarse al triunfo luego de conformarse el FRAP en 1956), permitieron visualizar en este camino una posibilidad mucho más real que en su par uruguayo. No debemos olvidar, que los comunistas chilenos adhirieron al camino pacífico antes que la realización del XX Congreso del PCUS, ya en 1951 con la conformación del FRENAP. Las resoluciones del Congreso soviético confirmaron el camino.

A su vez, la imposibilidad de la unificación de las izquierdas, incluso en el primer paso socialista-comunista, y el avance de la derecha, de las acciones anticomunistas y de las políticas represivas del gobierno uruguayo, también dan cuenta de la convicción del comunismo, de que la vía armada era la menos deseable pero la más probable. 
De esta manera, pareciera que los comunistas uruguayos, iban un paso atrás de su par chileno. Si bien la estrategia política era extremadamente similar, la posibilidad de la concreción de la misma en Chile, provocó que desde Uruguay se observara con detenimiento lo que iba sucediendo en el país vecino. 


\section{Socialismo o Miseria: la recepción del socialismo chileno en su par uruguayo (1956- 1967)}

En el presente capítulo, nos dedicaremos a analizar el recorrido ideológico que realizaron los Partidos Socialistas tanto en Chile como en Uruguay desde 1956 hasta 1967, con el fin de poder analizar la influencia que el socialismo chileno desarrolló sobre el uruguayo, intentando rastrear momentos de contacto y zonas de influencia.

1956, fue un año clave, para ambos partidos socialistas. En Chile comienzan los intercambios para la unificación del socialismo y se funda el FRAP. En Uruguay, es el inicio de un profundo y gradual movimiento interno, que producirá un giro en su estrategia política, su alineamiento internacional, etc. Analizaremos en este capítulo hasta 1967, cuando el Partido Socialista uruguayo es ilegalizado por el Poder Ejecutivo, junto con otras colectividades de la izquierda. A partir de allí, comienza otro periplo, que se profundizará con el avance autoritario en Uruguay y las etapas finales del largo camino por la unificación que transitó la izquierda uruguaya.

Organizamos el capítulo, en cuatro apartados. En el primero de ellos, nos dedicamos a analizar los encuentros entre socialistas uruguayos y chilenos, los momentos de contacto, dedicándonos particularmente a la experiencia de construcción del Secretariado Latinoamericano de la Internacional Socialista (IS), cuya sede funcionó en Montevideo y promovió un profundo intercambio entre los partidos socialistas de la región.

En el segundo apartado, analizamos el carácter de la revolución, como era ésta considerada para el socialismo chileno y uruguayo, y la definición de Revolución Democrática de los Trabajadores.

En el tercer apartado, analizamos el tema de las alianzas, la discrepancia de la alianza con la burguesía nacional y la propuesta de construir colectivos de clase; las enseñanzas del FRAP en Chile y la posibilidad de una acción común con el comunismo; el rechazo a la alianza con los comunistas en Uruguay y la fundación de la Unión Nacional y Popular (primera apertura del socialismo uruguayo).

En el último apartado, analizamos los caminos: los debates entre la vía pacífica y la vía armada, la necesidad de la unidad de acción para la revolución, y el involucramiento de militantes socialistas de ambos países en experiencias de militancia armada directa, así como la participación de ambos partidos en la OLAS. Cerramos el capítulo, con algunas apreciaciones finales. 
El origen del Partido Socialista en Chile, se remonta al año $1933^{114}$. En este contexto, donde los sectores de la izquierda venían discutiendo la consigna de crear Frentes Populares, si bien los socialistas se resistieron a ello en un primer momento, luego de una fuerte huelga ferroviaria reprimida por el gobierno de Alessandri en 1936 revisaron su posición y acordaron la idea de formar un Frente Popular antiimperialista y antireaccionario. El gobierno del Frente Popular, será clave para la línea política que impulsarán los socialistas en las décadas siguientes. Evaluándolo como insuficiente, en enero de 1943 en su IX Congreso, se impuso la línea de romper con la alianza. A diferencia de los comunistas, la experiencia del Frente Popular, mostró la necesidad de crear una coalición únicamente integrada por fuerzas de izquierda, siendo por lo tanto inconveniente insistir en un acuerdo con los radicales (y más adelante con la Democracia Cristiana).

La ilegalización del comunismo, provocó una fractura dentro del PS entre quienes apoyaron la medida y se denominaron Partido Socialista de Chile (PSCh) y el grupo mayoritario que se opuso a la proscripción, y pasó a denominarse Partido Socialista Popular (PSP), donde permanecieron la mayoría de sus líderes históricos, entre ellos Salvador Allende, Raúl Ampuero ${ }^{115}$, Clodomiro Almeyda ${ }^{116}$ y Carlos Altamirano ${ }^{117}$.

${ }^{114}$ Recordemos que el Partido Obrero Socialista, fundado en 1912, se transforma luego de su adhesión a la III Internacional en 1922 en el Partido Comunista de Chile. En 1932, se produjo una experiencia inédita en América Latina con la instauración de la breve República Socialista liderada por el militar de aviación, Marmaduque Grove. Si bien la experiencia duró solamente trece días, marcó la política chilena al materializar la posibilidad de un camino socialista. Al año siguiente, Grove se convirtió en el fundador del Partido Socialista, cuando se fusionaron: la Nueva Acción Pública, la Acción Revolucionaria Socialista, el Partido Socialista Marxista y la Orden Socialista.

${ }^{115}$ Raúl Ampuero (1917-1996), comienza a militar en 1934 en la Federación Juvenil Socialista, siendo uno de sus fundadores. En 1946 es elegido Secretario General del Partido Socialista de Chile. Luego de la división, en 1950 es nombrado Secretario General del Partido Socialista Popular. En 1953, fue electo Senador y reelegido en 1961 luego de la unificación del PSCh. En julio de 1967 es expulsado del PS acusándolo de no haber respetado la línea del Partido en la derogación de la llamada "Ley Mordaza" que restringía la libertad de prensa. Junto a otros parlamentarios y dirigentes funda la Unión Socialista Popular (USOPO). La USOPO si bien apoyó la candidatura de Allende en 1970, no integró la Unidad Popular. Luego del golpe de Estado, fue detenido hasta fines de diciembre de 1973, partiendo luego a su exilio en Italia. Regresa a Chile en 1989, donde solicita el reintegro al PS.

${ }^{116}$ Clodomiro Almeyda (1923-1997), ingresa al PSCh en 1941, participando del PSP luego del quiebre. Durante el segundo gobierno de Carlos Ibañez, fue Ministro de Trabajo y luego de Minería. Fue un destacado académico en las Escuelas de Derecho, de Ciencias Políticas y Administrativas, de Sociología, de Economía y Veterinaria de la Universidad de Chile. En 1966, fue director de la Escuela de Sociología de la Universidad de Chile y profesor de Actualidad Internacional en la Universidad Católica. Con la reunificación del Partido, es electo diputado para el período 1961-1965. Luego del triunfo de Salvador Allende, en 1970, es designado Ministro de Relaciones Exteriores. Luego del golpe de Estado, fue detenido y trasladado junto al resto de los miembros del gobierno al campo de detención Isla Dawson. Luego de su liberación, comienza un largo exilio en la República Democrática Alemana y México. Asume la Secretaría General del Partido en 1979. Regresó a Chile clandestinamente en 1987. Durante el gobierno de Patricio Aylwin (1990-1994) fue el Embajador de Chile ante la URSS.

${ }^{117}$ Carlos Altamirano (1922-) se vincula con el PSCh a mediados de la década del 40'. Durante la división del socialismo, permanece en el PSP, teniendo incluso cargos de gobierno durante un breve período de la 
Con motivo de la proclamación de Ibáñez como candidato presidencial del PSP en 1951, se separó un grupo liderado por Allende que se integra al PSCh, produciendo en su interior un cambio en su línea política. Serán quienes, producirán un acercamiento con los comunistas, a partir de la fundación del FRENAP, postulando la primera candidatura presidencial de Allende. La permanencia del PSP en el gobierno es de apenas 9 meses, cuando el aumento de la política autoritaria y de crisis económica, los llevará a la oposición en 1953. A partir de este momento, el Partido modificó su estrategia, con el fin de unificar al movimiento popular para llevar adelante la denominada "revolución chilena".

El Congreso de Unidad, se realiza finalmente en julio de 1957, y se elige a Salomón Corbalán $^{118}$ como su nuevo Secretario General. El nuevo PS, reafirmaba la línea del socialismo revolucionario, el rechazo a las alianzas con los partidos de la burguesía y se planteaban una actitud de colaboración con el PCCh, aunque manteniendo sus históricas críticas hacia el sector.

El proceso experimentado por el Partido Socialista uruguayo en este período muestra un claro ejemplo de radicalización política, producto también del contexto de la Guerra Fría. Recordemos que, en 1921 como producto de la transformación del Partido Socialista en Partido Comunista, luego de que el VI Congreso Extraordinario del PS resolviera incorporarse a la Tercera Internacional, el sector minoritario -encabezados por el histórico dirigente socialista Emilio Frugoni ${ }^{119}$-, en desacuerdo con estas formulaciones, rompe y refunda el Partido Socialista. Tal como señala, Jaime Yaffé

Presidencia de Ibáñez. Electo diputado por el período 1961-1965 y senador entre 1965 y 1973. Secretario General del PSCh entre 1971 y 1979. Fue un claro dirigente de la línea izquierdista del PSCh, a quien se le atribuye el conocido slogan de "avanzar sin transar". Luego del golpe militar, logra salir clandestinamente y se exilia en la RDA hasta 1979. Luego partirá para París, donde comienza el período de renovación del PS y de profundos debates internos. En este contexto, es expulsado del PS junto a otros militantes. Altamirano no acepta esta situación, y en 1980 convoca a un Congreso que se realiza en Francia. Esto produce una nueva ruptura en el Partido, existiendo hasta 1991 dos tendencias: Altamirano-Almeyda. Regresa a Chile en 1993, desligándose de la actividad política partidaria.

118 Salomón Corbalán (1925-1967), se vincula al socialismo en 1945 siendo parte de la Federación Juvenil Socialista desde su sector universitario en Concepción. Durante la división, formó parte del PSP. Es electo diputado en 1953. Fue elegido Secretario General del Partido, luego de la reunificación entre 1957-1961. Ese año es electo Senador.

${ }^{119}$ Emilio Frugoni (1880-1969), ingresa a las filas de Centro obrero socialista en 1904, iniciando un proceso que daría nacimiento al Partido Socialista del Uruguay en 1910, del cuál fue su primer Secretario General. Fue electo diputado por primera vez en 1911, siendo el primer diputado socialista. Siendo reelecto en 1920; $1928 ; 1934$ y 1940. Fue Decano de la Facultad de Derecho y en 1944 es nombrado Embajador uruguayo en la URSS, cargo que ocupa hasta su renuncia en 1946. Producto de estancia en la Unión Soviética escribe una dura crítica sobre dicha experiencia: La esfinge roja. Memorial de un aprendiz de diplomático en la Unión Soviética (1948). En 1963 renuncia al PS, por discrepancias internas, sobre todo luego del pésimo resultado electoral de la Unión Popular el año anterior. De sus obras se destacan: La revolución del machete (1934), Las tres dimensiones de la 
desde el punto de vista de su estrategia política, si bien revolucionario en sus fines últimos, el PS fue un partido reformista, que combinó la acción social y política, privilegiando las arenas sindical y parlamentaria, y la competencia electoral, en la cual nunca trascendió la condición de partido muy minoritario (2016, p. 127).

Sin embargo, desde mediados de la década del 50' comienza una profunda revisión de sus definiciones teóricas y fundamentalmente de su estrategia política, acompañado de una interpretación de la historia uruguaya y latinoamericana, principalmente a partir de los aportes teóricos de Vivián Trías ${ }^{120}$. Encabezados por militantes de la Juventud Socialista, se produce desde mediados de la década del 50'un movimiento interno con el fin de combatir la estrategia socialdemócrata encabezada por Frugoni. Fue el núcleo juvenil quien encarno los debates internos del Partido fundamentalmente hasta la asunción de Vivían Trías como Secretario General.

A diferencia del viraje comunista, el proceso de transformación del socialismo fue gradual, comenzando en el XXX Congreso de octubre de 1955 y confirmándose a comienzos de la década siguiente con la elección de Trías en el XXXII Congreso de enero de $1960^{121}$. Luego de esta derrota Frugoni abandona su participación en la dirección del Partido, y finalmente renuncia tres años después. Para varios militantes de la época, como José Díaz ${ }^{122}$, esta transformación implicó la refundación del Partido Socialista (1995, p. 15)

democracia (1944), Ensayos sobre el marxismo (1985) y Génesis, esencia y fundamentos del socialismo (1989), entre otras.

${ }^{120}$ Vivián Trías (1922-1980), ingresa las filas socialistas a fines de la década del 30’. En 1945 comienza sus estudios de Profesor de Filosofía y luego de Historia en Enseñanza Secundaria. En 1956 ingresa a la Cámara de Diputados, en sustitución del Dr. Mario Cassinoni que había sido electo Rector de la Universidad. Fue reelecto en 1958 y en 1960 se transformó en el Secretario General del Partido Socialista. Luego de las elecciones de 1962, el PS pierde su representación parlamentaria y Trías deja la Secretaria General del Partido. Fue electo nuevamente diputado en 1971, ya con la conformación del Frente Amplio. Luego del golpe de Estado, fue destituido de sus cargos docentes y detenidos en varias oportunidades. De sus obras principales, se destacan: $E l$ imperialismo en el Río de la Plata (1960), Reforma Agraria en el Uruguay (1962), Por un socialismo nacional (1965), Historia del imperialismo norteamericano (1977).

${ }^{121}$ En el XV Congreso Extraordinario de mayo de 1957, el sector juvenil logró aprobar una iniciativa que reformaba el reglamento del Partido, suprimiéndose la elección directa de los miembros del Comité Ejecutivo Nacional y de los cargos electivos. A partir de este momento, la elección se realizaría por el voto secreto de los delegados de los centros en el Congreso, impidiendo por lo tanto, que aquellos afiliados que ya no participaban activamente de la vida partidaria, pudieran tener influencia en las decisiones. Por otro lado, el Comité Ejecutivo aumentaría de 9 a 15 miembros.

${ }^{122}$ José Díaz (1932-), comienza a militar en el PS en el interior del país, siendo dirigente de la Federación de Estudiantes del Interior primero y de la Federación de Estudiantes Universitarios del Uruguay (FEUU) luego. Egresado de la Facultad de Derecho. Estuvo detenido varias veces antes del golpe de Estado, debiendo -luego del 27 de junio de 1973- partir hacia el exilio, primero hacia Argentina y luego a España. En 1984 fue electo diputado, cargo que mantuvo hasta el año 2005. Al asumir el primer gobierno frenteamplista, fue nombrado Ministro del Interior, cargo que asumió hasta su renuncia en 2007. En la actualidad, es el Presidente de la Fundación Vivían Trías. 
Como veremos en los apartados siguientes, luego de la derrota electoral de 1962 y 1966, el socialismo uruguayo pasó por un profundo período de debilitamiento, lo que provocó a su vez, una serie sucesivas de fracturas. Se termina de configurar además, el giro ideológico a partir del cual critican las posibilidades de cambios radicales dentro del sistema “democrático-burgués", y por ende, rompen con el reformismo y declaran lo inevitable del camino armado para la toma del poder. Tal como señala, Jaime Yaffé, "en cierto sentido, puede decirse, que el PS de Uruguay fue un caso de partido de la vieja izquierda que ensayó una reformulación radical a tono con algunas de las tendencias propias de la "nueva izquierda" latinoamericana" (2016, p. 128).

Entre fines de 1962 -fuera del terreno parlamentario- y hasta su integración al Frente Amplio en 1971, podríamos decir que el PS uruguayo profundizó sus tendencias rupturistas.

\subsection{Socialistas en Chile y Uruguay: los puntos de encuentro}

No teníamos un Partido con más amistad y con más sintonía que el Partido Socialista de Chile ${ }^{123}$

Al igual, que los comunistas, los contactos entre militantes del PS uruguayo y chileno, fueron en este período continuos y profundos. En las páginas de El Sol, podemos ver claramente no solo el seguimiento de los acontecimientos que iban sucediendo en el país vecino, sino también opiniones, documentos oficiales emanados de los Congresos del Partido Socialista de Chile, entre otros.

Hasta su unificación en 1957, el vínculo que los socialistas uruguayos mantenían era claramente con el PSP, fundamentalmente con -el por entonces Senador -Raúl Ampuero y Óscar Waiss ${ }^{124}$, no solamente desde el punto de vista personal, sino también en el seguimiento de su línea política. Vínculo que se mantuvo, luego de unificado el Partido. Como veremos en el apartado siguiente, Ampuero fue uno de los líderes socialistas chilenos que más accionar tuvo en el Secretariado Latinoamericano de la IS, que durante este período tuvo sede en Montevideo. Eso produjo, que el contacto con el socialismo uruguayo fuera casi cotidiano.

\footnotetext{
${ }^{123}$ Entrevista a José Díaz, realizada por la autora en Montevideo. Fecha: 12.09.2016.

124 Òscar Waiss (1912-1994), se vincula a las Juventudes Comunistas a fines de la década del 20'en la ciudad de Concepción. Fue expulsado por oponerse a la línea estalinista del Partido. En 1936 se incorpora al Partido Socialista de Chile. En 1948, integra el Comité Central del PSP. Durante el gobierno de la Unidad Popular, fue el director del diario La Nación. Luego del golpe de Estado, se exilia en la RDA. Regresa a Chile con la transición democrática.
} 
José Díaz, afirma que "la mayor influencia de la izquierda chilena en el Uruguay, fue de los socialistas chilenos en el socialismo uruguayo", mucho más que la podría haber ejercido el PCCh, ya que ambos partidos comunistas estaban alineados con las directivas del comunismo soviético. Fue en

esos años 50'y comienzos de los 60'ahí aparece la influencia del Partido Socialista de Chile que ya había avanzado en la Central Única de Trabajadores, o sea en la unidad sindical y ya había empezado a hacer ensayos de unidad popular. (...) Óscar Waiss (...) vino varias veces acá, nosotros le organizábamos conferencias, discutíamos con él, el proceso chileno, que cosas nos servían, que cosas no estábamos en condiciones nosotros, o sea que fue un intercambio muy franco, muy fluido, donde aparecían libros de ellos (...). Ampuero Díaz, Aniceto Rodríguez ${ }^{125}$, toda esa generación del PSP, que en definitiva fue la columna vertebral del socialismo chileno (...) El socialismo chileno, entonces incidió en esos dos ejes: unidad sindical (...) y la unidad política de la izquierda, la unidad popular.

Por otro lado, en enero de 1956, en medio del levantamiento popular que se estaba produciendo en Chile ${ }^{126}$, los socialistas uruguayos enviaron -al por ese entonces edil del PS-, Andrés Cultelli, "para recoger información directa de los acontecimientos y expresar personalmente nuestra solidaridad al partido hermano"127, luego de las gestiones que realizaron en Montevideo Enrique Muñoz y Camilo Casanovas, ambos militantes del PSP. Los sucesos, fueron seguidos de cerca a partir de las publicaciones del semanario socialista. En la crónica realizada por Cultelli, da detalles de la visita a una de las cárceles de Santiago,

abrazamos a los compañeros chilenos, advirtiendo cuan comunes son nuestros problemas y nuestras luchas, al tiempo que reafirmábamos la convicción de que la acción política y

\footnotetext{
${ }^{125}$ Aniceto Rodríguez (1917-1995), ingresa a las filas del Partido Socialista en 1940, estudiando ya Derecho en la Universidad de Chile. Secretario General de la Federación de Estudiantes de la Universidad de Chile entre 1940-1943. Diputado entre 1949 y 1953, siendo electo Senador por el período 1953-1961 y 1961-1969, siendo reelecto ese año hasta 1973. Secretario General del PS entre 1965-1967. Luego del golpe de Estado, comienza su exilio en Venezuela en dónde permanece hasta 1987. Entre 1990 y 1995 es designado Embajador en Venezuela, por el gobierno de Patricio Aylwin.

${ }^{126}$ Entre 1954 y 1957, la política autoritaria del gobierno de Ibáñez se profundiza y lleva de la mano un acrecentamiento de la protesta social, huelgas y paros, que alcanzan a servicios básicos como la salud, el transporte o la minería del cobre y la correspondiente detención de varios militantes sindicales y políticos. El momento culmine llega el 2 de abril de 1957. A fines de marzo de ese año, la situación económica es crítica. Una decisión gubernamental de aumentar el precio del transporte público, desata la movilización popular en respuesta en la ciudad de Valparaíso. El 1 de abril, la movilización llega a Santiago. Manifestaciones multitudinarias en las calles, con quema de gomas, apedrea de vehículos, destrozo de los bancos de las plazas y vidrieras, se desarrollan en ambas ciudades. El gobierno decreta el estado de emergencia, Carabineros pierde el control de la situación y el Ejército interviene asaltando el local del Partido del Trabajo (integrado por militantes comunistas ilegales) y destrozan la imprenta Horizonte, también de propiedad comunista. El local del PSP también es sitiado y se cortan todas las vías de comunicación. La revuelta dura finalmente varios días, y deja el saldo de 22 muertos y cientos de heridos.

${ }^{127}$ Boletín del Secretariado Latinoamericano de la Internacional Socialista. Mayo de 1956, Vol. 1, Nro. 3, p. 74.
} 
sindical de los trabajadores organizados no llegará hasta sus últimas consecuencias si no se desenvuelve dentro de una perspectiva continental y mundial. $(\ldots)^{128}$.

Al día siguiente, una carta enviada por Óscar Waiss desde la prisión a Vivián Trías, los insta a hacer pública la denuncia de la represión en Chile y de las condiciones de su reclusión $^{129}$. Varias son las notas de El Sol que durante todo este período, dan cuenta de los sucesos ocurridos en el país trasandino ${ }^{130}$.

En marzo de 1958, Clodomiro Almeyda -ya en ese momento destacado académico de la Universidad de Chile- es invitado a participar de los cursos de verano realizados por la Universidad de la República. En ese contexto, brinda la conferencia "El imperialismo en América Latina”. Su visita y conferencia, dan lugar a una extensa entrevista en El Sol donde analiza la política chilena, dentro del contexto latinoamericano ${ }^{131}$.

En octubre de 1960, el entonces Embajador de Chile en Uruguay, Raúl Latchman, informa de una visita de Waiss a Montevideo, donde "tomó contacto con los dirigentes socialistas uruguayos. (...) ataca al actual gobierno y hace un exagerado y falso análisis de la realidad chilena"132.

Por otro lado, la relevancia de la figura de Allende, comienza a visualizarse claramente también en este período, con varias visitas a Uruguay, invitado no solamente por los partidos de izquierda, sino también por varias organizaciones sociales e incluso la Universidad de la República. El 30 de setiembre de 1959, por ese entonces Senador de Chile, visita Montevideo invitado por un grupo de exiliados paraguayos residentes en Uruguay, con el fin de denunciar los atropellos cometidos por la dictadura de Stroessner. Luego, "invitado por el Presidente de

\footnotetext{
${ }^{128}$ El Sol. Andrés Cultelli. "Desde la cárcel de Santiago". 20.01.1956.

${ }^{129}$ El Sol. "La reacción antiobrera en Chile" y "La lucha de los compañeros chilenos". 27.01.1956.

${ }^{130}$ Por citar algunos ejemplos: "Rebeldía popular en Chile" (05.04.1957); "Ecos de los sucesos en Chile" (10.05.1957); "En Chile: 4000 presos en defensa de la democracia" (11.10.1957); "Chile: unidad socialista" (19.07.1957); "Estampas de Chile" (30.04.1958); "Estampas de Chile. En las poblaciones callampas" (09.05.1958); "El socialismo en Chile. Una conversación con Raúl Ampuero" (16.05.1958); "Chile debe votar con olfato" (29.08.1958); "La democracia liberal y el subdesarrollo en Chile". Julio César Jobet (12.01.1962); "Democracia y subdesarrollo. De Alessandri en adelante", por Julio César Jobet (09.02.1962); "Chile: duros y blandos" (20.06.1964); "FRAP: triunfo asegurado", por Haroldo Martínez (14.08.1964); "Desde Chile: la mentira, arma gastada", por Haroldo Martínez (21.08.1964); "Chile exclusivo 1964", enviado especial Guaraní Pereda (04.09.1964); "La encrucijada de Chile", por Salvador Allende (04.09.1964); “iQué pasó en Chile?" (11.09.1964); "Capitalismo o Socialismo": la derecha acepta el desafío" de Guaraní Pereda (01.10.1965); "Frei dos años después: Ni revolución, ni libertad", por Álvaro López (18.03.1966); "La lucha de la Juventud Socialista por la unidad de la Juventud antimperialista" (13.01.1967); "Opina Aniceto Rodríguez" (11.05.1967); "Almeida: en América Latina ha llegado la hora de la revolución" (19.05.1967).

${ }^{131}$ El Sol. "América Latina. Reportaje a Clodomiro Almeyda". 21.03.1958.

${ }_{132}$ Ministerio de Relaciones Exteriores de Chile. Archivo General Histórico. Embajada de Chile en Uruguay. Fondo Histórico. Año 1960. Volumen 5740. Oficio Confidencial Nro. 303/21.
} 
la Asamblea General y por el de la Cámara de Diputados (...), visitó el Parlamento uruguayo donde fue agasajado por sus colegas" 133

La misma visita se repetirá en agosto de 1961, con motivo de un acto organizado por la Federación de Estudiantes Universitarios del Uruguay (FEUU), el Comité Nacional de Apoyo a la Revolución Cubana, y el Comité de Intelectuales y Artistas de Apoyo a Cuba, en el contexto de la reunión del Consejo Interamericano Económico y Social (CIES) en Punta del Este. En paralelo, se organizó la Conferencia Popular Antiimperialista, en donde compartieron estrado Ernesto Guevara y Salvador Allende el 17 de agosto ${ }^{134}$. El Sol, afirmará

en pocas horas un par de conferencias, reuniones políticas y las inevitables entrevistas en la prensa llenaron la actividad en Montevideo de Salvador Allende, líder socialista chileno y presidente del FRAP. (...). Allende ha consolidado su prestigio "allende" la cordillera, en nuestro país, luego de su magnífica participación en el Paraninfo, donde un público que lo desbordaba siguió atentamente y de manera entusiasta su conferencia. (...) Para EL SOL y para el Partido, es un honor contar con la presencia de Allende, es también la ratificación de su militancia (...).

En el mismo contexto, el dirigente chileno brindó para la interna socialista la conferencia Aspectos de la revolución cubana. Conferencia de Salvador Allende, líder socialista chileno, Presidente del FRAP ${ }^{135}$.

En 1962, Salomón Corbalán visita Montevideo, invitado por el Comité Coordinador de Apoyo con la Revolución Cubana. Entrevistado por el seminario socialista, afirma "el pueblo de mi patria está con la revolución cubana, que penetró en el campesinado chileno, sector éste generalmente remiso a participar en las luchas políticas. Para nosotros, esto es una experiencia de gran importancia" ${ }^{" 136}$. Como veremos en los apartados siguientes, un elemento común de ambos partidos socialistas en este período, será el interés que demostrarán por la organización de los sectores rurales, campesinos o peones. Ambos, plantean que la alianza obrero-campesina, es la columna vertebral para acceder al poder. En el caso uruguayo, será

\footnotetext{
${ }^{133}$ Ministerio de Relaciones Exteriores de Chile. Archivo General Histórico. Embajada de Chile en Uruguay. Fondo Histórico. Año 1959. Volumen 5385. Oficio Nro. 346/96. El seguimiento de las actividades, fueron reseñadas por El Sol. "Salvador Allende entre nosotros" (25.09.1959).

${ }^{134}$ Además de las reconocidas figuras que se hicieron presentes ese día, el acto es recordado por el lamentable asesinato del Prof. Arbelio Ramírez, Profesor de Historia y miembro del PCU. Los momentos de tensión que se vivieron, comenzaron ya desde las primera horas de la tarde, cuando tres individuos armados ingresaron al local central de la Universidad de la República, amenazaron a los funcionarios que se encontraban preparando el local y tiraron bombas de olor antes de partir. Al finalizar la actividad, cientos de personas salieron hacia la principal avenida de la ciudad, coreando canciones de apoyo a Cuba. Arbelio Ramírez, fue alcanzado por un disparo, mientras se encontraba caminando por la calle de atrás de la Universidad rumbo a dar clases en un liceo nocturno de la zona. (Bacchetta, 2010)

${ }^{135} \mathrm{El}$ Sol. "Salvador Allende: Chile en poder de una minoría". 18.08.1961.

${ }^{136}$ El Sol. "Corbalán opina”. 26.01.1962.
} 
clave, la actuación de Raúl Sendic ${ }^{137}$-por ese entonces dirigente de la Juventud Socialistacon los trabajadores de la caña de azúcar del norte del país.

Otra de las formas habituales de contacto, fueron las visitas de delegaciones a Congresos o actividades organizadas por su Partido hermano. En 1963, Eduardo Galeano viajó a Chile con el fin acompañar a Allende, ya como candidato presidencial del FRAP a una gira por el sur, y entablaron desde allí una profunda amistad. Galeano, ya conocido escritor y periodista del semanario socialista, fue uno de los permanentes columnistas que siguieron de cerca el proceso chileno. Volvieron a encontrarse en 1964, ya para el fin de la campaña electoral y luego en 1967.

A fines de diciembre de 1964, Allende viaja nuevamente a Montevideo, acompañado esta vez del entonces Presidente de la Central Única de Trabajadores (CUT) y militante comunista, Luis Figueroa y de la Federación de Estudiantes de Chile (FECH), Pedro Felipe Ramírez $^{138}$-por ese entonces militante democratacristiano-, para participar en una acto en la explanada de la Universidad de la República de denuncia de la situación brasileña luego del golpe de Estado del 31 de marzo de ese mismo año. Además, fue recibido en la Casa del Pueblo, por el Comité Ejecutivo Nacional del Partido Socialista, en sesión pública, en la que estuvieron presentes miembros de la Comisión Departamental de Montevideo, de las Juventudes Socialistas y numerosos militantes ${ }^{139}$.

Desde 1965, los socialistas uruguayos contarán con una fuente privilegiada sobre los acontecimientos políticos chilenos. Guaraní Pereda, un joven militante socialista uruguayo decide en el verano de ese año, radicarse en Santiago y vincularse con el socialismo de aquel país $^{140}$. Hasta el golpe de Estado de 1973, Guaraní viajó varias veces a Montevideo y mantuvo

\footnotetext{
${ }^{137}$ Raúl Sendic (1925-1989), se vincula al Partido Socialista a mediados de los años 40', siendo estudiante de Derecho en la Universidad de la República. Siendo procurador, se traslada a Paysandú y Treinta Tres primero, y a Bella Unión más tarde, con el fin de asesorar jurídicamente a los trabajadores de la industria remolachera y azucarera que vivían en pésimas condiciones. Influenciado por la revolución cubana, a donde viaja en 1960, organiza pocos años después el coordinador, siendo fundador del Movimiento de Liberación NacionalTupamaros. Es detenido en 1970, siendo parte de la fuga de 111 detenidos en setiembre del año siguiente. En setiembre de 1972, luego de resistirse con la policía es detenido nuevamente, herido gravemente en el rostro. Siendo uno de los rehenes de la dictadura, permaneció detenido en pésimas condiciones 12 años.

${ }^{138}$ Pedro Felipe Ramírez, se vinculó al PDC a comienzos de la década de 1960. En 1966, en pleno gobierno de Eduardo Frei Montalva, fue nombrado gerente general del Servicio de Cooperación Técnica. En las elecciones de 1969, fue electo diputado y ese mismo año se casó Olaya Tomic, hija de Radomiro. Siempre vinculado al ala izquierdista del PDC, luego del triunfo de Allende comenzó un acercamiento hacia la UP, que lo llevó junto a otros miembros de la DC a renunciar a su partido y fundar la Izquierda Cristiana en octubre de 1971. En agosto de 1973 y hasta el golpe de Estado del 11 de setiembre, fue designado por el Presidente Allende, Ministro de Vivienda y Urbanismo. La figura de Pedro Felipe Ramírez, será clave en los vínculos entre la DC chilena y el PDC uruguayo, tal como veremos en el capítulo que sigue.

${ }^{139}$ El Sol. "Allende en la Casa del Pueblo". 24.12.1964.

${ }^{140}$ Guaraní Pereda viaja por primera vez a Chile en el verano de 1964, para participar como delegado de la FEUU en el Congreso Latinoamericano de Juventudes que se desarrolló en Santiago. Al año siguiente, decide radicarse allí por motivos personales. Durante todo este período, es uno de los columnistas principales de El Sol
} 
vínculos con los dirigentes de ambos partidos. Varias de estas discusiones, saldrán de su pluma en El Sol. De este proceso, recuerda

que hubo mucha influencia, pero las influencias ya directas. Almeyda había ido ya a Uruguay -después me enteré- a algunas escuelas de verano (...) donde expuso el, expuso Trías, expuso algunos otros que iban, personajes notables (...). Creo que había una relación pero de las elites de ambas izquierdas.

En abril de 1967, Allende viaja nuevamente a Montevideo, dicta una conferencia en la Facultad de Arquitectura, denominada El Desarrollo Económico de América Latina (reproducida íntegramente por $\mathrm{El} \mathrm{Sol}^{141}$ ), a la que asistieron las autoridades de la Universidad de la República. Después del acto concurrieron al desfile de protesta contra la Cumbre de Jefes de Estado y de Gobierno de la OEA que se estaba desarrollando en Punta del Este. ${ }^{142}$ En esa oportunidad, se reunió con varios militantes del Partido Socialista uruguayo, incluso

visitó Casa del Pueblo, en donde mantuvo un fructífero intercambio de noticias y opiniones con los integrantes del Comité Ejecutivo Nacional y tuvo oportunidad de establecer relación con compañeros de base, en una charla que ofreció, acerca de los graves problemas del continente ${ }^{143}$.

Galeano recuerda que en Montevideo lo acompañó a las reuniones políticas y a los actos partidarios. (Amorós, 2013, p. 218).

Eduardo Aparicio, se vincula a la Juventud Socialista a mediados de 1967, y afirma que la estructura organizativa del socialismo uruguayo, es inspirada por el socialismo chileno, a través del sistema de núcleos como una estructura de tipo centralista democrático, cuasi leninista, donde las células o los grupos de base se denominan núcleos.

Y [había] una cercanía del tipo político, porque tempranamente la izquierda uruguaya, especialmente los socialistas miraron (...) con mucho interés lo que pasaba en Chile y los procesos de la unidad, anteriores a la UP, el FRAP, etc. Y Allende está aquí en el Paraninfo

\footnotetext{
(también escribe para Época y Marcha) sobre los acontecimientos chilenos. Militante ya en Uruguay al PS, se vincula desde su llegada al país trasandino al PS de Chile. En 1967, ya es miembro del Comité Central de las JJSS. Luego del golpe de Estado del 11 de setiembre es detenido y trasladado al Estadio Nacional. Logra salir junto a otros uruguayos rumbo al exilio, gracias a la actuación del entonces embajador sueco Harald Edelstam y parte primero hacia Suecia y después hacia la RDA. En este período se reúne varias veces con Beatriz Allende en Moscú y en La Habana.

${ }^{141}$ El Sol. "El desarrollo de América Latina" por Salvador Allende. 21.04.1967.

${ }^{142}$ Ministerio de Relaciones Exteriores de Chile. Archivo General Histórico. Embajada de Chile en Uruguay. Fondo Histórico. Año 1967. Volumen 1. Oficio Nro. 395/208.

${ }^{143}$ El Sol. "Allende entre nosotros". 28.04.1967.
} 
de la Universidad en el acto cuando viene Guevara (...) y esa gestión es por la cercanía de los socialistas uruguayos con los chilenos.

Y más adelante agrega,

les copiamos las camisas a los socialistas chilenos (...) la discusión en la Juventud Socialista era si tenía que ser la camisa verde como la de los socialistas de allá o tenía que ser la camisa azul, que había sido la camisa de los socialdemócratas alemanes. La oposición al verde era para no tener ninguna confusión (...) con alguna inclinación guerrillerista, digamos ${ }^{144}$.

Triunfa la opción del verde, al igual que en el socialismo trasandino.

\subsubsection{Una experiencia de trabajo conjunto: El Secretariado Latinoamericano de la Internacional Socialista}

A mediados de 1955, los Partidos Socialistas de Uruguay y Argentina, realizaron las gestiones ante la IS para la constitución del Secretariado Latinoamericano de dicha Internacional. El 18 de octubre de ese mismo año, se resolvió su instalación con sede en Montevideo y la designación de Humberto Maiztegui como su Secretario. Su misión era "el intercambio de información y el establecimiento de contactos entre los partidos socialistas de América Latina"145.

Como parte del cumplimiento de dicho objetivo, se publicó un boletín mensual (en algunos momentos bimensual ${ }^{146}$ ), con el sumario de las reuniones del Secretariado, pero también donde se divulgaron no sólo actividades de cada uno de los Partidos, sino que además sirvió como difusor de ideas, intercambio de opiniones sobre la situación latinoamericana (a nivel general y no sólo de los países miembros) y las estrategias a seguir en cada uno de los contextos. Los informes de las delegaciones de cada uno de los sectores participantes, fueron claves para dichos intercambios ${ }^{147}$. Otro de los aportes interesantes de los boletines fue la

\footnotetext{
${ }^{144}$ Se vincula a la Juventud Socialista a nivel estudiantil en Secundaria en el año 1967. Luego del golpe de Estado, logra permanecer en Uruguay hasta el año 1977, que parte al exilio en Ginebra. Regresa al retorno de la democracia y hoy mantiene vinculaciones con la Fundación Vivían Trías.

${ }^{145}$ Boletín del Secretariado Latinoamericano de la Internacional Socialista. Marzo de 1956, Vol. 1, Nro. 1, p. 2.

${ }^{146}$ La publicación del Boletín tuvo dos épocas, la primera de 1956 a 1961 y la segunda desde 1964 a 1967 . En la segunda época, su publicación fue trimestral.

${ }^{147}$ Para el caso que nos interesa, se publicaron por ejemplo: "El Partido Socialista Popular y la última elección" (abril de 1956); "El Partido Socialista Popular y la candidatura del Gral. Ibáñez" (mayo de 1956); "El Partido Socialista de Uruguay contesta al Partido Comunista. Respuesta negativa a una proposición para constituir un frente común de lucha" (junio de 1956); "Una política nacional revolucionaria consecuente" de Aniceto Rodríguez (agosto de 1956); "Conclusiones del debate político del Comité Ejecutivo del Partido Socialista de
} 
incorporación de reseñas bibliográficas, sugeridas para la formación de los militantes, los que nos permite relevar un intercambio de lecturas comunes claves para la discusión política ${ }^{148}$. Los boletines, fueron editados durante quince años seguidos, y llegaban a todos los partidos del continente.

De inmediato, se iniciaron las gestiones para formar el Comité Consultivo del Secretariado Latinoamericano, al que invitaron a participar al Partido Socialista Popular de Chile. Lo novedoso de esta incorporación, era que el PSP no estaba afiliado a la IS, por lo que primó un criterio amplio, donde se priorizó el intercambio de información y el trabajo conjunto, no implicando de hecho ningún compromiso con la Internacional, dado el carácter consultivo del nuevo organismo.

Finalmente, las reuniones se convirtieron en momentos de encuentro, debates, formación de redes, y profundización de las vías de comunicación y contactos. Por lo mismo, se aceptó la integración en carácter de observadoras de otras delegaciones tampoco afiliadas a la Internacional. La idea era crear un primer escalón para la organización del movimiento socialista latinoamericano. Los representantes de cada país, fueron: Alicia Moreau de Justo y Américo Ghioldi, por el Partido Socialista Argentino, Raúl Ampuero y Federico Klein, por el PSP de Chile, y José Pedro Cardoso ${ }^{149}$ y Arturo J. Dubra por el Partido Socialista uruguayo.

El Comité Consultivo se reunió seis veces: en abril de 1956 en Montevideo; en diciembre de ese mismo año en Buenos Aires; en abril de 1958, con motivo de los 25 años del Partido Socialista en Chile, se reunió por lo tanto en la ciudad de Santiago; en febrero de 1960 en La Paz; la quinta y sexta reunión, se realizaron en Montevideo a fines de julio de 1960 y de abril de 1961 respectivamente.

En abril de 1956, en el contexto de la dura huelga que se estaba desplegando en Chile y la represión desatada por el gobierno, el Secretariado envió telegramas de apoyo a la actividad desarrollada por el PSP, condenando el accionar del Presidente de Chile, Carlos

Chile" y “Acuerdos del XIV Congreso Extraordinario del Partidos Socialista de Uruguay" (setiembre de 1956); "Chile en la encrucijada de su destino" (junio-julio de 1957); "Plataforma programática de la candidatura de Salvador Allende en Chile" y "Resoluciones del XXXI Congreso del Partido Socialista de Uruguay" (enerofebrero de 1958); "Declaraciones de Salvador Allende previas a la elección presidencial de Chile" (agostosetiembre de 1958); "Pronunciamiento del Partido Socialista ante la elección presidencial en Chile" (octubre de 1958); "Resolución sobre política nacional del PS de Uruguay" (mayo-junio de 1960); "El PS uruguayo reafirma su posición frente al Partido Comunista" (noviembre-diciembre de 1960); "Carácter de la revolución chilena" de Raúl Ampuero (marzo de 1961), entre otros.

148 Podemos ver allí, análisis sobre los textos de David Tieffenberg, Oscar Waiss, Julio César Jobet, Carlos Rama y otros autores latinoamericanos.

${ }^{149}$ José Pedro Cardoso (1903-1997), se acerca a la actividad política, como estudiante de Medicina a través de su militancia en la FEUU, de la que fue su fundador y primer Secretario General en 1929. Ingresa al Parlamento por primera vez en 1937, siendo parte de la Cámara de Diputados de forma ininterrumpida entre 1943 y 1959 , cuándo fue electo Senador. Cargo que ocupó hasta 1962. Con el retorno a la democracia, es electo Senador por el período 1985-1990 y es elegido Presidente del PS. 
Ibáñez, y solicitando la solidaridad del movimiento socialista internacional. En mayo de ese mismo año, El Sol informa de un acto realizado en el local central del Partido Socialista "Casa del Pueblo", en el que participaron delegados del PSP chileno (Raúl Ampuero y Federico Klein) y del PS Argentino (Alicia Moreau de Justo y Américo Ghioldi), en el marco del Secretariado Latinoamericano de la IS. En la nota publicada se resalta la fotografía de la delegación chilena reunida con Cardoso y $\operatorname{Coscia}^{150}$.

La tercera reunión, realizada en Santiago de Chile fue inaugurada en el Salón de Honor del Congreso Nacional y compartieron estrado Salvador Allende, Federico Klein por la Oficina Internacional del PSCh, Humberto Maiztegui por el Secretariado Latinoamericano de la IS, Vivian Trías por el PS de Uruguay y cerró el acto Salomón Corbalán ${ }^{151}$. Esta tercera conferencia, dio pie además, para la reunión de las Juventudes Socialistas de América, a la que asistieron representantes de Argentina, Chile y Uruguay y delegados del Movimiento 26 de Julio (Cuba) y del APRA (Perú). Como resolución más importante, debemos destacar la constitución de la Oficina de Relaciones de la Juventud Socialista de América Latina, cuya sede ha sido fijada en la ciudad de Montevideo. En el acta constitutiva de la Oficina, se expresa que dicho organismo "afirma su voluntad de luchar contra la explotación de las masas populares, de las cuales son responsables el imperialismo y las reaccionarias burguesías de todo el mundo. (...)".152

La cuarta reunión, se realizó en la ciudad de La Paz, Bolivia, en febrero de 1960. En esta oportunidad participaron desde Chile, Salvador Allende y Clodomiro Almeyda y desde Uruguay, Vivián Trías. La quinta y sexta reunión, se realizaron en Montevideo a fines de julio de 1960 y de abril de 1961 respectivamente, con motivo de analizar las políticas de solidaridad y apoyo con la revolución cubana. El PS uruguayo, mantuvo su participación activa en el Secretariado, incluso luego de haber abandonado la IS en enero de 1960, por el apoyo de ésta a la Sección Francesa de la Internacional Obrera por su actitud en Argelia.

Luego del triunfo de la revolución cubana, y del afianzamiento del giro radical de los partidos socialistas, las relaciones entre el socialismo latinoamericano y el europeo se tensaron cada vez más. Entre 1962 y 1963, a la interna de la IS se debatió el destino del Secretariado Latinoamericano, cada día más lejos de sus posiciones. Finalmente, la IS decidió una nueva política hacia América Latina, y en una circular de 1963, informaba a sus partidos miembros la eliminación del Secretariado Latinoamericano y del Comité Consultivo y de su

\footnotetext{
${ }^{150}$ El Sol. "El mitin de confraternidad socialista latinoamericana en Casa del Pueblo". 18.05.1956

${ }^{151}$ El Sol. "La Conferencia de Partidos Socialistas. Se realizó con éxito en Chile". 09.05.1958.

${ }^{152}$ El Sol. "Se realizó en Chile. Reunión de Juventudes Socialistas de América” 16.05.1958.
} 
reemplazo por el Buró Coordinador de la IS en América Latina. A su frente continuó Humberto Maiztegui y la sede se mantuvo en Montevideo, pero a partir de ahora sus acciones debían ajustarse a lo indicado por la IS. Esta situación se mantuvo hasta 1970, cuando se decidió mudar la oficina del Buró. "Sin embargo, las diferencias entre los partidos europeos y sus propios y crecientes problemas nacionales fueron relegando las políticas latinoamericanas de la organización y no se volvió a reflotar el Buró ni otra instancia de esa naturaleza." (Pedrosa, 2013, p. 35).

\subsection{El carácter de la revolución: de la "Revolución Democrática de Trabajadores" a la "Revolución Nacional y Popular".}

Una de las características del socialismo de esta época, fue su actitud profundamente crítica con la política soviética y con la adhesión irrestricta de ambos partidos comunistas a la misma. Además de las discrepancias vinculadas al apoyo a los sucesos de Polonia, Hungría y más adelante Checoslovaquia, la crítica principal estaba centrada en el etapismo pregonado por los comunistas. Lo que los socialistas rechazan era la necesidad de cumplir con las diversas etapas en el camino al socialismo, principalmente con la denominada democráticoburguesa, e impulsando entonces, la necesidad de acortar el camino, para favorecer desde un comienzo un cambio revolucionario estrictamente socialista. "La ausencia de una burguesía nacional, en estos países semicoloniales y dependientes, hacía que no fuera dable esperar las transformaciones democratizadoras, logradas en los países capitalistas (reforma agraria, industrialización, autonomía nacional), impulsados por una burguesía nacional, autónoma y creadora." (Walker, 1990, p. 136)

La principal crítica a la teoría de la revolución por etapas, se explicitó en Chile en 1953, cuando Oscar Waiss publicó Nacionalismo y Socialismo en América Latina, en donde establecía que:

la revolución democrático burguesa, ineludible históricamente, debe comprenderse como una etapa de la revolución socialista, durante la cual la clase burguesa será compelida a ubicarse entre los grupos reaccionarios sin tener la posibilidad de manejar las palancas de comando. Durante esta etapa, las formas superiores de gobierno adoptarán necesariamente una fisonomía de transición, de dictadura democrática con participación de diversas capas sociales. (Jobet, 1971, p. 18).

La clase revolucionaria, encargada de dirigir el proceso, era claramente el proletariado, por lo que tanto el carácter de la revolución como su objetivo debían estar exclusivamente 
centrados en los intereses de esta clase. Partiendo de este supuesto, se realizaron todos los esfuerzos teóricos de este período. Salomón Corbalán, en 1957, afirmará que la revolución

no es una revolución burguesa (...) debido al clásico argumento de que "las clases sociales quienes deberían asumir el papel revolucionario están comprometidas con sus antagónicas". Corbalán cree que este proceso se había dado con éxito en los países capitalistas avanzados, ya que fue "allí donde las condiciones objetivas se dieron favorables para su desarrollo", siendo allí la burguesía el motor de las "transformaciones serias y profundas en el sistema de producción feudal y artesanal”. Pero en las zonas periféricas, como Chile y América Latina, estas tendencias no podían desenvolverse debido al carácter particular de esta clase social, a la presencia del imperialismo y a la insalvable desigualdad con las naciones industrializadas. (Casals, 2010, p. 48).

Pero, -siguiendo al planteo realizado por Corbalán- la revolución tampoco podía ser socialista en una primera fase, ya que las condiciones para la realización de una revolución socialista solo pueden aparecer en los países que han llegado a un grado máximo de desarrollo capitalista. Por lo tanto, para lograr ese objetivo en Chile, era

necesario acelerar el crecimiento de todos los sectores del proceso económico, con el objetivo de que lleguen a un total desarrollo y generen las contradicciones necesarias que provoquen un cambio de sistema. Con una burguesía incapacitada de llevar a cabo estas tareas, el proletariado y sus partidos de vanguardia se constituían en los llamados a impulsarla. (Casals, 2010, p. 48).

En 1959, Salomón Corbalán, profundizará en este concepto, y propone al XVIII Congreso del Partido Socialista, la caracterización de la "Revolución Democrática de Trabajadores", siendo definida como "una revolución dónde el poder pasa de manos de la burguesía a manos de la clase trabajadora en un sentido amplio (...) [y dónde los objetivos a realizar] son coincidentes con aquellos de la revolución democrático-burguesa, pero son imposibles de realizar por la misma burguesía"153.

Nuevamente fue Salomón Corbalán, quien dos años después, ajusta el significado del concepto de "Revolución Democrática de los Trabajadores", estableciendo en su caracterización siete rasgos principales. El primero de ellos, establecía que la revolución debía “orientarse hacia el socialismo”, en tanto lo que se proponía era crear las condiciones necesarias para la transformación total del modelo capitalista. En segundo y tercer lugar, la revolución era "antiimperialista", en tanto implicaba la nacionalización de las riquezas básicas del país; "antifeudal", en tanto se proponía la extinción del latifundio y el desarrollo de una

\footnotetext{
${ }^{153}$ Revista Arauco, $\mathrm{N}^{\circ}$ 2, noviembre de 1959, p. 32-33.
} 
reforma agraria que transformara radicalmente el problema de propiedad de la tierra. En cuarto lugar, la revolución era de clase, "ya que la única clase social con autoridad histórica para cumplir los objetivos (...) es la clase trabajadora". El quinto y sexto elemento señalado por Corbalán, eran la caracterización de la revolución como "democrática”, ya que aspiraba a la "ampliación de la soberanía popular; y humana", en tanto tenía como objetivo supremo, "lo esencial del socialismo: la dignificación del hombre”. Por último, planteaba que la revolución era "americana", ya que los países subdesarrollados del continente tenían una serie de rasgos comunes que harían inevitable y necesaria la integración económica ${ }^{154}$.

Los sucesos de Chile de 1956, fueron recepcionados también por el socialismo uruguayo. En enero, Vivián Trías afirmaba que la crisis chilena

tiene raíces comunes y lo que es fundamental (...) requiere soluciones comunes. Todos somos forzadas marionetas; unos ya en acción y otros aguardando turno. Pero, también es verdad, que todos aspiramos, con pasión, a liberarnos de un eterno destino de títeres. Para ello es imprescindible entender que el juego histórico es uno solo y que en el no hay excepciones para nadie. O todos perdemos o todos ganamos. Por eso miramos los acontecimientos de Chile como algo propio, tan propio que allá se refleja y se dirime nuestro sentimiento, nuestra emancipación (...) Su drama es un acto de una comparsa que todos integramos $(\ldots) .^{155}$

Las crisis nacionales, eran entendidas por Trías, como parte de un proceso internacional que lo que mostraba en definitiva eran las fallas del sistema capitalista para generar un desarrollo sostenido y, por lo tanto, para disminuir el antagonismo de clase.

Con el giro ideológico desarrollado a lo largo de la década del 50’, el PS modificó su estrategia, planteando que era necesaria la realización de una "revolución nacional y popular", que pudiera disputarle el poder político a las clases dominantes, pero que sin copiar modelos, se basara en las características propias de cada país ${ }^{156}$. Tal como Trías afirmaba, la revolución

${ }^{154}$ Revista Arauco, No 22, noviembre de 1961, p. 9.

${ }^{155}$ El Sol. Vivian Trías. "El turno de la cueca”. 20.01.1956.

${ }^{156}$ Ya el concepto de "revolución" marcaba un quiebre con la anterior política del Partido Socialista liderada por Frugoni. En su concepción, el socialismo como representante de la clase obrera debía buscar la intervención de las clases trabajadoras en la vida política del país, el Partido oficiaba así de nexo entre los reclamos de la clase obrera y las decisiones gubernamentales. El cambio radical de la sociedad, no sería producto de un cambio revolucionario, sino de la evolución progresiva de la sociedad. Sin embargo, el sector encabezado por Trías, no descartó de plano la acción parlamentaria, pero si la ubicó en un lugar secundario. Era uno de los tantos frentes de acción, pero no el único ni el privilegiado. En 1961, afirman que

El P. Socialista no es un partido electoralista. Es un movimiento revolucionario. Quiere el poder para terminar con el privilegio y las estructuras económicas basadas en el sistema capitalista. Sabe que para ello es necesario realizar una revolución.(...) Las elecciones para los socialistas son un termómetro que indican, en determinado momento, el grado de apoyo popular. Nuestro fin no es el de ocupar posiciones 
debía ser nacional, "porque el socialismo no es una formula química, o una receta de cocina que puede aplicarse en cualquier sitio, con absoluta independencia de sus características propias y de su historia anterior". (1965, p. 30)

Para los socialistas, la revolución en los países subdesarrollados y dependientes, debía desarrollar dos fases, pero que eran parte de un único proceso. La primera fase de carácter nacional y una segunda fase ya directamente socialista. No había dos etapas, sino que era un proceso continuo. Para asegurar el paso de una fase a la otra, la conducción del proceso debía estar en manos del partido representativo de la clase obrera, que para ellos era el Partido Socialista. Pero, para la realización de la fase nacional, era necesaria la conformación de un movimiento amplio, con sectores antiimperialistas y antioligárquicos, que dieran nacimiento a un Frente Nacional y Popular. Este proceso, es el que Trías denominó como "Socialismo Nacional" ${ }^{\prime 157}$ (1965).

Ya desde mediados de los años 50', Trías había teorizado sobre la incapacidad de las burguesías nacionales de los países subdesarrollados para llevar adelante los objetivos de la revolución burguesa y la importancia de la lucha de las clases trabajadoras. Con motivo de la huelga llevada adelante en enero de 1956, El Sol, publica extensas notas referidas al movimiento de los trabajadores chilenos, así como a la línea política desarrollada por el PSP y acuerdan que "organizarse para la lucha, es el imperativo histórico de la clase trabajadora, porque es la única fuerza que con impulso avasallador puede barrer con los intereses creados de la burguesía, el latifundio y el imperialismo y, realizar la revolución socialista" ${ }^{\text {158 }}$.

Algunos meses después, la pluma de Trías afirmará

se trata de hacer la revolución burguesa, no como una meta finalista, sino como una etapa previa hacia el socialismo. Por ello la fórmula política adecuada consiste en partidos donde la clase obrera sea la vanguardia, la conductora y la orientadora, pero que expresen a las otras clases populares y, muy especialmente, a los campesinos. Es la única garantía de que la revolución burguesa no vuelva a fracasar ${ }^{159}$.

burocráticas en el Parlamento y en las Juntas. Usamos esos organismos como tribunas. Sabemos que poder será para los socialistas, solamente a través de un movimiento revolucionario. En eso estamos.

(El Sol. "Los socialistas y el Uruguay tradicional". 21.07.1961.)

${ }^{157}$ Por otro lado, la denominación de "socialismo nacional", evidenciaba el giro del clásico concepto "socialismo democrático" acuñado por el socialismo histórico. Jaime Yaffé, sostiene que el cambio en esta denominación que podría haberse denominado "socialismo democrático y nacional" - no era solamente una sustitución de términos, sino que mostraba de alguna manera el sutil desencanto de las nuevas generaciones respecto a las posibilidades de transitar hacia el socialismo a través del camino democrático. (Yaffé, 2016, p. 145). Como veremos, más adelante, ese giro será clave en las estrategias políticas de los socialistas durante la década del 60'. ${ }^{158}$ El Sol. "Las luchas sociales en Chile". 13.01.1956.

${ }^{159}$ El Sol. Vivian Trías. "La Rebelión de las orillas". 03.08.1956. 
Por otro lado, el carácter nacional de la revolución uruguaya, no implicaba su desvinculación de una concepción latinoamericanista. En realidad, el triunfo de un proceso revolucionario, era considerado un eslabón de la revolución latinoamericana, cuyo primer capítulo había sido escrito por la experiencia cubana ${ }^{160}$. La caracterización nacional de la revolución, pero sin desconocer el contexto latinoamericano, también fue una innovación de Trías, que rompió con los parámetros de la socialdemocracia europea con quien se identificaba Frugoni. Cortar con los lazos de dependencia que caracterizaba el enfrentamiento entre "el imperio" y "la colonia", permitiría la acción unificada de los países latinoamericanos.

\subsection{Disyuntivas en torno a la unidad}

Como señalamos en el capítulo anterior, una de las fundamentales dificultades que el proceso de unificación de la izquierda en Uruguay tuvo, fue la negativa del socialismo de aliarse con el Partido Comunista. Diferencia sustancial con el proceso chileno. Las discusiones sobre la unidad entre el PS y el PCU durarán más de una década ${ }^{161}$, casi con los mismos argumentos hasta 1965. Como veremos, a partir del allí el PS uruguayo produce un giro en su política, producto entre otras cosas de la derrota electoral de 1962, pero igualmente la alianza no va a poder concretarse hasta algunos años más adelante.

En Chile, si bien el socialismo y el comunismo habían formado una alianza, incluso desde antes de la fundación del FRAP en 1956, durante 1962 se producirá un debate que atraviesa varios tópicos de los intercambios de la izquierda en ambos países, que dieron lugar a lo que se conoció como "la polémica socialista-comunista" "162, pero que más allá de las diferencias no pondrán en tensión en ningún momento la unidad acordada.

\footnotetext{
${ }^{160} \mathrm{PS}$ (1965). Resolución política del XXXV Congreso Ordinario, Montevideo, Partido Socialista, p. 16.

${ }^{161}$ Para ver la negativa del socialismo, pueden revisarse en "El Sol": "Respuesta al Partido Comunista" (13.12.1957); "Respuesta de la Juventud Socialista a la Juventud Comunista" (25.09.1959); "Con El Popular" (21.07.1961); "Polemizando con El Popular. Una definición clara" (28.07.1961); "Con El Popular. Fin de una polémica" (01.09.1961); "Una polémica imposible: a propósito de la insistencia de El Popular" (04.05.1962); "Réplica a El Popular" (05.10.1962); "Los caminos hacia la Unidad" (12.07.1963); "En torno a la Unidad. Polemizando con El Popular" (26.07.1963); "Congreso del Frente de Izquierda. Reiteración de un camino" (30.08.1963); "Frente a errores de "El Popular". Defender la unidad de acción sin exclusiones" (03.04.1964); "Partido Socialista y FIdeL" (10.04.1964).

${ }^{162}$ Cuatro serán los motivos de debate: la división del mundo en bloques, el papel del PCUS dentro del movimiento revolucionario, la confirmación de la vía pacífica como forma de acceso al socialismo, y el lugar del marxismo en la teoría revolucionaria. Al respecto ver: "La polémica socialista-comunista" (1962), Santiago, Ed. Prensa Latina.
} 


\subsubsection{Del "Frente de Trabajadores" al "Frente Nacional y Popular": el problema de la alianza con la burguesía nacional}

Un primer esbozo, de la tesis conocida como "Frente de Trabajadores" estuvo ya en el programa socialista chileno de 1947. Dicha política, surgía tanto de la autocrítica realizada luego de la experiencia del Frente Popular, como de la caracterización de la revolución chilena. La segunda mitad de la década del cincuenta fue el momento de profundización y definición de esta línea. Formalmente es en el XVI Congreso General del PSP en 1955, cuando ésta se oficializa, como respuesta a la insistencia comunista de la revolución por etapas. El documento, que se aprueba en el Congreso, La situación económico-social y las tareas de la revolución chilena, planteó la necesidad de realizar cambios estructurales y revolucionarios de forma inmediata, que sirvieran a la vez de autocritica por las acciones desarrolladas durante el Frente Popular y particularmente durante el ibañismo.

Esta nueva línea, planteaba en su centro el agotamiento de las alianzas con los denominados partidos burgueses, restringiendo los posibles acuerdos únicamente a los partidos obreros y la Central de Trabajadores. Bajo la consigna revolución o miseria, quedaba de manifiesto que la estrategia para impulsar ahora, estaba basada en una clara política de clase. Se trataba de crear una fuerza política fuerte, "para acciones de fondo en una decidida lucha por la conquista del poder para el pueblo, y con el propósito de establecer una república democrática de trabajadores orientada hacia el socialismo (...).” (Jobet, 1987, p. 219). La línea desarrollada, valorará la unidad, pero una unidad no declarativa, sino una unidad en la acción y en las perspectivas.

Desde el punto de vista oficial, desde 1957 con su reunificación el PS confirmó su negativa a una alianza con el PR. Ya no se cuestionaba a la burguesía sólo por su incapacidad para la modernización del país, sino que comienza a ponerse en duda el "sistema burgués", debido a su invalidez para dar solución a los problemas sociales en aumento. En 1959, en la revista Arauco ${ }^{163}$, afirman que "ya en 1948 había quedado en claro la subordinación ideológica de esta clase a los supuestos del status quo, su docilidad frente al

\footnotetext{
${ }^{163}$ Órgano oficial del Partido Socialista, comienza a publicarse en 1959 con el fin de abrir un espacio para intercambiar sobre los diversos problemas que acontecen en el país y en el mundo, desde una óptica "crítica, revolucionaria y democrática". (Arrate y Rojas, 2003, tomo I, p.336). En su primer editorial, afirman "aparece esta revista en un momento en que el eco de la Revolución Cubana agita y conmueve a las masas trabajadoras del continente, encendiendo las esperanzas, y dándoles la oportunidad de aprovechar sus fecundas lecciones" (Revista Arauco, Nro. 1, octubre de 1959, p. 5). Se publica hasta febrero de 1967. Desde allí, las principales disputas públicas del PS comienzan a desarrollarse en las páginas de Punto Final.
} 
imperialismo yanqui, su identificación con los intereses democráticos y con reducidos sectores privilegiados de los estratos intermedios"164.

Incluso, la derrota en las elecciones de 1958, a diferencia de lo ocurrido en la interna comunista, significó para los socialistas la evidencia de la necesidad de una alianza clasista, exclusivamente proletaria. Salomón Corbalán, afirmará en su informe al XVIII Congreso General del Partido, que "la campaña presidencial y la forma en que las masas recogieron el llamado de sus partidos vanguardia demostró cuánta razón teníamos en abrir una alternativa distinta y nueva a la lucha proletaria"165. La estrategia entonces, era seguir profundizando la acumulación del FRAP en los sectores populares.

En setiembre de 1956, se realiza el XVI Congreso del PS uruguayo, llamativamente bajo la consigna Soluciones socialistas o miseria. Similar consigna que la planteada por su par chileno, en su Congreso realizado un año antes. En sus resoluciones finales, se afirma que

la declaración del Congreso a ese respecto implica una seria acusación a esos partidos, que no solo crean y multiplican las calamidades económicas, financieras y administrativas que abruman, a nuestro pueblo, sino que las agravan con su incapacidad para sortear los escollos de la crisis ${ }^{166}$.

Al año siguiente, reafirman que el camino hacia la toma del poder, obliga a tomar firmes determinaciones, entre las que se encuentra la "negativa a todo planteo unitario con fuerzas burguesas - partidos políticos tradicionales y cívico- y aquellas oportunistas que se mueven en el campo obrero, como el comunismo y el trotskismo" $" 167$.

Luego de los sucesos del 2 de abril en Santiago, los uruguayos reafirmarán que

los compañeros jóvenes, estudiantes y obreros, han demostrado que en la lucha activa y en la decisión combativa está el camino del enfrentamiento a una política que corroe el cuerpo y el espíritu de Chile y su pueblo. Están diciendo que allí está la fórmula para alcanzar la verdadera unidad: la unidad de corazón, de intereses y propósitos ${ }^{168}$.

El aliado de clase, no es entonces la burguesía nacional como planteaban los partidos comunistas, sino el campesinado. Al igual que planteaban los chilenos, lo importante era abrir

\footnotetext{
${ }^{164}$ Revista Arauco, $\mathrm{N}^{\circ} 1$, octubre de 1959, p. 2.

${ }^{165}$ Revista Arauco, N ${ }^{\circ} 2$, noviembre de 1959, p. 33-34.

${ }^{166}$ El Sol. "Soluciones socialistas o miseria. Resoluciones del XIV Congreso." 21.09.1956.

${ }^{167}$ El Sol. "Un programa de clase para los trabajadores. Política nacional". 13.12.1957.

${ }^{168}$ El Sol. "Los sucesos de Chile". 03.05.1957.
} 
la alianza sí, pero hacia los sectores populares. En el caso de Uruguay dejan en claro que "nosotros no incluimos en esta alianza de clases a la burguesía nacional."169

Para la realización de la fase nacional de la revolución era necesaria la conformación de este amplio movimiento, que diera nacimiento a un Frente Nacional y Popular. Siguiendo esta línea, desde fines de la década del 50'con el accionar de Raúl Sendic fundamentalmente con los trabajadores de la caña de azúcar en el norte de país, vemos un importante interés desarrollado por el PS uruguayo para organizar a los trabajadores del campo, fundamentalmente los arroceros, remolacheros y cañeros de Treinta y Tres, Paysandú y Bella Unión $^{170}$.

Pero además, una de las innovaciones claves planteadas por Trías, era la concepción de que en dicho Frente, podían ingresar sectores escindidos de los partidos tradicionales. Partiendo de la base de que la clase obrera, hasta ese momento, los acompañaba políticamente y que la clave estaba en llegar justamente a esas masas trabajadoras. Desde las páginas de $E l$ Sol, Trías insistía en que la clase obrera en Uruguay "no es ni comunista, ni socialista, es blanca y colorada" ${ }^{171}$. Como veremos, este será el camino para ampliar la alianza que tomará el socialismo uruguayo. Con dos claros objetivos, ampliar su influencia a sectores de las clases trabajadoras, y debilitar el caudal electoral de los partidos tradicionales.

\subsubsection{La alianza con el comunismo y las enseñanzas del FRAP en Chile}

Como vimos en el capítulo anterior, la unidad entre el socialismo y el comunismo en Chile se produjo incluso antes de la unificación del Partido Socialista (con la alianza entre el PCCh y el PSCh para la conformación del FRENAP en 1951) y luego con ambos sectores socialistas en la constitución del FRAP en 1956.

Salvador Allende, fue un claro defensor de la alianza con los comunistas durante todo el período. En su opinión, la unidad de la izquierda era condición indispensable para alcanzar los cambios revolucionarios. El Partido Socialista, tenía un importante papel que cumplir,

\footnotetext{
${ }^{169}$ El Sol. Vivián Trías. "Revolución Nacional y Revolución Socialista”. 22.06.1962.

${ }^{170}$ Desde las páginas de $\mathrm{El} \mathrm{Sol}$, se ve claramente el aumento de la atención a estos sectores. Por señalar algunas notas, "En la Casa del Pueblo. Se realizó el sábado un homenaje a los cañeros" (29.06.1962); "Reforma agraria: bandera de lucha de la Unión Popular" (09.11.1962); "Por la tierra y con Sendic" (20.02.1964); "La lucha por la tierra" de Vivian Trías (20.02.1964); "Reforma agraria y revolución" (06.03.1964); "Tierra ahora, una exigencia revolucionaria" (06.03.1964); "Trascendencia de la marcha de los cañeros" (13.03.1964); "Raúl Sendic, conductor sí, culto a la personalidad, no" de Vivian Trías (20.03.1964); "Tierra ahora! por las buenas o a las malas" (23.04.1965); "La lucha cañera, por las buenas o por las malas" de José E. Díaz (04.06.1965); "La libertad de Vique, Santana y Castillo. Tarea para la izquierda" (17.06.1966).

${ }^{171}$ El Sol. Vivián Trías. "La Unión Nacional y Popular". 01.06.1962.
} 
pero "solo lo va a cumplir en la medida que se haga en unidad (...) con todos los partidos que estén junto a la clase trabajadora". (Casals, 2010, p. 25).

En el XVIII Congreso, realizado en octubre de 1959, una de las discusiones claves, se produce a partir de la iniciativa comunista de fusionar las dos organizaciones. Para algunos militantes socialistas, la experiencia de actividades conjuntas de ambos sectores, permitiría la idea de implementar la militancia FRAP dejando de lado sus pertenencias partidarias. Con respecto, a la unidad en su nota hacia el PS, los comunistas señalan que "es de toda evidencia que estamos obligados a entendernos. En un momento (...) tendremos que llegar, incluso a la constitución de un solo partido marxista, sin prejuicio de la existencia de otras colectividades populares”. (Arrate y Rojas, 2003, tomo I, p.358). Para la mayoría de los socialistas, el lugar de la unidad socialista- comunista es claramente el FRAP, ya que - según Ampuero- es allí donde "el entendimiento de los dos partidos obreros experimenta una transformación positiva, se supera dialécticamente, adquiere una nueva calidad.” (Arrate y Rojas, 2003, tomo I, p.358). Los argumentos socialistas para rechazar la propuesta, se sostienen en base a dos manifestaciones: profundas discrepancias ideológicas y el alineamiento internacional comunista. Sin embargo, y más allá de las discrepancias -en algunos momentos álgidas- la alianza socialismo-comunismo no estuvo en duda en todo el período.

Como vimos en el capítulo anterior, la experiencia del FRAP, sobre todo luego de la importante votación de 1958, fue tomada por el comunismo uruguayo como argumento para la alianza. Los socialistas, mantendrán su negativa e incluso fundamentaran explícitamente lo conflictivo de copiar modelos externos, en este caso justamente el modelo del FRAP chileno. En 1961 señalan al respecto:

1. Las trasposiciones mecánicas de una realidad a otra, no son el método adecuado a aplicar por quienes se pretendan marxistas. (...).

2. En aquel país la lucha de los partidos de la clase obrera, había calado hondo en las masas populares. (...) Tanto el Partido Socialista como el Partido Comunista antes de la consolidación del FRAP, ya tenían un amplio respaldo en muchas zonas obreras. Y aun en las zonas rurales. Estos son hechos que dicta la realidad y no los deseos ${ }^{172}$.

Al año siguiente, reafirmarán "comenzando por Chile, y sin justipreciar la experiencia del Frente Revolucionario de Acción Popular, diremos que se ha gestado en una realidad objetiva y subjetivamente distinta, por lo que trasplantar al Uruguay dicha experiencia es (...), esquematismo y sectarismo combinados". Señalarán además que la crisis en Chile, es mucho

\footnotetext{
${ }^{172}$ El Sol. "Respuesta a El Popular" 01.09.1961.
} 
mayor que en Uruguay, porque la actuación del imperialismo comenzó más tempranamente, pero además allí no se ha dado el fenómeno que ocurre en Uruguay, dónde las grandes masas obreras canalizan su accionar a través de los partidos tradicionales.

\begin{abstract}
Allí un frente hace unos años derribó, aunque temporariamente, a la oligarquía; allí en 1952 los socialistas populares alineados con un movimiento de masas encabezado por Ibáñez derrotó a los radicales y a un frente de comunistas, socialistas de Allende, y otros; allí se gestó, con una amplitud que debemos reconocer a los comunistas chilenos y que los de acá no han tenido, la Central Única de Trabajadores, realmente única, que durante muchísimos años libró una batalla sindical que la ha habilitado para acciones más profundas favorables, incluso, a la unificación política de las fuerzas populares; allí hay un mosaico de partidos y una necesidad política de uniones y frentes que, sumados a las condiciones objetivas y al real significado de los comunistas y socialistas, explican el crecimiento electoral del FRAP. $(\ldots)^{173}$.
\end{abstract}

\title{
3.3.2.1. El rechazo a la alianza con el comunismo en Uruguay
}

La unidad no la vamos a conseguir haciendo gárgaras con esa palabra, no la vamos a conseguir en la mesa de los cafés, ni la vamos a lograr por decretos o declaraciones. La vamos a forjar en nuestra lucha diaria, sin sectarismos, con amplitud y visión revolucionaria en el sindicato, en el trabajo, en el barrio, en la universidad, y por sobre todo para los políticamente esclarecidos, dando el ejemplo.

(El Sol. "Unir abajo" 16.08.1963)

El rechazo a la política soviética, venía desde décadas atrás - ya influenciados por la evaluación de Frugoni luego de su larga estancia en la Unión Soviética-, lo que hacía inviable la alianza con los comunistas. "El PC no solo no era visto como un aliado posible, sino que, por el contrario era el principal adversario inmediato al que los socialistas se enfrentaban." (Yaffé, 2016, p. 135).

No podemos dejar de mencionar, que en este período el PS todavía era miembro de la IS, que también en 1956 descartó las posibilidades de alianza con los Partidos Comunistas ${ }^{174}$.

\footnotetext{
${ }^{173}$ El Sol. José Díaz. "En torno a la unidad: hechos, no palabras”. 16.03.1962.

${ }^{174}$ El Sol, publicó íntegramente la resolución de la IS, que señalaba: Los cambios de las tácticas comunistas que emergen del reciente Congreso del Partido Comunista de la Unión Soviética no constituyen una prueba fehaciente de un genuino cambio en los principios y en la política de la dictadura comunista. Por lo tanto, no existen motivos para que el Socialismo Democrático se aleje de la posición tomada, la que firmemente rechaza todo frente unido o cualquier otra forma de cooperación política con los partidos de la dictadura" (Resolución de la Internacional Socialista". 04.05.1956).

Una semana después, vuelven a publicar la resolución del bureau de la IS, que afirma:
} 
En marzo de ese mismo año, incluso antes de la primera carta del Partido Comunista uruguayo, la IS emitió una declaración en respuesta a las resoluciones del XX Congreso del PCUS, que fue publicada por el semanario socialista. En ella se afirmaba que

es requisito mínimo aun para estudiar la posibilidad de efectuar conversaciones de orden internacional, el restablecimiento de movimientos obreros realmente libres y democráticos en todos los países en que antes existían y donde han sido suprimidos o eliminados por la dictadura comunista. (...) Sería tonto y suicida que los partidos socialistas, y las organizaciones sindicales obreras antitotalitarias se prestasen al juego de dar al comunismo, la alternativa en su seno abriéndole los brazos como asociado en una causa común $(\ldots)^{175}$.

Como hemos visto en el capítulo anterior, el 25 de abril de 1956, Rodney Arismendi envía la primer carta al Comité Ejecutivo del Partido Socialista con un llamado a la unidad. La respuesta socialista enviada un mes después, rechaza la invitación alegando que

ahora intentaran recomponer lo que hace 35 años rompieron con la traición (...). Las 21 condiciones de Zinoviec(v) no fueron invención de Stalin. La 3ra Internacional nació con ellas. Las inspiró Lenin. Era una brutal consigna contra el Socialismo auténtico (...). No pueden culpar de nada de eso a Stalin. (...). Habría que dar por no producida, toda una larga época de traiciones, de criminales imposturas, de oscuras maniobras en perjuicio del proletariado y contra el socialismo democrático e internacional, para colocarnos a su lado, concediéndoles alternativa de amigos sinceros de la clase obrera y de los socialistas, que sistemática y torpemente traicionaron ${ }^{176}$.

La segunda respuesta del PS, llegó de la mano de su Secretario General -por ese entonces aún Emilio Frugoni- los primeros días de junio. En ella afirmaban que "por múltiples y poderosas razones que no ha de sernos posible enunciar sino muy someramente no aceptamos la alianza que se nos ofrece.” Dentro de esas múltiples razones, se encontraban nuevamente las discordias con las políticas llevadas adelante por la Unión Soviética, y la adhesión irrestrictica del Partido Comunista. Al punto de afirmar que "esta invitación al Partido Socialista no es originario del Comunismo uruguayo, sino que recoge una consigna

Socialismo y comunismo no tienen nada en común. Los comunistas se han dedicado a pervertir la verdadera idea del socialismo. Donde ellos están en el poder, han adulterado toda libertad, todo derecho de los trabajadores, toda mejora política y todo valor humano que los socialistas han ganado en una lucha que ha durado varias generaciones. Nosotros creemos en la democracia, ellos no. Nosotros creemos en los Derechos del Hombre, ellos se burlan de los mismos. Esto no ha cambiado por la refutación del stalinismo. (...) Ni tampoco podemos olvidar que a los socialistas se les niega todo derecho político en los países del bloque soviético y que muchos de sus miembros están todavía en prisión por el único crimen de creer que hay más de un camino al socialismo. (...). ("Socialismo y Comunismo. Declaración del Bureau de la I.S" 11.05.1956).

${ }^{175}$ El Sol. "La Internacional Socialista frente al comunismo". 23.03.1956.

${ }^{176}$ El Sol. "La invitación del comunismo". 25.05.1956. 
del XX Congreso del Partido Comunista de la Unión Soviética, donde el Partido uruguayo no tuvo ni siquiera voto".

El otro punto del desacuerdo, estaba vinculado con la defensa de la burguesía nacional:

El XVI Congreso del Partido Comunista uruguayo "resolvió" coincidentemente con el resto de los partidos comunistas americanos "la defensa de la burguesía nacional". Cuando más del 80 por ciento de la clase obrera uruguaya esta adherida a los partidos tradicionales, el Partido Comunista resuelve luchar por la defensa de la "burguesía nacional", lo que desnaturaliza la conciencia de clases (...).

\section{Y finalizaban, afirmando que el Partido Socialista}

para cumplir su misión necesita agrupar dentro de sus filas a toda la clase trabajadora que actualmente, en su inmensa mayoría, no se ha desprendido de los partidos tradicionales. Esa misión se vería entorpecida si nos confundiéramos con un Partido como el Comunista que tanta y tan justa resistencias tiene en las masas. $(\ldots)^{177}$.

Fue en este período, incluso, que los socialistas profundizaron en el planteo de una “tercera fuerza”. Esto también implicó un giro con respecto a la política internacional del Partido, ya que bajo el liderazgo de Frugoni, había una clara preferencia hacia el bloque liderado por Estados Unidos. Esta política antiimperialista, iba acompañada por un declarado apoyo a los movimientos anticoloniales que venían desarrollándose en África y Asia. Ellos mismos la definen como

la tercera fuerza, tajantemente diferenciada de la solución capitalista y de la solución soviética, sigue siendo la gran esperanza de la humanidad. Que esa tercera fuerza, la integran los movimientos revolucionarios con signo socialista, de las colonias y semi colonias, y los Partidos Socialistas de las metrópolis decididos a luchar en el autentico frente de la revolución proletaria y aquellos movimientos populares de liberación desatados en la órbita soviética $(\ldots)^{178}$.

La alianza con el comunismo era considerada además, como un impedimento para el acercamiento de otros sectores. En febrero de 1962, afirman

supongamos por un instante que los socialistas aceptáramos, por razones tácticas, el frente que proponen los comunistas. ¿Qué pasaría? Pues que los grupos que hoy aceptan formar el

\footnotetext{
${ }^{177}$ El Sol. "El Partido Socialista responde al Partido Comunista". 08.06.1956.

${ }^{178}$ El Sol. "Resoluciones del Congreso sobre política internacional". 13.12.1957.
} 
frente nacional y popular, no se plegarían. (...) Es decir, que al aceptar nuestro Partido la formación de una alianza con los comunistas, estaría de hecho frenando el desarrollo de un amplio frente que incluye a numerosos grupos y que incluirá a muchos más en un futuro inmediato $(\ldots)^{179}$

Como veremos en el apartado siguiente, el XXXIII Congreso, aprueba la resolución de comenzar contactos con otros sectores con el fin de concretar una alianza que pudiera encaminarse en la construcción de dicho movimiento "policlasista, antiimperialissta, nacional y popular" ${ }^{\prime 180}$. Este es el origen de la Unión Nacional y Popular, como veremos en el siguiente apartado.

\subsubsection{La Unión Nacional y Popular}

Como señalamos anteriormente, el XXXIII Congreso del Partido Socialista, realizado en marzo de 1962, aprueba continuar las conversaciones para establecer un frente opositor, con el fin de crear una amplia alianza para las elecciones que se realizarían a fines de ese mismo año ${ }^{181}$.

El instrumento político capaz de llevar adelante esa primera fase, no puede ser el Partido político clasista (expresión política de la clase obrera), sino el movimiento amplio que abarque a todas las clases sociales explotadas por la oligarquía y el imperialismo (...). Ese movimiento es la Unión Popular y su programa es el programa de la revolución nacional. ${ }^{182}$

Prosiguiendo con la estrategia de fragmentar el poder de los partidos tradicionales, el primer sector que ingresó a la alianza fue la agrupación Lista 41, liderada por el ex diputado Enrique Erro, escindido del Partido Nacional. Luego, se sumó la Agrupación Nuevas Bases $^{183}$, el Frente de Avanzada Renovadora ${ }^{184}$ y un grupo conocido como "ruralistas

\footnotetext{
${ }^{179}$ El Sol. "Frente Nacional y Popular. Una estrategia para el poder". 09.02.1962.

${ }^{180}$ El Sol. Vivián Trías. "La Unión Nacional y Popular”. 01.06.1962.

${ }^{181}$ La primera acción común, reunió durante ese mismo mes a la lista 41, el Partido Socialista, la Agrupación Nuevas Bases, el entonces diputado nacionalista Ariel Collazo, el dirigente cristiano Eduardo Payssé González y el exruralista José Claudio Williman, para formular un proyecto de reforma constitucional, para el que acordaron los temas que debía integrar, y designaron representantes que se encargarían de la redacción del proyecto. Finalmente, la iniciativa reformista no alcanzó el número de firmas requeridas al 25 de mayo de 1962 para habilitar la instancia de plebiscito. Ya en noviembre de 1961, las mismas agrupaciones habían realizado un trabajo en común para evitar la suba del boleto del transporte capitalino.

${ }^{182}$ El Sol. Vivián Trías. "Los socialistas en la Unión Popular". 09.11.1962.

${ }^{183}$ Fundada a mediados de 1959, por sectores provenientes de diversas procedencias y algunos independientes. Formaron clave de esta agrupación, figuras claves como Roberto Ares Pons, José de Torres Wilson y Helios Sarthou.

${ }^{184}$ Fundada en julio de 1961, por Eduardo Payseé González, quien se había escindido de la Unión Cívica poco tiempo antes. Esta es una de las primeras experiencias de alianza, entre socialistas y cristianos de izquierda.
} 
independientes" ${ }^{\prime 185}$. La exclusión del PCU, quedó establecida -además de los argumentos esgrimidos- por la posición de Enrique Erro. El mismo señaló en julio de 1962 que

claro está que en una Unión Nacional y Popular de orientales está excluida no sólo la camarilla oligárquica que destroza la riqueza nacional (...), sino también el Partido Comunista, que no es otra cosa que un apéndice de Moscú. No queremos ni cipayos de derecha, ni cipayos de izquierda ${ }^{186}$.

El Partido Nacional, impugnó la utilización del término "nacional", y la Corte Electoral falló a su favor, por lo que se presentaron a las elecciones de 1962, como "Unión Popular". Finalmente, ésta no logró captar el electorado que esperaba, sufriendo una dura derrota en las elecciones de $1962^{187}$ que trajo consigo importantes consecuencias a la interna del PS. En enero de 1963, su fundador y líder histórico -Emilio Frugoni- renuncia y se aleja definitivamente de la colectividad ${ }^{188}$. Fundará un tiempo después el Movimiento Socialista con escasa repercusión en la política nacional.

En diciembre de ese mismo año, se enfrentaron dos líneas que daban cuenta de las tensiones que comenzaban a manifestarse a la interna del Partido. Una de ellas, confirmó la tesis rupturista y profundizó la desconfianza hacia la posibilidad de un triunfo electoral, la estrategia era ahora formar un partido cerrado que se preparara para un camino revolucionario. La otra línea, buscó construir un nuevo movimiento de masas afín también a un proceso revolucionario. Finalmente, decidieron permanecer dentro de la UP y transformar al PS en un partido que pudiera insertarse en los diversos sectores privilegiados para el trabajo de masas.

Por otro lado, el conflicto con Enrique Erro por el usufructo de las bancas parlamentarias obtenidas, provocó la pérdida total de los escaños para los socialistas, que podrán recién recuperar luego de las elecciones de $1971^{189}$. Es decir, que durante cerca de 8

\footnotetext{
${ }^{185}$ Ex colaboradores del líder ruralista Benito Nardone, entre quienes se encontraban Alberto Methol Ferré y José Claudio William.

${ }^{186}$ Época. 01.07.1962. Citado por Duffau, 2008, p. 28.

${ }^{187}$ En las elecciones de 1958, el PS había alcanzado el 3,5\% de los sufragios (un Senador y tres Diputados). Para 1962, logró el 2,3\%, perdiendo su lugar en el Senado y obteniendo solo dos Diputados.

${ }^{188}$ Frugoni renuncia al Partido y crea la Junta Reorganizadora del Partido Socialista, con quienes comienza una disputa por el lema. En febrero, acusa de la mala votación a los jóvenes del PS quienes, "en vez de organizar un partido de acuerdo a sus mentalidades se les ocurrió infiltrar el nuestro." (Duffau, 2008, p. 34). El conflicto por el lema, dependería del resultado electoral de 1966. Finalmente, la Corte falla a favor de quienes permanecieron en el Partido. Los debates sobre la renuncia de Frugoni, pueden relevarse en Asesinato a traición. Culpas y culpables en la crisis del Partido Socialista (1963) y Causas de un alejamiento. Por qué se fue Frugoni del Partido Socialista (1966), entre otros.

${ }^{189}$ Enrique Erro encabezó la lista a diputados por casi todos los departamentos del país. Las dos bancas obtenidas fueron en Montevideo y Canelones, por lo que ambas correspondieron a Erro. El acuerdo, establecía que en este caso, la suplente por el Departamento de Canelones -María Soares de Lima- debía renunciar para
} 
años, los socialistas se transformaron en un partido extra parlamentario, aunque no por decisión propia. La desconfianza en el sistema electoral, la imposibilidad de contar con el parlamento como tribuna de denuncia y de proyección política, el aumento de la movilización social y los sucesos de la revolución cubana, produjeron que el socialismo uruguayo se fuera alejando cada vez más de sus postulados históricos.

Por otro lado, los golpes de Estado producidos en Guatemala, Bolivia y fundamentalmente en Brasil, y la intervención norteamericana en República Dominicana confirmaban "que los caminos democráticos para la revolución nacional (...) estaban agotados, porque el imperialismo estadounidense había demostrado ya suficientemente que no permitiría que prosperaran.” (Yaffé, 2016, p. 148). Cuba, entonces, mostraba el camino.

Por otro lado, el conflicto por la adjudicación de la banca, fue el motivo para terminar con la alianza, el 21 de junio de 1963 el PS abandona la UP ${ }^{190}$. Como veremos más adelante, los socialistas no descartarán la alianza con otros sectores, pero le darán una interpretación diferente, basado en la promoción de acciones comunes sobre la base de acuerdos concretos.

\subsection{El camino: entre el respeto a la legalidad y la vía armada}

Como veremos a lo largo del apartado, ambos partidos socialistas, estaban en un camino intermedio entre la insurgencia armada de tipo guerrillero y la vía pacífica, trabajando para el desarrollo de ambos caminos. Sin embargo, a medida que avanzaba el período, las discusiones sobre el uso de la violencia se hicieron cada vez más presentes. En un primer momento, ésta aparece en una actitud defensiva. "Si tenemos la vía democrática, sería absurdo despreciarla, pero también seria infundir un gran optimismo pregonar que la burguesía siempre respetará la democracia, aun cuando con ésta pierda todos sus privilegios. Esa predica no sería lógica"191. La teoría afirmaba que incluso ganando la izquierda las elecciones, las clases dominantes usarían la violencia para defender sus privilegios. En ese escenario, había que prepararse para defender el gobierno conquistado. Esta discusión, que comienza a fines de la década del 50'será clave en el desarrollo del gobierno de la Unidad Popular luego de 1970, y de las diversas tendencias y estrategias que se profundizarán en su seno.

permitir el ingreso de Vivián Trías. La diputada no sólo se negó a renunciar y se quedó con la banca, sino que poco tiempo después volvió al Partido Nacional.

${ }^{190}$ Para las elecciones de 1966, el nombre lo usará el grupo de Erro. El FAR abandona la UP en noviembre de 1963 y Nuevas Bases en enero del año siguiente.

${ }^{191}$ El Sol. "La palabra de las juventudes socialistas". 08.11.1957 
Posiblemente sea en ambos Partidos Socialistas, dónde el triunfo de la revolución cubana influyó más profundamente.

Comenzó de este modo, un proceso radicalizador de largo alcance que fue progresivamente desechando la opción sistémica de la izquierda, la legitimidad de las elecciones como vehículo de expresión, las posibilidades de sectores "no proletarios" de unirse a este movimiento y la interpretación ortodoxa de las etapas revolucionarias (...). (Casals, 2010, p.43).

Los sucesos del país caribeño, demostraban que era posible saltearse etapas, y comenzar a construir el socialismo de forma inmediata, construyendo una fuerza cuya columna vertebral fuese la clase trabajadora. Pero además, era una experiencia profundamente latinoamericana, no adscripta a la política de bloques, y que cuestionaba también la estrategia de la vía pacífica.

Poco meses después del triunfo, Allende viaja a La Habana se entrevista con Ernesto Guevara y regresa al país con la profunda convicción de apoyar el proceso, pero con la confirmación de que es inviable en Chile un intento insurreccional. Esta imposibilidad, se debía a dos razones: la primera, que el imperialismo norteamericano ya había sido alertado después de Cuba, de la posibilidad de realizar con éxito una insurgencia guerrillera y que por ende, iban a impedir que eso pudiera repetirse en cualquier país perteneciente a su área de influencia. Y en segundo lugar, porque establecía que el uso de la violencia era inherente a la burguesía. Es decir, que el uso de la misma por parte de la clase proletaria estaba justificada como reacción a los intentos de reducir los movimientos de la clase trabajadora. Por ello, lo imprescindible era profundizar el camino de la izquierda por la vía electoral.

Igualmente, ya en 1961, Salomón Corbalán explicitó las transformaciones que les provocó el triunfo de la revolución cubana,

no quiere decir que nosotros pensemos que hay que seguir exactamente el mismo camino de Cuba y hagamos como algunos afiebrados revolucionarios de gabinete que andan buscando algún cerro para transformarlo en su Sierra Maestra. Se trata de que en nuestro país, de acuerdo a nuestra realidad, debemos buscar el enfrentamiento de la clase trabajadora con la clase enemiga sin propiciar el entendimiento o la vía pacífica ${ }^{192}$.

El triunfo del proceso cubano, era para los socialistas la comprobación de la línea del "Frente de Trabajadores", ya que la exclusión de la burguesía nacional y la evidente

\footnotetext{
${ }^{192}$ Revista Arauco, No 19 , agosto de 1961, p. 6.
} 
posibilidad de acortar etapas, eran opciones factibles de conjugarse en un proceso rápido y exitoso de transformación de las estructuras sociales.

Quedaba claro, en su planteo que el Partido Socialista, buscaba el enfrentamiento de clase. Las críticas directas a la estrategia diseñada por el Partido Comunista eran claras,

esta vía pacífica tan anhelada por algunos partidos de izquierda es, aunque no se desee, un camino de conciliación. Que los trabajadores puedan llegar al poder por esta vía depende no de los trabajadores mismos sino de las clases oligarcas minoritarias. Si estas clases no se resisten por la violencia a entregar el poder al pueblo, significa que pacíficamente se resignan a su desaparición como clase opresora y ninguna justificación podría tener la violencia, porque no habría con quien desatarla. ${ }^{193}$

En el mismo momento, Óscar Waiss publica Vía pacífica o revolución. Ni dogmatismo, ni revisionismo: leninismo, en la que hace explícita referencia a los clásicos del marxismo para criticar el concepto de vía pacífica, el carácter opresor del Estado burgués, su imposibilidad de reformarlo y por ende, la necesidad inevitable de una revolución violenta para cambiar su naturaleza. Waiss, planteaba que toda la estrategia de la vía pacífica, estaba sostenida "sobre la debilísima base de algún párrafo aislado en que se admitió la remota posibilidad, la curiosa excepción, de que pudiera observarse alguna vez, una transferencia pacífica del poder, de manos de los opresores a los oprimidos" (1961, p. 8-17).

Y dos años más tarde, en setiembre de 1962, publicará El espejismo del 64 donde sostenía que

mantener el espejismo electoral es engañar a las masas y renunciar a la revolución y al socialismo. (...) La vía pacífica es el camino de la derrota; la estrategia exclusivamente electoral es un escamoteo de la voluntad histórica del pueblo. Solo la revolución, y los métodos de la revolución constituyen el arma de los trabajadores en este momento decisivo. (1962, p.1-2)

Sin embargo, es el PS quien en 1962 insta para que se oficialice la candidatura de Salvador Allende por el FRAP, para las elecciones de 1964. La decisión se basaba en el reconocimiento de que "la gran mayoría de los trabajadores chilenos solo esperan la proclamación oficial para incorporarse resueltamente a la lucha definitiva por la conquista del poder" ${ }^{\prime 194}$. Toda crítica a las excesivas tendencias electoralistas, fueron dejadas de lado al interior del Partido y por parte de sus principales teóricos se realizaron esfuerzos para

\footnotetext{
${ }^{193}$ Ídem, p. 17.

${ }^{194}$ Revista Arauco, $\mathrm{N}^{\circ} 25$, febrero de 1962, p. 20.
} 
legitimar la opción sistémica con los principios revolucionarios. Raúl Ampuero, por ejemplo, plantea en diciembre de 1962 que el centro del trabajo eleccionario debía ser el de "quienes están animando una gran empresa revolucionaria [con el protagonismo en] las organizaciones populares de los más diversos tipos, sindicales, de pobladores, campesinos, estudiantiles, de técnicos y profesionales". La tarea revolucionaria, en esta coyuntura, era "desafiar la formalidad de las instituciones burguesas en crisis"195. Según Ampuero, esto no significaba de ninguna manera, predicar la paz frente a las clases opresoras; en el caso de que se alteren las normas de la contienda electoral, las fuerzas "revolucionarias" tenían la obligación de agotar todos los caminos para hacer prevalecer su triunfo, incluso el de la violencia popular. Allende, mismo señaló que

si el gobierno y las fuerzas reaccionarias se pretenden erigir en empresarios de un fraude, de una nueva frustración, el pueblo de Chile sabrá encontrar el camino para defender la victoria. (...). Nosotros estamos usando el cauce legal, porque somos más fuertes. No queremos la violencia. El movimiento popular utilizará sus propias tácticas y experiencia. Que no se nos diga que vamos a copiar de otros pueblos de condición distinta ${ }^{196}$.

Sorpresivamente, en el XX Congreso realizado en febrero de 1964, se descartó la vía insurreccional y se apostó de lleno al triunfo en los comicios de fin de año. "Enfrentamos las elecciones (...), porque existen condiciones favorables para ganarlas, y porque ganándolas, ellas deben abrir una nueva etapa en el desarrollo de la revolución chilena. Además, porque objetivamente no existe otra opción." (Informe del Comité Central, citado en Walker, 1990, p. 141). Esta resolución fue la que promovió que un grupo de jóvenes de la ciudad de Concepción, abandonara el Partido, y fundara junto a otros sectores, a mediados del año siguiente el Movimiento de Izquierda Revolucionaria (MIR) ${ }^{197}$.

\footnotetext{
${ }^{195}$ Revista Arauco, N 29, junio de 1962, p. 7.

196 Ídem, p. 40.

197 En mayo de 1963, un sector de la Juventud Socialista de la ciudad de Concepción, dirigidos fundamentalmente por Miguel Enríquez y Bautista Van Schowen, fundan el periódico Revolución. Esta nueva fracción, comenzó a plantear la necesidad de romper con las prácticas sistémicas de lo que denominan como izquierda tradicional chilena, con el objetivo de unir a los "verdaderos revolucionarios" en una organización con una clara estrategia rupturista. Tal como ellos señalan, "la vía pacífica se ha mostrado como la pantalla revisionista para encubrir la colaboración de clases (...) sumiendo de esta manera al movimiento popular en un cretinismo electoral." (Arrate y Rojas, 2003, tomo I, p.367). En 1964, el grupo finalmente es expulsado del Partido. Como hemos visto en el capítulo anterior, el núcleo principal decidió unirse a la Vanguardia Revolucionaria Marxista. La derrota electoral del FRAP, en los comicios de setiembre de ese año, reforzarán la teoría de la inviabilidad de la "vía pacífica" y lo erróneo de la estrategia de la izquierda sistémica. El acuerdo de varios de los pequeños grupos rupturistas con este diagnóstico, será la clave para su unificación un año después en el Movimiento de Izquierda Revolucionaria. En sus orígenes mantendrán un claro acercamiento a la revolución china (fundamentalmente en su distancia con el proceso soviético). Como vimos en el capítulo anterior, finalmente los días 14 y 15 de agosto de 1965, en el local de la Federación del Cuero y el Calzado en Santiago de Chile, se realiza el Congreso de Unidad Revolucionaria que funda el MIR, del que participa entre
} 
El triunfo de la vía sistémica, y el esfuerzo destinado a ganar en las elecciones, significaban la victoria del sector liderado por Allende en la interna del Partido, hasta este momento. En el acto de cierre en el Teatro Ducal de Concepción, el candidato afirmó

declaro solemnemente que, por un voto más que yo obtenga seré Presidente de la Nación, pase lo que pase. Implacablemente vamos a utilizar la movilización de las masas para resguardar el derecho del pueblo de Chile a la vida; a quienes empleen la violencia, vamos a contestarles con la dura, la tremenda, con la decisiva violencia del pueblo, que es violencia multitudinaria ${ }^{198}$.

La tensión entre la teoría de respetar el orden institucional y la posibilidad de utilizar la violencia revolucionaria estaba latente.

En mayo de 1964, en el Pleno del Comité Central afirmaron que es mediante la participación institucional que "se busca hacer los cambios reales que abran la perspectiva hacia la construcción de una sociedad más justa, evitando el camino brusco y violento." (Walker, 1986, p. 57-58). Con una clara posición gradual, Allende identificó la etapa como de transición del capitalismo al socialismo. Una vez más, el acercamiento ideológico de Allende con los postulados comunistas se hacía evidente.

otros Andrés Pascal Allende, sobrino de Salvador. El evento ha sido organizado por una comisión presidida por Clotario Blest, y al que asisten 60 delegados, fundamentalmente provenientes de Concepción y Santiago. En su fundación se integran principalmente, los jóvenes socialistas que habían roto con el PS el año anterior; un sector minoritario de jóvenes comunistas en disidencia con su Partido, como Luciano Cruz; el colectivo denominado Vanguardia Revolucionario Marxista; militantes de un pequeño partido denominado Partido Socialista Popular y sindicalistas denominados "clasistas" encabezados por Clotario Blest. Se elige como Secretario General a Enrique Sepúlveda, mientras que Miguel Enríquez, liderará el conocido como "sector no tradicional” y asumirá la jefatura del movimiento dos años después. Como movimiento político, trascenderá el discurso ideológico, y llevará a la práctica la estrategia armada a partir del desarrollo de "acciones directas". De hecho, en la discusión sobre las vías de acceso al poder, hacen una clara opción por la vía armada, bajo la forma de "guerra prolongada", la que sería funcional a la construcción de una fuerza social revolucionaria de origen popular, que desarrollaría una insurrección general. Más allá de la influencia guevarista, la estrategia -tal como ellos mismos explicitan- no implica una copia mecánica de la idea "foquista", debido a que este camino quedaría subordinado al trabajo en los "frentes de masas". Además, se planificaba el conflicto en un ambiente urbano, dejando al sector rural como el lugar para construir el "doble poder", alternativo al burgués. En diciembre de 1967, se realiza el III Congreso del MIR en el local del PS (lo que nos muestra claramente la simpatía de un cierto sector del PS, y los vínculos que se mantenían entre ambos sectores) en San Miguel, donde Miguel Enríquez asume la jefatura del movimiento y se estructura la estrategia política de lucha armada, en consonancia con el surgimiento de nuevos movimientos guerrilleros en Brasil, Bolivia, Uruguay y Colombia.

${ }^{198}$ Revista Arauco, N 50, marzo de 1964, p. 14. 


\subsubsection{La santa violencia de los de abajo: de la derrota electoral a la vía armada}

Incluso llegará el momento como lo enseña la historia que frente a la violencia de la burguesía de los de arriba estalle la santa violencia de los de abajo. Esta será la hora heroica de las definiciones para los militantes que harán historia.

("El Sol”. 14.06.1963)

La estrepitosa derrota en las elecciones de 1964 en Chile (con el antecedente de lo sucedido en 1958), fue tomada por varios colectivos como la constatación de que el camino electoral no era viable. Las tendencias rupturistas existentes tanto en socialistas como en comunistas, reforzaron su teoría, como hemos señalado. A partir de este momento, la izquierda transitará hasta el golpe militar de 1973, por un período de tensión entre las corrientes que siguieron apostando por el camino institucional y quienes se volcaron directamente hacia el camino armado.

El caso socialista, será particular en este escenario, porque seguirá oscilando a medio camino entre ambas posiciones. Según Moulián,

las condiciones generales del período 1964-1970 permitieron que esa doble crítica de la estrategia llamada "reformista", aquella que afirmaba la necesidad inmediata del socialismo y aquella que señalaba la necesidad de la vía armada, empezara a tomar cuerpo y a provocar efectos políticos. $(2006$, p. 251).

La situación que se generó a la interna del Partido, fue realmente conflictiva. Raúl Ampuero, en su artículo El socialismo a la ofensiva, se dedicó a defender las posiciones oficiales tomadas por el Partido durante la campaña electoral, y rechazó las posturas que llamaban al abstencionismo para las elecciones parlamentarias de $1965^{199}$. Sin embargo, la sensación luego de las elecciones fue de derrota. El FRAP logra mantener su votación, pero se produce un enorme triunfo de la DC, alcanzando la mayoría absoluta. El Comité Central del PS, manifiesta su optimismo por el logro de mantener la votación, ante el avance democratacristiano y el retroceso del resto de los partidos. Claramente, esta postura no era compartida por los sectores más críticos, que lograron adelantar el XXI Congreso, que finalmente se realiza en Linares en junio de 1965 y que marca el triunfo del ala izquierda del sector. Se aprobó un extenso documento, redactado por uno de los representantes del ala

${ }^{199}$ Revista Arauco, Nro. 58, noviembre de 1964. 
izquierdista y futuro Subsecretario General del Partido -Adonis Sepúlveda ${ }^{200}$-, en el que se hacía una profunda crítica sobre la situación interna, responsabilizando a la dirección partidaria de haber desviado la línea revolucionaria, hacia una acción sistémica y paralizadora. El documento señala que "fuimos arrastrados (...) por una puerta falsa, al respeto de la institucionalidad burguesa y a la política de las vías pacíficas (...).” Y agrega, que quienes creyeron en el camino electoral "deben asumir también ahora la cuota de responsabilidad que les corresponde en la derrota". Finaliza, diciendo que "nuestra estrategia descarta de hecho la vía electoral como método para alcanzar nuestro objetivo de toma del poder." (Citado por Walker, 1990, p. 144)

En esta composición interna, ni Ampuero, ni Allende formaron parte del Comité Central, siendo varios de los nuevos integrantes elegidos por primera vez. El sector que había estado en la dirección anteriormente quedó claramente reducido, lo que muestra el proceso de radicalización que estaba viviendo el partido. Según la nueva orientación, "Allende habría despilfarrado este potencial revolucionario y sus posiciones ayudaron a aumentar el caudal reformista”. (Casals, 2010, p. 136). De hecho, este descenso de la influencia de la figura de Allende a la interna de la colectividad, provocará nuevamente tensiones cuándo se lo vuelva a designar como candidato para las elecciones de 1970, como veremos en el último capítulo.

Las discusiones producidas en Chile a la interna del socialismo y los sucesos producidos a nivel electoral, fueron recepcionados en Uruguay, y fueron alimento para las discusiones que venían produciéndose, fundamentalmente luego de las elecciones de 1962.

Las esperanzas en que la vía electoral era un camino, se mantendrán hasta dichos comicios, y comenzarán a revisarse o incluso ser desechadas luego del fracaso de Allende en las elecciones de 1964.

Luego de la derrota socialista de 1962, José Díaz, afirma que "aunque el camino de las urnas sea difícil. Abriremos todos los caminos que sean necesarios" ${ }^{201}$. La estrategia no era todavía, desechar el camino electoral, sino la profundización del trabajo con los sectores populares. "El FRAP chileno, hoy en vísperas de su triunfo electoral, se construyó a través de

\footnotetext{
${ }^{200}$ Adonis Sepúlveda (1919-2005), ingresa al Partido Socialista en 1936. Es elegido Secretario General del Partido Socialista entre 1971-1973. El 21 de mayo de 1971, fue Senador en reemplazo de Salvador Allende, cargo que ocupó hasta el golpe de Estado de 1973. Se exilia en México, y luego en Francia y Bélgica. Regresa a Chile en 1990, dedicándose a la reconstrucción del Partido Socialista, aunque se opone al sector moderado del mismo.

${ }^{201}$ El Sol. “El difícil camino de las urnas” José Díaz. 30.11.1962.
} 
más de veinte años de tanteos, derrotas, persecuciones, divisiones internas en los partidos, etc. La impaciencia no es (...) revolucionaria" ${ }^{202}$.

Sin embargo, la derrota electoral de Chile en 1964, sí comenzará a plantear que el camino electoral estaba cerrado. Carlos Pérez, militante socialista, evaluará desde El Sol que el fracaso del FRAP, no implicaba solamente la pérdida de los comicios, sino que además "en aras de la conquista de la Presidencia, (...) sacrificó posiciones estratégicas, y tácticas vitales para la acción revolucionaria",203.

Julio Louis ${ }^{204}$-militante aún del PS- será otra de las voces que evaluarán la derrota chilena como el fin del camino democrático. Discutiendo con el dirigente comunista chileno, Luis Corvalán, quien ante la pregunta de si el FRAP no lograba el triunfo en 1964 significaba la derrota de la vía pacífica afirmó que "en Cabo Cañaveral (...) fracasaron varias tentativas de colocar en órbita naves cósmicas. Y ello no significó el fracaso de la tesis acerca de la posibilidad de la conquista del espacio cósmico (...)". Es decir, que el resultado adverso en una tentativa por conquistar el poder político a través de la vía pacífica no podría invalidar la tesis general sobre dicha vía. Louis, responde que

no obstante, es preciso tener presente que la vía pacífica ha sido cercenada, como el camino ideal para la liberación popular, una y otra vez en nuestra América. Cabe, pues afirmar, que si el pensamiento de Luis Corvalán era ya sumamente discutible antes de las elecciones del 4 de setiembre, luego de realizadas éstas, como esperanza de futuro, se nos ocurre, constituye una auténtica promesa de ceguera. (...).

Y finaliza con el argumento de que la caída de Goulart, fue precedida de las mayores demostraciones de masas que apoyaron a las medidas reformistas a lo largo y ancho de todo el Brasil.

Y es que, no bastan las simples movilizaciones pacíficas de masas para detener la mano criminal de los poderosos. (...) La experiencia del FRAP (...) es una fuente preciosa de enseñanzas. Crear conciencia revolucionaria, organizar a los explotados desde Arica a Tierra del Fuego, y desde los Andes hasta el Pacífico, son pasos esenciales hacia la liberación obrera y popular. Minimizar el saldo obtenido es ingenuo o torpe. (...) Tal vez

\footnotetext{
${ }^{202}$ El Sol. "La derrota de hoy nutre la victoria de mañana". 13.12.1962.

${ }^{203}$ El Sol. Carlos Pérez. "El resultado de las elecciones en Chile”. 09.10.1964.

${ }^{204}$ Julio Louis (1938-) proviene de una familia socialista. Su padre era cercano a la línea de Emilio Frugoni. Se acerca a la Juventud Socialista a mediados de los años 50', siendo nombrado su Secretario General en 1955. En 1965, producto de los profundos debates que estaban sucediéndose a la interna del Partido, rompe con éste y funda el Movimiento de Unificación Socialista Proletario (MUSP). Profesor de Historia, egresado del Instituto de Profesores Artigas, de donde egresa en 1968. En 1970, rompe también con este Movimiento y funda el Movimiento Marxista, por el que es detenido entre 1975 y 1985.
} 
Chile haya llegado (...) al punto en que las posibilidades de crecimiento de las fuerzas revolucionarias dentro de las actuales estructuras políticas se agoten.

El argumento de Louis, se basaba en que si bien era correcto aprovechar los instrumentos de la "democracia burguesa" para crecer, insistir en las posibilidades ilimitadas que ésta ofrece

debilita ideológicamente a los combatientes revolucionarios. (...) Nada nos complacería más que imponer la finalidad humanitaria del marxismo, del socialismo, sin un gesto de dolor, sin una expresión de odio, sin una gota de sangre. Procuraremos hacer todo lo posible para que éste sea el camino que se transite. Pero la experiencia nos indica que no debemos ignorar el valor de los fusiles, porque los propios privilegiados obligan a este tipo de lucha no deseada por ningún hombre del pueblo. ${ }^{205}$

En enero de 1965, los socialistas publicarán una nota tomada de Arauco, en el que se evalúa lo sucedido. "Se han perdido 30 años en una estrategia deformada que ha impedido fraguar una verdadera conciencia de clase en los trabajadores. (...). Ahora es el instante en que debemos iniciar nuestra tarea verdaderamente revolucionaria.",206

En julio de 1965, con motivo de la realización del XXI Congreso del PS chileno, Guaraní Pereda realizará una profunda evaluación de los acontecimientos que será publicada en el semanario socialista. Allí, y como parte de su autocrítica por lo sucedido, afirmará que “en el planeta, en su santa zona occidental y cristiana (...), las elecciones tradicionales donde las hay, no son más que una mascarada, de la que usan y abusan y ponen en desuso los explotadores de todos los colores"207

\subsubsection{Unidad de acción para la revolución}

Nuestro trabajo debe ser encaminado hacia los objetivos que lleven al pueblo al poder, $\mathrm{y}$ esto se logrará cuando hayamos unido en forma REVOLUCIONARIA y no simplemente electorera, a todos los trabajadores de nuestro país para hacer algo más que tener una buena bancada: para hacer la REVOLUCIÓN

(El Sol. "Treinta y tres: inicua explotación”. 27.02.1965)

\footnotetext{
${ }^{205}$ El Sol. Julio Louis. "Las naves cósmicas del pacifismo". 06.11.1964.

${ }^{206}$ El Sol. “Chile ¿cuál es el camino?” 09.01.1965. [Nota de Espinoza Orellana, extraída de Arauco]

${ }^{207}$ El Sol. "Desde Chile. Y ahora, pasar a la ofensiva". 03.07.1965.
} 
Luego de la pésima experiencia electoral de 1962 y del conflicto con el acuerdo electoral con Erro, los socialistas uruguayos no descartarán la ampliación de su política de alianzas, pero si le darán un giro en su concepción.

Para llevar adelante la fase de la revolución nacional, el Partido Socialista sigue considerando imprescindible la alianza de todas las clases explotadas por el imperialismo y la burguesía nacional bajo la dirección del proletariado "y su auténtico Partido". Pero, no establecidas en un frente electoral, sino que

promoverá el acuerdo sobre puntos concretos de acción común con las diferentes tendencias ideológicas (...). Por eso, será en función de la práctica revolucionaria y no de preconceptos, que se determinarán el futuro instrumento político de la revolución nacional. (...). Este movimiento de masas servirá para extender en todas las clases populares una mayor conciencia revolucionaria imprescindible, también, para el cumplimiento de nuestra estrategia global. (...). UNIDAD DE ACCIÓN - pues- y LUCHA IDEOLÓGICA ${ }^{208}$.

La unidad de acción era el camino conducente, a la creación a futuro del Frente de la Revolución, sin la determinación de que grupos lo conformarán con anterioridad. Su integración será el resultado "de la lucha, del comportamiento en los hechos de cada uno de sus posibles integrantes. (...)”. En 1964, plantean que

para los socialistas, la manera de procesar una verdadera unificación de las izquierdas, para construir un verdadero Frente de Trabajadores (bien distinto de los Frentes Democráticos de Liberación), es necesario trabajar juntos en acciones concretas, desarrollando la unidad de acción en el movimiento obrero popular y en los distintos frentes de trabajo. Con ello, creamos las condiciones necesarias y adecuadas, para el surgimiento del Frente Político de la Revolución Nacional. (...).

Esto implicaba no dejar de lado ningún camino, sin subestimar la lucha electoral,

que apreciamos desde un ángulo marxista -ni ilusionismo reformista ni abstencionismo anarquista- los socialistas uruguayos trabajamos afanosamente en los dos planos del quehacer revolucionario: en la lucha de masas -para radicalizarlas- y en la organización de los focos explosivos de la sociedad uruguaya, para desarrollar las nuevas formas de organización y lucha. (...). Unidad para la Revolución; Revolución por el pueblo explotado unido $^{209}$.

\footnotetext{
${ }^{208}$ El Sol. "Caminos hacia la revolución uruguaya”. 05.07.1963.

${ }^{209}$ El Sol. "Los caminos de la izquierda: unidad de acción para la revolución”. 16.10.1964.
} 
La inclusión del concepto de "Frente de Trabajadores" histórica consigna del socialismo chileno, es tomada ahora en esta nueva estrategia política.

Una de las convocatorias claves a una acción común es ya a fines de 1964, y está vinculada al apoyo de las marchas cañeras ${ }^{210}$. En diciembre de ese año, el PS invita al FIdeL, al Frente de Avanzada Renovadora y a la Federación Anarquista Uruguaya (FAU) a coordinar acciones para el apoyo a los cañeros. El FIdeL plantea su discrepancia a realizar acciones conjuntas vinculadas con este tema ${ }^{211}$. Finalmente la declaración propuesta, será firmada únicamente por las tres organizaciones restantes con la exclusión del FIdeL ${ }^{212}$.

El mismo argumento, será utilizado para participar de la Mesa por la Unidad del Pueblo, organizada también en 1965, valorando la importancia de la unificación electoral de las izquierdas, sobre la base del programa de la revolución nacional,

\begin{abstract}
llamando públicamente con tal fin, a las distintas fuerzas de la izquierda, especialmente las que componen el Frente Izquierda de Liberación. (...). Lo ha hecho también, al prever las contingencias de la lucha electoral sobre bases inspiradas en dos conceptos que se unen y se complementan, la acción unificada de las fuerzas políticas de la izquierda y al mismo tiempo, la necesidad de que en esa unidad en el campo electoral, el Partido Socialista mantenga su indeclinable personalidad, su individualidad propia y su total independencia. $(\ldots) .^{213}$
\end{abstract}

Encaminada ya la unidad sindical, y realizado con éxito el Congreso del Pueblo, "el año 1966 será un año clave para el pueblo uruguayo. Debe ser el año en el cual se sientan las bases para forjar la Unidad Popular, sin la cual, no conoceremos la victoria" ${ }^{214}$. Esta vez, la discusión sobre que lema utilizar será lo que dificultará, la unificación de la izquierda ${ }^{215}$. Finalmente, y al no llegar a un acuerdo, resuelven que en las actuales circunstancias, el

\footnotetext{
${ }^{210}$ La Unión de Trabajadores Azucareros de Artigas (UTAA), organizados por Raúl Sendic, realizó en los años 1962, 1964, 1965, 1968 y 1971 marchas a pie hacia la ciudad de Montevideo, con dos reivindicaciones: el cumplimiento de la legislación laboral vigente y la expropiación del latifundio. Por más información, ver Merenson, Silvina (2016). Los peludos. Cultura, política y nación en los márgenes del Uruguay, Buenos Aires, Ed. Gorla.

${ }^{211}$ El Sol. "La prisión de Sendic, la lucha por la tierra y los grupos de izquierda. Una narración objetiva". 09.01.1965. La discrepancia fundamental del FIdeL estaba en vincular la defensa de Sendic (en ese momento detenido en Argentina), con la lucha por la tierra.

${ }^{212}$ El Sol.”Una declaración unitaria". 27.02.1965.

${ }^{213}$ El Sol. "Después del Congreso, se abre otra etapa". 01.10.1965.

${ }^{214}$ El Sol. "Forjar la Unidad Popular". 31.12.1965.

${ }^{215}$ El PCU, planteó que todos los partidos del acuerdo vayan bajo el lema del FIdeL, propuesta que recibió el inmediato rechazo socialista. Además de los argumentos ideológicos, el PS necesitaba que el lema "Partido Socialista" participara de los comicios, por la discusión por el nombre que mantenía con el sector liderado por Frugoni. De hecho, Julio Castro, Carlos María Gutiérrez y Héctor Rodríguez, realizaron la propuesta de ir a los comicios bajo el lema "Partido Socialista", propuesta que fue rechazada por los comunistas.
} 
Partido participará con la denominación "Socialista",216, aunque manifiestan su interés en seguir participando de la Mesa por la Unidad del Pueblo. Para las elecciones de 1966, participan entonces bajo el lema Izquierda Nacional.

Más allá de esta discrepancia, la estrategia de la unidad de acción se mantendrá durante todo este período. En enero de 1967, y ante el avance autoritario del gobierno, llamarán a integrar el Comité Nacional para la Defensa de los Derechos Individuales y las Libertades Públicas.

Fue acuerdo unánime de la reunión constitutiva dar publicidad una lista de locales donde se recibirán denuncias de cualquier clase de atentados a los derechos individuales y de las personas o entidad que han sido o pudieran ser afectadas por la represión policial $(\ldots)^{217}$.

El acuerdo lo firman, FAU, PCU, PS, MRO, Movimiento de Acción Popular Uruguayo (MAPU), Época, El Sol, El Popular, entre otros. La profundización de la crisis en Uruguay, los lleva a plantear nuevamente la realización de acciones comunes coordinadas ${ }^{218}$.

\subsubsection{Militantes socialistas en acciones armadas. De "El Coordinador" al "Congreso de Chillán"}

Hoy día nos podría dar más garantías individuales un revólver bien cargado que toda la Constitución de la República y las leyes que consagran derechos, juntos. (El Sol. “¿Un revólver o la constitución?” de Raúl Sendic. 15.11.1963).

Derrotados electoralmente, sin representación parlamentaria y fuertemente influenciados por la revolución cubana, un colectivo de militantes del PS uruguayo se involucraron en lo que se conoció como El Coordinador, germen que dará nacimiento al Movimiento de Liberación Nacional- Tupamaros en 1965. Lo interesante, es que desde 1963 a 1965, este colectivo no solamente siguió siendo miembro del PS, sino que ocupó cargos de dirección.

Luego de la derrota electoral de 1962, la dirección del PS accedió a la propuesta de preparar un grupo que se encargara de la seguridad del partido, fundamentalmente para los militantes que participaran de movilizaciones e incluso la protección de los militantes en caso de un golpe de Estado. Según Efraín Martínez Platero, por ese entonces militante socialista,

\footnotetext{
${ }^{216}$ El Sol. "XXI Congreso del Partido Socialista. Resolución central". 18.03.1966.

${ }^{217}$ El Sol. "Comité Nal. de Defensa de las Libertades Públicas". 20.01.1967.

${ }^{218}$ El Sol. "Unidad de acción y lucha ideológica. El socialismo se dirige a otras fuerzas de izquierda". 01.12 .1967
} 
fue Vivián Trías quien lo invita a formar parte del grupo de autodefensa con la intención de "preparar al partido y a la juventud para instancias de mayor radicalización del proceso político." (Duffau, 2008, p. 45). El Partido organizó tres grupos, encargados de la autodefensa, respondiendo a una disposición geográfica: litoral, zona este del país y un tercer grupo en la zona centro-sur. Con esta estructura funcionaron hasta mediados de 1963, cuando se produjo el asalto al Club del Tiro Suizo ${ }^{219}$. Carlos Riverós, afirma que

el Partido Socialista siempre pensó que lo mejor era la democracia y el camino democrático, pero con la tesis que teníamos de que la burguesía no iba a largar el poder así nomás y que había posibilidades de que pasara lo que pasó en España y lo que después pasó en Chile, teníamos la tesis que otros grupos de izquierda tenían de buscar la forma de estar preparados para si se daba una situación revolucionaria, poder actuar incluso con las armas si era necesario. Y en ese sentido, se formó en el Partido una serie de grupos con gente que no estaba en los cargos más visibles del Partido en ese momento, a partir del año $62^{\prime}$, en que se empezó a preparar en cierto sentido, dentro de lo que se pueda decir, militarmente ${ }^{220}$.

En esta primera época, los militantes que formaban parte de los grupos de autodefensa, mantuvieron además sus actividades dentro del partido, ya que la integración a los mismos era clandestina o por lo menos se manejaba con ciertos criterios de seguridad básicos. Este colectivo, se fue conformando como una corriente a la interna del PS, afín a la preparación de un aparato militar y a su vez, en franca discrepancia con la línea trazada por el propio partido. Encabezada justamente por el grupo que se encontraba en el litoral del país, liderados por Raúl Sendic, y que había comenzado a trabajar con los cañeros del norte del país, agrupados en UTAA (Unión de Trabajadores Azucareros de Artigas). La idea de Sendic, desde un comienzo fue abrir el tema de la defensa de la tierra hacia otros sectores y que no quedara solo reivindicado por el Partido Socialista. Integrantes del Movimiento de Apoyo al

\footnotetext{
${ }^{219}$ En marzo de 1963, el PS había recibido la invitación de ocupar la estancia de Silva y Rosas y la Valentina Palmas (30.000 hectáreas en total) en la ciudad de Bella Unión y no desocuparlos. La decisión fue negativa y confiaron en que ninguno de sus militantes iban a llevar adelante la propuesta. A la vez, Vivían Trías denunciaría en el Parlamento la necesidad de tierras para los cañeros, pero el conflicto con Erro por el cuál el Partido se quedó sin representación parlamentario, frustraron la acción. El $1^{\circ}$ de agosto de 1963, se realizó una de las primeras acciones armadas de El Coordinador, que consistió en el robo de armas al Club de Tiro de la localidad de Nueva Helvecia, en el Departamento de Colonia, que servirían justamente para la ocupación de las estancias señaladas. La camioneta que transportaba las armas volcó en la ruta hacia Paysandú y varios fusiles quedaron desparramados en el lugar. El contacto fue de Raúl Sendic con otro militante socialista Humberto González Perla y las armas quedaron finalmente guardadas en el local del PS en Paysandú. Las tensiones a la interna y la autonomía que el sector de Sendic iba obteniendo eran cada vez más evidentes.

${ }^{220}$ Ingresa a la Juventud socialista en 1949, militando ya en la Agrupación vanguardia del liceo nocturno de Montevideo. Como representante de la Juventud Socialista realiza en la década del 50'un largo viajo por Latinoamérica y Europa. Durante la dictadura militar es detenido varias veces. Se mantuvo en contacto con el PS hasta entrada la transición democrática.
} 
Campesino (MAC), fueron los primeros en vincularse con el tema y tomar contacto con los militantes cercanos a Sendic. Su pedido de coordinación, fue el germen de lo que un tiempo después se llamó El Coordinador, y al que se sumaron también el MIR y la FAU. En marzo de 1963, Sendic -todavía dentro del PS- escribe una columna en El Sol, titulada “¿Un revolver o la Constitución?", donde dejaba en claro su posicionamiento político:

\begin{abstract}
¿No habrá llegado la hora de devolver los golpes, de escarmentar a los aprendices de fascistas antes de que se reciban de fascistas? ¿No tendremos que reprocharnos más tarde de haber fomentado la violencia con nuestra tolerancia infinita? Ahora que no podemos esperar, -consuelo tonto al fin- de que nuestro diputado socialista proteste con nosotros en Cámara podríamos ponernos a pensar en serio. Pensar en protegernos ya que no podemos pensar que nadie lo haga por nosotros. Tal vez así lleguemos a asumir nuestro propio rol en la historia ${ }^{221}$.
\end{abstract}

La acción del Tiro Suizo, la detención de algunos de sus miembros y el escape de Raúl Sendic $^{222}$, son el alerta para que las organizaciones comiencen a analizar su vínculo con los partidos de origen. Varias de las organizaciones de izquierda, respaldaron a Sendic y llamativamente Frugoni se ofrece para ejercer su defensa jurídica. El PS le propuso apoyo político y jurídico para que centrara su militancia en las acciones legales. Aunque estaba clandestino y perseguido por la justicia, seguía siendo miembro del Partido e incluso integrante de su Comité Ejecutivo, lo que provocaba además allanamientos a locales partidarios.

Mientras tanto El Coordinador continuó con sus acciones en otras zonas del país. En Montevideo, se destaca la creación de los "Comandos del hambre", robo a supermercados y el reparto de lo obtenido en las zonas periféricas de la ciudad. El Sol incluso saludó la iniciativa. En sus páginas definieron a los "Comandos del hambre", como el símbolo de "ese mañana tan cercano en el que el pueblo entero sabrá conquistar sus derechos por sus propios medios "223.

No obstante, la tensión que se vivía a la interna del socialismo, debido al estado público que tomó la acción y la vinculación directa con sus militantes, Eleuterio Fernández Huidobro, sostiene que el 25 de abril de 1964 se aprobó el ingreso al Coordinador de los militantes provenientes del $\mathrm{PS}^{224}$. (1986, p. 130) Los socialistas fueron aceptados para

\footnotetext{
${ }^{221}$ El Sol. “¿Un revólver o la constitución?” de Raúl Sendic. 15.11.1963

${ }^{222}$ Desde Paysandú, la policía detectó movimientos y detuvo a varios de los militantes que habían realizado el robo. Sendic logra escapar y llega a Bella Unión.

${ }^{223}$ El Sol. Editorial. 27.12.1963.

${ }^{224}$ Para poder ingresar, debieron realizar una "prueba" que consistía en el robo de 540 kilos de geilinita de la Compañía Nacional de Cemento Sociedad Anónima, ubicada en la ciudad de Pan de Azúcar en el Departamento de Maldonado.
} 
ingresar, y a partir de allí, una resolución del Partido habría autodisuelto los grupos de autodefensa. (Duffau, 2008, p. 55). Esto no significa, que todos sus integrantes, se hubieran involucrado en las tareas de El Coordinador, muchos volvieron a centrar su actividad en las actividades legales del PS.

El momento de ruptura, comienza a mediados de 1964, cuando solicitan apoyo económico para mantener las actividades. Ante la respuesta negativa, debieron realizar acciones que les permitiera conseguir el financiamiento necesario ${ }^{225}$. En diciembre de 1964, Sendic es finalmente detenido en la costa argentina -junto a Anacleto Silveira y Juan Bentín-, y trasladado a la Cárcel de Paso de los Libres. El PS inició una gran campaña para lograr su liberación y llamó a sus militantes a "salir a la calle con fervor, por el justiciero reclamo de la libertad de Raúl Sendic y sus hermanos cañeros "226. Este hecho, no impidió que entre febrero y abril de 1965 se realizara una nueva marcha cañera hacia la capital del país.

En mayo, los miembros de El Coordinador resolvieron llamar a un plenario, para discutir sobre su futuro político. En la reunión, conocida como el "Simposio de Parque del Plata”, se acordó: que sería la lucha armada el camino que aseguraría el triunfo revolucionario y la instalación de un foco guerrillero como núcleo disparador. Las discusiones sobre estos temas provocaron que varias de las organizaciones se alejaran del grupo. José Díaz, en representación del PS, aseguró que no estaban dispuestos a abandonar la actividad parlamentaria. "Nuestra posición era que el Uruguay no estaba maduro para una acción de tipo armado, porque los caminos democráticos no estaban cerrados." (citado por Duffau, 2008, p. 82). El segundo día, se dio por finalizada la tarea de El Coordinador y se aprobó la creación de una nueva organización- el Movimiento de Liberación Nacional-Tupamaros-. Quienes no estuvieron de acuerdo, abandonaron el Simposio, entre ellos el PS.

El problema continuó siendo la doble militancia de varios de los socialistas que hasta este momento, permanecieron en el Partido. Esta situación se mantuvo, incluso luego de la primera Convención de los ya "Tupamaros" en enero de 1966. De hecho, en el XXXV Congreso del PS realizado en setiembre de 1965, fueron elegidos como miembros del Comité

\footnotetext{
${ }^{225}$ El 11 de junio de 1964, se produce el robo a la sucursal del Banco de Cobranzas, ubicado en Montevideo, llevado a cabo por un grupo de cañeros, pero sin conocimiento ni del Coordinador, ni del PS. Como consecuencia, tres militantes de UTAA y del Partido Socialista, fueron detenidos: Julio Vique, Nelson Santana y Atalivas Castillo. La tensión con el PS aumentó. Tanto desde El Sol, como desde UTAA se afirmó que la acción había sido exclusiva responsabilidad de sus autores. Cuatro meses después, el 14 de octubre de 1964, otros tres militantes socialistas fueron participes de un hecho delictivo. Julio Marenales, Alberto Giménez, y Jorge Manera, realizan el asalto a otro banco, son detenidos por la policía y permanecieron en prisión hasta mediados del año siguiente. Esta vez, desde las páginas del semanario socialista, no se realizó ninguna referencia al hecho. Sin embargo, dos referentes del PS oficiaron de abogados defensores de los detenidos: José Díaz del grupo de los cañeros y Ruben Caggiani de los detenidos del 14 de octubre.

${ }^{226}$ El Sol. "Raúl Sendic está preso". 24.12.1964.
} 
Ejecutivo Nacional dos integrantes de la nueva organización: Julio Marenales y Jorge Manera $^{227}$. De hecho, buena parte de la dirección original del MLN-T tiene origen socialista y se mantenía dentro del partido.

El quiebre final, se produjo el 22 de diciembre de 1966, cuando la nueva organización decide realizar el robo a la fábrica de FUNSA. El descubrimiento de uno de los autos robados para el operativo y el alerta a la policía, provocó un enfrentamiento en donde muere el militante Carlos Flores y otras decenas deben pasar a la clandestinidad. En ese contexto, solicitaron ayuda a los partidos legales de la izquierda. Sendic logra reunirse con Arismendi, y éste le ofrece dinero, pasaportes y ayuda para salir del país. El PS, restringió la ayuda solo a sus militantes, lo que provocó la renuncia de los que aún seguían integrando las filas socialistas. La carta de renuncia de Sendic, fundamentaba que "no puedo pertenecer a una organización que limita la solidaridad.” (Duffau, 2008, p. 101).

Luego de realizada la reunión de la OLAS, -que analizaremos en el apartado siguiente, y de la muerte del Che en Bolivia, a fines de noviembre de 1967 el PS chileno realiza en la ciudad de Chillán su XXII Congreso, en el que radicaliza su línea política, se define por primera vez como marxista- leninista y postula el carácter inevitable y legítimo de la violencia revolucionaria para la toma del poder. Confirma su rechazo al gobierno y declara el fracaso de la política económica del Presidente Frei. Dos días antes de iniciado el congreso, Augusto Olivares, publica en la revista Punto Final, una extensa entrevista a Clodomiro Almeyda con un título sugerente para las discusiones del momento: "Dejar a un lado el ilusionismo electoral." (Amorós, 2013, p. 240)

Se reelige a Aniceto Rodríguez, como Secretario General. En la votación para los miembros del Comité Central, obtienen las dos primeras mayorías: Carlos Altamirano y Rolando Calderón, dirigente de la Confederación Campesina Ranquil y quien será en unos años, la figura más importante de la organización político- militar del PS. Actúa también, el

\footnotetext{
${ }^{227}$ En este Congreso, se produce además una escisión, luego de que un grupo numeroso de la Juventud Socialista proponga una redefinición del partido que los llevara a constituirse como el auténtico partido del proletariado, denominado Partido Proletario Revolucionario. Entendían que la crisis que estaba viviendo el país, no tenía otra salida posible que la revolución proletaria, que sería un proceso único e ininterrumpido, pero con dos fases: una nacional y popular liberadora que sería la que sentaría las bases para la segunda etapa socialista-proletaria. El Congreso se saldó con la derrota de este grupo, que expulsados del Partido fundan el Movimiento de Unificación Socialista Proletario (MUSP). La resolución del Congreso se aprobó por 227 votos contra 225, lo que nos da la pauta de los diversos conflictos intestinos por los que el Partido estaba atravesando. (Rey Tristán, 2005, p. 305) Julio Louis, miembro de los jóvenes socialistas que rompen con el Partido, recuerda que el socialismo termina "partido a la mitad, debido a que José Díaz convenció de último momento en contra de la posición de la minoría a la postre, a gente de Fraile Muerto que cambio el voto de lo que había traído. Entonces, ahí lo que fue el MUSP se abrió y yo también".
} 
denominado "grupo de los elenos", -con clara referencia al ELN boliviano-, creado para canalizar las actividades de solidaridad y apoyo a la guerrilla en Bolivia. Este grupo está integrado entre otros, por: Elmo Catalán ${ }^{228}$, Arnoldo Camú, Celsa Parrau, Félix Huerta y Beatriz Allende.

En las resoluciones del Congreso se afirmó:

la violencia revolucionaria es inevitable y legítima. Resulta necesariamente del carácter represivo y armado del estado de clase. Constituye la única vía que conduce a la toma del poder político y económico, y a su ulterior defensa y fortalecimiento. Solo destruyendo el aparato burocrático y militar del estado burgués, puede consolidarse la revolución socialista". El corolario de esa visión era que el PS consideraría "las formas pacíficas o legales de lucha (...) como instrumentos limitados de acción, incorporados al proceso político que nos lleva a la lucha armada. (Riquelme, 2009, p. 89)

Allende, fue el gran derrotado de este Congreso, no logrando un lugar ni siquiera como miembro del Comité Central. En palabras del militante socialista Jaime Suárez,

en el debate del Congreso fue la voz contestataria a la mayoría aplastante de delegados. Para Allende era fundamental ampliar el FRAP y respaldar la revolución cubana, pero era necesaria una política de alianza más flexible y era muy obvio que un Partido que proclamaba como forma de lucha la vía armada no iba a lograr una ampliación del frente político. (Suárez, 2008, p. 124).

El uruguayo Carlos Riverós, participó del Congreso de Chillán como invitado en representación del Partido Socialista. De las discusiones producidas allí, recuerda

\begin{abstract}
Allende ahí sostenía la posición, que a la postre resultó errada, de que por vía democrática podía llegar al poder un gobierno popular. (...) justamente, ahí el tema que se estaba discutiendo era como reaccionaba la derecha al crecimiento de los movimiento populares. Esa era la discusión (...). Hubo grandes movilizaciones, realmente la gente estaba muy enfervorizada con la posibilidad de llegar al gobierno y hacer transformaciones, como las inició Allende.
\end{abstract}

Lo llamativo, es que luego de las resoluciones del Congreso, el PS no se abocó en su totalidad a la preparación de un aparato armado que le permitiera la pugna por el poder. Lo mismo que había sucedido años atrás en Uruguay, parecía ahora repetirse en Chile. Un sector

\footnotetext{
${ }^{228}$ Elmo Catalán, parte hacia Bolivia en 1968 para unirse a la guerrilla en Teoponte del ELN. Allí es asesinado el 8 de junio de 1970. La Brigada Muralista Elmo Catalán del Partido Socialista de Chile, lleva su nombre en homenaje.
} 
del Partido, se encontraba en las arduas y duras negociaciones para la proclamación del candidato presidencial para las elecciones de 1970 (y las parlamentarias de 1969), a la vez que otro sector comenzaba a realizar sus primeros ensayos armados.

En julio de 1968, se produce el conflicto del fundo San Esteban ${ }^{229}$, donde el "aparato armado" del PS, realiza su primera acción directa y a partir del cual varios dirigentes como Rolando Calderón, Exequiel Ponce y Carlos Lorca, entre otros, forman lo que se llamará “Organa", una tendencia interna militar clandestina, que irá aumentando en los años venideros y que tendrá sus propios contactos y organización en los diversos regionales del Partido.

A fines de este mismo año, Carlos Altamirano es acusado luego de una conferencia de “insultar al Ejército", detenido y por lo tanto, separado de su cargo parlamentario. Desde la prisión, Altamirano publica el documento El Parlamento, tigre de papel, donde deja en claro que la clave de la lucha no es el recinto parlamentario sino la lucha de masas. Es en el contexto también del retorno de OLAS, donde las luchas institucionalistas, habían quedado absolutamente descartadas. Tal como él mismo señala,

han perdido para siempre su validez las antiguas alianzas de partidos con menguados objetivos, inmediatistas o electoreros; los arreglos de pasillo, las soluciones de conciliación (...). La capacidad de rebelión del pueblo chileno no se ha perdido, está a la vista, de ello hay testimonio a diario en los combativos y heroicos movimientos gremiales (...). Sólo falta una dirección audaz y resuelta (...) que llame a todas las fuerzas revolucionarias -sin exclusiones de ninguna naturaleza- y las conduzca con decisión por el camino de la revolución chilena. (Altamirano, 1968, p. 6)

A su vez, alineado con las políticas comunistas, de construir alianzas amplias se encontraba Allende, no solo con el PCCh -como veremos- sino también con otros partidos progresistas. Parecería que el discurso político radical producido en ambos partidos, entraba en tensión con una práctica política que en ciertos aspectos mantenía una opción sistémica. La elección de Aniceto Rodríguez en Chile, representante del ala más moderada del Partido, entraría dentro del juego de estas contradicciones.

\footnotetext{
${ }^{229}$ El conflicto campesino, comienza siendo por un tema salarial, que rápidamente se radicaliza y se transforma en la toma del fundo. Allí la Comisión Agraria Socialista (CONAS) y la Brigada Universitaria Socialista (BUS), organicen tareas de apoyo político y defensa ante una posible represión. Tanto Allende, como Altamirano y otros parlamentarios socialistas se hacen presentes, y Rolando Calderón junto a otros militantes de la juventud se integran al grupo de defensa. Finalmente, la acción es reprimida por Carabineros y sus dirigentes terminan encarcelados.
} 


\subsubsection{Socialistas uruguayos y chilenos en la OLAS}

Las reuniones de la Conferencia Tricontinental en enero de 1966, será otro motivo de encuentro entre los socialistas chilenos y uruguayos. Con dicho fin, en marzo de ese año un militante del socialismo uruguayo (cuya identidad no se aclara), lleva a Chile el mensaje del Secretario General del PS y mantiene una larga reunión con Aniceto Rodríguez, por ese entonces Secretario General de su par chileno. "El Comité Ejecutivo Nacional de nuestro Partido, ha resuelto elevar a los socialistas chilenos un memorándum sobre la Tricontinental, y promover una reunión conjunta para considerar, asimismo, las relaciones orgánicas de los Partidos Socialistas latinoamericanos y movimientos afines" ${ }^{, 230}$.

Dos meses después se anuncia la llegada a Montevideo, de una delegación del Partido Socialista de Chile, encabezada por Eduardo Ruiz, miembro del Departamento Internacional de dicho partido. En el informe publicado sobre dicha actividad, se afirma que

es evidente que dentro de las fuerzas antimperialistas se perfila una poderosa corriente que no se detiene en metodología alguna para impulsar la lucha de liberación y plantea la necesidad de la preparación y organización revolucionaria que nos capacite par las instancias decisivas. De ahí que la coordinación de estas fuerzas es esencial para enfrentar al enemigo común ${ }^{231}$.

Un mes después, ambos partidos volverán a reunirse en la ciudad de Buenos Aires, con el fin de intercambiar puntos de vista sobre la situación latinoamericana y fundamentalmente sobre la necesidad de aumentar los contactos que se habían debilitado luego de clausurada la experiencia del Secretariado Latinoamericano de la IS. A su vez, se acordó promover el funcionamiento de Comités Nacionales de la OLAS y volver a reunirse "en Montevideo o en Santiago, y si es posible con la participación de otras fuerzas y movimientos",232.

Previo a la reunión en La Habana, entre junio y julio de 1967 El Sol, publica dos largas notas de Carlos Altamirano, "El combate continental" y "La lucha armada debe tomar forma de guerra de guerrillas", en las que se reafirma que el camino inevitable era el armado y donde Cuba era el ejemplo a seguir. En la extensa publicación, señala:

\footnotetext{
${ }^{230}$ El Sol. “Socialismo latinoamericano". 04.03.1966.

${ }^{231}$ El Sol. "Reunión Socialista Latinoamericana". 13.05.1966.

${ }^{232}$ El Sol. "Coordinación socialista latinoamericana". 17.06.1966.
} 
nosotros, formados en la vieja escuela del teatro clásico, aún continuamos hablando de alianzas políticas, de pactos electorales, en Cuba, nadie habla de alianzas políticas, ni de pactos electorales, ellos preguntan por los frentes guerrilleros. Aquí nosotros hablamos de partidos políticos, allá ellos hablan de ejércitos del pueblo. Para ellos, político revolucionario es el que se hace en el combate guerrillero, de la sierra, o de la montaña, no el que se forma en la lucha municipal, sindical o en los pasillos parlamentarios. (...). No son políticos revolucionarios los que aspiran a mantener o restablecer hipotéticas garantías individuales centro de farsas democráticas representativas. (...). A la fuerza interamericana de paz de los reaccionarios, debe responderse con la fuerza armada guerrillera, continental, de los revolucionarios. (...). La lucha debe ser armada. El imperialismo no será derrotado por la vía pacífica ${ }^{233}$.

En medio de estos debates, se reunirá por primera y única vez entre el 31 de julio y el 10 de agosto de 1967 en La Habana la OLAS, creada justamente a instancias de la delegación socialista, integrada por Salvador Allende, Clodomiro Almeyda y Walterio Fierro ${ }^{234}$.

Como vimos en el capítulo anterior, en el caso uruguayo, el FIdeL fue el encargado de la preparación de la delegación nacional, por su anterior participación en la Conferencia Tricontinental en enero del año anterior. Su actitud, fue cerrada a la inclusión de otros grupos políticos. La participación del socialismo uruguayo en dicha Organización, nuevamente vuelve a vincularlos con su par chileno. Eduardo Aparicio, recuerda que

\begin{abstract}
Allende era el Presidente de la Tricontinental y las gestiones de Allende son las que viabilizan la participación de una delegación dentro de la delegación uruguaya de representantes del Partido Socialista en la OLAS. El Comité Uruguay OLAS estaba mayoritariamente controlado por el Partido Comunista, que practicó una política de fuerte exclusión, quedaron también fuera otros sectores, entre ellos el propio MLN (...). Pero bajo la mediación de Allende es que se logra incluir a los socialistas en la delegación de la OLAS. Ahí van José Díaz y Reinaldo Gargano.
\end{abstract}

José Díaz, confirma esta hipótesis: "fue Allende, que pasó por acá y nos dijo ustedes tienen que ir". Tres meses después de finalizada la OLAS, el PS uruguayo realiza su XXXVI Congreso, en el que reafirma "la conquista del poder mediante la lucha armada, forma de lucha fundamental y única vía para el cumplimiento de dicho objetivo; y la unidad

\footnotetext{
${ }^{233}$ El Sol. Carlos Altamirano. "El combate continental". 30.06.1967 y "La lucha armada debe tomar forma de guerra de guerrillas" 07.07.1967.

${ }^{234}$ Según Marcelo Casals, la participación de Allende en la OLAS y su acercamiento a la dirigencia cubana tuvo entre cosas, el objetivo de legitimar su figura ante el sector más rupturista de su propio partido. Por otro lado, le permitía renovar su imagen política, rompiendo el estereotipo de político tradicional y moderado, que le atribuían desde estos sectores. (2010, p. 252-253). En febrero del año siguiente, siendo Presidente del Senado, acompañó a tres guerrilleros cubanos sobrevivientes de la guerrilla del Che en Bolivia, que habían logrado entrar a Chile desde el norte. El gobierno optó por expulsarlos y deportarlos a Tahití, lugar al que Allende personalmente los acompañó.
} 
revolucionaria de las clases populares, imbuidos de la ideología del proletariado" ${ }^{\text {235 }}$. La estrategia era trabajar dentro de las instituciones democráticas, pero alertados de que a medida de sus posibilidades de acción legal se iban estrechando, no quedaba alternativa de tomar otros caminos. La ilegalización del PS, decretada justamente por su adhesión a la OLAS, confirmaba en los hechos esta hipótesis ${ }^{236}$

\subsection{Algunas apreciaciones finales}

Resulta bastante claro, que en el período señalado (1956-1967), el PS uruguayo protagonizó un giro ideológico que lo llevó de ser un sector que apostaba a la legalidad institucional, que se encontraba alineado con el bloque occidental dentro de la guerra fría, y que mantenía su lealtad a las posiciones de la IS, a delinear su política cada vez más crítica al sistema electoral, y a generar en su seno, corrientes rupturistas que serán claves en la política uruguaya de los años siguientes.

En medio de esas transformaciones, los vínculos con su par chileno se profundizaron tanto en los contactos orgánicos, como a través de las actividades del Secretariado Latinoamericano de la IS. Podemos detectar no sólo lecturas comunes, sino un seguimiento del accionar del socialismo chileno que realizaba su par uruguayo. Las acciones represivas tomadas por el gobierno de Ibáñez y la estrategia desarrollada por el PSP, confirmó en Uruguay, lo acertado de la alianza obrera con otros sectores populares y la importancia de las manifestaciones callejeras, como táctica política. Las coordinaciones además de denuncia de lo que sucedía en la capital trasandina fueron evidentes.

De la misma manera, los contactos en actividades, y Congresos, también fue clave y permanente, incluso en contextos de profundos debates internos como el caso del Congreso de Chillán en 1967, o incluso tomando casi las mismas consignas, como el caso de "revolución o miseria" adaptada por su par uruguayo como "socialismo o miseria".

Desde el punto de vista ideológico, compartían en primer lugar la caracterización de la revolución sin etapas. Establecida ésta en dos fases: la nacional (que cumpliría con los objetivos no llevados a cabo por las burguesías) y la propiamente socialista.

\footnotetext{
${ }^{235}$ El Sol. "Resoluciones del XXXVI Congreso Socialista. Línea Política Nacional". 01.12.1967.

${ }^{236}$ Las organizaciones ilegalizadas habían firmado en diciembre de 1967 un acuerdo político, conocido como el Acuerdo de Época, en el cual se comprometían a seguir las resoluciones aprobadas en la reunión de la OLAS. Este será el argumento para que el Poder Ejecutivo -el 12 de diciembre- emita el Decreto de ilegalización del PS, la FAU, el MIR, el MRO y la clausura de El Sol y Época. Decreto 1788/967. En: Registro Nacional de Leyes y Decretos (1967), Montevideo, 1968, p. 2135.
} 
Además, podemos detectar una clara influencia en el socialismo uruguayo en algunos aspectos claves: la estrategia del Frente de Trabajadores chilena es tomada por su par uruguayo, en tanto concepción de una amplia alianza de los sectores populares, dirigidos por el proletariado y del que quedaba radicalmente excluida la burguesía nacional.

Dentro de esta estrategia, el socialismo uruguayo difería, en la posibilidad de alianza con el comunismo, tal como hemos señalado anteriormente. La razón de este primer "anticomunismo" arraigado en el socialismo uruguayo y que lo diferenciaba sustancialmente de su par chileno, podríamos ubicarlo -quizás- en el origen mismo de ambos partidos socialistas. Como hemos señalado, en 1921 con la transformación del Partido Socialista en Partido Comunista, luego de que el VI Congreso Extraordinario del PS resolviera incorporarse a la Tercera Internacional, el sector minoritario -encabezados por Emilio Frugoni-, rompe y re-funda el Partido Socialista. De esta manera, el nacimiento mismo del PCU es analizado como la primer traición hacia el socialismo uruguayo. Queda explícitamente establecido, en la primera carta de respuesta al PCU, donde el socialismo se niega a conformar una alianza.

Por otro lado, hasta 1960 el PS uruguayo fue miembro de la Internacional Socialista, que sobre todo en la segunda mitad de la década del 50' rechazó de plano las posibilidades de alianza con el comunismo. También podríamos pensar, que el socialismo chileno al no ser parte de la IS, pudo manejar con mayor libertad, lo que consideraba estratégico para su realidad nacional. No quedó por fuera de los debates teóricos, pero esto no le impidió sus acuerdos con el comunismo.

Sumado esto, la experiencia de Frugoni en la Unión Soviética y a las prácticas sectarias de las que eran acusados los comunistas de la época, podrían explicar, el ferviente rechazo a lograr acciones comunes en este primer momento. Como veremos, esta línea se irá flexibilizando, a medida también que esta primera generación dirigente del PS vaya perdiendo poder.

La experiencia del FRAP y fundamentalmente las derrotas electorales de 1958 y 1964 , fueron el argumento de confirmación -fundamentalmente luego del fracaso electoral de 1962 en Uruguay- de que el camino electoral estaba cerrado.

Sin embargo, ninguno de los dos partidos socialistas, más allá de las discusiones, abandonan el camino electoral. Por el contrario, será la vía triunfante en el período siguiente. Parecería que en este primer momento, ambos profundizan la estrategia de no cerrar ningún camino. El análisis de las dificultades de las urnas, los lleva a habilitar todos los métodos de lucha. En el caso uruguayo, además, producto de las circunstancias que lo alejan de la 
actividad parlamentaria y del uso de este como cantera de proyectos, denuncias, etc., lo obliga a replantearse el camino.

Es innegable, según lo analizado anteriormente, la influencia que la revolución cubana generó en el socialismo de ambos países. La ilegalización de diciembre de 1967 del socialismo uruguayo, es el punto culminante del proceso de radicalización. De alguna manera, vendría a confirmar que el camino institucional no era una opción viable. 


\section{Como en Chile, Democracia Cristiana ${ }^{237}$ : la recepción de la democracia cristiana chilena en su par uruguayo (1958-1967)}

En el presente capítulo, nos dedicaremos a analizar el recorrido ideológico que realizaron los Partidos Demócratas Cristianos tanto en Chile como en Uruguay desde 1958 hasta 1967, con el fin de poder examinar la influencia que la democracia cristiana chilena desarrolló sobre la uruguaya, intentando rastrear momentos de contacto y zonas de influencia.

En el año 1958, comienza un proceso interno en la Unión Cívica del Uruguay, que dará como resultado su transformación en Partido Demócrata Cristiano a comienzos de 1962. Como veremos, ambas Democracias Cristianas, nacen como producto de giros internos de otros partidos políticos, la Unión Cívica en el caso uruguayo y la Falange Nacional en el caso chileno. Al igual que en los capítulos anteriores, analizaremos las zonas de influencia hasta fines de 1967. Tomaremos los años que van desde 1968 hacia fines de 1971, donde los diversos sectores avanzan hacia la unidad de las izquierdas y la realización de las primeras elecciones nacionales con la coalición formada, como el cierre de un ciclo y por lo tanto, merecedor de un análisis privilegiado.

Organizamos el capítulo, en seis apartados. Al igual que en los dos capítulos anteriores, el primero se dedica a analizar los puntos de contacto entre los militantes de ambas democracias cristianas, dando particular atención a su participación en la Organización Demócrata Cristiana de América (ODCA).

El segundo apartado, analiza la caracterización que los democratacristianos realizan de la revolución: cristiana, democrática y en libertad; la importancia de realizar cambios profundos, pero dentro de la legalidad institucional y con la democracia como modelo.

En tercer lugar, reflexionamos sobre el tema de las alianzas: las discusiones a la interna de la Democracia Cristiana chilena y la estrategia del "camino propio", la estrategia en Uruguay también de mantenerse sin alianzas en las elecciones de 1962, y finalmente la recepción de la campaña y el triunfo de Frei en 1964.

En cuarto lugar, damos cuenta de las tensiones a la interna de la DC chilena en los primeros años del gobierno de Eduardo Frei Montalva (1964-1967), la recepción en Uruguay de dichas tensiones y su influencia en el PDC uruguayo, las elecciones de 1966 y las referencias al modelo del país trasandino.

${ }^{237}$ El Ciudadano. 01.10.1964. Tapa. 
En el quinto apartado, analizamos los caminos: entre la vía no capitalista de desarrollo y el socialismo comunitario. En este tema en particular, los dirigentes chilenos jugaron un rol clave en lo que tiene que ver con el desarrollo teórico de estas dos propuestas. Por ello, hemos dedicado especial atención a estos lineamientos y como los mismos fueron recibidos por su par uruguayo. No debemos dejar de señalar, que en este apartado, nos excedimos temporalmente de la propuesta realizada en todo el capítulo llegando hasta el año 1971. Debido a que estas reflexiones tuvieron diversos recorridos hasta ese momento, decidimos analizarlo como una unidad. Finalmente, realizamos algunas apreciaciones finales.

En julio de 1957 en Chile, la Falange Nacional y el Partido Conservador Socialcristiano se fusionan, y junto a desprendimientos de otras organizaciones políticas, dan nacimiento al PDC. Su fundación, será también un hecho clave para la izquierda, no solamente por la relevancia política que tendrá en los próximos años -logrando el acceso al gobierno poco tiempo después-, y por su capacidad de representación popular alternativa, sino también porque su ubicación como partido de "centro" lo transformará en la balanza que inclinará la política hacia la izquierda o hacia la derecha, tal como veremos a lo largo de todo el período.

Con el surgimiento del PDC chileno, nacía una fuerza que desde 1957 hasta 1965 experimentó un crecimiento electoral constante. Era un partido policlasista (cuya integración iba desde la burguesía industrial o sectores vinculados al poder económico hasta dirigentes estudiantiles, obreros y campesinos), pero a la vez basado en una sólida doctrina de raíz cristiana, que intentaba ser una alternativa equidistante tanto del capitalismo liberal como del socialismo tradicional. De esta manera, las reformas de la sociedad capitalista, que proponían eran consideradas una etapa en la construcción de un nuevo tipo de sociedad.

Esta concepción no desapareció, y ni siquiera se podría decir que se debilitó, cuando la organización se convirtió en acción del gobierno. Aun más, desde principios de la década del sesenta se intensificaron en la Democracia Cristiana los debates sobre la definición y las características del proyecto alternativo. (Moulián, 2006, p. 224)

En 1961, se produce un cambio clave en la interna de la Iglesia Católica chilena que va a favorecer ampliamente el crecimiento de la DC. El cardenal Raúl Silva Henríquez reemplazará a monseñor Caro, y junto con el obispo de Talca -Manuel Larraín- le darán un nuevo impulso al polo reformista católico. En setiembre de 1962, a través de la carta pastoral El deber social y político en la hora del presente, la Iglesia Católica abandona al Partido 
Conservador y vuelca su apoyo hacia la $\mathrm{DC}^{238}$. A la vez que llama a realizar cambios estructurales profundos que permitan la salida de la crisis, reafirman su lucha contra el comunismo, y fomentan el desarrollo de una serie de instituciones con el fin de contribuir a la elaboración del programa político de Frei, para la campaña de 1964. Ejemplos como el Centro Bellarmino, el Instituto Latinoamericano de Estudios Sociales y el Centro para el Desarrollo Económico y Social de América Latina, muestran no sólo el compromiso de recursos, sino también la disposición de cuadros técnicos decisivos para la conformación del equipo que llevará a la DC al gobierno ese mismo año.

Por otro lado, un grupo de jesuitas nucleados en la revista Mensaje ${ }^{239}$, señalan claramente que "hay una revolución en marcha", frente a la cual los cristianos no pueden quedar indiferentes: o se la combate o se la acompaña. Es un desafío para la izquierda entonces, enfrentar a una DC que también se integra en el plano del debate de ideas, y que tiene cada vez más vínculos con el mundo popular. Un ejemplo de ello, es la publicación temprana del libro de Jorge Ahumada, En vez de la miseria ${ }^{240}$, donde se propone un claro programa reformista.

Luego de su ascenso al gobierno en setiembre de 1964 -con el comienzo de la Presidencia de Eduardo Frei Montalva-, y de los debates a su interna sobre las acciones a realizar, comienzan a visualizarse con claridad, tendencias que -como veremos- provocarán distanciamientos a lo largo del período. Influenciados además, por los sucesos del continente: crisis económica, fuertes desigualdades sociales, aumento de la conflictividad, mayor organización obrera, y el fermento revolucionario producido por el triunfo de la revolución cubana, impulsó también a sectores cristianos a ir tomando una línea política, que los volcaba más hacia la izquierda. En el caso chileno, esto se acentuó a la interna, porque el acceso al gobierno, les permitía discutir fuera de la teoría las posibilidades y voluntades reales de hacer cambios radicales. Tal como señala Tomás Moulián, “en todo partido ideológico con una

\footnotetext{
${ }^{238}$ Raúl Silva Henríquez fue parte del ala reformista del Concilio Vaticano II, y junto con su nombramiento consigue el ascenso de una serie de obispos reformistas que apoyaran causas sociales y lograrán ser mayoría en la Conferencia Episcopal chilena. Entre ellos, podemos destacar a Enrique Alvear, Carlos Camus, Jorge Hourton, Tomás González, Carlos Contreras, Fernando Ariztía.

${ }^{239}$ La revista Mensaje, comenzó a editarse en el año 1951 fundada por el Padre Alberto Hurtado. Siguiendo a Romeo Pérez, en las páginas de la revista se define el concepto de revolución como

un cambio total, profundo y rápido de las estructuras en una determinada sociedad, lo cual comporta nuevos equilibrios políticos, es decir, nuevos equilibrios en las relaciones de poder dentro de esa sociedad. La teoría de la revolución de "Mensaje" distingue la vinculación de un movimiento revolucionario con la doctrina (o sea los valores últimos que lo inspiran) de la relación del movimiento revolucionario y la ideología, es decir la descripción de una sociedad y de sus conflictos cruciales. Puede mantener, así, el cristiano la fidelidad al cuadro de valores que lo inspira y a la vez asumir una ideología que conduzca a la revolución, al cambio rápido, completo y profundo de las estructuras sociales. (1987, p. 26)

${ }^{240}$ Publicado en 1958, Santiago, Ed. Pacífico.
} 
orientación de cambio de sociedad se genera una tensión, cuando accede al gobierno y no puede realizar su sociedad ideal. Es eso exactamente lo que sucedió con la Democracia Cristiana desde 1967 en adelante" (2006, p. 224). Por otro lado, "era [también] un gran desafío para la izquierda: enfrentar a un gobierno que, con objetivos distintos (...) movilizaba al pueblo con un programa que, en muchos aspectos, era similar al de ellos”. (Nercesián, 2016, p. 9)

En el caso uruguayo, el PDC nace del centro mismo de la Unión Cívica, donde jugó un rol protagónico, el abogado laboralista Américo Plá Rodríguez ${ }^{241}$, quien desde fines de la década del 50' venía promoviendo la realización de "reuniones democratacristianas" mensuales, con el fin de mejorar la formación ideológica de los militantes. Surgieron a la vez a la interna de la Unión Cívica, dos corrientes claves en el proceso renovador. Por un lado, la Juventud Demócrata Cristiana (JDC), que ya en 1958 había publicado el Manifiesto de la Juventud Demócrata Cristiana, donde realizaba un importante desarrollo de su ideario político, estableciendo como principios el respeto a la persona humana, la defensa inalienable a la autodeterminación de los pueblos y por ende a cualquier forma de imperialismo y de régimen autoritario, y en donde establecía que el régimen ideal era la democracia, basado en la libertad religiosa, moral, política y económica. Las luchas por la Ley Orgánica de la Universidad, realizadas ese mismo año y la influencia de la revolución cubana, de comienzos de 1959, irán abriendo una brecha entre la juventud y los líderes históricos del Partido. Romeo Pérez, plantea que a partir de las primeras medidas de reforma social radical que adopta la revolución cubana, como la reforma agraria, la reforma urbana, las nacionalizaciones de compañías en manos norteamericanas, "se desata al interior de la Unión Cívica una confrontación que va cobrando intensidad en los meses sucesivos, y que enfrenta, casi diríamos en términos institucionales a la juventud con la dirección del Partido”. (1987, p. 19) Salvo algunos dirigentes progresistas como Tomás Brena o Dardo Regules, el resto de la dirigencia condenará las posiciones de la juventud.

Una segunda corriente, está integrada por el denominado Movimiento Social Cristiano, formado entre otros por los miembros del movimiento Economía y Humanismo (fundado por el sacerdote dominico francés Jean Louis Lebret) y liderado en Uruguay por

\footnotetext{
${ }^{241}$ Américo Plá Rodríguez (1919-2008), fue un destacado abogado laboralista. Se integra a la actividad política en la Unión Cívica, siendo parte activa del proceso de transformación de ésta a PDC. Fue electo diputado entre 1963-1967 y senador suplente entre 1971-1973. Decano de la Facultad de Derecho de la Universidad de la República entre 1994 y 1998.
} 
Juan Pablo Terra ${ }^{242}$, que -aunque menos radicalmente- apoyaba las posiciones renovadoras de la Juventud.

Otro punto de desencuentro, fue la cuestión de ser un partido confesional o no. En el documento antes señalado, los jóvenes democratacristianos abrían sus puertas a todos aquellos que adhirieran a sus postulados, pero sin necesidad de una práctica confesional. Sí era fundamental la creencia en Dios, así como la defensa de las libertades humanas, el respeto a la dignidad de la persona, y la promoción de una convivencia pacífica, basada en la libertad, la igualdad y la justicia. Ya fundado el PDC, en una nota de El ciudadano, Radomiro Tomic ineludible referencia chilena-, afirmaba

somos partidos de inspiración cristiana, pero no somos ni queremos ser ni tendríamos derecho a ser "partidos confesionales". No somos un partido de católicos, para católicos solamente. (...) Abrimos nuestras filas sin discriminaciones a católicos y a protestantes, a cristianos y a no cristianos, sin más condiciones que la de ser leales a nuestros programas y a nuestra disciplina, para construir todos juntos, ellos y nosotros, la nueva sociedad y el mundo nuevo que los tiempos reclaman ${ }^{243}$.

A nivel internacional, se declaraban a favor de la autonomía de los pueblos y condenaban cualquier forma de totalitarismo e imperialismo (incluido claramente el soviético), a la vez que proponían la profundización de la integración latinoamericana.

El conflicto con el sector histórico, de la aún Unión Cívica, fue llegando a un punto de tensión tal, que en 1961 la JDC abandona el sector. En solidaridad, también lo hace el Movimiento Social Cristiano, exigiendo una definición programática progresista. En concreto, reclamaban que el partido se orientara hacia la toma del poder, y no solamente a asegurarse su representación en el Parlamento:

para obtener la realización de un programa de la envergadura del propuesto, se requiere que la acción del Partido se oriente decididamente hacia la conquista del poder. El ejercicio de éste será el medio de lograr la transformación profunda de las estructuras vigentes. Será

\footnotetext{
${ }^{242}$ Juan Pablo Terra (1924-1991), dirigente del Movimiento Social Cristiano, jugó un papel clave en la fundación del PDC uruguayo. Arquitecto de profesión, impulsó una serie de propuestas vinculadas a la vivienda. Fue electo diputado entre 1967-1971, siendo elegido Senador ese mismo año. Fue fundador del Frente Amplio. A nivel internacional, participó de las actividades de la Internacional Demócrata Cristiana. Fue además consultor de numerosos organismos internacional como la CIDE, CEPAL, Naciones Unidas o UNICEF. Fundador del Centro Latinoamericano de Economía Humana (CLAEH). Al retorno de la democracia se aleja de la coalición frentamplista, y en 1989 vuelve a postularse al senado esta vez, acompañando desde el PDC el Nuevo Espacio, pero no alcanzó los votos suficientes.

${ }^{243}$ El Ciudadano. "Unidad y diversidad", por Radomiro Tomic. 30.11.1962.
} 
superado así el estilo de una actuación que se limita a la obtención de una representación parlamentaria con valor de testimonio únicamente ${ }^{244}$.

Para eso era imprescindible, abrir el colectivo a la entrada de los más amplios sectores del pueblo, integrando fundamentalmente a las clases populares en la dirección partidaria. Por ende, profundizar el trabajo militante a nivel de bases, sindicatos, gremios y organizaciones profesionales. "Transformar a la Unión Cívica del Uruguay en un partido popular." (Ilha López, 2016, p. 22). La Unión Cívica, cierra así un profundo ciclo de disputas, con dos escisiones de bastante importancia.

Finalmente, el 25 de febrero de 1962 y luego de profundos debates, la Convención Nacional de la Unión Cívica, define su transformación en Partido Demócrata Cristiano, con la reincorporación del Movimiento Social Cristiano, y dos pequeños núcleos provenientes del Partido Nacional ${ }^{245}$ y del Partido Colorado ${ }^{246}$. "La transformación (...) no es un mero cambio de nombre, es otra cosa, y sobre todo quiere ser una transformación radical, drástica." (Pérez, 1987, p. 20) En el momento mismo de su fundación, el ala conservadora de la Unión Cívica se retira, en desacuerdo con el giro ideológico que estaba tomando el nuevo partido, pero a la vez esto permite un acercamiento de nuevos militantes sindicales y juveniles. "El modelo que orientó la transformación de la Unión Cívica fue el PDC chileno y los PDC europeos gobernantes. Fue un intento de modernización política”, afirma Romeo Pérez. (1984, p. 15).

Como veremos, frente a la estructura verticalista heredada de la Unión Cívica ${ }^{247}$, los sectores más renovadores emprendieron una pugna interna por el poder de la organización, impulsando nuevos candidatos y una línea política con un claro tinte progresista. Esto provocó en 1963, una importante renovación en los miembros de los órganos directivos.

Las teorizaciones de la revista chilena Mensaje y los planteos realizados por el Concilio Vaticano II y más adelante la Conferencia Episcopal de Medellín en 1968, llevaron a la profundización de un modelo que se proponía profundas reformas. A nivel nacional, el liderazgo progresista de la Iglesia, bajo el arzobispado de Carlos Parteli, inculcó a varios cristianos el valor de la acción social y comunitaria. De esta manera, los militantes

\footnotetext{
${ }^{244}$ Movimiento Social Cristiano (cerca de 1960). Manifiesto. Tomado de Ilha López, 2016, p. 111.

${ }^{245}$ Encabezados por el Dr. Carlos Varela, Dr. José Pedro Urioste y Juan F. Arteaga. Carlos Varela abandonará el PDC en 1970, cuando éstos acuerden ingresar al Frente Amplio, negándose a una alianza con los comunistas.

${ }^{246}$ Encabezado por el Dr. Eugenio Baroffio (que abandona el partido luego de las elecciones de 1962) y César Charlone Ortega, quién luego será Encargado de Negocios de la Embajada uruguaya en Santiago hasta el golpe de Estado de 1973.

${ }^{247}$ A partir de la cual, por ejemplo, la dirección digitaba las candidaturas al Parlamento, las Juntas Departamentales, etc.
} 
democratacristianos, comienzan a vincularse más fuertemente con las organizaciones del movimiento popular, en las cuales no habían desarrollado una inserción destacada.

Como desarrollaremos más adelante, también resultó clave, la vinculación con otras experiencias. El caso chileno, se constituyó luego del triunfo de Frei en 1964, en el ejemplo latinoamericano, y fue el que mayor conexión tuvo con el PDC uruguayo ${ }^{248}$.

Desde el liderazgo de Frei Montalva y las reformas impulsadas por su revolución en libertad a las vicisitudes por las que atravesaron tanto Frei como su partido (...) así como la línea más izquierdista y renovadora de la DC con Radomiro Tomic (...) influyeron de gran manera en el PDC uruguayo, en sus formulaciones políticas e ideológicas. (Ilha López, 2016, p. 90).

El período que va entre 1962 y 1966, son los años de lucha interna, justamente por el giro que iba tomando esta transformación partidaria. Jugó también un rol clave, la fundación del CENCADEC (Centro de Capacitación de la Democracia Cristiana), a instancias de la Juventud y con el objetivo de perfeccionar la formación política e ideológica del sector. María Elena Martínez, por ese entonces secretaria de la JDC, señala "no le podíamos tener envidia a la escuela de cuadros del Partido Comunista o del Partido Socialista. (...). Fue una época de una militancia muy interesante (...),249.

Como veremos, estos cambios que se radicalizan en el período siguiente, también fueron de la mano, del recorrido realizado por el ala más a la izquierda de la Democracia Cristiana chilena. Y tal como veremos, en el próximo capítulo, será clave para que el PDC uruguayo juegue un rol articulador en la conformación del Frente Amplio en 1971 y evite un quiebre interno como si sucedió en su par chileno.

Siguiendo con la nueva línea de transformación del partido, ampliaron sus esfuerzos militantes en el mundo sindical, estudiantil, cultural, orientados a transformarse en un partido de masas. Esta orientación a la izquierda provocó además, que la primera línea de la vieja dirigencia de la Unión Cívica, renuncie al nuevo partido. En 1964, Juan Vicente Chiarino, Horacio Terra Arocena (padre de Juan Pablo Terra), Tomás Brena, Gladys Freire de Addiego,

\footnotetext{
248 Otra clara influencia, estuvo marcada por el COPEI (Comité de Organización Política Electoral Independiente) de Venezuela, quién de la mano de Rafael Caldera accederán a la Presidencia de dicho país en 1969.

${ }^{249}$ Proviene de una familia católica vinculada a la Unión Cívica. Abogada de profesión, fue la Secretaria de la JDC durante los años $60^{\prime}$ y asistió a numerosos detenidos políticos. Viaja a Chile en varias oportunidades durante el gobierno de Eduardo Frei Montalva. Luego del golpe militar, se exilia en España, regresando a Uruguay a comienzos de la transición democrática. Durante el primero gobierno del Dr. Tabaré Vázquez, fue designada Directora de la Derechos Humanos, dependiente en ese entonces del Ministerio de Educación y Cultura. En la actualidad, mantiene su militancia frenteamplista y es la Prosecretaria de la Comisión Administrativa del Poder Legislativo.
} 
José María Robaina y Erasmo Petingi, se retiraron del sector. Un año después, lo hizo Venancio Flores ${ }^{250}$, quedándose con la única banca en el Senado ${ }^{251}$. Ese mismo año, la totalidad de los miembros del Movimiento Social Cristiano piden la afiliación al PDC, disolviendo en los hechos el movimiento y la JDC, reingresa al nuevo Partido en este mismo contexto. Sumado al auge que produjo el triunfo de Frei en Chile, y de cara a las elecciones de 1966, el PDC con el nuevo giro que había tomado, transitaba a la interna una clara sensación de auge.

En contacto con otras juventudes partidarias, con los sectores obreros y estudiantiles e incluso con otros sectores a nivel internacional y latinoamericano, se fue produciendo no sólo una democratización de la estructura interna, sino también una radicalización de su línea partidaria. En 1967, el liderazgo progresista de Juan Pablo Terra, era notorio. Ese mismo año, se produjo una importante renovación de los miembros de la Junta Nacional del partido, que hizo que el núcleo histórico quedara en minoría, dando lugar a los sectores juveniles, con ideas más de avanzada. Para Romeo Pérez, “a partir de 1967, el proyecto originario del Partido Demócrata Cristiano es sobrepasado.” (1987, p. 30).

\subsection{Cristianos en Chile y Uruguay: puntos de encuentro}

Ya desde 1962, apenas transformada la Unión Cívica en PDC y durante todo el período analizado, desde las páginas de sus medios de prensa, se realiza un seguimiento de los sucesos chilenos, incluso en algunos casos reproduciendo directamente artículos de la revista Política y Espíritu, perteneciente a la DC chilena ${ }^{252}$.

\footnotetext{
${ }^{250}$ Quién será luego Canciller, durante la presidencia de Jorge Pacheco Areco entre 1968-1970.

${ }^{251}$ Este núcleo, fundó -junto a quienes habían renunciado en 1962- de cara a las elecciones de 1966 el llamado Movimiento Cívico Cristiano, no logrando representación parlamentaria. De hecho, las elecciones de 1966 serán el enfrentamiento de la vieja dirigencia de la Unión Cívica, unida ahora en este nuevo Movimiento, y la nueva conducción del PDC. Como veremos más adelante, éstos últimos, obtienen una votación considerable, pese a perder la banca en el Senado, y obtienen tres diputados.

${ }^{252}$ Como ejemplos: El Ciudadano: "El PDC chileno sigue creciendo", 16.03.1962; "Declaración chilena" [se da a conocer la declaración de la Junta Nacional del PDC chileno, sobre la situación política del país trasandino] 29.06.1962; "La Democracia Cristiana en el mundo. Dos nuevos triunfos chilenos. Notable avance de la DC en la Central Única de Trabajadores y elección del primer diputado del primer circuito de Santiago", 05.10.1962; "La Revolución, la Democracia y el Movimiento Popular", 05.04.1963; "La revolución, la democracia y el movimiento popular" [Segunda parte] 26.04.1963; "Economía de América Latina" por Eduardo Frei, 21.06.1963; "Economía de América Latina" por Eduardo Frei. [Segunda Parte] 28.06.1963; Nos visitó un regidor de Santiago de Chile" [José Pablo Domínguez] 26.07.1963; "Revolución en América Latina. Cambio integral de las estructuras. Reforma o revolución en libertad", 31.12.1963; "La verdad sobre Chile" 21.05.1964; "FREI: América Latina confía en él. Expectativa general en torno a Chile" 31.08.1964; "La mujer uruguaya homenajea a Frei" 22.10.1964; "La Iglesia en Chile. Y la voluntad de cambio de los chilenos" 28.11.1964. De Frente: "Demócrata Cristianos" 21.11.1966; "Hora cero de la revolución en libertad" 13.03.1967.
} 
En julio de 1962, Eduardo Frei, es recibido por el Congreso Departamental de Montevideo del PDC uruguayo y la versión taquigráfica de sus palabras, son publicadas íntegramente por el periódico El ciudadano. Allí hace mención, a la profunda amistad que mantenía con el histórico dirigente de la Unión Cívica, Dardo Regules, fallecido el año anterior. Como veremos en el apartado siguiente, Regules había sido una figura clave en la conformación de la ODCA, que también integraba el dirigente chileno. En ese contexto, por otra parte, Frei viaja numerosas veces a Montevideo. De sus palabras, en dicha ocasión, se desprende una clara intención latinoamericanista de la Democracia Cristiana chilena,

yo estoy íntimamente convencido de que no se saca absolutamente nada con tener éxito en un país si no lo tenemos en numerosos países. (...) A medida que pasa el tiempo, esa visión latinoamericana y continental va adquiriendo caracteres absolutamente precisos. (...) Los principios son comunes y las planificaciones dependen mucho de las tesituras de los hechos y del fenómeno nacional. ${ }^{253}$

Como veremos, fundamentalmente para las elecciones nacionales de 1966, el PDC uruguayo vivirá como un deber lograr el triunfo con el fin de seguir el camino chileno.

El vínculo, se profundizó también en el área de la formación académica, algunos como José Luis Veiga ${ }^{254}$, estudiaron en el Instituto Latinoamericano de Estudios Sociales (ILAES) ubicado en Santiago y dependiente de los jesuitas- por lo que residieron allí algunos años durante el ascenso de la Democracia Cristiana. Según recuerda Jorge Rodríguez, "la Juventud Demócrata Cristiana chilena y la Juventud Demócrata Cristiana uruguaya tenían un vínculo fuertísimo" ${ }^{255}$. Miguel Vasallo, también militante de la JDC uruguaya, reafirma esta idea, “iban, venían, íbamos, sí. (...). Había seminarios, había reuniones, relativamente fluidas sí, se leían documentos de un lado y del otro. (...) Hubo varios compañeros que estuvieron"256.

\footnotetext{
${ }^{253}$ El Ciudadano. "Eduardo Frei se dirige a los militantes demócrata cristianos". 03.08.1962.

${ }^{254}$ José Luis Veiga, se vincula a la JDC siendo estudiante justamente en el año 1964. En 1967 viaja a Chile a estudiar en el ILAES y se vincula fuertemente con la JDC del país hermano. Regresa a Uruguay a fines de 1969, con la experiencia y los debates recorridos por la DC chilena, claramente alineado con la línea tomicista. En 1971, promotor de la fundación del Frente Amplio, es electo diputado. Actualmente, es el Director de la Secretaría de Comunicación Institucional de la Presidencia de la República.

${ }^{255}$ Nació en Chile en 1959. A los cuatro años, sus padres resolvieron venirse a vivir a Montevideo. De familia vinculada a la democracia cristiana chilena, recuerda que en su casa en Montevideo, su padre recibía prensa del país trasandino, fundamentalmente la revista Ercilla. Ingresa a la Facultad de Derecho en 1977, se afilia a la JDC dos años después. Participa de la fundación de la Asociación Social y Cultural de Estudiantes de Enseñanza Pública (ASCEEP), siendo parte de la Generación 83`. Fue Secretario de la Bancada Parlamentaria del PDC, vinculado a las diversas administraciones frenteamplistas de la Intendencia de Montevideo por más de 20 años, actualmente es el coordinador de Relaciones Institucionales de dicho organismo y Presidente del PDC.

${ }^{256}$ Miguel Vasallo, también se vincula a la JDC a los 16 años, en 1964. En su calidad de tal, viaja junto a una delegación de jóvenes comunistas al bloque socialista. Acompaña a Líber Seregni, en su visita a Chile en 1973. Milita a nivel estudiantil como estudiante de Agronomía. Ex director del Instituto Nacional de Colonización, actualmente es docente de la Facultad de Agronomía.
} 
Pero tampoco, es menor señalar, que guiados por los informes del Embajador de Chile en Uruguay, el interés por las transformaciones de la DC uruguaya también eran seguidos por su par chileno. A medida que el proceso autoritario iba avanzando, también el Embajador informaba de detenciones, allanamientos, etc., que ocurrían en Uruguay. Por ejemplo, en octubre de 1965, luego de aprobado el decreto de Medidas Prontas de Seguridad el 7 de ese mismo $\mathrm{mes}^{257}$, se informa de la detención de "un grupo de manifestantes demócrata cristianos en la Plaza Libertad de la capital, que protestaban por las medidas adoptadas por el gobierno. Fueron detenidos algunos dirigentes de dicho partido, recobrando la libertad al día siguiente (domingo 10)" 258 .

Por otro lado, el rol de la Embajada se transformó claramente con respecto al vínculo entre ambas DC. De denunciar o preocuparse por el peligro "comunista" cuando viajaba algún representante de la izquierda chilena, pasó a colaborar ampliamente en mejorar y profundizar el vínculo entre ambos partidos. Por citar un ejemplo, en octubre de 1966 con la visita de los diputados Luis Maira y Osvaldo Giannini a fines del mes siguiente, el Ministro de Relaciones Exteriores chileno le solicita a la embajada "programarles conferencias de prensa, charlas y entrevistas con periodistas, universitarios y dirigentes sindicales, fin expongan la labor realizada dos años Gobierno Presidente Frei"259. Igualmente, la visita no llegó a concretarse. Consultados los dirigentes uruguayos, Adolfo Gelsi y Américo Plá, consideraron inconveniente por la fecha cercana a las próximas elecciones nacionales (realizadas el domingo 27 de noviembre) ya que “cualquier intervención pública de los diputados demócratacristianos chilenos podía ser objetada como intervención política foránea en los asuntos uruguayos (...)" ${ }^{260}$ La Embajada funcionaba así casi que como oficina partidaria, siendo un medio de comunicación habitual entre ambos partidos. En mayo de 1967, luego de la celebración de la Junta Nacional del PDC uruguayo en la ciudad de Rocha, Juan Pablo Terra y Daniel Sosa Díaz (Presidente y Secretario del Partido respectivamente) acercan a la Embajada las resoluciones aprobadas referidas a la realización de la Conferencia de

\footnotetext{
${ }^{257}$ Bajo el lema "Los derechos se defienden ejerciéndolos", el PDC organiza un acto público en la Plaza Libertad (en el centro de Montevideo) contra las medidas impuestas en ese entonces por el gobierno del Partido Nacional en manos de Alberto Heber. El mismo fue disuelto por la policía y varios de sus dirigentes fueron detenidos. Romeo Pérez, señala que este hecho, insignificante en apariencia, sirve para mostrar y definir una línea política que traspasa los métodos tradicionales, y que se afirma "en el impulso que da la convicción de ejercer en plenitud nuestros derechos contra la prepotencia de un gobierno, promotor de una clara política oligárquica." (Pérez, 1984, p. 17)

${ }^{258}$ Ministerio de Relaciones Exteriores de Chile. Archivo General Histórico. Embajada de Chile en Uruguay. Fondo Países. Año 1965. Volumen 20. Ofício Nro. 879/420.

${ }^{259}$ Ministerio de Relaciones Exteriores de Chile. Archivo General Histórico. Embajada de Chile en Uruguay. Fondo Países. Año 1966. Consulado. Aerograma Nro. 129.

${ }^{260}$ Ministerio de Relaciones Exteriores de Chile. Archivo General Histórico. Embajada de Chile en Uruguay. Fondo Países. Año 1966. Embajada. Oficio Confidencial Nro. 1199/93.
} 
Presidentes, con el fin de que la "hiciera llegar al Gobierno y, por su intermedio, al Partido Demócrata Cristiano de Chile" 261 .

El 4 de noviembre de 1966, el por entonces Embajador de Chile -Enrique Cañas Flores- informa que

en un foro radial y de televisión que se hizo antes de ayer, entrevistado el Diputado Américo Plá sobre varios puntos políticos de actualidad se le preguntó con marcada intención si la democracia cristiana uruguaya recibía ayudas de la democracia cristiana chilena. El Diputado señor Plá contestó que aparte de la "ayuda ideológica, espiritual y fraternal con los demócratas cristianos chilenos, no conocía otra que pudiera alguien referirse". ${ }^{262}$

Héctor Lescano, recuerda que había un vínculo muy estrecho con la Juventud Demócrata Cristiana chilena,

que estaba más cerca del pensamiento más de izquierda del PDC uruguayo, tomando como referentes muy fuertes el caso de Radomiro Tomic, que jugó un papel muy importante en la formación nuestra y en el entusiasmo de alguna manera. (...). Hay muchos compañeros de mi generación que tienen hoy fotos con Don Eduardo Frei Montalva. Iban delegaciones de la Juventud a reuniones en Chile (...).

Y más adelante agrega, "nos sentíamos un poco los hermanos menores"263. Incluso recuerda que durante el período dictatorial en Uruguay (1973-1985), el archivo del PDC estuvo guardado en la casa de Renán Fuentealba (hijo), que vivía en ese momento en la ciudad de Montevideo, y gozaba de inmunidad diplomática por su cargo en el Programa de Naciones Unidas para el Desarrollo (PNUD). Si bien, la anécdota, supera el período analizado en este capítulo, nos muestra concretamente el nivel de acercamiento de ambos partidos durante todo este período.

\footnotetext{
${ }^{261}$ Ministerio de Relaciones Exteriores de Chile. Archivo General Histórico. Embajada de Chile en Uruguay. Fondo Países. Año 1967. Volumen 2. Oficio Nro. 546/303.

${ }^{262}$ Ministerio de Relaciones Exteriores de Chile. Archivo General Histórico. Embajada de Chile en Uruguay. Fondo Países. Año 1966. Embajada. Oficio Confidencial Nro. 1232/100.

${ }^{263}$ Héctor Lescano, comienza a militar a nivel barrial en Punta Gorda a los 14 años, vinculado a la JDC en 1962. Fue luego dirigente estudiantil, siendo estudiante de Veterinaria. Secretario General de la JDC y del PDC. Luego de la transición democrática, fue electo diputado por Montevideo, ocupando el cargo por una década. Fue condecorado por la Orden Bernardo O'Higgins por su constante lucha parlamentaria por la democracia en Chile. Desde el 2005 al 2012, fue nombrado Ministro de Turismo y Deportes. Desde el año 2015 a la actualidad, es el Embajador de Uruguay en la República Argentina.
} 


\subsubsection{La Organización Demócrata Cristiana de América (ODCA)}

En abril de 1947, a iniciativa del dirigente de la Unión Cívica del Uruguay -Dardo Regules- se reunieron por primera vez en un encuentro en Montevideo, varios líderes demócrata cristianos de América Latina, con el fin de intercambiar opiniones respecto a la creación de una organización que nucleara los diversos partidos afines a la democracia cristiana que se estaban desarrollando en el continente. La creación de los respectivos PDC en Italia y Francia, fueron motores para la concreción de esta iniciativa. En la resolución final, se aprobó la decisión de crear un movimiento que superara los estados nacionales, con el fin de realizar "una verdadera democracia política, económica y cultural sobre la base del humanismo cristiano". (Molt, 1971, p. 11). De este primer congreso, participaron representantes de cuatro países: Brasil, Argentina, Uruguay y Chile. La actuación de Dardo Regules entre 1947 y 1949, fue clave en la conformación de este espacio de coordinación latinoamericano, dónde además forjó una profunda amistad con quién luego sería el Presidente de Chile, Eduardo Frei Montalva. Jorge Rodríguez, de familia chilena y militante de la JDC uruguaya, afirma que "de ahí en más se inició un proceso de mucha cercanía”. Por otro lado, existía un vínculo profundo entre Frei y Plá Rodríguez, ambos Profesores universitarios de Derecho Laboral. Jorge Rodríguez agrega,

eran amigos, tenían una relación muy fluida. Plá tenía mucha relación con Patricio Aylwin también y eso influyó mucho en la fundación de la Democracia Cristiana en el 62'. Si Plá hubiera seguido predominando en la Democracia Cristiana uruguaya, cosa que más o menos lo logró hasta el 66'y después perdió el dominio a favor de Juan Pablo Terra, el PDC hubiera tenido una impronta mucho más similar al PDC clásico de Aylwin y de Frei.

De estos primeros encuentros, surgen las primeras definiciones conjuntas de las futuras democracias cristianas de América, donde se revela una inspiración social reformista más desarrollada. Una definición clave, y que marcará la acción demócrata cristiana en el futuro, está vinculada con el acuerdo de concebir a la democracia como el régimen privilegiado para llevar adelante las propuestas de esta colectividad.

La segunda conferencia, se realizó también en Montevideo, dos años después y contó además con la participación de delegados de Perú y Colombia. En esta reunión, se dio nacimiento a la ODCA, -y el establecimiento de su secretariado permanente en Montevideo- y de la Juventud Demócrata Cristiana de América (JUDCA). 
Si bien, el acuerdo a la nueva organización estaba dado, hubo que esperar siete años para la realización de un nuevo encuentro, esta vez en Santiago de Chile, en diciembre de 1955. De esta oportunidad, participaron Argentina, Bolivia, Perú, Uruguay, Brasil, Chile y un observador de Colombia. Es importante señalar que por primera vez, participaron representantes de los partidos demócratas cristianos europeos, y de varios representantes de Europa oriental ${ }^{264}$ que se encontraban en el exilio y "daban su contribución para formar un bloque contra el comunismo, cuya amenaza empezaba a hacerse sentir en América Latina" (Molt, 1971, p. 14). Luego de esta reunión, el secretariado se estableció en Chile.

En San Pablo, en 1957, tuvo lugar el cuarto Congreso; en 1959 se desarrolló nuevamente en Santiago de Chile el quinto y en 1964 en Caracas, el sexto.

Si bien en una primera instancia, la organización se abocó fundamentalmente a la planificación de los Congresos, estos comenzaron a tener cierta relevancia, porque permitían no solamente el conocimiento e intercambio entre los dirigentes de varios países, sino por la "uniformidad con respecto a los programas y a la voluntad política de los demócratas cristianos latinoamericanos." (Molt, 1971, p. 14)

En diciembre de 1963, la ODCA se reunió en Montevideo, congregando representantes de cerca de 13 países. En esa ocasión, se realizó un homenaje a Dardo Regules, en el cementerio, cuyo orador principal fue el democratacristiano chileno Tomás Reyes ${ }^{265}$.

Carlos Baráibar, era por ese entonces un joven funcionario de la Dirección Nacional de Estadística y Censos, y recién afiliado al PDC uruguayo. Llega a Chile en 1965, con el fin de perfeccionar sus estudios en Estadística, y se acerca al PDC chileno que venía en ese momento, de un importante triunfo en las elecciones de marzo de ese mismo año. Se vincula, con la secretaría de la JUDCA que tenía su oficina funcionando allí, como representante de la JDC uruguaya.

Chile además era como el París de América Latina, donde confluían los pensamientos de distinta naturaleza, de izquierda (...) sobre todo, con mucha fuerza. (...). Entonces había muchos organismos internacionales que funcionaban ahí, había eventos, había congresos, había mucha actividad (...) Venia mucha gente de América Latina, me acuerdo que la consigna de aquella época era "América del mañana, Demócrata Cristiana", era la idea de

\footnotetext{
${ }^{264}$ Se encontraban presentes, delegaciones de Checoslovaquia, Hungría, Lituania, Polonia y Yugoslavia, además de la Democracia Cristiana italiana y el Partido Nacionalista Vasco.

${ }^{265}$ El Ciudadano: "Próxima semana: Demócrata Cristianos de América en Montevideo" 06.12.1963 y "Hacia la integración" 31.12.1963.
} 
la Democracia Cristiana con un proyecto progresista, alternativo a la revolución cubana que era el otro que estaba en América Latina. ${ }^{266}$

\subsection{El carácter de la revolución: cristiana, democrática y en libertad}

Nuestra revolución busca la libertad, cuya forma es la democracia ${ }^{267}$

La discusión a la interna de las Democracias Cristianas, con respecto al carácter de la revolución y las vías para acceder al poder, tuvo -en este período- un desarrollo menor, en comparación con los dos sectores de la izquierda tradicional. Esto no implicaba que no fuera motivo de debate, sino que los principios ideológicos básicos de este sector político, produjeron acuerdos internos consensuados sobre los caminos a seguir.

En este sentido, y como señalamos anteriormente, el régimen que habían definido como el ideal para desarrollar sus programas de gobierno, era la democracia, definida como

a) régimen de derecho, el cual supone competencia a texto expreso, contrapesos institucionales, jurisdicción de los jueces independientes sobre todas las relaciones del derecho, inclusive los actos de gobierno; b) regla de consentimiento, lo que supone elección de los gobernantes por sufragio universal en un sistema electoral que atribuye un voto a cada persona y régimen de opinión pública, en especial, con prensa exenta de coacción directa o indirecta del gobierno; c) sistema de responsabilidad y de publicidad para todo gestor y toda gestión (...); d) garantía de pluralidad de partidos políticos (...); e) reconocimiento y organización jurídica de la comunidad universal de los hombres, sin prejuicio de los Estados particulares; f) autonomía de los grupos fundamentales: familia, empresa, sindicato, escuela; g) difusión de la propiedad privada y justicia social; h) rechazo de todo absolutismo autoritario (...). (Paysee González, 1972, p. 122-123).

En el caso chileno, por ejemplo, la defensa irrestricta del respeto al pluralismo político, llevará a la entonces Falange Nacional a oponerse a la aprobación de la Ley de Defensa de la Democracia, que implicaba la ilegalización del Partido Comunista, tal como vimos anteriormente.

\footnotetext{
${ }^{266}$ Comienza su militancia en la JDC, a fines de la década del 50'. En 1965, se traslada a vivir a Santiago de Chile, donde se vincula a la DC y particularmente a las actividades de la JUDCA. Influenciado profundamente por las ideas de Radomiro Tomic, vuelve en 1970 a Uruguay a impulsar la fundación del Frente Amplio. es electo diputado en 1971. Mantiene su militancia en el PDC, hasta 1989, cuando dicho sector decide romper con el Frente Amplio. En desacuerdo con esta resolución, mantiene su integración frenteamplista y se acerca en 1994 a Asamblea Uruguay, sector liderado por Danilo Astori. Es electo nuevamente diputado por el período 19952000, y reelecto en dos oportunidades hasta el año 2010. En 2005, asume como Senador en representación de Danilo Astori, cuándo este asume el Ministerio de Economía. Actualmente jubilado, mantiene su militancia frentamplista.

${ }^{267}$ JDC (1965) Manifiesto para una nueva generación. Tomado de Ilha López, p. 152-153.
} 
Era claro, entonces, que la contienda iba a darse exclusivamente en el terreno electoral. A medida que la década del 60'avanza, las discusiones al respecto irán variando, pero para este período estas definiciones eran de acuerdo obligatorio para quién quisiera sumarse a las filas democratacristianas.

Igualmente, al igual que sus pares comunistas y socialistas, también abrazaron la idea de "revolución", cristiana, democrática y en libertad, será para los chilenos, las características de esta revolución hasta 1967. El PDC, se proponía sí la realización de transformaciones profundas de las estructuras nacionales, pero siempre dentro de la democracia. La idea de "reforma estructural", de la mano del respeto de la institucionalidad vigente. Como veremos, a medida que el gobierno de Frei avance en sus propuestas, se dará una pujante lucha interna con respecto a que sociedad construir, hasta donde avanzar con las medidas, con qué sectores aliarse, etc., que provocarán duros desgajamientos a la interna del sector. La discusión entre reforma y revolución, comenzaba a hacer tangible en un partido que había accedido al gobierno.

En el caso uruguayo, ya Américo Plá, en su libro Principios de la Democracia Cristiana, había establecido en 1959 que la democracia era el régimen institucional al que debía aspirar el Partido, basado en el respeto a la persona humana, el reconocimiento de los derechos esenciales, la defensa de las libertades públicas, la defensa del Estado de derecho (que implicaba el sumo respeto a la Constitución y la ley), la separación de poderes, el sufragio universal, la pluralidad de partidos políticos, la participación popular a todos los niveles, y por ende, el rechazo a cualquier forma de totalitarismo. Ya en la misma resolución de constitución del PDC, se afirmaba que "el partido abre sus puertas a cuantos deseen luchar por un ideal comunitario servido por una auténtica democracia, contraria a cualquier dictadura de cualquier signo y a todo totalitarismo de izquierda o derecha"268. Se rechazaba la lucha de clases, en tanto se la consideraba la generadora de conflictos. Las clases debían integrarse y no destruirse mutuamente. En 1963, decían explícitamente

que cómo partido democrático y cristiano, rechaza todos los métodos de violencia física o moral; condena la incitación a la lucha de clases, al odio, a la intervención demagógica en las decisiones de Gobierno y Administración. El partido es pluriclasista por esencia, y entiende que para bregar por la justicia social no es preciso movilizar las pasiones de un

${ }^{268}$ El Ciudadano. "Declaración de legisladores del PDC". 30.03.1962. 
partido clasista, ya que el egoísmo colectivo, como el individual, es incapaz de conquistar la justicia verdadera ${ }^{269}$.

Tal como señala Julio Ilha López, las “soluciones para la renovación social impulsadas las democracias cristianas serían (...): la popularización de la propiedad, la visión humana del trabajador, la transformación de la empresa, los medios pacíficos de promover la justicia social". (2016, p. 15) El camino, claramente, estaba dado por métodos pacíficos y que respetaran la legalidad vigente. En la obra anteriormente señalada, Plá reafirma, "lograr la transformación por la vía de la evolución y no por la vía de la revolución”. (1959, p. 80).

Luego de fundado el PDC, hay dos documentos claves, ambos de 1962, el Manifiesto a la ciudadanía del país, y el Llamado a los jóvenes, firmado este último exclusivamente por Américo Plá. Si bien el documento, como veremos más adelante, sí plantea la necesidad de realizar cambios estructurales, la palabra "revolución" no aparecerá en ninguno de los documentos de esta primera época. En el primero de los documentos señalados, se afirma explícitamente que "la situación de América Latina exige urgentemente la adopción de soluciones de acelerada transformación social dentro de los cauces democráticos"270.

En agosto de ese mismo año, desde las páginas de El ciudadano, los democratacristianos afirmaban:

en una época como la nuestra, en la que al decir de un agudo escritor francés, el mundo entero padece de "revolucionaritis", se nos pregunta a menudo si nosotros, los demócratas cristianos, somos o no revolucionarios. (...). Si al hablar de revolucionarios, queremos referirnos al contenido de la transformación social que propugnamos, debemos responder decididamente por la afirmativa. (...). Deseamos y luchamos por una transformación auténtica y enérgica, que cambie del fondo a la cúspide, todo lo que está mal en la sociedad contemporánea. (...). Pero si al hablar de revolucionarios, aludimos al sistema elegido para lograr la transformación, la respuesta es negativa. Nosotros luchamos por una revolución democrática, o sea, dentro de la democracia, utilizando los cauces jurídicos, y sin salir del orden institucional. (...). La renovación puede ser rápida, urgente y hasta inmediata; pero debe respetar el orden de derecho. $(\ldots)^{271}$.

Será entonces en su medio de prensa, que el término "revolución" comience a aparecer vinculado a este sector. En una nota del mismo día, que la cita anterior, afirman:

\footnotetext{
${ }^{269}$ El Ciudadano. "Declaración sobre orientación partidaria". 24.05.1963.

${ }^{270}$ PDC (1962). Manifiesto a la ciudadanía del país. Tomado de Ilha López, 2016, p. 114.

${ }^{271}$ El Ciudadano. “¿Somos revolucionarios?” 03.08.1962.
} 
lo que ocurre es que vivimos en un tiempo de revolución. Y los demócratas cristianos no hemos de temer al decir que lo sabemos; aún más, es indispensable que proclamemos nuestro propósito de hacer la revolución, con nuestros métodos y con nuestro signo. De lo contrario, estaríamos demás. Y la revolución se hará, porque es ya inevitable, si no por nosotros, contra nosotros. $(\ldots)^{272}$.

Tanto Julio Ilha López como Romeo Pérez, ambos investigadores de la historia del PDC uruguayo, afirman que el concepto de "revolución" aparece incorporado explícitamente por la discursiva democratacristiana, justamente en 1964, y luego del triunfo de Eduardo Frei en Chile, cuyo slogan de campaña fue "Revolución en Libertad".

En la asimilación del concepto de revolución por el PDC influye el programa de "Revolución en Libertad" con que Eduardo Frei llega a la presidencia de Chile (...), y la teoría revolucionaria desarrollada desde una óptica cristiana por la revista "Mensaje", publicada por los jesuitas chilenos en el mismo período. (Pérez, 1987, p. 26).

El concepto implicaba sí la importancia de realizar cambios profundos y acelerados, pero con la convicción además de que no era necesaria su realización por medio de la violencia. Por otro lado, de la mano del giro ideológico que se produjo a su interna y del proceso de radicalización, fundamentalmente de los sectores juveniles, se comenzó a plantear la necesidad de un cambio revolucionario, que se opusiera fuertemente al sistema capitalista y al imperialismo. Igualmente, a lo largo de todo este período, habrá una irrestricta defensa a la democracia como régimen privilegiado, donde se respeten los derechos individuales, el pluralismo ideológico, el sufragio universal, etc. En enero de 1964, en plena campaña electoral chilena, El ciudadano, replica un artículo de Política y Espíritu, en donde se reafirma este concepto.

La democracia es la afirmación fundamental de la democracia cristiana. Es la condición misma de las restantes afirmaciones. De ahí que nuestro Partido luche, en primer lugar, por la democracia. La entendemos en un sentido pluralista, o sea, basada en el principio de la igualdad de derechos para todos los ciudadanos ${ }^{273}$

Es en 1965, que la JDC publica el documento Manifiesto para una nueva generación, donde proclamaba a la democracia como la única posibilidad política para la libertad. Entendiéndola, no solamente como una expresión política, sino también económica y social. Para llegar al gobierno del pueblo, era necesaria una igualdad económica, que implicaba la

\footnotetext{
${ }^{272}$ El Ciudadano. “Tiempo de revolución. La Democracia Cristiana y la hora actual”. 03.08.1962.

${ }^{273}$ El Ciudadano. "La democracia cristiana, las minorías privilegiadas y la revolución en libertad”. 30.01.1964.
} 
distribución de las riquezas, y una democracia social, que asegurara la igualdad de oportunidades. Para el desarrollo de una verdadera democracia, entonces, debían darse en las mismas condiciones de igualdad, tanto la democracia política, como la económica y la social. La convicción democrática, debía asegurarse sobre bases populares y no sobre las elites o los grupos privilegiados. Tal como el mismo documento señala,

ninguna reforma puede llegar a cambiar el espíritu que rige el sistema. Exigimos, pues, una revolución: un cambio radical de los postulados ideológicos en que se basa la sociedad, un cambio radical del sistema político en que se sustenta, un cambio radical de las estructuras económicas, sociales y culturales que oprimen al pueblo ${ }^{274}$.

La revolución era considerada entonces una necesidad urgente, y la forma de llevarla adelante era pacífica, como forma de resguardar la vida y la dignidad humana. Aunque, consideraban que se debían estar preparados para el uso de otros caminos, por si se llegaba a un agotamiento de la vida pacífica, fundamentalmente el camino hacia la revolución, estaría dado por la concientización y movilización de las masas, que garantizaría la participación real de los sectores populares.

Creemos que la revolución debe hacerse por medios pacíficos (...). Para que sea necesario recurrir a la vía violenta deben cumplirse las siguientes condiciones: 1) que el sistema anterior atente contra el bien común o viole derechos humanos (..);2) Uso previo de los medios pacíficos (...). En primer lugar, se deben usar medios pacíficos legales. Si el régimen los traba (...), se pasa a los medios pacíficos ilegales. Si tampoco fuera suficiente se pasa a los medios violentos. (...);3) Los efectos de la revolución violenta deben compensar los trastornos que provoca: no cabe recurrir a la violencia por cambios insignificantes $(\ldots)$; 4) Contar con racional esperanza de éxito (...). O sea, la revolución violenta es un problema político, según el caso. Esperemos que sea posible, en Uruguay, el triunfo por medios pacíficos. Pero debemos estar preparados y organizados por si se da el caso de que la vía pacífica se considere cerrada ${ }^{275}$.

El proceso revolucionario estaría marcado por dos etapas: la toma del poder por la vía legal, es decir, garantizar el triunfo electoral; y una segunda etapa, de construcción del Estado popular con el fin de orientarlo a garantizar los intereses del pueblo, en la construcción de una sociedad comunitaria.

Para encauzar ese proceso, se necesitaba la participación popular, encabezada por un partido de vanguardia, integrado mayoritariamente por trabajadores y dotado de una ideología

\footnotetext{
274 JDC (1965). Manifiesto para una nueva generación. Tomado de Ilha López, 2016, p. 152.

275 Ídem, p. 153-154.
} 
revolucionaria. Para eso era imprescindible, abrir el partido hacia los sectores populares. El rechazo hacia el "revolucionarismo" y la teoría del foco, se basaba en la convicción de que la revolución debía ser llevada adelante por el pueblo organizado y no por un grupo de "iluminados".

Igualmente es interesante señalar brevemente, que el asesinato en febrero de 1966 de Camilo Torres en Colombia, también produjo ciertas tensiones internas. En octubre de ese año, en De Frente, dedicaban una extensa nota a dar cuenta de su lucha, de su origen familiar e incluso, de una cierta justificación del uso de las armas en tanto el contexto de violencia existente en Colombia así lo permitía ${ }^{276}$. Mauricio Langón, recuerda que

en ese momento (...), vino la madre de Camilo Torres, que ya lo habían matado, que era el héroe de la época, imaginate además cura y guerrillero (...). El verdadero tema era que considerabas un héroe un tipo que había peleado con las armas, y lo considerabas formalmente, porque la reunión era en la casa del Partido. Lo consideraba el Partido formalmente ${ }^{277}$.

Un año después, en el primer aniversario de su muerte, reproducen las palabras de homenaje que el Partido Social Demócrata Cristiano de Colombia le realiza al cura asesinado $^{278}$. Lo interesante de este proceso, es que si bien, hay militantes católicos que se vinculan con la guerrilla, fundamentalmente con el Movimiento de Liberación NacionalTupamaros, esto no es producto de una fractura organizada a la interna del PDC sino de alejamientos individuales. Desde el punto de vista orgánico, estaba claro y fuera de discusión, de que el camino era el electoral y democrático.

\footnotetext{
${ }^{276}$ De Frente. "La angustia revolucionaria del cura Camilo Torres". 31.10.1966.

${ }^{277}$ Mauricio Langón, proviene de una familia vinculada a la Unión Cívica. Comienza su militancia en la JDC en 1962, recién transformado en PDC. Poco tiempo después ingresa a estudiar Filosofía, al Instituto de Profesores Artigas, porque lo que siempre estuvo vinculado a la formación teórica de los militantes. En 1969, luego de profundas discrepancias se aleja del sector y se vincula a la Organización Popular Revolucionaria- 33 Orientales (OPR-33) brazo armado de la Federación Anarquista Uruguaya. Se exilia en Argentina, luego del golpe de Estado y regresa a Uruguay en el comienzo de la transición democrática. En la actualidad es militante frenteamplista independiente.

${ }^{278}$ De Frente. "Homenaje de la Democracia Cristiana a Camilo Torres". 31.03.1967.
} 


\subsection{Las alianzas: el "camino propio" y las dificultades de un acuerdo con la izquierda}

En 1951, por ese entonces, dos jóvenes falangistas -Jacques Chonchol ${ }^{279}$ y Julio Silva Solar $^{280}$-, publicaron el libro titulado Hacia un socialismo comunitario, donde proclamaban la urgente necesidad de abolir el sistema capitalista. Silva Solar, a su vez, publicó ese mismo año $A$ través del marxismo, donde intentaba compatibilizar las tesis de Marx con la doctrina cristiana. Estas tempranas propuestas, iban de la mano con la posible constitución de un acuerdo con la izquierda tradicional, germen de lo que luego será una importante tendencia a la interna de la DC chilena.

Es en este contexto, -y como respuesta a esta tesis- que Jaime Castillo Velazco ${ }^{281}$, teoriza sobre la idea que se conocerá como "el camino propio", que implicaba la convicción de que el PDC chileno, era el único capacitado para llevar adelante una revolución, basada en los principios socialcristianos. El rechazo a la política soviética, y el acuerdo de una distancia equidistante entre el capitalismo y el comunismo, volvían inviable un acuerdo con la izquierda chilena de la época.

\footnotetext{
${ }^{279}$ Jacques Chonchol (1926-), se vincula a la entonces Falange Nacional a fines de la década del 40'. Agrónomo, egresado de la Universidad de Chile, trabaja en el Ministerio de Tierras y Colonización, y en la Dirección de Economía Agrícola del Ministerio de Agricultura. Al asumir Eduardo Frei, la Presidencia de Chile, se le encomienza la vicepresidencia del Instituto de Desarrollo Agropecuario (INDAP), con la responsabilidad de dirigir el proceso de Reforma Agraria implementado por el gobierno. En 1969, producto de profundas tensiones a la interna del PDC y del propio gobierno, renuncia al INDAP y al Partido, y funda el Movimiento de Acción Popular Unitario (MAPU). En 1969, se integrarán a la Unidad Popular (UP) e impulsarán la candidatura de Allende al año siguiente. Al triunfar electoralmente la UP, es designado Ministro de Agricultura, con el fin de profundizar el proceso de Reforma Agraria, comenzado en el gobierno anterior. En 1971, se aleja del MAPU y se suma a las filas de la Izquierda Cristiana. Fue Ministro hasta el 01.11.1972. Luego del golpe de Estado de 1973, se exilia en Paris y trabaja como Director del Instituto de Altos Estudios para América Latina. Regresa a Chile en 1994, siendo crítico de la camino de la izquierda luego de la transición democrática.

280 Julio Silva Solar (1926-2014), comienza su actividad política en la Falange Nacional, siendo nombrado Presidente de la JDC en 1954. En 1965, fue electo diputado por el PDC. En la crisis de 1969, también rompe con la DC y se suma a la filas del MAPU, por lo cual es electo diputado por el período 1969-1973. En 1971, se aleja del MAPU y se suma a las filas de la Izquierda Cristiana. En 1973, parte exiliado hacia Roma, regresando a Chile en 1982. Con la transición democrática se afilia al Partido por la Democracia, siendo electo en 1992 Concejal por Santiago.

${ }^{281}$ Jaime Castillo Velasco (1914-2003), se vincula al Partido Conservador siendo estudiante de Derecho en la Universidad de Chile, de la cuál egresó en 1935. Bajo el gobierno de Eduardo Frei, fue Ministro de Tierras y de Colonización (1965-1967) y de Justicia (1968-1969). Luego del golpe militar, se exilia en Caracas, donde funda la Comisión Chilena de Derechos Humanos en 1978. Defendió varias causas de exiliados chilenos e incluso el asesinato del ex Canciller Orlando Letelier en Washington. Al regreso de la democracia en Chile, el Presidente Patricio Aylwin lo incorpora a la Comisión Nacional de Verdad y Reconciliación (Comisión Rettig), encargada de realizar un informe sobre las violaciones a los DDHH, durante la dictadura militar. Fue profesor de la Universidad de Chile y la Universidad Católica, en la Escuela de Ciencias Políticas; dirigió la revista Política y Espiritu; presidió el Instituto de Formación y de Estudios Políticos (IDEP), fue miembro de la Comisión Ideológica Mundial de la Democracia Cristiana y fundador y director del Secretariado Latinoamericano de Derechos Humanos. En los últimos años de su vida le correspondió presidir el Instituto Chileno de Estudios Humanísticos (ICHEH), organismo de reflexión de corriente social-cristiana (vinculado al Partido Demócrata Cristiano), entre 2000 y 2003.
} 
Para las elecciones de 1958, el PDC refrendó la línea política denominada "camino propio" que implicaba la construcción y el fortalecimiento del Partido, sin alianzas ni con la derecha ni con el FRAP. "Se prefirió preservar la pureza del proyecto y de la alternativa, se privilegió la constitución de la identidad del movimiento antes que un triunfo comprometido, que hubiera requerido, en las condiciones de 1958, un pacto formal con la derecha". (Moulián, 2006, p. 213). En 1960, en la primera Convención Nacional el Partido

reafirma su inalterable línea de oposición al comunismo (...) Por eso no puede existir entre ambas fuerzas ni alianzas ni pactos políticos, parlamentarios, ni electorales. En consecuencia, el Partido tampoco podría celebrarlo con el FRAP integrado por estas fuerzas de una manera determinante.

Y luego,

reitera su posición filosófica, doctrinaria, política, económica y social antagónica al capitalismo. Sus concepciones sobre la persona humana y sus derechos, la familia, la organización social, la economía y el Estado, son incompatibles con el espíritu y estructuras del orden social capitalista. Por esta razón, el Partido Demócrata Cristiano no puede entrar en compromisos con las fuerzas que sostienen la concepción individualista de la vida social ${ }^{282}$

En el acuerdo de Millahue, adoptado el 8 y 9 de abril de 1961, se señalaba que "el capitalismo y el marxismo no son soluciones eficaces para los problemas concretos de la nación chilena en la actual realidad histórica" ${ }^{283}$.

Sin embargo, las tendencias a la interna de la DC venían consolidándose. En diciembre de 1962, el entonces presidente del PDC, -Senador Renán Fuentealba ${ }^{284}$-, esboza a la interna de su colectividad la idea de un posible acercamiento al FRAP. El motivo surge a partir de la iniciativa del Partido Democrático Nacional de una posible alianza con la izquierda, lo que provocaría un amplio acuerdo del que la DC quedaría excluida. Esta

\footnotetext{
${ }^{282}$ PDC (1960). Documentos de la Primera Convención Nacional, Santiago de Chile, p. 7-8.

${ }^{283}$ Revista Política y Espíritu. "Chile, el pueblo respalda a la Democracia Cristiana", Nro, 259, abril de 1961, p. 48.

${ }^{284}$ Renán Fuentealba (1917-), se vincula tempranamente a la Falange Nacional, estudiando Derecho en la Universidad Católica de Chile, de donde egresa en 1943. Fundador de la DC en 1957. Fue electo Diputado por el período 1957-1965 y luego Senador entre 1965 y 1973. Electo Presidente Nacional de la DC en tres períodos: 1961, 1963-1965 y 1971-1973. En el momento del golpe de Estado, fue uno de los promotores de la declaración del "grupo de los 13" que rápidamente se opusieron al derrocamiento de Allende. Exiliado en Costa Rica al año siguiente, se dedico a la docencia universitaria y fue asesor del Ministerio de Economía de dicho país. En 1979, fue nombrado Presidente de la ODCA. Retornó a Chile en 1983, colaborando con la formación de la Alianza Democrática. Intendente de la IV Región de Coquimbo entre 1990-2000. Desde el 2013 es el abogado Jefe de la Dirección de Asesoría Jurídica de la Municipalidad de La Serena.
} 
propuesta, anticipa una vez más, el surgimiento a la interna de la democracia cristiana de un sector contrario a un acuerdo con la derecha, y que serán quienes propongan más adelante, la estrategia de la "vía no capitalista de desarrollo". La intención de Fuentealba fracasó, no sólo por discrepancias a la interna de su propio partido, sino por el desacuerdo de algunos sectores de la izquierda. Como hemos visto en los capítulos anteriores, es el PCCh quien acepta en primer lugar el acercamiento y desde las filas socialistas el rechazo es inmediato. Igualmente, será este sector, integrado fundamentalmente por Agustín Gumucio ${ }^{285}$, Alberto Jerez, Julio Silva Solar, Vicente Sota, Renán Fuentealba y Bosco Parra, que declaran para la campaña electoral de 1964 que tampoco serán "el balón de oxigeno de la derecha". (Arrate y Rojas, 2003, tomo I, p.370).

En las elecciones municipales de marzo de 1963, el FRAP mantiene su votación (que alcanza un 29,5\%) y el PDC logra transformarse por primera vez, en el primer partido político del país (logrando un 22,7\%). Poco después de estas elecciones, proclaman a Frei como su candidato para los comicios siguientes y el Frente Democrático -alianza de conservadores, liberales y radicales- hace lo mismo proclamando a Julio Durán. El FRAP había propuesto con anterioridad, una nueva candidatura del socialista Salvador Allende, tal como hemos visto anteriormente.

En marzo de 1964, luego del "naranjazo" y sumado al resultado electoral de 1958 donde el FRAP casi accede al gobierno y al importante avance de las fuerzas de izquierda en los comicios de marzo de 1963, dan la pauta que si no se produce un giro electoral, Allende será el ganador en las elecciones nacionales de setiembre. "Inmediatamente de conocidos los resultados electorales los voceros demócrata cristianos plantearon que constituían la "única alternativa real al marxismo", dado que eran, al contrario del Partido Radical, una fuerza en crecimiento.” (Moulián, 2006, p. 219). Esta confirmación, precipita la disolución del Frente Democrático, y transforma el cuadro electoral, al volcar su caudal en apoyo al candidato de la DC. A su vez, la influencia de la política norteamericana y el desarrollo de la "Alianza para el Progreso"286 como camino para evitar una segunda "revolución cubana", aportaron un claro apoyo norteamericano al candidato, Eduardo Frei Montalva.

\footnotetext{
${ }^{285}$ Rafael Agustín Gumucio (1909-1996), fue miembro del Partido Conservador y luego uno de los fundadores de la Falange Nacional. En 1957, fue elegido el primer Presidente del PDC. Entre 1955 y 1965 fue Diputado por Santiago y entre 1965 y 1973 Senador. En 1969, romperá con el PDC y fundará el Movimiento de Acción Popular Unitaria (MAPU) y dos años después la Izquierda Cristiana. En 1973, fue designado Embajador de Chile en Francia, por el Presidente Salvador Allende, cargo que no logra asumir debido al golpe de Estado. Permaneció allí en calidad de exiliado hasta 1983.

${ }^{286}$ La percepción de una posible ola revolucionaria (tras la inspiración de la revolución cubana) en América Latina, fue la preocupación central del gobierno de John F. Kennedy a partir de su asunción al gobierno de Estados Unidos en 1961. Su estrategia se centró en el impulso de un plan de transformaciones estructurales y de
} 
Esta línea del "camino propio" operó desde este momento como el modelo estratégico de la organización, aplicado incluso en 1964 cuando, finalmente los sectores de derecha, aceptan implícitamente apoyar a Frei e inclinar la balanza hacia el triunfo de lo que consideraban el "mal menor".

Las discusiones a la interna del mundo católico, tampoco fueron irrisorias. La actitud de la Iglesia, dirigida entonces por el Cardenal Silva Henríquez, tampoco fomenta un posible acuerdo con la izquierda. Si bien, tendían a una posición progresista, incluso dentro de la propia Iglesia, la revista Mensaje, señala en 1963 que "de ninguna manera, nos parece lícito que un católico contribuya a que el marxismo se instale en nuestra patria." (Arrate y Rojas, 2003, tomo I, p.365).

Frei, era entonces, considerado el candidato que aseguraba la contención al comunismo, intensificados los discursos entre "democracia y comunismo" en el marco de la Guerra fría y la revolución cubana. Más allá de estos movimientos, el triunfo de Frei no se explica únicamente por el apoyo de la derecha y los fondos provenientes de Estados Unidos. También fue clave, el apoyo logrado en amplios sectores sociales, fundamentalmente jóvenes. La DC enarbola la consigna de la "Patria Joven" para remarcar su compromiso con los cambios. El 21 de mayo de 1964, en plena campaña electoral, la JDC chilena, realizó lo que se conoció como la "Marcha de la Patria Joven", recorriendo el país desde Arica a Puerto Montt, a pie, llegando a Santiago desde varias columnas, exactamente un mes después.

Finalmente, Eduardo Frei, triunfa obteniendo un 56\% de los votos. Seguido por Salvador Allende, que alcanzaría un 39\%; y el candidato radical que lograría solamente un 5 $\%$ de apoyo. Se produce por primera y única vez a lo largo de todo el siglo XX, el triunfo de un candidato que es impulsado por un solo partido. El contexto general es de movilización: jóvenes y estudiantes en las calles, se intensifica la actividad de los partidos políticos, se produce el surgimiento de nuevos grupos armados inspirados en el triunfo de la revolución cubana, se desarrolla la prensa y los medios de comunicación, se producen importantes transformaciones en la Iglesia, todas expresiones del proceso de cambios que venía experimentando la sociedad chilena y latinoamericana.

desarrollo económico (como la reforma agraria y la tributaria, que permitiera una redistribución más equitativa de los ingresos), por una parte y de reconversión de las fuerzas armadas latinoamericanas en una fuerza militar de aniquilación de la "amenaza revolucionaria interna", que se expresarían en lo que se conoce como "Alianza para el Progreso" y la "Contrainsurgencia", respectivamente. Luego del asesinato de Kennedy a fines de 1963 y de la asunción de Lyndon Johnson al gobierno norteamericano, se privilegió la dimensión de intervención político militar y de contrainsurgencia, por sobre la dimensión de impulso al desarrollo. (Riquelme, 2009, p. 7274). 
Durante los primeros años de gobierno, la DC mantuvo un aumento electoral, que le permitió en las elecciones parlamentarias de 1965, contar con una mayoría propia en la Cámara de Diputados. Sin tener la necesidad de negociar ni con la izquierda, ni con la derecha, la idea del "camino propio" se fue confirmando en este período. Este apoyo, comenzará a descender en 1967, y se profundizará dos años después cuando en las siguientes parlamentarias muestre una caída del 40 al 32\%.

Como veremos, si bien esta idea generará fuertes fricciones a la interna del Partido, éste logrará mantenerse fuera de alianzas electorales durante todo el período analizado.

\subsubsection{El "camino propio" en Uruguay: ni liberalismo, ni marxismo (1962)}

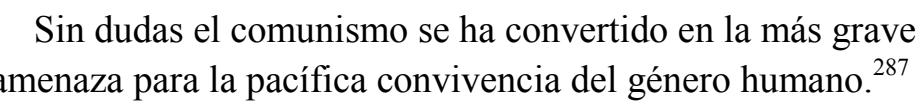

En esta primera etapa, las posibilidades de acuerdo entre la izquierda (que como vimos anteriormente, se encontraba en un duro debate entre socialistas y comunistas) y el PDC en Uruguay, eran quizás igual de complicadas que en Chile. El discurso anti marxista, propugnado por los demócratas cristianos, era cotidiano en sus medios de prensa.

Por otra parte, al igual que el socialismo criticaban la política soviética, y la férrea adhesión del comunismo nacional. Según su teoría, los partidos marxistas se veían contaminados por una concepción materialista de la vida, donde además en aras de la socialización y estatización, suprimían las libertades individuales si estas iban en detrimento de una correcta aplicación de sus políticas. Tal como el mismo Plá señala, "pretenden, en definitiva, encontrar la justicia sacrificando la libertad. Esto se ve bien en el comunismo, donde se elimina totalmente la libertad y se cae en todos los abusos y excesos del totalitarismo". (1959, p. 67). Como vimos anteriormente, el rechazo a la lucha de clases, iba también en esta línea. Capitalismo y comunismo, eran vistos como caminos equivocados, ya que en definitiva, ambos implicaban la concentración de la propiedad (ya sea en manos de los grandes grupos de poder o en manos del estatismo). La clave estaba entonces, no en la abolición de la propiedad privada, sino en la distribución de los capitales, en lo que denominaron "empresas comunitarias" (cogestión y participación de los trabajadores en los beneficios).

${ }^{287}$ El Ciudadano. “Como combatir el comunismo”. 26.10.1962. 
Luego de fundado el PDC, la retórica antimarxista se mantiene. En uno de sus primeros documentos, Manifiesto a la ciudadanía del país, la necesidad de mantenerse equidistante tanto del capitalismo como del marxismo, a quienes condena por igual, es clara.

El dilema es cada vez más: o un materialismo marxista que suprime las libertades públicas, esclaviza al hombre y destruye las relaciones fraternas, o la Democracia Cristiana, que postula las libertades de todos, defiende los sagrados derechos del ser humano y construye un mundo de justicia y de paz, sin odio y sin violencias ${ }^{288}$.

En agosto de ese mismo año, afirmaban

los que queremos una revolución verdadera, pero en paz y sin violencia ¿cómo actuamos? Ni hacemos, ni actuamos. Nos dejamos encasillar en los esquemas que la derecha y la izquierda prefabrican. Y carecemos de una posición propia que destruya la falsa oposición de los dos frentes. La derecha es el pasado. Pero la izquierda marxista no es el futuro. La revolución marxista es también el pasado. (...). ¿Entonces? Entonces es la hora de la democracia cristiana. (...) Depende de nosotros, en nuestro país, que la definición sea por la persona, por la libertad, por la democracia y por la justicia. $(\ldots)^{289}$.

En julio de 1962, Eduardo Frei viaja a Montevideo, para concurrir al Congreso de Pax Romana. En ese contexto, los periodistas de El ciudadano, le hacen un amplio reportaje sobre la realidad política chilena, donde Frei explica la integración del FRAP y de la derecha y afirma: "entre ambas corrientes, surge cada día más potente una fuerza demócrata cristiana, integrada por nuestro Partido, en torno al cual se agrupan sectores populares que quieren una profunda transformación social sin signo marxista. (...)"290.

Para las elecciones de 1962, entonces, el PDC uruguayo también fue sin alianzas electorales. En agosto, afirmaban

si puede parecer ocioso decir que no hay posible alianza, entre democracia cristiana y marxista, en cambio es útil -y quizás hasta necesario- afirmar que un demócrata cristiano no puede participar en cualquiera de los movimientos que se postulen defensores de la democracia, sino está dispuesto a poner los puntos sobre las íes, es decir, si no está dispuesto a sostener que lo que nosotros entendemos por democracia no es algo de alcance meramente político, sino de alcances sociales ineludibles, que permita la existencia de ciudadanos auténticos (...). Vale decir que se marcha a una división de dos frentes: marxismo y democracia cristiana. Por eso es la hora de esta última. (... $)^{291}$.

\footnotetext{
${ }^{288}$ PDC (1962). Manifiesto a la ciudadanía del país. Tomado de Ilha López, 2016, p. 115.

${ }^{289}$ El Ciudadano. "Con los ojos abiertos". 03.08.1962.

${ }^{290}$ El Ciudadano. "Eduardo Frei Montalva habla para nuestros lectores". 27.07.1962.

${ }^{291}$ El Ciudadano. "Tiempo de revolución. La Democracia Cristiana y la hora actual”. 03.08.1962.
} 
La discusión, en 1962, de que el escenario político nacional se debatía entre "marxismo y democracia cristiana" parece bastante forzado, si uno mira los resultados electorales, donde la izquierda (sumando la UP y el FIdeL) más el PDC, no alcanzan al 10\% del electorado nacional.

Incluso remiten como argumentos a la carta pastoral del Episcopado chileno, que reproducen casi íntegramente en El Ciudadano. Recordemos, que en setiembre de 1962, a través de la carta pastoral "El deber social y político en la hora del presente", la Iglesia Católica abandona al Partido Conservador y vuelca su apoyo hacia la DC. Allí se afirmaba, que

el comunismo se opone diametralmente al cristianismo. (...) En esa doctrina no queda lugar alguno para la idea de Dios. (...) ellos siembran el odio, exacerban las diferencias de clases sociales y procuran que la lucha de clases se haga violenta y destructiva de todo orden actual. Todas las instituciones, partidos o personas que se opongan a esta cruzada de destrucción, que según ellos es necesaria para acelerar la llegada del nuevo orden, deben ser aniquilados sin distinción alguna, como enemigos del género humano. (...). No es posible la colaboración con el comunismo (...).

Pero también rechazan el liberalismo,

que esto no haga olvidar empero a los católicos que la Iglesia ha condenado los abusos del liberalismo capitalista. (...) Es deber imperioso y urgente de los católicos el procurar una renovación profunda y rápida de ese estado de cosas no cristiano. $(. . .)^{292}$.

En noviembre, a cinco días de las elecciones nacionales- la voz será la de Tomic, que afirmará en el medio de prensa del PDC uruguayo

somos contrarios al comunismo. Somos sostenedores del hombre como valor supremo del Estado, y de la libertad política como la única forma que aceptamos de organización de la sociedad. Rechazamos toda forma de conciliación doctrinaria entre el comunismo y la Democracia Cristiana. Pero no somos tampoco la Liga de Anticomunistas del mundo ${ }^{293}$.

Como veremos más adelante, el matiz de separación de Tomic con el anti-comunismo será clave para posibles acuerdos, aunque fueran concretos y temporales entre la izquierda y la Democracia Cristiana.

\footnotetext{
${ }^{292}$ El Ciudadano. “Apelación a la conciencia cristiana”. 19.10.1962.

${ }^{293}$ El Ciudadano. "Unidad y diversidad", por Radomiro Tomic. 30.11.1962.
} 
La disputa en estas elecciones, estaba más centrada a la interna de los sectores democratacristianos en Uruguay, ya que era la primera elección que el PDC se presentaba bajo esa denominación, luego de la renovación de comienzos de ese mismo año. Las elecciones, servían entonces como consulta popular de apoyo (o no) a estas nuevas tendencias. Finalmente, si bien descendió su caudal electoral, mantuvo casi intacto el apoyo con el que contaba la Unión Cívica ${ }^{294}$.

\subsubsection{La recepción de la campaña electoral de Frei en Uruguay (1963-64)}

Por un lado el FRAP. Por otro el PDC. Por un lado la revolución con signo marxista.

Por otro lado la revolución en la libertad. Por un lado, el hombre instrumento del Comité Central del Partido Único. Por otro, el hombre íntegro en el pleno ejercicio de su libertad, realizando el ideal del hombre nuevo en un mundo de comunidad y justicia. Por un lado, un ser instrumento de un Estado materialista y ateo. Por otro, un ser con alma para el ejercicio de su libertad y con capacidad racional para postrarse ante la Soberana Majestad del Creador. Por un lado, la uniformidad desesperante de la clase única. Por otro, la diversidad de las vocaciones y de las opciones en la unidad comunitaria. (... $)^{295}$

Finalizados los comicios del año 1962 en Uruguay, los sucesos de la campaña chilena -municipales en 1963 y nacionales en 1964- comienza a tomar cada vez mayor espacio en los debates y medios de prensa del PDC uruguayo. El aumento del caudal electoral de la DC en Chile, confirmaba también aquí que era posible triunfar en las elecciones con el "camino propio”. Como señalamos, luego de la elección de regidores el 7 de abril de 1963, si bien el FRAP aumenta su votación, el PDC logra transformarse por primera vez, en el primer partido político del país. Pocos días después, El ciudadano titulaba, "La Democracia Cristiana es la fuerza más grande de Chile ${ }^{, 296}$, ofreciendo a sus lectores un panorama electoral del vecino país.

El 27 y 28 de junio de 1964, mientras Chile se encontraba en plena campaña electoral, el PDC uruguayo realizaba su Convención Nacional, donde aprobaba su línea política para el período. En su documento final, se afirmaba la necesidad de una

\footnotetext{
${ }^{294}$ En las elecciones de 1958 la Unión Cívica había obtenido 37.625 votos, y el PDC obtuvo en 196235.703.

${ }^{295}$ El Ciudadano. "Chile hacia la revolución en libertad. Panorama electoral" 31.08.1964.

${ }^{296}$ El Ciudadano. 26.04.1963.
} 
transformación total y radical. El examen dinámico de la realidad agrega un nuevo elemento a esta transformación: el de la rapidez. Con esta tercera característica, queda concertado el planteo revolucionario del Partido. Al afirmar la necesidad de la revolución en libertad, el Partido Demócrata Cristiano niega todo posible compromiso con el actual régimen. La actuación del Partido Demócrata Cristiano está dirigida hacia la conquista del poder por vías democráticas, para desde allí realizar la organización social que postula ${ }^{297}$.

Pocos meses después, comenzaron de lleno el seguimiento a la campaña política para las elecciones nacionales a realizarse al año siguiente, así como a la difusión del programa político de la "Revolución en Libertad"298. En este período, contaron con un informante calificado: José Royol -militante del PDC- haciendo uso de una beca otorgada por la Organización Mundial de la Salud, había pasado varios meses en Chile estudiando Pediatría Clínica y Social. Allí, se vinculó a la DC chilena y envió algunas opiniones a la prensa partidaria uruguaya sobre los acontecimientos políticos del entorno chileno ${ }^{299}$.

Como vimos, las posibilidades de que la izquierda ganara las elecciones, y la “campaña del terror" realizada por la prensa chilena, tuvieron su eco también en Uruguay. En mayo de 1964, en plena campaña electoral, afirmaban:

si gana Frei, el panorama se aclara. Chile se habrá de encaminar hacia un proceso radical de reformas, dentro del orden institucional establecido. Si gana Allende se pueden prever dos cosas: a) en primer lugar, que haya un cuartelazo de las fuerzas de la reacción sin candidato en esta elección, b) que lo dejen gobernar. Un cuartelazo significaría incorporar a otro país en el camino de la violencia y la revolución armada como corolario inmediato. Un gobierno marxista -segunda posibilidad- no podría realizar la revolución, pues enfoca los problemas parcialmente y sin profundidad al tener una equivocada concepción de la persona humana. (...) La victoria de Frei permitirá alentar a la Revolución en Libertad. El triunfo de Allende desnivelaría la balanza a favor del totalitarismo de derecha o el marxismo inefectivo. (...). La identidad de destinos es suficientemente clara como para valorar en sus reales dimensiones los sucesos de los países hermanos, a los efectos de ilustrar la elección que hagamos de nuestros métodos revolucionarios ${ }^{300}$.

Varias son las notas que dan cuenta, del seguimiento a los sucesos chilenos, que no tiene sentido referir aquí, dado que la mayoría confirman los mismos argumentos. Sí es importante señalar, que los debates entre la posibilidad de triunfo entre el FRAP y la DC, fueron planteados en términos de elegir entre "marxismo o democracia cristiana", o de evitar el "peligro comunista", lo que de alguna manera, seguía dificultando las posibilidades de una

\footnotetext{
${ }^{297}$ PDC (1964). Línea política del PDC. Tomado de Ilha López, 2016, p. 138.

298 El Ciudadano. "FREI: un plan de gobierno y la Revolución en Libertad" 09.08.1963; "Discurso de Frei presagiando el triunfo final" 17.09.1964.

${ }^{299}$ El Ciudadano. "La DC chilena: Revolución en Libertad”, por José Royol, 19.07.1963

${ }^{300}$ El Ciudadano. "Venezuela- Brasil- Chile. Procesos diferentes". 07.05.1964.
} 
alianza entre estos sectores también en Uruguay. De hecho, en setiembre de 1965, el PDC no participa de la constitución de la Mesa por la Unidad del Pueblo. Las diferencias en este período entre comunistas y cristianos, hacía impensable una posible acción conjunta.

Sobre las opciones políticas en chile, en agosto de 1964, opinaban

para el comunismo es la primera vez que puede acceder al gobierno de un país por las vías del sufragio. Su coalición con los socialistas y otros grupos menores no le restan su aspiración totalitaria. La victoria de Allende es el triunfo del comunismo lisa y llanamente. (...).

Para luego agregar,

para la Democracia Cristiana es también la primera vez que está a punto de asumir las responsabilidades de gobierno en una nación americana. Y deberá hacerlo en un país cuya condición económica y social acusa gravísimo deterioro. Es decir: de ganar la Democracia Cristiana no solamente deberá gobernar sino también $-\mathrm{y}$ profundamente- reformar. (...). Nosotros confiamos en el PDC chileno. (...) confiamos sobre todo en la fuerza de los ideales, que también son los nuestros, a jugarse en los próximos comicios ${ }^{301}$.

\section{4. “América del mañana, Democracia Cristiana”: los primeros años de la DC en el gobierno (1964-1967) y su impacto en Uruguay}

Más allá de las notables diferencias en cuanto a programa político propuesto por los sectores de izquierda, fue durante la administración de Eduardo Frei que comenzaron a desarrollarse varias de las políticas que serán profundizadas durante el gobierno de la Unidad Popular. Las claves, en esta línea fueron la reforma agraria, que modificó centralmente la estructura de la propiedad rural y que fomentó la sindicalización campesina ${ }^{302}$; la “chilenización del cobre” que asoció al Estado con la gran minería; la política de promoción popular $^{303}$, orientada a organizar a las grandes masas populares a través de la creación de organizaciones locales; una política laboral de libertad sindical y negociación colectiva; el impulso a un ambicioso programa de construcción de viviendas y la reforma del sistema

\footnotetext{
${ }^{301}$ El Ciudadano. "La Democracia Cristiana: esperanza continental". 13.08.1964.

${ }^{302} \mathrm{La}$ reforma agraria fue posible por un acuerdo entre el PDC y la izquierda, que apoyaron una reforma constitucional en 1967, que establecía entre otras cosas, la subordinación del derecho de propiedad de la tierra al cumplimiento de una función social. Por otro lado, fue la medida del gobierno que los enfrentó más con la derecha, fundamentalmente con el Partido Nacional y los gremios empresariales.

${ }^{303}$ Siguiendo a Teo Valenzuela, podemos definir las políticas de promoción popular que consistían en "educar a la comunidad en sus barrios, crear juntas de vecinos para organizar las demandas por la vivienda, alcantarillado, pavimento, y equipamiento social, fue una escuela nacional de participación.” (2014, p. 94).
} 
educacional y los programas estatales de educación popular. Tal como señala Tomás Moulián, "si se compara el programa del gobierno de Frei con programas anteriores que propiciaron se llega a la conclusión de que se trataba de un reformismo avanzado, con un proyecto coherente y global”. (2006, p. 222). En el mismo sentido, Eneida Novoa había señalado algunos años antes que Frei, "se autotitula revolucionario, se anuncia como un sistema nuevo cuya experiencia ha vivir el país para salir de su crisis.” (1972, p. 63).

Algunos meses antes de la asunción de la Democracia Cristiana al gobierno, y a consecuencia del golpe de Estado en Brasil, comenzaron a llegar varios militantes e intelectuales cristianos exiliados, que fueron acogidos en Chile (y también en Uruguay). Muchos de ellos se encontraban vinculados a la acción de la Iglesia, y concretamente a Acción Popular. Eran cristianos comprometidos y con una clara orientación hacia la izquierda, que impactarán directamente en el colectivo chileno.

Las tensiones entre las diversas tendencias internas, comenzaron a profundizarse, al poco tiempo de inaugurado el gobierno de la DC. Dos sectores, comenzaron a hacerse claramente visibles: el oficialista -liderado por Frei- que defendió durante todo el período los avances del gobierno y el ala "rebelde", integrado fundamentalmente por miembros de la JDC, que con una propuesta claramente más radical, finalmente rompen con el Partido en 1969, luego de la discusión sobre la "vía no capitalista de desarrollo" y de la masacre de Puerto Montt ${ }^{304}$, tal como veremos más adelante.

Durante la Junta Nacional realizada en junio de 1965, el sector "rebelde" intenta ganar la dirección del Partido, proponiendo al senador Alberto Jerez a la Presidencia. Con un claro giro hacia la izquierda, Julio Silva Solar, uno de sus principales representantes, afirmará en esta reunión que

el ideal del cristiano no puede ser hoy una sociedad dividida en clases donde los trabajadores son explotados y de cuya explotación ha salido y continúa saliendo la opulencia, el privilegio y el honor de la clase superior. En cambio parece más próximo a sus principios que su ideal sea el de una sociedad de trabajadores, de compañeros o camaradas, una sociedad sin clases. (Arrate y Rojas, 2003, tomo I, p.393).

Triunfa el candidato de Frei, Patricio Aylwin, por 224 contra 188 votos. Empieza entonces, a desarrollarse un sector "tercerista", que intentará mediar en la pugna entre los

\footnotetext{
${ }^{304}$ Una toma de terrenos en Puerto Montt, es desalojada por la fuerza por Carabineros, y son asesinados ocho pobladores y heridos cerca de cuarenta. La represión provoca el repudio inmediato, y se producen manifestaciones y actos en solidaridad con los pobladores. Los sectores de izquierda, atribuyen la responsabilidad de la masacre al Ministro del Interior, Edmundo Pérez Zujovic.
} 
"rebeldes" y los seguidores de Frei. Son parte de este sector: Radomiro Tomic, Bosco Parra, Luis Felipe Ramírez y Luis Maira. La suma del sector "rebelde" y el sector "tercerista", será la que le dará a la DC un importante sector progresista, y que -como veremos- tendrá cada vez mayor autonomía con respecto a las políticas más conservadoras impulsadas por el gobierno.

A medida que la política represiva de Frei avanza, las críticas de este sector se hacen cada vez más claras. Luego de los sucesos de la mina El Salvador, de marzo de $1965^{305}$, y al realizarse el Congreso Nacional del PDC en agosto de ese mismo año reafirman: "queremos ser muy francos: la base real de nuestro poder así como su justificación moral descansa en nuestra fidelidad a la tarea fundamental de hacer la revolución. Si no la hacemos, nuestro poder se desmorona." (Arrate y Rojas, 2003, tomo I, p.404).

A lo largo del gobierno de Frei, el sector "rebelde" irá conformándose como una verdadera corriente nacional a la interna del PDC. Sumado a la radicalización y el desarrollo de la Juventud del Partido. Rodrigo Ambrosio ${ }^{306}$, por entonces su principal dirigente, condena en julio de 1966 la política del gobierno de mantenerse dentro del status quo. En su documento Las dos vías de la Revolución en Libertad, propone "la revolución hoy día es la transición del capitalismo a una sociedad socialista, y el socialismo comunitario no representa una etapa intermedia entre capitalismo y socialismo, sino otra forma de socialismo". (Arrate y Rojas, 2003, tomo I, p.406). Como veremos más adelante, esta definición del socialismo comunitario, como una nueva forma de socialismo, generará tensiones tanto en Chile como en Uruguay.

En las elecciones municipales de abril de 1967, la DC desciende un $8 \%$ en su caudal electoral. Es en este contexto, que se produce un acuerdo entre la izquierda y la DC vinculado con la cuestión agraria, y se logra aprobar una ley de sindicalización campesina que establece los sindicatos de trabajadores agrícolas, su derecho a huelga y a negociación colectiva y funda el Fondo de Educación y Extensión Sindical, con el fin de capacitar a los trabajadores para el fortalecimiento de las organizaciones sindicales. Este antecedente de buen entendimiento, es que el promoverá la aprobación de la Ley de Reforma Agraria en julio de

\footnotetext{
${ }^{305}$ El 11 de marzo, con el objetivo de disolver una reunión sindical en la mina El Salvador, los militares disparan y dan muerte a seis obreros y dos mujeres, y provocan más de treinta heridos.

${ }^{306}$ Rodrigo Ambrosio (1941-1972), comenzó su vida política siendo estudiante de Sociología en la Universidad Católica, acercándose a la Democracia Cristiana. Luego estudió Derecho en la Universidad de Chile y realizó estudios sobre marxismo en la École Pratique des Hautes Études en Francia bajo la dirección de Louis Althusser. En 1967, fue elegido Presidente de la JDC. Luego de su regreso de Francia, se acercó al sector rebelde, que propugnó un acercamiento con la izquierda. En 1969, fue miembro del grupo que rompe con la DC y funda el MAPU, integrando la Unidad Popular. Fallece prontamente, en un accidente de tránsito, el 19 de mayo de 1972 regresando de actividades partidarias en la ciudad de Valparaíso.
} 
1967. Esteban Teo Valenzuela, señala que son justamente la reforma agraria y la política de promoción popular las claves, para entender el proceso de radicalización política que vivieron ciertos sectores dentro de la DC (2014, p. 93). Varios de los cuadros que romperán con el partido y fundarán unos años más adelante el MAPU, fueron durante el gobierno de Frei, actores claves en estas áreas. Fue en aumento la organización sindical obrero-campesina, luego posteriormente penetrada por estos sectores más a la izquierda ${ }^{307}$.

Eran los tiempos de la polarización en que el rostro ahora organizado de los excluidos y las ideas revolucionarias de la época (de vaticanas a cubanas) fueron el campo fecundo para los discursos redentoristas que se apoderaron de sindicatos, fundos, universidades, y parroquias. La sensación política fue la de estar en medio de límites desbordados, y la revolución se implantó como una utopía al alcance del pueblo organizado. (Teo Valenzuela, 2014, p. 95).

En junio de ese mismo año, Rafael Agustín Gumucio es elegido Presidente del Partido (en una alianza entre "rebeldes" y "terceristas"). Rodrigo Ambrosio queda a cargo de la Presidencia de la Juventud, y se propone el inicio de un proceso de transformación profunda en su interna. A partir de este momento, la izquierda democratacristiana desarrolla en adelante una activa tarea de consolidación orgánica. Comienza a editar el periódico Documentación, Ideología y Política, que sirve como canal de comunicación entre los militantes, a la vez que les proporciona formación teórica y logran armar una importante estructura política a nivel nacional. La JDC encabeza una cruzada en la interna del Partido, con el fin de dar un giro en varios aspectos. El primero de ellos, es rectificar la línea de la política laboral contraria a la unidad sindical, que había sido planteada por el gobierno. En segundo lugar, lograr una efectiva autonomía del Estado con respecto del empresariado. Y por último, lograr un acuerdo pro unidad de las fuerzas populares. Estos jóvenes que se agrupaban en torno a Ambrosio diagnosticaban que el problema del gobierno de Frei no era la intensidad del programa de reformas sino la falta de revolución. (Teo Valenzuela, 2014, p. 105)

A partir de 1967, el gobierno de Frei experimentó un giro en su política económica, en el que operaron el aumento de la inflación y el problema de las alianzas para las siguientes elecciones nacionales. Como veremos, en el capítulo que sigue, esta será una de las razones fundamentales de las divisiones internas que se profundizan en este momento. Pero además, ahondó la distancia entre la DC y los sectores de izquierda.

\footnotetext{
${ }^{307}$ En los primeros momentos, la política de promoción popular, fue duramente criticada por los partidos de izquierda. La idea de organizar a los vecinos para reivindicar el acceso a determinadas políticas, y además mediada por el Estado, iba en detrimento de la idea del choque con las clases dominantes, la lucha de clases, etc. La discusión al fin y al cabo entre reforma y revolución.
} 
Desde que la Democracia Cristiana se convirtió en un partido de masas con posibilidades de acceder al gobierno, dejando de ser el partido de una elite intelectual cristiana, comenzó a vivir un dilema. Si se analizaban los discursos dos posibilidades convivían en esa organización. Una era ser un partido reformista-desarrollista, que no pretendía sustituir al sistema capitalista, sino modernizar y humanizar el capitalismo atrasado que existía en la sociedad chilena. La otra era ser un partido revolucionario alternativista, cuyo proyecto ideal y final era sustituir el sistema capitalista por una forma nueva de sociedad, diferente de los socialismos históricos. (...) El partido que llegó al gobierno en 1964 tenía estas "dos almas" y las dos constituían partes de él, componentes legítimos y no negados. (Moulián, 2006, p. 229)

Estas dos almas, fueron la que se enfrentaron en el conflicto de 1967. Para el sector más a la izquierda, el viraje del gobierno fue la demostración de que su obra estaba limitada por lo que "era aceptable para el sistema capitalista". (Moulián, 2006, p. 230). El sector rupturista, empezó a visualizar que para no abandonar la tradición comunitaria y el espíritu popular del partido, debían romper y vincularse con la izquierda.

La disputa entre el sector "rebelde", integrado mayoritariamente por el sector de la Juventud, tuvo un punto de inflexión con el conflicto desatado por los estudiantes de la Universidad Católica, la mañana del 11 de agosto de $1967^{308}$. Las tensiones se profundizarán igualmente en los años siguientes, hasta 1969 en que este sector finalmente abandona el Partido, para luego sumarse a la fundación de la Unidad Popular.

\footnotetext{
${ }^{308}$ Chile despertó con un hecho que será clave en la conformación política del país: los alumnos de la Pontificia Universidad Católica, dirigidos por el presidente de su federación estudiantil, el democratacristiano Miguel Ángel Solar, toman la casa central de la Universidad con la exigencia de una profunda reforma. El movimiento ocurrido en la Universidad Católica, despierta la solidaridad inmediata de la CUT, de las juventudes comunistas y democratacristianas, de la Acción Universitaria Católica y de los profesores de la Escuela de Psicología de dicha Universidad. Rodrigo Ambrosio, por entonces presidente de la JDC, declara que es el Partido Demócrata Cristiano el que tiene la responsabilidad de dirigir el movimiento, e insta a la FEUC a "continuar la toma y el paro hasta la conquista del triunfo". (Arrate y Rojas, 2003, tomo I, p.421). Famosas fueron las declaraciones del diario "El Mercurio", quién denuncia que el movimiento es liderado por los comunistas. Esta información falsa, impulsa a los estudiantes a desplegar un enorme cartel en la fachada de la Casa Central de la Universidad Católica, con el mensaje: Chilenos: jel Mercurio miente!. El Presidente Frei, se dirige al Cardenal Silva Henríquez para solicitarle su mediación en el conflicto. Designado mediador por el Vaticano, el Cardenal logra un acuerdo con los estudiantes por el cual se acepta el cogobierno y se designa prorrector a Fernando Castillo Velazco, quien poco tiempo después será nominado Rector.
} 


\title{
4.4.1. ¡Hoy en Chile, mañana en Uruguay! ¡Revolución en Libertad! ${ }^{309}$ : las repercusiones del triunfo de Frei en Uruguay
}

También para nosotros los uruguayos nos urge invitar a la historia para esta campaña formidable de la revolución en y con libertad. Desde el fondo del alma, hay una gran llamada que nos invita con apremio a tomar en serio la vida y la acción sinceramente, con firme moral y ánimo resuelto, para seguir el ejemplo de los hermanos chilenos. (...) ¡Salud Eduardo Frei! ¡Salud gran visionario y gran gestor de esta revolución augural! Vamos tras tus pasos y el encuentro con la historia ${ }^{310}$.

Romero Pérez, afirma que en primer lugar, el Partido "se vio tonificado por el triunfo del PDC chileno”. (1984, p. 16). Héctor Lescano, recuerda la noche que ganó Frei,

\begin{abstract}
en términos muy militantes, porque me acuerdo -yo tenía una voz bastante potente- y entonces en un coche recorríamos las calles de Punta Gorda y de barrios cercanos con aquel slogan "hoy en Chile, mañana en Uruguay" y celebrando la llegada de Eduardo Frei Montalva al gobierno de Chile. Así que me acuerdo perfectamente y tratamos en ese momento, de forma muy modesta de vincularlo y de soñar con que si eso se estaba dando en Chile, donde había una presencia fuerte, de un partido importante, continuación de la vieja Falange chilena, que podía darse en Uruguay.
\end{abstract}

Al día siguiente -sábado 5 de setiembre- partió desde la sede central del Partido, una caravana que se dirigió en primer lugar hacia la Plaza Independencia, luego hacia la Embajada de Chile, para luego retornar a la sede central.

Ese desfile de júbilo y triunfo resultó un golpe poderoso para todos los que menosprecian al PDC juzgándolo, sin autoanalizarse como la resultante de un conjunto de estructuras arcaicas. (...) Para concluir una inquietud: debemos considerar que esta caravana no fue sino el primer bostezo de un partido que recién despierta. Que ese despertar sea definitivo está en nuestras manos y la fórmula es una sola: TRABAJO ${ }^{311}$.

La semana de festejos, concluyó el martes 8 con un homenaje al PDC chileno y en particular a la figura de Frei, en la Plaza Libertad. Según el medio de prensa partidario, calcularon en 2500 los asistentes.

\footnotetext{
${ }^{309}$ El Ciudadano. "Caravana de la Libertad". 17.09.1964.

${ }^{310}$ El Ciudadano. "Chile vive la Democracia Cristiana". 17.09.1964.

${ }^{311}$ El Ciudadano. "Caravana de la Libertad”. 17.09.1964.
} 
Aún nuestras retinas recuerdan aquella muchedumbre alborozada, que al final soportando frío y agua se mantuvo en pie inconmovible (...), que agitando banderas chilenas y uruguayas no cesaban de gritar: HOY EN CHILE, MAÑANA EN URUGUAY. (...). Creemos sinceramente que estas (...) notas fundamentales de la Democracia Cristiana chilena marcan por su importancia trasandina la pauta de lo que debe ser y será aquí ahora y luego en nuestro querido Uruguay, el Partido Demócrata Cristiano. $(\ldots)^{312}$.

Una semana después del triunfo de Frei, el por entonces Encargado de Negocios de la Embajada chilena en Uruguay -Ernesto Espinoza Montt-, informa que

la lucha presidencial que se seguía sin mayor interés pasó, después de la elección complementaria de Curicó, a convertirse en tema de trato cotidiano (...). Las noticias sobre Chile pasaron a ocupar no sólo las primeras páginas, sino que también los editoriales de todos los diarios y revistas orientales que enfocaban la elección chilena como una etapa decisiva en la vida continental. De esta manera, la opinión pública uruguaya siguió paso a paso las últimas alternativas del proceso electoral y llegó a abrazar como propias una de las dos tendencias en pugna que simplifico como pro-democracia y pro-comunismo (...) $)^{313}$

El 17 de setiembre, El ciudadano, dedica varias páginas a reseñar la importancia del triunfo democratacristiano en el país vecino, incluida una importante foto de tapa con la cara del futuro Presidente ${ }^{314}$. Vuelven allí a resurgir los argumentos contrarios a los postulados de la izquierda tradicional. En este sentido, el pueblo chileno había mostrado una importante lección,

entre la revolución marxista y la revolución en libertad, se definió claramente por la revolución en libertad. (...). Revolución que se hará por el cauce de la democracia y con el profundo sentido personalista y comunitario que se bebe en la fuente prístina del Evangelio y se vigoriza y construye con el aporte de todos los hombres de buena voluntad. (...). El triunfo de la Democracia Cristiana en Chile adquiere así también un sentido augural y representa el aletear primero pero firme de una esperanza ${ }^{315}$.

Pocos días después de la asunción de Frei, agregan "si en Cuba se inició una revolución hipotecada y entregada en los brazos del marxismo leninismo, en Chile comienza un sincero y efectivo proceso revolucionario que no claudicará ante ningún imperialismo"316.

\footnotetext{
312 El Ciudadano. "Magnífica concentración Demócrata Cristiana. Una multitud en la Plaza Libertad vivo al PDC, a Chile y a Frei". 17.09.1964.

${ }^{313}$ Ministerio de Relaciones Exteriores de Chile. Archivo General Histórico. Embajada de Chile en Uruguay. Fondo Países. Año 1964. Volumen 15. Oficio Nro. 479/221.

${ }^{314}$ El Ciudadano. "Ha comenzado la revolución en libertad". 17.09.1964.

${ }^{315}$ El Ciudadano. "Proyección internacional de las elecciones chilenas". 17.09.1964.

${ }^{316}$ El Ciudadano. "Chile y América”. 14.11.1964.
} 
Es interesante señalar, que en el relato construido, hay una profunda necesidad de vincular al Uruguay, como parte de ese proceso liberador, de respeto a la democracia, a los canales institucionales. En su narración, recogen la bandera de aquellos primeros democratacristianos que en 1912 levantaron esa consigna en Uruguay, “el primer país donde se habló de Democracia Cristiana en el continente (...)”. La importancia de esa gesta de comienzos de siglo, se reafirma con el hecho de

que Eduardo Frei y sus compañeros vinieron a Montevideo para estudiar la formación de su partido, como vinieron luego americanos de distintos países para comenzar en éstos el movimiento demócrata cristiano. (...). La semilla se sembró aquí en el Uruguay. La cosecha se recoge hoy allá en Chile. $(\ldots)^{317}$.

El $1^{\mathrm{o}}$ de octubre, Ernesto Espinoza Montt, envía a su Canciller el informe sobre los principales acontecimientos de la política uruguaya del mes de setiembre. Allí, se da cuenta de las repercusiones que la elección presidencial chilena tuvo en la política interna uruguaya.

Tal como informé a US. el triunfo del Senador Frei dio lugar a manifestaciones espontáneas de tipo popular, pero también a algunas organizadas por la Democracia Cristiana local, que celebró la victoria como suya. Esta actitud provocó una fuerte reacción en los partidos tradicionales en contra del Partido Demócrata Cristiano oriental al cual acusaron de pretender obtener una ganancia de un evento político que se originó en condiciones completamente diferentes a las que imperan en este país, ya que, a su juicio, la contienda electoral chilena planteó una alternativa peligrosa: democracia o comunismo. Resulta para ellos que el triunfo es el de la democracia y no el de un determinado sector político. $^{318}$

Las referencias a la importancia del triunfo de Frei como ejemplo a seguir, se mantendrán por lo menos hasta fines de 1964. En octubre, afirmaban que el triunfo del PDC chileno

traduce una aspiración, determina un hecho histórico y plantea una profunda responsabilidad. (...). De ahora en adelante el pueblo sabe que puede recorrer un camino cierto de libertad, de justicia, de orden y de paz, de reconocimiento y de atención a sus angustias, de seguridad en el cumplimiento de la prédica expuesta, de garantía en los hombres que han asumido el compromiso. El terreno está preparado para que la instancia chilena se repita en los demás países. Un mismo sentimiento, una igual aspiración, una

\footnotetext{
${ }^{317}$ El Ciudadano. "Cuando los clarines suenan. La nueva independencia. Frei Presidente". 17.09.1964.

${ }^{318}$ Ministerio de Relaciones Exteriores de Chile. Archivo General Histórico. Embajada de Chile en Uruguay. Fondo Países. Año 1964. Volumen 14. Oficio Confidencia Nro. 520/66.
} 
idéntica inquietud se manifiesta mediante los movimientos demócrata cristianos del continente. (...)

Aparecía allí, la enorme responsabilidad local,

la obligación de organizarnos desde ya para que dentro de dos años demos al país el ejemplo de una colectividad fuerte, unida, prestigiosa, que sabe a dónde va, para lograr nuestra propia alineación uruguaya en el movimiento latinoamericano. (...) El Partido abre sus puertas para que se forme la gran columna que ha de reeditar la liberación chilena. $(\ldots)^{319}$

Por supuesto, que el día de la asunción de Frei una numerosa delegación de cerca de cincuenta militantes de la Democracia Cristiana, concurrieron a Santiago para asistir a tan importante evento. La noticia da cuenta, además, de una improvisada visita a la residencia de quién asumiera la Presidencia de Chile, donde fueron recibidos por el Presidente y su esposa. Múltiples contactos se establecieron entre los militantes del Partido uruguayo y su par chileno, así como entre los dirigentes nacionales y representantes de partidos hermanos de otros países ${ }^{320}$. María Elena Martínez, recuerda de los contactos con el gobierno de Frei,

íbamos mucho, yo conocí a Frei padre en Valparaíso (...) que estaba la casa presidencial de verano. $\mathrm{Y}$ un verano fuimos, hicimos toda una recorrida, nos fuimos al sur con los estudiantes a hacer casitas. Teníamos mucha amistad, la gente chilena era la más cerca a nosotros. (...).

A fines de 1964, deja de salir El ciudadano, producto también del proceso de renovación interna, acuerdan para los años subsiguientes sacar un periódico con un nuevo formato más accesible. De Frente, saldrá entonces a mediados de 1965 y hasta 1967. El 31 de diciembre, se despiden de sus lectores reafirmando: “(...) La victoria de Chile sigue repercutiendo en nuestros corazones. Pero más aún trasciende en nuestro deber.... A repetirla en el Uruguay" 321 .

Ahora bien, además de la recepción del triunfo chileno en los meses posteriores a la realización de los comicios, el ejemplo electoral y las primeras medidas del gobierno, tuvieron un rol destacado en la campaña nacional que la Democracia Cristiana realiza para las

\footnotetext{
${ }^{319}$ El Ciudadano. "Como en Chile: Democracia Cristiana". 01.10.1964.

${ }^{320}$ El Ciudadano. "Nutrida delegación a Chile". 14.11.1964.

${ }^{321}$ El Ciudadano. "Arriba corazones!” 31.12.1964.
} 
elecciones de 1966. A la vez, las tensiones que comienzan a profundizarse en Chile, también producen alineamientos con su par uruguayo.

Entre enero y marzo de 1965, se realizan elecciones internas, donde triunfa el sector renovador, que va ganando cada vez más espacio interno. Se elige una nueva Junta Nacional que será presidida por Adolfo Gelsi. En este contexto, el 7 de abril, sin previo aviso, Venancio Flores anuncia en el Senado su desvinculación del PDC, y su vinculación con la banca al Movimiento Cívico Cristiano. La Democracia Cristiana, queda entonces, sólo con representación en la Cámara de Diputados.

En abril de ese mismo año, el PDC participa por primera vez de un acto público, junto a otros grupos políticos, con motivo de denunciar la invasión norteamericana en República Dominicana. El debate, comenzaba a darse, entonces sobre si se debía participar en actos junto al PCU. La JDC a su vez, organizó un acto junto a todas las Juventudes antiimperialistas, sobre el mismo tema. Recordemos que salen en este período el Manifiesto para una nueva generación y el Socialismo comunitario. "El PDC se comenzó a perfilar sólidamente como partido opositor al sistema capitalista, revolucionario y anti-imperialista." (Pérez, 1984, p. 17). Las vinculaciones a nivel del Partido con el sector "tomicista" y a la vez los profundos acercamientos entre ambas juventudes, acercaban a la Democracia Cristiana, cada vez más hacia los sectores progresistas y con tendencias hacia la izquierda. Como veremos en el próximo capítulo, luego de que varios miembros del sector "rebelde" rompan con el Partido, será un punto de tensión para los jóvenes uruguayos y sus contactos orgánicos con su par chileno.

Las voces disidentes con respecto a lo que estaba sucediendo en Chile, comienzan a tener eco también en Uruguay. Héctor Lescano, recuerda que el gobierno de Frei

lo vivíamos en parte, con un sentimiento de culpa y en particular a nivel de la Juventud éramos bastante críticos, o sea, habíamos sido permeables a las críticas de la izquierda podríamos decir (...). De cualquier manera, siempre nos sentimos muchos más cerca de la Juventud que tenía aspectos críticos y de parte del liderazgo de la DC chilena encabezada por Radomiro Tomic, por ejemplo y otros tantos, que aún formando parte del gobierno (...), tenían críticas al gobierno.

Mientras tanto, en su medio de prensa, en mayo de 1966 afirmaban

tras año y medio de gobierno democristiano en Chile, Chile ha comenzado a caminar. Lentamente. Muy lentamente, quizás. Pero con seguridad. De qué vale una revolución violenta si ella engendra siempre la contrarrevolución? Frei ha preferido el camino de la 
ley, más lento y engorroso, para sus reformas. Quizás por esta elección sea más ejemplar que por las propias reformas que intenta hacer en Chile. Una ley permanece, un fusil puede ser herido de muerte por otro fusil. (...). Fidel Castro -hay que nombrarlo porque representa, bueno o malo, uno de los mayores intentos de independencia que conoce América- hizo una revolución. (...) No se dan cuenta que lo que hizo Castro fue una guerra. (...). La diferencia está en los medios que se utilizan para alcanzar esas metas y en las metas mismas. Pero la acción humana revolucionaria es idéntica en ambos casos ${ }^{322}$.

En setiembre de 1966, en plena campaña electoral, los sucesos del Congreso de la DC chilena, son relatados con detalle en De Frente. Dando cuenta de las tres líneas existentes a la interna del Partido, finalizan afirmando: "hay que decirlo con claridad: la Revolución en Libertad no pasa, por ahora, de ser un proceso parcial, intermitente y frágil." Se destaca la Reforma Agraria y la organización popular, y se evalúa la política en el campo sindical como

una omisión extremadamente grave. El PDC le está exigiendo a Frei que, de una vez por todas, lance la Revolución en Libertad como proceso de transformación global, a partir de algunas rupturas decisivas con el sistema vigente que aún no han sido hechas. (...) El régimen tomaría definitivamente, en tal caso, uno de los caminos de la encrucijada en que se encuentra: revolución o reformismo ${ }^{323}$.

Comenzada ya la campaña electoral de 1966, María Elena Martínez, recuerda que contaron con apoyos de Italia y de Chile, sumado a

un militante fuerte de la Democracia Cristiana de Osorno, que estuvo seis meses trabajando con nosotros. (...). Eran gobierno y además estaban mucho más preparados, tenían los lugares de formación en América eran en Venezuela (...) y Chile (...) Tenía buena formación política, pero sobre todo vino a encajarnos, en cómo trabajar. Estuvo por lo menos seis meses, por lo menos. (...). Y el día de las elecciones había dirigentes chilenos acá.

La consigna de campaña chilena, de "revolución en libertad", también fue retomada en Uruguay. A mediados de 1966, reafirman

se nos hace una responsabilidad y obligación ineludible, a todos aquellos que queremos y amamos el país a integrarnos en una decidida REVOLUCION EN LIBERTAD, que nos asegure dentro del orden y la justicia una verdadera transformación en nuestro caduco

\footnotetext{
${ }^{322}$ De Frente. "Chile: el camino del heroísmo". 09.05.1966.

323 De Frente. "Revolución o reformismo en Chile: en setiembre podría quedar despejada la incógnita". 15.08.1966.
} 
sistema. Para realizarnos en una auténtica justicia social para bien de todos los uruguayos. $(\ldots)^{324}$.

El 21 de noviembre, una semana antes del acto electoral, el periódico del PDC uruguayo, titulaba "El domingo nace la Revolución en Libertad"325

A fines de octubre, emulan la "Marcha de la Patria Joven": varias columnas provenientes del interior del país, llegaron a un gran acto en Montevideo el 29 de ese mismo mes, como forma de inaugurar el Congreso Nacional de la Juventud ${ }^{326}$. A la vez, a nivel del Partido también recorrieron durante catorce días, varios puntos del país, en lo que denominaron como "La caravana de la mayoría naciente", que finalizó el viernes 25 de noviembre - dos días antes de los comicios- con un acto en el Obelisco de Montevideo.

El resultado fue desalentador, para el importante movimiento previo que desarrollaron, sin posibilidades reales de seguir el ejemplo de su par chileno. Tal como señala Romeo Pérez, "el resultado electoral fue deslucido para las expectativas exageradamente optimistas y provocó la pérdida del Senador, lo que limitaría la actuación parlamentaria posterior." (1984, p. 18)

Finalmente obtuvieron tres lugares en la Cámara de Diputados: Sebastián Elizeire por Paysandú, Humberto Ciganda por San José y Juan Pablo Terra por Montevideo, perdiendo nuevamente su representación en la Cámara alta. Jorge Rodríguez afirma que,

en el 66' la Democracia Cristiana lleva un candidato a la Presidencia propio que es Gelsi Bidart, pero que es simbólico, pero lleva a Plá Rodríguez de candidato a Senador y Juan Pablo Terra de candidato a Diputado y Plá por muy poquitos votos no sale Senador y Juan Pablo sale Diputado. Eso lo mató a Plá y Juan Pablo inicia una orientación mucho más a la izquierda (...).

El liderazgo progresista de Juan Pablo Terra, que venía ya perfilándose desde su reingreso al partido en 1964, toma ahora una proyección mucho más importante y de alcance nacional. Su lugar en el Parlamento, le sirve no solamente, para promover varios proyectos de ley con sensibilidad social, sino también para consolidar su liderazgo fuera de la capital.

En mayo de 1967, deja de salir De Frente, como consecuencia de fuertes discrepancias internas con respecto a su orientación. Quedan cerrados, temporalmente, los canales de comunicación con la opinión pública y con la masa de adherentes no militantes. Comienza a

\footnotetext{
${ }^{324}$ De Frente. "Juventud campesina". 04.07.1966.

325 De Frente. Tapa. 21.11.1966

326 De Frente. "La Marcha de la Patria Joven", 24.10.1966; "Reflexiones sobre la marcha de la Patria Joven", 07.11.1966.
} 
formalizarse una tendencia discrepante, liderada por María Amelia Urretavizcaya, Carlos Varela Rodríguez, y Julio Daverde, que operará activamente hasta fines de 1970. Esta tendencia, aunque menor en su interior, no comulgaba con el giro hacia la izquierda que el Partido venía transitando y finalmente, rompen cuando se funda el Frente Amplio.

José Luis Veiga, llega a Chile en 1967, y recuerda que en ese momento

son los primeros grandes cruces entre lo que era la unidad del pueblo de Radomiro Tomic y lo que era el gobierno o la posición de Aylwin, Jaime Castillo y unos cuantos más del PDC chileno. Y a nivel de juventudes se produce también lo que después termina en la izquierda. La Juventud Demócrata Cristiana era Pedro Felipe Ramírez, que termina en la Izquierda Cristiana, era Juan Enrique Vega que termina en el MAPU (...). Nosotros sin embargo acá sosteníamos, dentro del Partido, no romper el Partido. (...). Y eso lo que hizo fue, en la Juventud Demócrata Cristiana, abroquelarse en el Partido, con las discusiones propias de Juventud-Partido.

La convicción de no quebrar el Partido en Uruguay, será clave, para dos procesos fundamentales. La primera, porque si las tendencias internas hubieran tenido la implicancia que tuvieron en Chile, la Democracia Cristiana se habría quebrado en dos partidos menores, impidiéndole posiblemente jugar el importante rol que jugó para la fundación del Frente Amplio algunos años después. Es imposible comparar la magnitud, y el caudal electoral y militante entre ambos partidos, sumado a que en uno de ellos eran gobierno. El desgaste procesado también en ese recorrido influyó notoriamente en sus quiebres internos. La discusión, además, en Chile se producía en el plano de los hechos, eran gobierno y por lo tanto, las medidas, y las formas de llevarlas a cabo, tenían consecuencias directas en la vida política del país. Cosa que claramente, no sucedía en Uruguay, donde las disputas seguían estando en el plano teórico. Esto llevó a que el PDC uruguayo, se mantuviera unido, y que a la interna hubiera ganado cada vez más terreno el ala más izquierdista. Este proceso, como veremos en el capítulo siguiente, será la clave para que la Democracia Cristiana casi en su totalidad, apoyara y promoviera, finalmente, la posibilidad de crear una alianza con los "marxistas". 


\title{
4.5. El camino: la vía no capitalista de desarrollo y el socialismo comunitario
}

La democracia cristiana chilena, estaba a la vanguardia desde el punto de vista de producción teórica, entre los partidos democratacristianos latinoamericanos. Ya señalamos que a comienzos de la década del 50' Jacques Chonchol y Julio Silva Solar, publicaron el libro titulado Hacia un socialismo comunitario, donde proclamaban la urgente necesidad de abolir el sistema capitalista. Esa primera obra, tendrá sus derivaciones teóricas a mediados de la década del 60'tanto en Chile como en Uruguay.

Ya en 1962, recién fundado el PDC uruguayo afirmaba

\begin{abstract}
en nombre del más puro cristianismo reclamamos una transformación radical del mundo capitalista. (...) La solución [está] en la multiplicación de los pequeños y medianos propietarios (...). La estructura de la vida agraria quedará transformada cuando logremos multiplicar los pequeños y medianos terratenientes (...). La estructura de la empresa industrial y comercial se transformará gradualmente; primero por la participación más justa de los trabajadores en las utilidades (...), segundo, por su acceso al nombramiento y vigilancia de la gerencia por medio de comités paritarios, y definitivamente, cuando por medio del Contrato de Sociedad, los obreros pasen del carácter de asalariados a socios y copropietarios de la empresa. (...) Al llegar a esta última etapa, al Contrato de Sociedad, queda eliminada la esencia misma del capitalismo: la separación del capital y el trabajo. (...). Y es una de las más contundentes demostraciones de la superioridad de nuestra revolución social ${ }^{327}$.
\end{abstract}

La JDC uruguaya, publica en 1965 el documento Socialismo comunitario, con el fin de definir el concepto y dar soluciones en el plano económico. El aporte de los teóricos chilenos sobre el tema, que serán la base de lo publicado en Uruguay, es directa. En el mismo documento, los autores señalan que "esta publicación es una modificación del trabajo original chileno solo en aquellos puntos en que sus postulados no se adaptan totalmente a la realidad uruguaya" 328 .

Allí se planteaba la necesidad de desarrollar una nueva sociedad, que tendría cuatro características fundamentales: personalista (la persona humana sería el centro de esta nueva sociedad), pluralista (respeto a todas las opciones políticas, de credo, educacionales, etc.), democrática (considerando a la democracia real como régimen político ideal) y comunitaria (socialización comunitaria de los bienes de producción), única manera de lograr la democracia social.

\footnotetext{
${ }^{327}$ El Ciudadano. "Una revolución más profunda que el marxismo". 20.07.1962.

328 JDC (1965). Socialismo comunitario. Una concepción nueva, revolucionaria, auténtica, humana. Tomado de Ilha López, 2016, p. 163.
} 
En 1966, se realizó el II Congreso del PDC chileno, donde fue motivo clave de debate el concepto de "socialismo comunitario" y de "revolución en libertad". Según la reseña del evento, realizada desde Montevideo, fueron Jaime Castillo, Jacques Chonchol y Julio Silva Solar, los que centralizaron los debates.

Chonchol y Silva Solar, exigiendo definiciones concretas, avanzadas, de izquierda revolucionaria. Jaime Castillo, con su voz tranquila, exigiendo claridad en los conceptos y advirtiendo contra el "enamoramiento de las palabras" y contra la tendencia a las comparaciones. (...) "algunos quieren ser más socialistas que los socialistas, y les parece necesario agregar la palabra socialista a nuestra palabra comunitario, y no advierten que en el sentido en que un demócrata cristiano usa la palabra comunitario, resulta redundante agregarle la palabra socialista”. Comunitarismo es más amplio que socialismo y su origen social cristiano haría innecesario pedir prestadas palabras a doctrinas ajenas, de acuerdo al ideólogo más caracterizado del PDC chileno ${ }^{329}$.

Algo similar, planteará Juan Pablo Terra, quién también se mostró crítico con respecto al uso del término "socialismo". En este sentido, afirmaba en 1969:

la expresión socialismo es suficientemente amplia e indeterminada como para que pueda admitirse que el comunitarismo es un socialismo. Si el socialismo señala una afirmación de la importancia de lo social, de la naturaleza social del hombre y de la necesidad de buscar su realización plena en la aceptación de la vida social; o si significa una aspiración igualitaria; o si significa la liquidación del predominio social del capitalista y de sus poderes emergentes de la propiedad; si significa un humanismo social, la designación de socialismo es adecuada. Pero si se cae en la vieja definición de la supresión de la propiedad privada en los medios de producción, si se piensa que es la nacionalización de los medios de producción, entonces la definición no es adecuada. (2014, p. 133).

Como ya hemos señalado, la clave estaba dada en la concepción de que tanto el capitalismo como el marxismo tenían concepciones materialistas y absolutistas de la propiedad, mientras que el planteo de sociedad comunitaria, se basaba justamente en su carácter mixto de la propiedad.

Un año después, en 1967, la nueva Junta del Partido chileno -en manos ahora del sector "rebelde"-, encargará a una Comisión Político Técnica la redacción de un documento que será clave en el desarrollo democratacristiano en este período. El informe denominado "Proposiciones para una acción política en el período 1967-1970 de una vía no capitalista

${ }^{329}$ De Frente. "Chile: hacia una sociedad comunitaria". 10.10.1966. 
de desarrollo”, fue realizado por Jacques Chonchol, Tomás Reyes, Luis Maira, Vicente Sota, Julio Silva, Carlos Massad, y Pedro Felipe Ramírez. En el mismo se señala claramente, que

los democratacristianos deseamos un crecimiento económico que nos aleje en lugar de comprometernos con los criterios capitalistas (...). El Partido Demócrata Cristiano rechaza en consecuencia como contraria a sus postulados, la alternativa de convertirse en el "partido del desarrollo chileno" sin otras especificaciones, busca en cambio la perspectiva de orientar la obtención del desarrollo económico hacia la construcción de una nueva sociedad de trabajadores, solidaria, democrática y popular (...). La vía no capitalista de desarrollo es un conjunto de tareas destinadas a asegurar la plena realización de los objetivos del programa de gobierno de 1964, avanzando desde ya la constitución de un sistema económico social comunitario que sustituya al régimen capitalista (...). (Citado por Arrate y Rojas, 2003, tomo I, p.410).

A la interna del Partido y del propio gobierno el documento provocó una profunda discusión. La principal crítica, en manos de los sectores más conservadores, señalaba que de esta forma se aleja al PDC de su línea doctrinaria fundante que es el "Humanismo Cristiano y no el Humanismo Marxista" (Arrate y Rojas, 2003, tomo I, p.408).

En enero de 1968, se reúne la Junta Nacional Extraordinaria de la DC. El objetivo del Presidente Frei, es intervenir directamente para lograr terminar con el sector "rebelde" en la dirección del Partido. Finalmente Frei triunfa, y la directiva renuncia. Pedro Felipe Ramírez, es expulsado de su cargo de gobierno -era el Gerente General del Servicio de Cooperación Técnica- por decisión del entonces Ministro del Interior, Edmundo Pérez Zujovic y Jacques Chonchol renuncia en solidaridad a su cargo como Director del Instituto de Desarrollo Agropecuario (INDAP), dependiente del Ministerio de Agricultura. Como veremos en el capítulo siguiente, este colectivo, será quien fundará el Movimiento de Acción Popular Unitario (MAPU) en 1969, siendo parte fundante de la Unidad Popular y luego del gobierno de Allende; integrándose en 1971 a la Izquierda Cristiana (IC).

El desarrollo teórico, llegará a su punto culmine en este período. La definición de sociedad comunitaria y sus características se profundizarán más bien, en los primeros años de la década del 70'. En 1971, la revista teórica de la JDC -Encuentro- publica un artículo de Jacques Chonchol y Julio Silva Solar (ya integrados ambos a la IC), titulado Principios del comunitarismo, en el que entendían esta nueva sociedad fundada en el principio de que la tierra y los bienes productivos estuvieran en manos de los trabajadores. El crecimiento no estaría dado por el afán de lucro propio del capitalismo, sino por "la voluntad colectiva de todo el pueblo que se hace dueño de la economía y que organiza planificadamente su ascenso como comunidad, sin diferencias de clase.” Y más adelante agregaban, 
creemos objetivamente que es una forma de socialismo, un socialismo comunitario. ¿Por qué? Porque el socialismo es el régimen en que los bienes productivos de carácter social pertenecen a la comunidad. Esa es su base. Esa es también la base de la idea comunitaria ${ }^{330}$.

En Uruguay, además esta misma estrategia, se puede visualizar por lo menos en dos documentos de la JDC, Bases para una opción revolucionaria, del año 1969 y Bases ideológicas, de 1971 y en el Programa de Principios del PDC de 1970. Esta etapa era considerada una etapa de transición hacia el socialismo comunitario, donde sería necesario utilizar las estructuras propias del capitalismo, pero con una nueva orientación. En este momento, los trabajadores y el Estado tendrían el control de los medios de producción, y se haría una planificación económica basadas en las necesidades populares y no con el fin del lucro.

Por otro lado, la Democracia Cristiana uruguaya también adhiere a los postulados de una "vía no capitalista de desarrollo", siguiendo los escritos realizados por Frank Hinkelammert en Chile, a quien invitan a realizar cursos de formación con la JDC uruguaya. Carlos Baráibar, recuerda que "tuvo mucha influencia en la Juventud Demócrata Cristiana de Uruguay, que lo invitamos a hacer charlas, cursos, conferencias, una serie de cosas".

Como veremos en el capítulo siguiente, estas definiciones doctrinarias, generaran profundos quiebres en Chile; a la vez, que serán la base ideológica fundamental con la que los democratacristianos uruguayos acuerden promover y participar activamente en la unidad de las izquierdas.

\subsection{Algunas apreciaciones finales}

De los tres casos analizados, es en el PDC dónde se ve más claramente la influencia de su par chileno. Nacidos ambos como giro progresista de partidos más conservadores, su vinculación fue incluso anterior a la transformación de ambos en Democracias Cristianas.

En este sentido, jugó -en primer lugar- un rol fundamental la coordinación establecida en la ODCA y -en segundo lugar- las relaciones personales de los principales dirigentes de ambos partidos, tal como hemos visto.

Claramente, la DC chilena fue un modelo clave no sólo para el Uruguay, sino para las Democracias Cristianas del continente. Su acceso al gobierno, tempranamente en 1964, les

\footnotetext{
${ }^{330}$ Revista Encuentro, Nro. 3, octubre de 1971, p. 113-119.
} 
garantizó la mirada de otros colectivos con el mismo ideario. La posibilidad de alcanzar el gobierno, manteniéndose en una postura equidistante tanto del marxismo como del capitalismo, y respetando las leyes del juego electoral y la democracia, era posible. La concreción (o no) en el plano de la práctica de lo que se venía postulando, constituyó en Chile el laboratorio de América Latina. Esto fue lo que provocó, claramente las tensiones internas, y las rupturas en Chile, que tuvieron su correlato en Uruguay. De hecho, para las dos elecciones nacionales ocurridas en este período el PDC también irá sin alianzas políticas y, como vimos sostendrá un importante anticomunismo que lo llevará entre otras cosas a no integrarse a la Mesa por la Unidad del Pueblo. La campaña del terror, realizada contra Allende en 1964, también fue utilizada en Uruguay, denunciando el "peligro comunista".

En 1966, si un distraído se guía solo por la prensa de la DC uruguaya, se convencería que el debate electoral estaba dado entre dicho sector y "el marxismo". Bastante lejos de la realidad política nacional, si tomamos en cuenta que la izquierda no superaba junta el $10 \%$ del caudal electoral. Al igual que en Chile y en medio de la Guerra Fría, la cuestión estaba en denunciar el comunismo y en defender la democracia.

Se produjo a su vez, una experiencia de intercambio directo: varios de los principales dirigentes de la Juventud Demócrata Cristiana de Uruguay, vivieron de manera directa el gobierno de Frei y las tensiones chilenas, ya que producto también de la cercanía, varios se encontraban radicados en Santiago.

El apoyo directo en financiamiento y en logística, para las elecciones de 1962 y 1966 en Uruguay, también quedaron claramente evidenciados.

Más allá de las tensiones, en este período se acordaron ciertos postulados básicos del accionar político: la defensa de la democracia como modelo de organización de la sociedad, la libertad de partidos, la defensa de la persona humana, la disputa en el campo únicamente electoral y dentro de la legalidad institucional. Si bien, en ambos casos los sectores juveniles, tuvieron planteamientos más radicales en cuánto a la estrategia a desarrollar, esto no provocó escisiones orgánicas hacia los movimientos armados, más allá de posibles alejamientos individuales.

El PDC uruguayo, fundamentalmente a partir de la consolidación del liderazgo de Juan Pablo Terra, se alineó claramente con los postulados de Radomiro Tomic, fundamentalmente a partir de 1967, tal como veremos en el próximo capítulo. De hecho, este alineamiento será el que les permitirá aliarse con el resto de la izquierda en la fundación del Frente Amplio. 


\section{Unidad sin exclusiones: de la Unidad Popular al Frente Amplio (1968-1971)}

El período que va desde 1968 y hasta 1971, constituye una unidad por varias razones. En primer lugar, el 6 de diciembre de 1967 fallece el entonces Presidente de Uruguay, Gral. (R) Óscar Gestido y asume la Presidencia Jorge Pacheco Areco, Vicepresidente hasta ese momento. Las huellas de un Uruguay en crisis, se profundizarán, dando paso a un ciclo de claro avance del autoritarismo. A la semana de asumir la Presidencia - el 12 de diciembre-, firmaba el decreto 1788/967 que marcaría la constante de lo que sería el período. Así, se decretaba la disolución del Partido Socialista, la Federación Anarquista Uruguaya, el Movimiento Revolucionario Oriental ${ }^{331}$, el Movimiento de Acción Popular Uruguayo, el Movimiento de Izquierda Revolucionaria y el Grupo de Independientes vinculados al diario "Época", así como dicho medio de prensa y el semanario socialista "El Sol".

En junio de 1968, la instalación nuevamente de Medidas Prontas de Seguridad (MPS), y el decreto de congelación de salarios y precios (el salario real llegó al nivel más bajo de la década y la inflación alcanzó un 183\%), dejaron en claro la orientación del nuevo gobierno, período que estuvo caracterizado por la restricción de libertades individuales, el avance de la represión, censura a la prensa, aumento de los detenidos por razones políticas, denuncias de torturas en centros policiales y militares, militarización de funcionarios públicos ${ }^{332}$, allanamientos a locales universitarios, intervención de la Enseñanza Secundaria, surgimiento de grupos de extrema derecha ${ }^{333}$, enfrentamientos callejeros con la policía, entre otras, que fueron respondidos con paros, huelgas, ocupaciones de los lugares de trabajo y estudio. La solicitud de suspender las MPS por el Parlamento, fue desconocida por el Poder Ejecutivo en numerosas oportunidades.

Es en este contexto, que se constituye en marzo de 1968 -a iniciativa de la Convención Nacional de Trabajadores (CNT)- el Movimiento por la Defensa de las Libertades Públicas y la Soberanía, que además de los partidos de izquierda, contó con la adhesión de varios legisladores de los partidos tradicionales, dirigentes sindicales,

\footnotetext{
${ }^{331}$ Pocos días antes, el MRO había roto con el FIdeL por la opinión del PCU sobre la OLAS.

${ }^{332}$ Ante los conflictos en diversos servicios estatales e incluso en la banca privada, se dispuso la militarización de sus funcionarios, ello implicaba entre otras cosas, considerar desertor a quien no se presentara a trabajar y eso justificaba, por ejemplo, su despido.

${ }^{333}$ Como la "Juventud Uruguaya de Pie" (JUP) o el "Comanda Caza Tupamaros", que realizaron atentados de diferente naturaleza contra militantes de izquierda, sindicales y estudiantiles. El 31 de julio de 1971, aparece el cadáver acribillado del estudiante Manuel Ramos Fillipini, cuya muerte se autoatribuyó el "Comando Caza Tupamaros".
} 
intelectuales y religiosos ${ }^{334}$. Este trabajo en conjunto, -sumado al Congreso del Pueblo en 1965 y a la unificación sindical en la CNT en 1966- fue un antecedente clave, también para la futura conformación del Frente Amplio. El accionar del Movimiento, se vio dificultado por las opiniones con respecto a la invasión soviética en Checoslovaquia de 1968. Mientras el PCU la respaldó, el PDC y otros colectivos abandonaron por esa razón el Movimiento.

En agosto de ese mismo año, es asesinado en una manifestación estudiantil, el militante de la Juventud Comunista y estudiante de Odontología, Líber Arce ${ }^{335}$. Fue el cambio en las reglas de juego, cuando se empezó a "normalizar" que las distintas movilizaciones sociales fueran reprimidas, incluso con el uso de armas de fuego.

Desde la asunción de Pacheco, por otro lado, un grupo de legisladores habían comenzado a coordinar ciertas acciones con el fin de enfrentar la política del gobierno desde el recinto parlamentario: intentando impedir la instalación de MPS, denunciando los abusos policiales y las torturas a los detenidos políticos, así como la censura a la prensa. La figura de Zelmar Michelini ${ }^{336}$, que finalmente rompe con el partido de gobierno e integra las filas fundadoras del Frente Amplio, será clave (aunque no la única) en este aspecto. Tal como señala, Aguirre Bayley, "sin autoridades, ni programas comunes, el Frente Amplio ya existía en el Parlamento como única opción real al régimen de Jorge Pacheco Areco.” (2005, p. 32).

\footnotetext{
${ }^{334}$ Para ver la diversidad de su integración, formaron parte de este Movimiento: Óscar Maggiolo (rector de la Universidad de la República), Carlos Quijano (director del semanario Marcha), José Pedro Cardoso (PS), Edmundo Soares Netto (FIdeL), Mauricio García (cura católico), Julio de Santa Ana (Pastor evangélico), y los diputados: Héctor Guitérrez Ruiz (Partido Nacional), Hugo Batalla (P. Colorado), José Luis Massera (PCU) y Juan Pablo Terra (PDC), y los senadores: Alba Roballo (P. Colorado), Francisco Rodríguez Camusso (P. Nacional), Enrique Rodríguez (PCU), Reynaldo Gargano (PS), Adolfo Aguirre González (FIdeL) y el Presidente de la CNT José D’Elía. (Markarián, 2006, p. 211).

${ }^{335}$ A él le siguieron, en setiembre de 1968 Susana Pintos y Hugo de los Santos; en enero de 1969 el obrero municipal Arturo Recalde; Leonardo Beledo en mayo de 1970, en julio de 1971 Heber Nieto y en setiembre Julio Spósito. Por señalar sólo los estudiantes entre 1968 y 1971.

${ }_{336}$ Zelmar Michelini (1924-1976), ingresa a la política en la Federación de Jóvenes Batlllistas a fines de la década del 40', siendo dirigente estudiantil de la Facultad de Derecho. Fue también dirigente de los empleados bancarios, y entre 1947 y 1951 se desempeñó como el Secretario del Presidente Luis Batlle. En 1954 es electo diputado, siendo reelecto en 1958. En 1962, funda la Lista 99 "Movimiento por el Gobierno del Pueblo" dentro del Partido Colorado, siendo en las elecciones de ese año reelecto diputado. A lo largo de su vida, ejercerá el periodismo en varios medios: Acción, Hechos, El Diario, Marcha, Respuesta y La Opinión (Buenos Aires). En 1966, fue electo Senador. Al año siguiente, el Presidente Óscar Gestido, lo designa Ministro de Industria y Comercio, cargo al que renunciaría meses después por discrepancias con la política autoritaria del gobierno. En 1971, ya en el Frente Amplio, es reelecto Senador. Luego del golpe de Estado de junio de 1973, se exilia en Buenos Aires, siendo uno de los principales denunciantes de las violaciones a los DDHH que ocurrían en Uruguay. El 18 de mayo de 1976, fue secuestrado junto a Héctor Gutiérrez Ruiz (miembro del Partido Nacional y hasta el golpe de Estado, Presidente de la Cámara de Diputados). Dos días después, los cuerpos de los dos ex legisladores, junto a dos militantes tupamaros -William Whitelaw y Rosario Barredo- fueron ubicados acribillados dentro de un auto en Capital Federal.
} 
Aunque no todos los legisladores que se opusieron al gobierno, fueron fundadores luego de la coalición de izquierda ${ }^{337}$.

En este mismo contexto, un grupo de militares de jerarquía, renunció a las Fuerzas Armadas, también en desacuerdo con el aumento de su papel represor durante el gobierno de Pacheco. En noviembre, el Gral. Líber Seregni ${ }^{338}$, renunció a su cargo como Comandante de la Región Militar Nro. 1, una de las más importantes del país.

Como hemos señalado en los capítulos anteriores, el contexto de radicalización de la izquierda, se tradujo en algunos casos en el surgimiento de grupos armados, cuya acción se desarrollará también en este período ${ }^{339}$. Este contexto, que se profundizará hasta el golpe de Estado, del 27de junio de 1973, será uno de los motores que promoverá el surgimiento del Frente Amplio el 5 de febrero de 1971.

Entre 1968 y 1970, se producirán en Chile acontecimientos claves, que irán marcando también la realidad uruguaya. Al igual que en Uruguay, el gobierno de Eduardo Frei, también se encamina hacia un avance represivo: persecución de dirigentes de la izquierda (con detención incluso de representantes parlamentarios), represión a la toma de terrenos y al

\footnotetext{
${ }^{337}$ No todos los legisladores de los partidos tradicionales que apoyaron este bloque opositor, acordaron luego su integración al Frente Amplio. El caso de Amílcar Vasconcellos, sea quizás el más reconocido. En el caso de Michelini, al comienzo intentó formar un bloque opositor a la interna de su propio partido, a la vez que se oponía a una posible alianza con los comunistas. Pero a medida que el autoritarismo avanzaba, fue uno de los actores claves en la conformación de un frente de oposición al gobierno.

${ }^{338}$ Líber Seregni (1916-2004), se vincula a la política en 1937 en las actividades de solidaridad con la Segunda República española. En 1933, había comenzado sus estudios en el Liceo Militar, llegando a ser General para el año 1963. Fue jefe de la Región Militar Nro. 2 con asiento en San José y de la Región Militar Nro. 1, la más importante del país con asiento en Montevideo. Pidió su pase a retiro en noviembre de 1968, en discrepancia con la política autoritaria del gobierno. A partir de allí, profundizó sus actividades políticas. Cercano a Michelini, en 1971 es el primer candidato a la Presidencia del recién fundado Frente Amplio. Luego del golpe de Estado, es detenido el 9 de julio de 1973, liberado en forma provisoria el 2 de noviembre de 1974. El 11 de enero de 1976, es arrestado nuevamente y dos años después condenado por el Supremo Tribunal Militar, a 14 años de prisión. Es liberado el 19 de marzo de 1984. Presidente del Frente Amplio, fue nuevamente su candidato presidencial en 1989. En 1996, renuncia a la Presidencia del FA y funda el Centro de Estudios Estratégicos 1815. En el año 2003 anunció su retiro de la política.

${ }^{339}$ Por citar algunos ejemplos, entre 1968 y 1971 el Movimiento de Liberación Nacional- Tupamaros (que si bien fue la principal organización armada, no fue la única), realiza las siguientes acciones: en 1968, secuestro de Ulises Pereyra Reverbel (asesor del Presidente y Director de la empresa estatal de luz- UTE); en 1969: asalto a la financiera Monty, voladura de las instalaciones de la General Motors (en coincidencia con la visita de Nelson Rockefeller a Uruguay), secuestro de Gaetano Pellegrini Giampietro (dirigente de la Asociación de Bancos y director de dos medios de prensa, en medio de un conflicto bancario), copamiento a la ciudad de Pando, en homenaje al aniversario de la muerte del Che (deja como saldos numerosos detenidos y tres tupamaros muertos en manos de la policía), asalto al Banco Francés e Italiano y el envío de sus libros de contabilidad a la justicia; en 1970: fuga de 13 presas política de la cárcel de mujeres, asalto a la sucesión de Mailhos llevándose en oro el equivalente a 300 mil dólares, asesinato del Inspector de Policía Héctor Morán Charquero (implicado en torturas a detenidos), robo de armas del Centro de Instrucción de la Marina, secuestro y asesinato de Dan Mitrione (norteamericano, integrante de la CIA y asesor de la Jefatura de Policía) y de Aloysio Díaz Gomide (cónsul brasileño), secuestro del norteamericano Claude Fly, atentado a la planta textil de Sudamtex; en 1971: secuestro de Geoffrey Jackson (embajador británico en Uruguay), fuga masiva de la Cárcel de Punta Carretas, secuestro del Fiscal de Corte, Dr. Guido Berro, entre otras.
} 
movimiento sindical -que se tradujo en masacres importantes con el asesinato de militantes obreros y campesinos-, el crecimiento de las organizaciones armadas que también profundizarán su accionar en este período, paros, huelgas, tomas en la Universidad, etc. Este será el motivo claro de la división del PDC chileno entre 1968 y 1969, con un importante giro hacia la izquierda de un sector que mostrará en el accionar la posibilidad de que cristianos y marxistas puedan ser parte de una alianza común. Fundamentalmente, luego de la fundación del MAPU y de su integración a la Unidad Popular. Dentro de la DC, la candidatura -no sin conflictos internos- de Radomiro Tomic y sus teorizaciones sobre la necesidad de una unidad social del pueblo, serán claves para el alineamiento de la Democracia Cristiana uruguaya, tal como veremos.

Para el resto de la izquierda, la fundación de la UP, como síntesis final de una alianza amplia, integrada por varios sectores políticos y con representantes de varias clases sociales que logra acceder al gobierno por la vía electoral, mostrará finalmente que la vía pacífica era posible. Su recepción en Uruguay, será el impulso final, que promoverá a la izquierda a constituir el Frente Amplio.

Organizamos el capítulo, en 5 apartados. En el primero de ellos, damos cuenta de los sucesos ocurridos en el país trasandino: las diferencias a la interna de la DC y su quiebre definitivo; el proceso de conformación de la UP, y finalmente las elecciones de setiembre de 1970 y la proclamación de Salvador Allende como Presidente de la República.

En el segundo apartado, analizamos los recorridos de la izquierda uruguaya entre 1968-1970, centrándonos en la recepción de los acontecimientos en Chile y en las transformaciones que el triunfo de la Unidad Popular incentivará en Uruguay.

En el tercer apartado, nos centramos en la fundación del Frente Amplio y en los primeros acuerdos llevados adelante ya por este colectivo.

En el cuarto, damos cuenta de los principales sucesos de la campaña electoral de 1971, en lo que tiene que ver exclusivamente en los vínculos o los puntos de contacto con sus pares chilenos; así como la constitución del primer comité de base del Frente Amplio en el exterior, creado en la ciudad de Santiago. Finalmente, realizamos algunas apreciaciones finales. 
5.1. Abrir las grandes alamedas, por donde pase el hombre libre: la construcción de la Unidad Popular, las elecciones de 1970 y el triunfo de Salvador Allende

\subsubsection{Los últimos años del gobierno de Frei: la Democracia Cristiana entre el camino propio y la unidad del pueblo}

Como vimos en el capítulo anterior, las tensiones a la interna de la DC chilena con respecto a las medidas que debía tomar el gobierno de Frei se venían profundizando hacia los últimos años de su administración. Habíamos señalado, que en 1967 producto del documento "Proposiciones para una acción política en el período 1967-1970 de una vía no capitalista de desarrollo", se produjo una intensa discusión que en definitiva cuestionaba los alcances del gobierno y promovía una línea estratégica de hacia dónde seguir. Finalmente el oficialismo, encabezado por el propio Presidente de la República triunfa en la discusión interna, y los miembros de la dirección integrantes del sector "rebelde" renuncian al órgano directivo. A partir de este momento, el enfrentamiento interno será cada vez más profundo.

En julio de 1968, Rodrigo Ambrosio, deja su cargo de Presidente de la JDC, y apoya la tesis de la unidad de la izquierda. Declara públicamente, refiriéndose a las elecciones de 1970, las diferencias irreconciliables que separan al sector progresista de la DC con el Partido:

para la campaña presidencial del 70 deben desaparecer del mapa político las alternativas centristas o terceristas, que encubren, distorsionan y amortiguan la vida social real del país, para dar paso a dos frentes compactos y excluyentes: el de la derecha y el imperialismo, por un lado, y el movimiento popular por el otro, es decir, el Frente de la Reacción y el Frente de la Revolución, orientado a la difícil construcción de una economía socialista. (Arrate y Rojas, 2003, tomo I, p.432).

Los sectores a la izquierda del partido aún gobernante, plantearon que la clave era entonces una alianza de clase, cuya columna vertebral serán los trabajadores del campo y la ciudad, siendo el fin de dicha unidad la construcción del socialismo.

En agosto de 1968, los "rebeldes" y "terceristas" de la DC, en alianza con Radomiro Tomic, recuperan la dirección del partido, y eligen a Renán Fuentealba como su Presidente. Luego de la masacre de Puerto Montt, en marzo de 1969, la JDC emite un comunicado donde exigen la inmediata expulsión del Ministro del Interior y rompen de hecho definitivamente con el Partido.

Ya en las elecciones parlamentarias de marzo de ese mismo año, la DC pierde la mayoría absoluta en la Cámara de Diputados (baja la votación del 42,20\% alcanzado en 1965 
al 29,78\%); la derecha nuevamente unificada en el Partido Nacional, recupera su representación y el FRAP la aumenta (pasa del 22,62\% de 1965 al 30,29\%) y el PCCh logra convertirse en la tercera fuerza política del país.

El centro (...) reformista y alternativista, produjo esa doble centrifugación. Por una parte impulsó a la derecha hacia su derecha y a la izquierda hacia su izquierda. (...) se crea un escenario que tiende a los tres tercios. Cada una de las fuerzas camina sola y como cada una tiene peso político el desenlace es problemático (Moulián, 2006, p. 231-232).

A fines de abril, la crisis de la DC empezó a precipitarse hacia la primera escisión importante que sufrió, cuando los parlamentarios Julio Silva Solar y Alberto Jerez, entregaron el documento El camino de la unidad popular, en el que insistieron en que el partido debía resolver su indefinición ideológica, apostar por la sustitución del capitalismo y buscar la confluencia con la izquierda.

En mayo la Junta Nacional de la DC, se reúne en medio del enfrentamiento entre los dos sectores: la izquierda con el freísmo. La alianza entre "terceristas" y "rebeldes", encabezados por Tomic, presenta un informe que rechaza cualquier tipo de acuerdo con la derecha y afirma directamente el objetivo de la Unidad Popular, aunque esta implique apoyar un candidato externo. La propuesta oficialista, redactada por Jaime Castillo Velazco, insiste en el "camino propio", y logra triunfar por escaso margen: 233 contra 215 votos. El momento de quiebre era inevitable. Rafael Gumucio renuncia a su militancia democratacristiana, acompañado de Silva Solar, Jacques Chonchol y Vicente Sotta.

Apenas dos semanas después de la reunión de la Junta Nacional fundan el Movimiento de Acción Popular Unitaria (MAPU), integrado además por varios dirigentes de la JDC, entre ellos: Rodrigo Ambrosio, Enrique Correa y Jaime Gazmuri, Manuel Antonio Garretón, Tomás Moulián, José Miguel Insulza, entre otros, provenientes del movimiento estudiantil de las Universidades Católicas de Santiago y Valparaíso ${ }^{340}$.

\footnotetext{
${ }^{340}$ En el mismo acto de fundación se designa a la Comisión Coordinadora Nacional del Movimiento, presidida por Jacques Chonchol. En su informe, deja ya en claro la voluntad unitaria con los partidos tradicionales de la izquierda, así como la caracterización del gobierno progresista de la DC como un rotundo fracaso.

Queremos ser claros (...) no habrá unidad popular en contra de los partidos políticos de la izquierda, construirla exige desterrar el sectarismo y un total respeto por el pluralismo de ideas y creencias. La unidad es la condición para hacer la revolución en Chile y construir una sociedad socialista y comunitaria (...). Arrate y Rojas, 2003, tomo I, p.441).

En agosto, la asamblea constituyente elige finalmente a Jacques Chonchol como Secretario General y a Jaime Gazmuri como subsecretario. En discordancia, Ambrosio se abstiene de integrar la dirección y postula la estrategia del "frente revolucionario" más cercano al PS de Altamirano. En su teoría, la vanguardia proletaria "nace de las entrañas de la lucha social y no del calentamiento electoral de los partidos". (Arrate y Rojas, 2003, tomo I, p.443). Igualmente, el MAPU se integra al proceso de conformación de la Unidad Popular. En este primer período, hasta noviembre de 1970, fue la etapa de elaboración y desarrollo de lo que denominaron "Frente Revolucionario", que al igual que los socialistas tenía una connotación clasista, es decir que estaría
} 
La formación del MAPU, como una “organización que desde el principio asumió una clara orientación socialista, significó que se terminaba el monopolio político del "cristianismo avanzado" por parte de la Democracia Cristiana”. (Moulián, 2006, p. 230). Implicó por otra parte, el desplazamiento hacia el campo socialista de sectores cristianos, lo que rompió con la idea del divorcio irreconciliable entre cristianismo y socialismo marxista. Tomás Moulián afirma que es el MAPU, el "primero de los partidos integrantes de la Unidad Popular que surgió con un discurso de ruptura con lo que se denominaba el reformismo.” (2006, p. 246).

Luego de la ruptura, "los terceristas" y Tomic permanecen en el Partido, a partir del acuerdo que se realiza en la Junta Nacional con el objetivo de buscar la "unidad social del pueblo". Pero la resolución aprobada, les permite ofrecerle a la izquierda un acuerdo en torno a la candidatura de la DC que es rechazado desde su origen. Pablo Neruda, recuerda que Tomic fue a verlo a su casa en Isla Negra. "El quería una alianza más amplia de las fuerzas progresistas (...) bajo el título de Unión del Pueblo. Tal propósito resultaba imposible; su participación en las negociaciones cupríferas inhabilitaba su candidatura en la izquierda política”. (2013, p. 467).

En agosto de 1969, entonces, la DC proclama oficialmente la candidatura de Radomiro Tomic a la Presidencia para las elecciones nacionales de 1970, confirmando una vez más, la tesis del camino propio. Aunque el mismo candidato, había sostenido que "no habrá candidatura Tomic sin unidad popular" (Arrate y Rojas, 2003, tomo I, p.444), acepta. La candidatura de Tomic, se visualiza como cercana a la UP, en tanto proclama la profundización de las reformas iniciadas en el gobierno anterior. En su programa: "Tarea del pueblo", da por agotado el sistema capitalista, y proclama la necesidad de una "revolución chilena, democrática y popular", para lo que sería clave la profundización de la participación popular. A su vez, postula la profundización de la reforma agraria y la reforma bancaria, así como la nacionalización total de las minas del cobre. De alguna manera, sus objetivos, dejaban entrever que las medidas implementadas por la "revolución en libertad" eran también para él insuficientes.

\footnotetext{
integrado por partidos y organizaciones exclusivamente obreras. La diferencia central, estaba dada por lo que consideraban sus organizaciones de base, dándole un rol preponderante a los movimientos sociales más que a los partidos políticos. Esto se debía, a que según esta concepción los partidos estaban "contaminados de tradicionalismo político, es decir, infectados por su participación y connivencia dentro del sistema democrático liberal”. (Moulián, 2006, p. 246).
} 


\subsubsection{Proceso de fundación de la Unidad Popular}

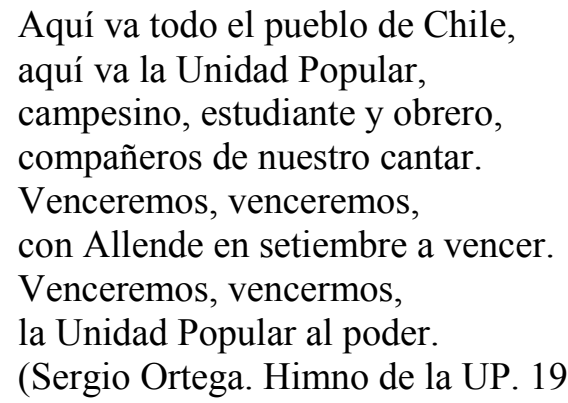

Aquí va todo el pueblo de Chile, aquí va la Unidad Popular, campesino, estudiante y obrero, compañeros de nuestro cantar.

Venceremos, venceremos, Venceremos, vencermos, la Unidad Popular al poder.

(Sergio Ortega. Himno de la UP. 1970)

Entre 1967 y 1970, la izquierda en general desarrollaría una gran capacidad para canalizar las demandas sociales no cumplidas por el gobierno demócrata cristiano, en un contexto de expansión de la politización y la organización de las masas populares, impulsadas incluso desde el propio gobierno.

En junio de 1967, la izquierda del Partido Radical, logra importantes avances con respecto a su política de alianzas con el $\mathrm{FRAP}^{341}$. En la transformación de su programa, se incluyen cambios profundos como la reforma agraria, la nacionalización del cobre y los grandes bancos. En la XXIV Convención Nacional, realizada en junio de 1969, afirman que "la unidad de las fuerzas y colectividades populares era el más idóneo instrumento político para construir la nueva sociedad y realizar, en consecuencia, el cambio social y económico"342. (Casals, 2010, p. 227). La institucionalidad, mientras ésta se mantuviese, sería el ámbito ideal para la concreción de los objetivos; en caso contrario, la "violencia creadora" sería la directriz oficial de toda la izquierda revolucionaria. Este giro de la política radical, fue rápidamente bien recibido tanto por el PCCh como por el MAPU.

El resultado de las elecciones parlamentarias de marzo de 1969, donde si bien los partidos del FRAP, obtienen avances en su caudal electoral, fue evaluado de manera disímil para la izquierda tradicional chilena. Mientras que el PCCh lo catalogó como un "triunfo", que consolidaba tanto la estrategia sistémica como la alianza con los socialistas; para el PS el

\footnotetext{
${ }^{341}$ Ya fines de 1966, un acuerdo entre el FRAP y el PR, habían permitido elegir a Salvador Allende como Presidente del Senado y al radical Luis Fernando Luego como vicepresidente. Es el primer antecedente de acuerdo, entre los socialistas y los radicales. El triunfo del ala izquierdista del PR, que aprobó la alianza en la UP, a su vez expulsó del partido a un numeroso grupo de sus antiguos dirigentes (entre los que se encontraba el ex candidato presidencial Julio Durán y tres diputados), que formaron el Partido Democracia Radical con un claro acercamiento hacia el Partido Nacional. En 1970, directamente apoyarán a Alessandri.

${ }^{342} \mathrm{Al}$ igual que en otros partidos, fue la Juventud quien encabeza el giro hacia la izquierda también del PR. No es menor señalar, que luego de esta Convención, pasaron a llamarse "Juventud Radical Revolucionaria". El cambio de nombre, significaba la consolidación de "una metodología, un compromiso y una acción dirigidas a propiciar un cambio revolucionario, profundo, e irreversible que destruya la sociedad capitalista actual y a todos sus sostenes." (Casals, 2010, p. 228).
} 
resultado confirmó que el país "desde un punto de vista electoral, no parecía tener posibilidad de una salida democrática y popular". (Casals, 2010, p. 216).

En junio de 1969, el PS realiza un pleno del Comité Central con el fin de analizar justamente el resultado electoral. En el mismo -luego de un acalorado debate- se oficializa la línea del "Frente Revolucionario", propuesta por Altamirano y el ala más a la izquierda del Partido. En su opinión, los grupos de izquierda que estuvieran a favor de un cambio real, debían integrar un amplio Frente Revolucionario, en el cual tendrían un lugar todos aquellos que desearan la liberación nacional, a fin de conquistar el poder e iniciar el camino hacia el socialismo. En la reunión se enfrentan directamente las posiciones de Altamirano por un lado, y Allende por otro, partidario nuevamente de una alianza más amplia y que finalmente resultó minoritaria. Coherentes con su línea política, advertían del peligro de la estrategia reformista de la vía pacífica, demasiado confiada en las posibilidades del camino electoral. Sin embargo, y más allá de estas declaraciones, la práctica política del PS fue en sintonía con la corriente minoritaria. Esto es, integrar la UP, en una alianza no clasista sino amplia, y con fuerzas marxistas y no marxistas. Julio César Jobet, plantea que el giro hacia la izquierda realizado por la dirigencia del PR y el quiebre por izquierda de la DC y la conformación del MAPU, favorecieron a que el PS aceptara sus incorporaciones a la alianza, fundamentalmente previendo el aislamiento político en caso de mantenerse intransigentes en su línea dura. Esto, de ninguna manera implicó, el silencio del ala izquierdista que continuaban planteando la necesidad de mantener sus objetivos revolucionarios, con los métodos necesarios para ello. (1987, p. 336)

Poco tiempo después, el clima de tensión continúo profundizándose, cuando en octubre siguiente, el general Roberto Viaux, encabece un motín en el Regimiento Tacna, conocido como "tacnazo"343. Finalmente la operación es desmantelada, Viaux fue pasado a retirado, y condenado solamente a trescientos días de cárcel, pena que se le conmutó por una suerte de libertad condicional. A partir de este episodio, el Gral. René Schneider fue nombrado comandante en jefe del Ejército.

\footnotetext{
${ }^{343}$ Lo interesante del episodio, es la reacción que provoca en las fuerzas de izquierda. Allende, y otros parlamentarios del FRAP se presentan inmediatamente en La Moneda, para mostrar su lealtad al Presidente. Actitud similar tuvo el PCCh que inmediatamente condenó el intento de sublevación militar. En cambio, en el PS, aunque la mayoría de la dirección condenó la postura, hubo algunos dirigentes simpatizantes con los sublevados. Carlos Lazo, lo confirma al señalar el Partido Socialista "tuvo el pecado de tentarse algunas veces con los golpes militares o la invocación a la vía armada, en la ingenua creencia de que ello podría favorecer la ascensión de la izquierda al poder". (Arrate y Rojas, 2003, tomo I, p.448).
} 
Finalmente, luego de un llamado encabezado por socialistas y comunistas, el 9 octubre de 1969, en la antesala del Salón de Honor del Congreso Nacional y luego de profundas tratativas en la interna de cada uno de los partidos se funda la Unidad Popular, que suma al FRAP a radicales, al MAPU y la Acción Popular Independiente (API) ${ }^{344}$. Se constituyó un comité coordinador integrado por dos representantes de cada partido ${ }^{345}$. Las dos líneas que venían expresándose ya en la interna del FRAP, se continúan en este período, y la discusión se mantiene en los dos principales puntos de debate: la amplitud de la alianza y el carácter del programa (grado de avance de las medidas que llevarían al socialismo).

Mientras tanto el PCCh, realiza su XIV Congreso Nacional en noviembre, en el que reafirman la necesidad de ampliar la alianza. Bajo la consigna "Unidad Popular para un Gobierno Popular", el Congreso insistió en consolidar la nueva alianza recientemente creada, así como abrirla para atraer nuevos sectores que compartan sus postulados, con el fin de "abrir paso a la revolución chilena" (Pinto, 2005, p. 11). A diferencia de lo que había ocurrido con el FRAP, se debía avanzar y poder integrar a otras fuerzas sociales y políticas que le dieran un sólido sostén al futuro Gobierno Popular. El objetivo de crear la Unidad Popular era, siguiendo a los postulados del PCCh "alcanzar el poder en las siguientes elecciones y hacer la revolución". (Venegas, 2003, p. 47).

Claramente, la Unidad Popular, era la concreción de un deseo que los comunistas venían promoviendo por lo menos, desde mediados de la década del 50', fundamentalmente por la inclusión del Partido Radical y de sectores cristianos, representados por el MAPU.

Y también por las vías, la creación de la UP, implicaba para los comunistas la reafirmación de la vía pacífica ${ }^{346}$. En este sentido, fue el partido que menos conflictos internos tuvo, en relación a la defensa irrestricta de la vía chilena al socialismo. En ese mismo Congreso, se aprueba el Programa del Partido Comunista de Chile, que no difería del último aprobado en el X Congreso de 1956, que implicaba la necesidad de la implementación de la

\footnotetext{
${ }^{344}$ Agrupamiento de ex ibañistas cercanos a Allende y encabezados por Rafael Tarud.

345 Por los socialistas: Aniceto Rodríguez y Adonis Sepúlveda, por los comunistas: Luis Corvalán y Orlando Millas, por los radicales: Carlos Morales y Orlando Cantuarias, por el MAPU: Rafael Agustín Gumucio y Jaime Gazmuri, por los social-democrátas: Esteban Leyton y Juan Tuma y por la API: Alfonso David Lebón y Guillermo Ovalle.

${ }^{346}$ Pero además, seguían siendo fieles a lo promulgado por el PCUS. Según Alonso Daire la UP había llegado a ser la más alta expresión (histórica) del teórico "modelo Brezhnev" acerca de los regímenes de tipo frente de liberación nacional. Así lo señalaba el documento de la Conferencia de PC y obreros de 1969, (vía pacífica, programa de nacionalizaciones, gran aparato estatal, propiedad estatal). (1988, p. 221-222)
} 
etapa democrático-burguesa como transición hacia una sociedad socialista, y nuevamente la caracterización de la revolución como antiimperialista, antioligárquica y antifeudal ${ }^{347}$.

La UP comienza de inmediato la discusión sobre la propuesta de programa de gobierno y la designación del candidato. Con respecto al programa, este sintetizó de algún modo las contradicciones que se venían desarrollando en la izquierda, intentando satisfacer a todos los miembros de la alianza ${ }^{348}$. Tal como se señala, en el documento programático (aprobado el 17 de diciembre de 1969), la UP conforma su estrategia en lo que se conocerá como vía chilena al socialismo. Y sostiene la nacionalización del cobre, de los monopolios industriales estratégicos, del comercio exterior, bancos, seguros y grandes empresas en sectores claves de la economía, con el fin de constituir el "Área de Propiedad Social” que sería dirigida por el estado con participación de los trabajadores. Se propone además, una profundización de la reforma agraria, la reestructuración del poder legislativo a través de la creación de una única cámara denominada Asamblea Popular y un conjunto de medidas con el fin de mejorar la calidad de vida de los sectores populares.

Con respecto al candidato, las disputas no fueron menores. El PCCh, propone al escritor Pablo Neruda; el MAPU a Jacques Chonchol; el PR al senador Alberto Baltra; y la API a Rafael Tarud. El PS proclama Allende, luego de una insólita reunión de su Dirección Nacional en la cual la mayoría de sus miembros se abstiene, trece votos a favor y catorce abstenciones, entre quienes se encontraron Carlos Altamirano, Clodomiro Almeyda y Aniceto

\footnotetext{
${ }^{347}$ Las discusiones en torno a las medidas implementadas durante el gobierno de Allende, exceden a esta tesis. Sin embargo, no es menor señalar, que la diferenciación en la caracterización de la revolución entre socialistas y comunistas, serán en definitiva la base de los conflictos durante el gobierno. Entre el gradualismo comunista y el "avanzar sin transar" del socialismo, se encontraba una estrategia política y una caracterización de la etapa disímil, que influía directamente en las acciones de gobierno: medidas a tomar, ritmos, etc.

${ }^{348}$ El Programa fue construido en base a tres premisas básicas. La primera premisa, era un diagnostico de las dificultades sociales y la propuesta programática necesaria para solucionarlos. En este sentido, se afirmaba que Chile era un país capitalista, y que el capitalismo como sistema estaba atravesando una profunda crisis. $\mathrm{La}$ segunda premisa, consistía en una dura evaluación del gobierno de la Democracia Cristiana, caracterizándolo como un nuevo gobierno de la burguesía al servicio del capital nacional y extranjero y que por lo tanto, no habría logrado modificar ningún aspecto clave del país. La tercer premisa, fue la identificación del responsable de que el modelo social chileno fracasase, identificándolo con el imperialismo norteamericano. Basándose en estos postulados, el Programa afirmaba que era necesario un cambio radical y profundo de las estructuras del país, que implicaba la necesidad de la construcción del socialismo en Chile. (Casals, 2010, p. 243-245). La definición es lo suficientemente ambigua, como para saltear la histórica discusión socialista-comunista sobre las etapas de la revolución, que hemos desarrollado en los capítulos anteriores. Y que serán los generadores de conflicto, en el momento de llevar a la práctica los postulados del gobierno. Algo similar sucedió con respecto, a las vías para llevar adelante dichos postulados. Si bien el programa era electoral y por lo tanto, iba en sintonía con los defensores de la vía pacífica, se nombraron una serie de medidas (como la redacción de una nueva Constitución, la creación de la Asamblea del Pueblo en sustitución del Parlamento y la transformación del Poder Judicial) que fueron interpretadas de forma diferente por lo menos entre comunistas y socialistas.
} 
Rodríguez ${ }^{349}$. En este contexto, Allende renuncia a su candidatura, debido a las "lamentables dificultades" para llegar a un acuerdo.

Finalmente el PS, rechaza la renuncia de Allende y Alberto Baltra y Pablo Neruda declinan la suya para asegurar un acuerdo unitario. El 20 de enero, el MAPU emite una declaración en la que propone que el candidato provenga de los dos partidos más vinculados con la clase obrera. Finalmente el 22 de enero, Tarud declina su candidatura, por lo que luego de más de cuatro meses de negociaciones, Allende es proclamado candidato de la UP.

\subsubsection{Las elecciones de 1970 y el triunfo de Allende}

No será un gobierno comunista, ni socialista ni radical, será el gobierno de las fuerzas que componen la Unidad Popular, algo auténticamente chileno y de acuerdo a nuestra realidad nacional. (Salvador Allende. Conferencia de prensa. 4 de setiembre de 1970)

A partir de febrero de 1970, entonces, los partidos habían proclamado ya a sus candidatos: la DC iría con Tomic, el Partido Nacional con Jorge Alessandri y la -ahoraUnidad Popular nuevamente con Allende.

Al igual que en 1964, la derecha desarrolló otra "campaña del terror", con apoyo financiero de los Estados Unidos. Pero, la campaña de la UP fue distinta que la anterior, logrando esta vez una mayor movilización y organización de su estructura militante. Por otro lado, el apoyo del movimiento de muralistas (como las Brigadas Ramona Parra y Elmo Catalán), artistas, e integrantes de lo que se conoce como Nueva Canción Chilena, le impondrán a la campaña un aire de alegría, optimismo y festejo.

Una de las novedades de esta campaña, fue la creación de casi quince mil comités de la Unidad Popular, a lo largo de todo el país. Organismos unitarios, que le dieron un importante dinamismo al trabajo electoral. Lamentablemente, y a pesar de varias exhortaciones por mantenerlos, los comités desaparecerán luego del triunfo del 4 de setiembre. Tal como señala Winn, "sus oponentes podían controlar la prensa y los medios, pero lo partidarios de Allende dominaban las calles y los muros.” (2013, p. 45)

Las tensiones se agudizan en medio de la campaña electoral. En abril de 1970, el militante democratacristiano y jefe de la Corporación de Reforma Agraria de la provincia de

\footnotetext{
${ }^{349}$ Aniceto Rodríguez, era quién que competía a la interna del Partido para ser candidato a la Presidencia para las elecciones nacionales de 1970. Sostenía que las tres derrotas anteriores de Allende, no lo hacían ya un buen candidato. Sin embargo, con el argumento de no dividir al socialismo renuncia a su candidatura y se realiza la insólita votación mencionada. En realidad, en una recorrida por los 35 comités regionales del PS, el resultado era desastroso para Rodríguez (sólo dos lo apoyan), confirmando que la militancia apoyaba a Salvador Allende.
} 
Linares -Hernán Mery- es asesinado al tomar posesión legal -luego de la expropiación- de un fundo en Longaví. En mayo, es descubierta una actividad de entrenamiento militar, realizada por militantes socialistas en Chaihuín (cercano a Valdivia), y reprimida luego de un importante despliegue policial. Son detenidos varios militantes, todos socialistas, entre los que se encuentra Rigoberto Quezada, por ese entonces Presidente de la Federación de Estudiantes Secundarios. A partir de esto, Allende se reúne con la dirección clandestina de "Organa", con el fin de solicitarles que colaboren políticamente con la campaña (y persuadirlos de moderar sus prácticas) y prepare a sus cuadros para la defensa del futuro gobierno. En julio, la CUT llama a un paro general, como alerta sobre el peligro que puede correr el régimen democrático en este contexto. Aunque la movilización tiene un éxito relativo, en uno de los actos que se realizan, se produce un enfrentamiento con carabineros, donde muere un estudiante y hay varios heridos. Diagnosticando al país, como producto de una profunda crisis, las elecciones de 1970, representaron en si mismas "una coyuntura de decisiva relevancia, puesto que se constituyó en la arena de combate de distintas, opuestas y excluyentes concepciones políticosociales en pugna". (Casals, 2010, p. 252)

Para varios de los sectores de la izquierda, esta es quizás la última oportunidad brindada al camino electoral. Pero a medida que la campaña se desarrollaba, un ambiente de optimismo fue haciendo posible la creencia en el triunfo. Incluso el MIR, que en un comienzo llamó a abstenerse, luego de varias reuniones con Allende, acuerda suspender sus acciones armadas, colabora con el grupo de seguridad del candidato y llamó a sus militantes (aunque no de forma pública) a votar por la UP. Tal como señala Miguel Enríquez,

formulamos una política, que en general, consistió en no llamar masivamente a la abstención electoral, en no proponernos el sabotaje electoral y en no desarrollar nosotros actividad electoral propiamente tal, pero al mismo tiempo, reconocer, en el terreno electoral, a Allende la representación de los intereses de los trabajadores. (Amorós, 2015, p. 123-124).

Igualmente, el MIR no llamó públicamente a votar por la UP, como si lo había hecho la Vanguardia Revolucionaria Marxista- Rebelde en 1964. Max Marambio, también militante del MIR, señala con respecto a esta decisión, que "en la campaña de 1970, decidimos darle una oportunidad y dejarlo perder tranquilo.” (2009, p. 84) El diálogo entre Allende y el MIR, estaba dado, al punto tal que fueron fundamentalmente militantes miristas quienes se encargaron de la seguridad del Presidente, luego del triunfo del 4 de setiembre, en 
coordinación con el grupo de los "elenos" del $\mathrm{PS}^{350}$. Frente a las elecciones, la actitud pública fue de abstención, pero confirmando que en el caso de que la UP triunfara, el camino sería la preparación de "nuestros nacientes aparatos armados, nuestros cuadros y todo cuanto tenemos" para la defensa militar de lo conquistado ${ }^{351}$. (Casals, 2010, p. 260)

En medio de la campaña electoral, Allende y Tomic, se reúnen para un diálogo y suscriben un acuerdo: si cualquiera de ellos triunfa pero sin reunir la mayoría absoluta, el ganador recibirá el apoyo de su competidor en el Congreso para ser proclamado Presidente. El 4 de setiembre de 1970, Allende obtiene la primer mayoría relativa con el 36,3\%, Alessandri el $34,9 \%$ y Tomic el $27,8 \%$ de la votación. Es por este acuerdo que finalmente, Salvador Allende logra acceder a la presidencia, tras lograr el respaldo de la Democracia Cristiana en el Congreso Nacional ${ }^{352}$.

Las reacciones a la interna de la DC con disímiles. Mientras un sector de la Juventud, sale a las calles a festejar la victoria de Allende, el ala más conservadora negocia con la derecha un posible acuerdo con Alessandri. Juan Enrique Vera, dirigente regional de la JDC, fue a felicitar junto a otros compañeros al triunfador, bajo la consigna ¡Tomic presente, Allende presidente!. (Amorós, 2013, p. 272). Sumado a esto, Bernardo Leighton, declara en el Canal 9 esa misma noche, que le había impresionado contemplar a sus compañeros

\footnotetext{
${ }^{350}$ La "Organa", la fracción militar del PS, se unifica con el grupo denominado "los elenos", donde participan entre otros la hija del Presidente -Beatriz "Tati" Allende-. Desde el momento del ascenso al gobierno, tendrá una presencia significativa en la dirección del PS (fundamentalmente luego del congreso de La Serena de 1971), a la vez que serán quienes conformen el Grupo de Amigos del Presidente (GAP). De esta manera, se unen al conjunto mirista que había custodiado la seguridad del Presidente durante la campaña electoral. Entre noviembre de 1970 y setiembre de 1973, Beatriz Allende, fue el canal fundamental de comunicación entre Enríquez y el Presidente. Se conocían ya de su militancia estudiantil en la Universidad de Concepción, y la "Tati" tenía una afinidad política muy cercana al MIR. A lo largo del tiempo, y mientras se desarrolle el gobierno, los militantes miristas se irán retirando progresivamente de este grupo, por discrepancias con las políticas llevadas adelante. El acercamiento entre el MIR y Allende, implicó además que los primeros días de enero de 1971, los recibiera en su domicilio particular y le propusiera a Miguel Enríquez incorporarse a su gabinete como Ministro de Salud, ofrecimiento que éste rechazó. Por otro lado, el 4 de enero de 1971 -apenas dos meses después de asumir la Presidencia- el gobierno firmó el decreto 2.071, por el que indultó a 36 militantes del MIR y 7 de la Vanguardia Organizada del Pueblo. De esta manera, los principales líderes miristas pudieron abandonar la clandestinidad.

${ }^{351}$ Tres días antes de las elecciones, el $1^{\circ}$ de setiembre desde Punto Final, se afirmaba que

si el enfrentamiento se produce (...). Deberá empujarse a los obreros a intentar hacer producir las fábricas ocupadas, los campesinos hacer suyas las tierras ocupadas y si es posible también hacerlas producir, los sin casa conquistar sus terrenos, etc. Solo trabajadores ejerciendo sus derechos y el poder estarán dispuestos a jugarse por entero por la defensa del triunfo electoral. (Casals, 2010, p. 260).
}

Sin renunciar a la lucha armada, sí realizan un giro en su discursividad, dando lugar a la importancia de la movilización de masas, más que a la necesidad de "armar al pueblo". (Pinto, 2005, p. 23)

${ }^{352}$ Según la Constitución de 1925 -vigente en esos días- si un candidato no lograba la mayoría absoluta en la votación, el Congreso Pleno debía proclamar al vencedor entre las dos primeras mayorías. En este escenario, los votos de la DC serían los que definirían si la Presidencia de Chile se le entregaba a la izquierda o a la derecha. Como veremos, los días posteriores al 4 de setiembre, las negociaciones para los votos en el Congreso serán intensas. 
compartiendo la alegría del triunfo de la UP. La principal avenida de Santiago, se transforma en una fiesta, esperando las palabras del futuro Presidente.

Tomic reconoce la victoria de Allende, inmediatamente, siendo de hecho, el primero en hacerlo, al día siguiente de las elecciones. El 10 de setiembre, el Presidente del PDC Benjamín Prado- en cadena de radio y televisión señala que es necesario que Allende "de garantías a todos los chilenos de que en su gobierno permanecerán vigentes los valores fundamentales de una sociedad pluralista" (Arrate y Rojas, 2003, tomo I, p.466), para que la DC lo apoye en el Congreso. Una semana después, el nuevo presidente de la JDC -Luis Badilla-, se pronuncia formalmente por el apoyo a Allende. El 22, la directiva nacional del Partido aprueba un informe que presentará a la UP para su firma, el objetivo es que el "Estatuto de garantías democráticas" se incorpore a la Constitución. Sin embargo, el Ministro de Hacienda -Andrés Zaldívar- alerta por cadena nacional de una supuesta fragilidad financiera del país en este nuevo contexto, contribuyendo ampliamente con la sensación de caos provocada por los sectores más conservadores. En la reunión de la Junta Nacional de la DC, se presentan entonces nuevamente dos caminos: el del sector progresista, que propone apoyar a Allende y la aprobación del Estatuto, encabezada por Tomic, Fuentealba, Leighton, Badilla y los ex ministros Gabriel Valdés, Gustavo Lagos y Máximo Pacheco, entre otros; y el ala más conservadora que propone que el Estatuto sea redactado sólo por la DC, sin acuerdo con la UP (Allende recibiría los votos en el Congreso si aprueba sin modificaciones la propuesta de Estatuto de la DC), encabezado por Juan de Dios Carmona y apoyado por Patricio Aylwin, y los ex ministros Andrés Zaldívar, Patricio Rojas y Carlos Figueroa, entre otros. Finalmente es aprobado el acuerdo con la UP.

El PCCh, confirma la legitimidad democrática de la UP y acuerda la búsqueda de acercamientos con la DC. Dentro de esta tesis, se encuentra también el MAPU, que se manifestará a favor del acuerdo con los sectores democráticos del país. El PS, también será fiel con sus postulados de la época y rechazará cualquier posible acuerdo con la DC, ya que este implicaba mantener el orden social establecido. Solo la movilización de masas, será la garante de que el candidato triunfador sea proclamado y pueda cumplir con su programa. Finalmente, luego de una serie de tensas negociaciones, el PS cede y la UP aprueba el acuerdo con la DC.

Igualmente, en el período que va desde el triunfo electoral hasta su asunción como presidente dos meses después, marcará la tónica de los obstáculos del gobierno y de la 
reacción de la derecha ${ }^{353}$. El 22 de octubre, un grupo de extrema derecha intenta secuestrar al Comandante en Jefe del Ejército, Gral. René Schneider, con el fin de provocar un golpe de Estado. Schneider se resiste y es asesinado. En sus funerales, Allende confirma que su sucesor será el Gral. Carlos Prats.

Dos días después, Salvador Allende es proclamado Presidente. Tal como señalan Arrate y Rojas, "accede al poder del estado una coalición y un mandatario marxistas que aseguran categóricamente que la revolución socialista se hará respetando los mecanismos democráticos e institucionales." (Arrate y Rojas, 2003, tomo I, p.470). De los parlamentarios con derecho a voto, 153 votaron por Allende, 35 por Alessandri y 7 lo hicieron en blanco. Ningún democratacristiano rompió el mandato del voto.

El 4 de noviembre de 1970, entonces, Allende asumirá la Presidencia dando comienzo a lo que se conocerá como vía chilena al socialismo ${ }^{354}$. En un Estadio Nacional repleto, por

\footnotetext{
${ }^{353}$ Ya desde el día siguiente a las elecciones, hay conversaciones entre un sector de la DC y la derecha con el fin de impedir la proclamación de Allende en el Congreso. Se le ofrece a Frei, por ejemplo, que si la DC vota por Alessandri, este asumiría, renunciaría y en una segunda elección la derecha votaría por Frei para consagrarlo Presidente. El domingo 6, Enrique Ortúzar (un importante dirigente del comando de Alessandri), convoca a los medios de comunicación para informarles que negarían el derecho a Allende a ser considerado Presidente electo y convocaban al PDC a votar por su candidato, para "salvar a Chile del marxismo". En este contexto, el 13 de setiembre se organizó el Movimiento Patria y Libertad, una organización de extrema derecha cuyo primer objetivo era mostrar la inviabilidad de un futuro gobierno de Allende. Convoca a una masiva concentración "antimarxista", se producen atentados en dos supermercados y en las torres de alta tensión con el fin de dejar sin energía eléctrica a algunos sectores de Santiago. Tal como fue reconocido en el Informe Church del Senado norteamericano, la CIA realiza una amplia campaña con el fin de evitar el triunfo de Allende, entre lo que se encuentra el intento de soborno de algunos parlamentarios para evitar su apoyo en el Congreso chileno, hasta la promoción de una golpe de Estado. Agustín Edwards (dueño entre otras cosas del poderoso diario El Mercurio), viajó directamente a Washington para solicitar al gobierno de Nixon que resolviera directamente el asunto. El 15 logra reunirse con Kissinger en la Casa Blanca, y horas más tarde con el director de la CIA, Richard Helms. Luego de eso, es la reunión de ambos (Kissinger y Helms) con Nixon, donde este ordena "salvar a Chile". A partir de allí, se puso en marcha el "Plan Fubelt", consistente en un conjunto de acciones encubiertas para enturbiar el clima, y secuestrar al comandante en jefe del Ejército, Gral. Schneider. Según reveló, el Informe Church, entre el 5 y el 20 de octubre siguiente, la CIA en Santiago intentó comunicarse en más de veinte ocasiones con los altos mandos de las Fuerzas Armadas y Carabineros para promover un levantamiento. El papel del Gral. Schneider fue clave, en la defensa de la institucionalidad democrática del país, que finalmente paga con su vida.

${ }^{354}$ El término "vía chilena al socialismo", había sido acuñado por Salvador Allende a lo largo de la década del 60 ', establecido como un proceso revolucionario que se desencadenaría luego de que una amplia alianza de sectores de izquierda accediera al gobierno (articulada en torno a socialistas y comunistas, pero no excluyente), que contara con el respaldo de organizaciones obreras, campesinas y de pobladores, así como colectivos de intelectuales. A partir de allí, comenzaría un proceso de transición del capitalismo dependiente al socialismo, que implicaría: el relevo en el poder de la oligarquía por el pueblo, el desplazamiento de la hegemonía de la burguesía por la clase trabajadora, la construcción de un nuevo modelo económico, pero a través de una vía pacífica y respetando la legalidad vigente, las prácticas democráticas, el pluralismo político y las libertades ciudadanas (Riquelme, 2009, p. 81). No podemos dejar de señalar, que cumplieron un papel clave en dicha formulación teórica los escritos de Joan Garcés, cientista político catalán, muy cercano al entorno del Presidente. En palabras del propio Allende,
}

aspiramos a encontrar soluciones a los problemas chilenos basadas en la realidad socio económica y política chilena, según nuestras tradiciones y particularidades (...). Nosotros no tenemos la intención de exportar nuestras ideas y nuestros métodos. Solo hemos demostrado, que en las condiciones reales de un país como Chile, la vía electoral y pacífica es perfectamente válida para que el pueblo llegue al poder. Ahora tenemos que demostrar que en estas condiciones es posible adoptar medidas 
decenas de miles de personas, pronunció su primer discurso como Presidente de Chile, haciendo un llamado a los miles de invitados internacionales que lo escuchaban allí:

digan que aquí la Historia experimenta un nuevo giro. Que aquí un pueblo entero alcanzó a tomar en sus manos la dirección de su destino para caminar por la vía democrática hacia el socialismo. Este Chile que empieza a renovarse, este Chile en primavera y en fiesta siente, como una de sus aspiraciones más hondas, el deseo de que cada hombre del mundo sienta en nosotros a su hermano. (Allende, 1973, p. 30).

\subsection{El avance del autoritarismo en Uruguay y la recepción de los sucesos chilenos (1968- 1970)}

El 23 de junio de 1968 -a sólo diez días de la instalación de las Medidas Prontas de Seguridad-, Juan Pablo Terra, realizó públicamente un llamado por radio y televisión, con dos propuestas políticas determinantes: la convocatoria a elecciones anticipadas, y a la conformación de un frente de partidos y sectores de oposición a la política autoritaria del gobierno. Igualmente, en este primer momento, ninguna de las dos propuestas llegó a concretarse, aunque la misma fue relanzada en varias oportunidades durante este período.

Jorge Rodríguez, señala que en este "contexto cuando Juan Pablo habla, en Chile todavía era posible un acuerdo de la Democracia Cristiana y la izquierda chilena". De hecho, es casi simultáneamente que Ambrosio deja su cargo en la JDC y comienza a plantear la necesidad de la unidad de las izquierdas. Héctor Lescano afirma, que Rodrigo Ambrosio era "sin duda un referente para todos nosotros. (...). Había vínculos estrechos, digamos, con los jóvenes democratacristianos especialmente con la línea más disidente (...)"

El PDC uruguayo, se encontraba en su mayoría alineado con la política tomicista de Unidad social del Pueblo e incluso, mantuvo contactos cercanos con aquellos militantes de la JDC que se habían ido hacia el MAPU y luego hacia la Izquierda Cristiana ${ }^{355}$.

En 1969 y 1970, desde las páginas de Flecha -el semanario editado oficialmente por el PDC- se mantuvo un profundo contacto con las desavenencias que se venían produciendo en

que representen un camino hacia el socialismo, manteniéndonos en la estrecha cornisa de la democracia representativa y con pleno respeto a las libertades públicas. (Amorós, 2013, p. 303).

El documento clave, donde el Presidente deja en claro, su camino de estrategia política es el Mensaje Anual al Pleno del Congreso del 21 de mayo de 1971.

${ }^{355}$ La Izquierda Cristiana (IC) fue fundada en octubre de 1971, cuando varios miembros del sector "tercerista" rompen finalmente con el partido, y apoyan el gobierno de Allende. La IC se incorpora rápidamente a la Unidad Popular. No es menor señalar, que si bien la mayoría respaldaban las opciones estratégicas de Tomic, éste permanecerá en el PDC. 
su par chileno, (fundamentalmente a partir del quiebre del MAPU y del lanzamiento de la candidatura presidencial de Radomiro Tomic), así como los principales acontecimientos de los últimos años del gobierno de Eduardo Frei Montalva y luego del triunfo de la UP con las conversaciones entre dicho sector y la DC para lograr su apoyo en el Congreso Nacional ${ }^{356}$.

En setiembre de 1969, recién lanzada la candidatura de Tomic, el PDC uruguayo daba a conocer su propuesta política y la herramienta que desde Chile se consideraba la más adecuada para llevarla adelante. Así, se afirmaba que

el instrumento más adecuado para realizar en Chile una revolución popular y democrática, [implicaba] el acuerdo de la Democracia Cristiana con las fuerzas sociales y las fuerzas políticas comprometidas en la sustitución del régimen capitalista, podría permitir cumplir lo esencial de esa muy difícil tarea revolucionaria. En otras palabras, la Unidad Popular $(\ldots)^{357}$.

Entre diciembre de 1969 y enero de 1970, el PDC y el PCU mantuvieron un duro enfrentamiento periodístico, desde Flecha y El Popular, respectivamente. La discordia surgió cuando el 12 de diciembre, Terra manifestó que no estaba dispuesto a un acuerdo bilateral PDC-PCU, en el marco de las discusiones por la unidad de las izquierdas:

si usted ahora pregunta sobre un posible acuerdo bilateral entre el Partido Demócrata Cristiano y el Partido Comunista o el FIdeL por otro, le contesto: no es posible. Las diferencias son demasiado profundas para olvidarlas por una combinación oportunista que a nada llevaría. Esto no excluye que coincidamos en ciertos casos, por ejemplo al resistir la dictadura de la derecha, o al defender los sindicatos o los salarios. No somos frentistas de cualquier frente....

El argumento se basaba, en que una alianza exclusiva de comunistas y demócrata cristianos, no cambiaba el mapa electoral, e incluso podría perjudicar a cada grupo. "La posición es clara: se está dispuesto a integrar una gran fuerza popular, democrática, nacional, progresista", 358 .

En enero de 1970, lanzada ya la campaña de Tomic, el PDC uruguayo publica una larga entrevista en la que el candidato chileno da a conocer varias de sus propuestas así como la caracterización de la etapa política en la que el país se encontraba. Allí Tomic, señala que

\footnotetext{
${ }^{356}$ Por citar algunos ejemplos, en Flecha se puede ver: "Chile y la nacionalización de Anaconda", 08.08.1969; "Pauta chilena con alcance latinoamericano. Un estatuto para las inversiones extranjeras" 20.10.1969; "Tomic primero! Expulsan al que había falseado la encuesta", 17.08.1970; "Chile: un diálogo trascendente" 13.10.1970; "Triunfó Frei!" 27.10.1969; "Se definen las bases del programa democristiano trasandino mientras se alistan todos los candidatos" 20.04.1970; "PDC chileno: coincidencias y discrepancias con el gobierno" 25.06.1971; "En Chile la Democracia Cristiana mantiene posiciones". 30.04.1971.

${ }^{357}$ Flecha. "Radomiro Tomic es el candidato del PDC chileno. Buscará acelerar la revolución". 01.09.1969.

${ }^{358}$ Flecha. "Genio y figura". 22.12.1969.
} 
la revolución popular es anticapitalista y anti-imperialista. El factor dinámico por excelencia de la revolución chilena deben ser las capas profundas de la nación, las vastas mayorías nacionales oprimidas y alienadas por su orden social minoritario. En una palabra el pueblo. (...) La idea matriz de mi programa se expresa en dos palabras: participación popular. Participación popular en el poder político, en el orden social, en el poder económico y en las fuentes del poder cultural. Cuando sea el pueblo, y no determinadas minorías quien tenga el control y la participación dominante en estos cuatro centros decisivos de poder, se habrá hecho en Chile la revolución ${ }^{359}$.

El Partido Comunista, mantendrá durante todo este período, la insistencia hacia el camino unitario $^{360}$. Al día siguiente y en plena discusión sobre la elección del candidato a la Presidencia de la República en Chile, el PCU reafirma que si algo muestra la experiencia del país trasandino,

es que la unidad de las fuerzas de izquierda es capaz de abrir al pueblo una auténtica perspectiva de poder. Y los hechos muestran al Partido Comunista (...) como un combatiente sin tregua para plasmar esa unidad en todos los planos de la acción política ${ }^{361}$.

Pocos días después, agregan que la Unidad Popular, "abre una gran perspectiva al pueblo chileno, coloca en el orden del día el problema cardinal del poder, dinamizará su campaña electoral. Es un gran ejemplo del que debe aprender el pueblo uruguayo, sus partidos de izquierda, sus fuerzas populares" ${ }^{\prime 362}$.

La Comisión Nacional del PDC, el 22 de febrero siguiente, emite una declaración en la que reitera el llamado de 1968 a la conformación del frente opositor, mensaje que vuelve a proclamar el 28 de junio. Va a ser clave, en este período el rol jugado por la JDC a favor de la unidad. Dos documentos serán fundamentales en este período, Bases para una opción revolucionaria de 1969, y Frente Amplio para unir al pueblo, justamente de setiembre de 1970, mostraran que el camino de la unidad, es una clara posición estratégica del conjunto del

\footnotetext{
${ }^{359}$ Flecha. "La revolución popular es anticapitalista y anti-imperialista. Flecha entrevista a Radomiro Tomic: estamos ante una coyuntura excepcional para unir al pueblo chileno". 19.01.1970.

${ }^{360}$ Varias son las notas que desde El Popular y Estudios confirman este camino. Por citar algunos ejemplos, en El Popular: "Una idea que se abre paso, la unidad", 12.01.1970; "Nuestra fuerza y nuestra misión" 01.02.1970; "La imprescindible unidad", 02.02.1970; "La unidad, tarea madura", 12.02.1970; "El pueblo unido salvará al país", 11.08.1970; "La hora de la unidad", 24.08.1970; "También en el Uruguay se logrará la Unidad Popular", 12.09.1970; "Se aprobó llamado para Amplio Frente", 08.10.1970; "Vibrante llamado para un amplio frente de unidad", 09.10.1970;

${ }^{361}$ El Popular. "Unidad de izquierda". 20.01.1970.

${ }^{362}$ El Popular. "La candidatura de Unidad Popular en Chile". 25.01.1970.
} 
partido $^{363}$. Para este momento, se estaba consolidando ya lo que se conocerá como Grupo de los $\mathrm{Cinco}^{364}$, que era quienes intercambiaban sobre estos primeros acuerdos.

En abril de 1970, llegan a Santiago luego de un lamentable episodio en Quito algunos uruguayos democratacristianos que se encontraban en el Congreso de la JUDCA que se estaba realizando en dicha ciudad ${ }^{365}$. Lescano recuerda que llegan a Chile

a la campaña de Tomic y le acompañamos en varias cosas. Recuerdo como si fuera hoy, un acto en Rancagua, exclusivamente de mujeres y el hablándole a las mujeres (...). Sentimos siempre gran admiración por Radomiro Tomic y otros líderes Bernardo Leigthon, Renán Fuentealba (...).

Carlos Baráibar, recuerda que Radomiro Tomic, lo invita a incorporarse a su campaña electoral. Tal como él mismo señala,

yo compartía con él, pero no compartía que la Democracia Cristiana fuera compitiendo con la Unidad Popular (...). Yo le digo: Don Radomiro con el cariño que le tengo, quiero decirle que yo me regreso a mi país para formar la Unidad Popular en Uruguay, año 70'.

En julio, la Convención Nacional del Partido Demócrata Cristiano, había dejado en suspenso la proclamación de candidatos a la Presidencia para las elecciones de 1971, en virtud de la posibilidad de lograr un acuerdo amplio con otras fuerzas progresistas. Un mes después, desde las páginas de Marcha, Juan Pablo Terra, llamaba nuevamente a unirse contra el gobierno. A la semana siguiente, el PCU llamó a la formación de una alianza, que trascendiera el escenario electoral del año siguiente.

La campaña electoral de 1970, también fue seguida de cerca. Los comunistas uruguayos envían a Niko Schvarz -periodista y militante comunista-, para que desde Chile

\footnotetext{
${ }^{363}$ En dicho documento, se afirmaba esa es la tarea: conformar y organizar un gran frente de masas que a través de una auténtica unidad popular forje el instrumento de lucha necesario para tomar el poder, desplazando del mismo a las minorías privilegiadas y sustituyéndolas por las grandes mayorías populares del Uruguay. (JDC, 1970, p. 12.)

${ }^{364}$ Arismendi, Bonavita, Terra, Michelini y Rodríguez Camusso.

${ }^{365}$ El día 12 de abril de 1970, es asesinado en Quito el estudiante universitario Milton Reyes, Presidente de la Federación de Estudiantes Universitarios de Ecuador. Al día siguiente, el por entonces Presidente de Ecuador, Velazco Ibarra, invita a las delegaciones internacionales que se encontraban en el Congreso a un cocktail en la Casa Presidencial. Algunas de las delegaciones extranjeras, entre quienes se encontraban los uruguayos y los chilenos prefirieran realizar un homenaje al estudiante asesinado el día anterior. Ese desaire, provocó que por la noche, fuerzas policiales los retiraran del hotel dónde estaban hospedándose e incluso violando la inmunidad parlamentaria (varios de los chilenos eran diputados) los echaran del país y los trasladaran en un avión hasta Santiago de Chile.
} 
informe sobre los pasos de la campaña. Es llamativo, el relato sobre el importante acto realizado en agosto en la ciudad de Valparaíso. Allí Schvarz relata

el mitin comienza, son 5 en punto y las abigarradas columnas de los cerros que habíamos visitado en la mañana (...), toman ubicación detrás de seis cuadras de público apelmazado en la avenida principal. Un grito desde el micrófono, al que responde el coro multitudinario:

¿Somos o no somos? ¡SOMOS!,

¿Vamos o no vamos? ¡VAMOS!

¿Vemos o no vemos? ¡VEMOS!

Con Allende ¡venceremos! $!^{366}$

Este mismo cántico, será utilizado por Líber Seregni para los actos frenteamplistas, solamente cambiando el final: "con el Frente ¡venceremos!"367.

En ese mismo contexto, Rodney Arismendi es entrevistado por la Televisión chilena, nota en la que destaca

el enorme interés con que las fuerzas democráticas y avanzadas del Uruguay observaban el proceso chileno y la próxima elección del 4 de setiembre, subrayando la trascendencia de la unión del conjunto de las fuerzas populares y de izquierda, logro histórico de la clase obrera y el pueblo de Chile ${ }^{368}$.

El camino recorrido por el socialismo, fue un tanto más difuso. Entre 1967-1970, se mantuvo ilegalizado, y navegó - tal como señala Javier Gallardo- “entre las dos aguas de la vieja y la nueva izquierda" (1995, p. 108). En primer lugar, no haber logrado una banca en el Parlamento luego de las elecciones de 1966, impidió que este contara con ese terreno como tribuna de denuncia, a la vez que lo privó de ser parte de las acciones conjuntas que a nivel parlamentario se venían desarrollando. Si nos guiáramos únicamente por las páginas de Izquierda y El Oriental, los dos semanarios publicados durante la ilegalidad del partido, vemos claramente una centralidad por lo acontecido en Cuba, y por resaltar la figura y los aportes teóricos de Ernesto Guevara.

A comienzos del 70' mantenían la idea de la unidad, pero para la revolución, más que "un simple acuerdo para dos o tres leyes posibles que no abrirían camino hacia un cambio hondo, o para un plan destinado a quedar en las palabras, como lo dice la experiencia histórica

\footnotetext{
${ }^{366}$ El Popular. "El grandioso mitin de la Unidad Popular en Valparaíso". 31.08.1970.

${ }^{367}$ Según los entrevistados consultados, el cántico se utiliza desde 1971 y es común escucharlo aún en cualquier actividad del Frente Amplio. Lo que no pudimos ubicar, fue el punto de contacto directo entre este acto en Valparaíso y Líber Seregni o su comando de campaña.

${ }^{368}$ El Popular. "Arismendi en la TV chilena". 31.08.1970.
} 
frentista de algunos países"369 Al igual que su par chileno, confirmaban que el objetivo seguía siendo entonces, la unidad de acción para la revolución y la creación por lo tanto, de un Frente Revolucionario.

La no creencia en el tránsito pacífico no nos tiene que confundir frente a los acontecimientos reales, como ser el de las próximas elecciones. (...) Y nosotros, los que no ciframos mayores esperanzas en el parlamento y en los procesos electorales, nos preguntamos: ¿la cuestión consiste en irse para las casas a esperar que pase la tormenta electoral? ¿o tenemos que estar de alguna manera presentes en ese acto trascendente de la lucha de clases? No vacilamos en lo segundo, porque la agitación en el seno del proceso será el instrumento más educativo que podamos encontrar para la masa $(\ldots)^{370}$.

El mismo 4 de setiembre de 1970, la declaración de la Comisión Nacional del PDC, reiteraba

su disposición a transitar los caminos necesarios, para hacer realidad un amplio Frente Nacional Popular y Democrático abierto a grupos de todos los sectores sin excepciones, como alternativa de lucha y de poder para la transformación del país ${ }^{371}$.

Pocos días después del triunfo electoral de la UP, el PDC comienza una ronda de intercambios con todos los sectores políticos, incluido el FIdeL ${ }^{372}$. El mapa político había sido modificado y en esta ocasión "se trató con resultado auspicioso, las posibilidades de una acción de todas las fuerzas populares de oposición a la política del gobierno, tanto en lo inmediato como en los planos electoral y post-electoral". ${ }^{373}$ Dos días después, y manteniendo los mismos argumentos, El Popular titula "Como en Chile, la Unidad Popular para la Victoria" ${ }^{374}$. Arismendi argumentará luego de las primeras reuniones con el PDC, que

el triunfo de la unidad en las recientes elecciones chilenas, además, ha sido una contribución poderosa a esta corriente unitaria que crece en nuestro país, por la experiencia formidable que arroja y por el aliento que la victoria ha significado para todas las fuerzas anti-imperialistas del continente ${ }^{375}$.

\footnotetext{
${ }^{369}$ El Oriental. “Unidad, sí, para una auténtica revolución”. 16.01.1970.

${ }^{370}$ El Oriental. "Las tres tareas". 02.10.1970.

${ }^{371}$ Flecha. "Comisión Nacional, declaración". 13.10.1970.

372 En octubre de 1970, el PDC había mantenido reuniones con el Senador Vasconcellos, la Lista 99 de Michelini, el sector de Alba Roballo (del Partido Colorado), el FIdeL, el Partido Socialista, y el Movimiento Socialista y con el sector del Senador Rodríguez Camusso, y el Movimiento de Rocha (ambos del Partido Nacional), y personalmente con Líber Seregni y Carlos Quijano. (Ilha López, 2014, p. 13)

373 El Popular. "Hacia una amplia Unidad Popular. Auspiciosa reunión del Frente Izquierda y el PDC". 24.09.1970.

${ }^{374}$ El Popular. "Como en Chile, la Unidad Popular para la Victoria”. 26.09.1970.

${ }^{375}$ El Popular. "Una cuestión madura”. 26.09.1970.
} 


\subsection{1. “Había llegado la revolución": la recepción en Uruguay del triunfo de Allende}

(...) lo esencial de Chile, la gran experiencia a recoger es la unidad. También en el Uruguay sólo con el signo de la unidad el pueblo ha podido avanzar ¿y cómo no va a ser posible que ese pueblo encuentre como en Chile una expresión política unitaria? ¿cómo no buscar el camino que lo capacite para estar en condiciones de librar la batalla contra las clases dominantes encaramadas en el poder? ? $^{376}$

Mientras, aquí en el Uruguay, en el duro batallar de todos los días contra los mismos enemigos, la militancia revolucionaria redobla los esfuerzos para abrir caminos liberadores, los hermanos chilenos tienen la hermosa y grande responsabilidad de ser ejemplo para todos los oprimidos del mundo. (...). Para nosotros, marxistas (...): expropien a los expropiadores, liberen al hombre, construyan el socialismo. Estamos con ustedes ${ }^{377}$.

Los sucesos que dieron el triunfo de Salvador Allende, el 4 de setiembre de 1970, fueron seguidos de cerca por los sectores de la izquierda uruguaya. Con el fin de estar presentes, en el día de la elección viaja a Santiago, Luis Tourón -importante dirigente del PCU-, que además de reunirse con la dirección del Partido Comunista chileno, participa del Pleno de su Comité Central y de la imponente manifestación de la noche del triunfo. "Fue inmenso (...) inmensa multitud, con inmensa alegría, con formidable espíritu combativo",378

La noche del triunfo de Allende, el FIdeL realiza una concentración de festejo en su sede central. En ese mismo acto, Luis Pedro Bonavita, afirma que

lo que ya está demostrado en las elecciones presidenciales de Chile, es que la unidad de las fuerzas populares y progresistas es una alternativa de poder cierta. (...). La experiencia chilena, por otra parte, nos ratifica en el propósito de luchar hasta el fin por lograr nosotros también la unidad de las fuerzas progresistas alineadas en un gran Frente Político capaz de acceder al poder ${ }^{379}$.

Moriana Hernández, estuvo presente en dicho festejo, y afirma que ese día "había llegado la revolución y era más cerca que Cuba y no solo por geografía sino por historia política” Jorge Mazzarovich, recuerda que

la victoria de Allende fue un gran impulso al proceso de construcción de la unidad completa, si nosotros miramos que en el 70' es la victoria de Allende y que en febrero del $71^{\prime}$ se une y se constituye el Frente Amplio, alguna ligazón histórica de influencia positiva tiene que haber.

Y más adelante agrega,

\footnotetext{
${ }^{376}$ El Popular. “¿Puede el pueblo hallar la expresión unitaria? 11.09.1970

${ }^{377}$ El Oriental. “A la conquista del futuro”. 06.11.1970.

${ }^{378}$ El Popular. "Regresó de Chile Luis Tourón. Conmovido saludo de Allende al pueblo uruguayo". 18.09.1970.

${ }^{379}$ El Popular. "Luis Pedro Bonavita: Chile muestra que la Unidad Popular, es alternativa de poder". 05.09.1970.
} 
la noche de la victoria de Allende, se formó -en el Uruguay los democratacristianos tenían camisas naranjas, los socialistas verdes y los comunistas teníamos rojas, nos decían el semáforo con toda razón- entonces armamos con las camisas (...) sentados en el suelo de la explanada la UP, creo que también llegamos a formar el nombre de Allende. (...) Sentíamos la victoria como propia. ${ }^{380}$

Al día siguiente, convocan a un acto en la Explanada Municipal, con la oratoria de Bonavita, Arismendi y Aguirre González, todos ellos integrantes del FIdeL. Dando cuenta de esa importante manifestación, al día siguiente se afirmaba desde las páginas de El Popular,

que siente la victoria de la Unidad Popular como suya propia, ya que el triunfo de Allende que si es histórico para Chile, está destinado a tener inmensa repercusión internacional, como la mejor expresión de una América Latina, que ya no es simplemente el patio trasero del imperialismo yanqui (...). La principal lección a extraer, pues, es la necesidad de significar aquí también la unidad, que le dio la victoria al pueblo chileno $(\ldots)^{381}$.

Una semana después, el 11 de setiembre, realizarán un acto para analizar exclusivamente la victoria popular en Chile y el camino de la unidad en Uruguay. El Partido Comunista incluso, organizó una rifa para asistir a la asunción de Allende. El 8 de setiembre, se ofrecía "Viaje a Chile con El Popular, a festejar la victoria de la Unidad Popular. 2 pasajes en avión ida y vuelta. 10 días de estadía para dos personas" 382.

La gran enseñanza entonces del triunfo electoral de la UP, está marcado para los comunistas en lograr finalmente la unidad de los sectores de la izquierda uruguaya.

El día en que esa dispersión se supere, en que todos los sectores populares actúen como una sola fuerza para enfrentar a la derecha, al imperialismo y a la oligarquía, otro gallo cantará en nuestro país. Eso es (...), la médula y la sustancia del ejemplo chileno ${ }^{383}$.

Incluso la UJC, afirmará en el mismo momento que

los jóvenes uruguayos debemos tomar el ejemplo de la juventud chilena, unirnos en la izquierda, contribuir a forjar la unidad popular, la fuerza política que corona las luchas del

\footnotetext{
${ }^{380}$ Foto de tapa. Jorge, agrega casi al finalizar la entrevista, que muchos años después, el día que salió de la cárcel

demoré mucho en llegar a mi casa (...) porque en la puerta de casa había como una concentración que se produjo (...). Antes de subir a mi casa, una persona me abrazó, en el medio de la gente y con la cabeza gacha y me dijo: "un abrazo de Chile para vos". (...). Nunca supe quien era. (...) Para mí fue una cosa maravillosa.

${ }^{381}$ El Popular. "La victoria en Chile y el ejemplo de la unidad". 06.09.1970.

${ }^{382}$ El Popular. 08.09.1970.

${ }^{383}$ El Popular. "La gran lección”. 12.09.1970.
} 
movimiento de masas de la CNT, del estudiantado, etc., y abre una nueva realidad en el país ${ }^{384}$.

El 15 de setiembre, Niko Schvarz es recibido en un acto en el Palacio Sudamérica, con el fin de que exponga sobre el proceso electoral y el triunfo de la Unidad Popular ${ }^{385}$. El 3 de octubre el PCU, realizará un importante acto con motivo del 50 aniversario de su nacimiento, en el que participará una importante delegación chilena ${ }^{386}$. Allí Luis Corvalán reafirmaba la idea de que

si la experiencia chilena tiene algún valor, ésta radica en algo que todos los pueblos también saben por su propia experiencia, en que para abrirse paso hacia el porvenir es vital la lucha y la unidad de todas sus fuerzas, el entendimiento de todos los que quieren la transformación de la sociedad ${ }^{387}$.

Para dicha conmemoración, llega además de la mano de Luis Tourón, el saludo del futuro Presidente de Chile. En sus palabras, Allende exalta

la emoción de gratitud que ha embargado a Chile al comprobar la identificación genuina con sus anhelos testimoniada por el pueblo uruguayo a raíz de la lucha por la Presidencia de la República, librada entre nosotros y que condujo a que la Unidad Popular y su candidato triunfaran en la elección. $(\ldots)^{388}$.

El 5 de octubre, El Popular titulaba “¡Ahora le toca al Uruguay!”, y refirmaba una vez más que

la llave maestra para ir al encuentro de ese Uruguay del mañana es la unidad, porque como lo proclama la consigna venida desde atrás de la cordillera andina y que corrió de boca en boca en el mitin grandioso: ¡El pueblo unido jamás será vencido! ${ }^{389}$.

Para la asunción de Allende el 3 de noviembre, viajó una importante delegación de la izquierda uruguaya, integrada entre otros por el Presidente del FIdeL -Luis Pedro Bonavita- y la edila por el Departamento de Canelones -Dora Achenbach y el acto fue seguido por la

\footnotetext{
${ }^{384}$ El Popular. Separata de la UJC. "Unidad Popular también en el Uruguay”. 12.09.1970.

${ }^{385}$ El Popular. "Celebrando la victoria del pueblo chileno". 15.09.1970.

${ }^{386}$ El Popular. "Chile en el acto del 3 en el Palacio Peñarol: hablará Luis Corvalán sobre el triunfo de la Unidad Popular.” 18.09.1970.

${ }^{387}$ El Popular. "Luis Corvalán exaltó la victoria de la Unidad Popular en Chile”. 04.10.1970.

${ }^{388}$ El Popular. "Cálido saludo de Salvador Allende”. 04.10.1970.

${ }^{389}$ El Popular. “¡Ahora le toca al Uruguay!”. 05.10.1970.
} 
prensa partidaria minuto a minuto ${ }^{390}$. Rodney Arismendi, que compartió varios encuentros con Allende, antes y después de su asunción como Presidente de Chile, recuerda que "me invitó a la asunción del mando, después a comer con él, y se empeñó mucho en que le dejara una carta con mis opiniones sobre las posibilidades reales de llegar al socialismo por una vía no armada”. (Barros Lemez, 1987, p. 156)

Vivían Trías desde el Partido Socialista, también visita a Salvador Allende, inmediatamente luego del triunfo. Eduardo Aparicio, recuerda "perfectamente (...) como trasladó eso al Partido y a los jóvenes. Y eso tuvo una fuerza muy grande (...)”.

A la semana siguiente, los socialistas uruguayos asumían que

\begin{abstract}
los chilenos han roto las reglas del juego. (...). Los pueblos latinoamericanos asisten, jubilosos, al ejemplo de Chile. [Pero, reafirmando a su vez que] una cosa es el gobierno, otra el poder real y otra la revolución. Esto no lo ignoran los poderosos. Y tratan, desde ya de hacer todo el daño posible a Chile antes de que comience el gobierno popular (...). ¿Se permitirá a Allende realizar las hondas transformaciones que pasen el poder de manos de una minoría a brazos del pueblo chileno? Esta es la interrogante fundamental. ${ }^{391}$
\end{abstract}

El triunfo de la Unidad Popular aparecía entonces como una guía a tener en cuenta, pero no como un ejemplo a repetir sin matices. En primer lugar, es un modelo que no puede copiarse mecánicamente, por que las condiciones del autoritarismo en Uruguay, la ilegalidad de los partidos (insistencia que mantendrán durante todo el período), la censura a la prensa, etc., provoca un contexto distinto para la acción política. Pero además, también es necesario mirar -señalan- las dificultades por las que ha atravesado la izquierda uruguaya para poder trabajar en conjunto sobre la base de acuerdos mínimos.

¿Quita esto trascendencia en el Uruguay al triunfo popular de los chilenos? De ninguna manera. El tiene y tendrá una inmensa repercusión porque permite calibrar hasta qué punto la unidad sobre bases claras, forjadas en medio de una lucha ideológica muy clara y por momentos dura y áspera (...), es un instrumento decisivo para derrotar al enemigo oligárquico-imperialista ${ }^{392}$.

Una semana después reafirman que,

\footnotetext{
${ }^{390}$ El Popular, "Hoy asume Allende" [Tapa], 03.11.1970; "En medio de clamoroso entusiasmo el pueblo entró con Allende al Palacio de Gobierno", 04.11.1970; "El primer discurso de Allende como Presidente de Chile", 10.11 .1970

${ }^{391}$ El Oriental. "Chile: las raíces de la victoria" 11.09.1970.

${ }^{392}$ El Oriental. "El triunfo de la Unidad Popular en Chile y nuestra realidad". 11.09.1970
} 
no es la primera vez que los éxitos de otros se han utilizado como méritos propios para afirmar en el Uruguay conceptos tácticos que no funcionan. En el caso concreto de las elecciones chilenas, algunos han salido con celeridad a plantear que esos hechos corroboran sus tesis en el Uruguay (...) La historia hasta el presente, no aporta ningún caso en el cual las fuerzas revolucionarias hayan conquistado el poder y realizado una revolución por la vía electoral ${ }^{393}$.

\section{Eduardo Aparicio, sostiene que}

en la realidad chilena nos veíamos reflejados en la perspectiva de una lucha política, revolucionaria, por el socialismo, en términos de masas, donde se daban o se combinaban la utilización de todos los métodos de lucha, porque había métodos extra parlamentarios, ocupación de tierras, auto-organización, autodefensa, pero contrapuesta a la idea de la guerrilla foquista

Sin embargo, luego del triunfo y fundamentalmente de la asunción el 3 de noviembre, el discurso parece girar de la desconfianza a un apoyo claro al futuro gobierno. El vínculo entre ambos partidos socialistas, y el apoyo final al gobierno popular, provocan que también una importante delegación concurra a la ceremonia de toma de mando. Aniceto Rodríguez, envía una invitación personal para asistir a Oscar Maggiolo (Rector de la Universidad), Carlos Quijano (Director de Marcha) y José Díaz ${ }^{394}$. Éste último, se encontraba preso en Punta Carretas el 4 de setiembre de 1970. Antes de la asunción de Allende, sale en libertad definitiva, ya con la invitación personal del futuro presidente para acudir a la ceremonia. Recuerda:

Yo salí de la cárcel con la invitación de Allende, que eso capaz me facilitó que no me metieran en el CGIOR ${ }^{395}(\ldots)$. Allí fuimos con Trías y otra tropa de socialistas uruguayos y teníamos amigos y amigas en Chile, eran nuestro gran referente (...).

José Pereira recuerda que el día de la asunción de Allende, "los latas estábamos como enloquecidos. No era que lo viéramos como una cosa ajena. (..) Había sido un salto cualitativo y estoy seguro que sirvió mucho para dar el paso socialista-comunista". ${ }^{396}$ Luis Senatore en esta misma línea afirma,

\footnotetext{
${ }^{393}$ El Oriental. "El triunfo en Chile y nuestra unidad popular". 18.09.1970.

${ }^{394}$ Ministerio de Relaciones Exteriores de Chile. Archivo General Histórico. Embajada de Chile en Uruguay. Fondo Países. Año 1970. Embajada. Oficios Confidenciales y aerogramas. Aerograma Nro. 64.

${ }^{395}$ Centro General de Instrucción para Oficiales de Reserva (CGIOR). Muchas veces los detenidos eran liberados por orden del juez, y a la salida detenidos nuevamente por MPS y trasladados al CGIOR.

${ }^{396}$ José Pereira, ingresa a las filas del Partido Socialista en la Facultad de Medicina. Muy cercano a José Pedro Cardoso, participa de la fundación del Frente Amplio. Durante el gobierno de Tabaré Vázquez, desempeñó tareas en el Ministerio de Salud Pública. Permanece en el PS hasta nuestros días.
} 
que impactó mucho ver el proceso unitario como una cosa viviente y sobre todo que tenía chance de triunfo. (...) Sobre todo acá, creo que al Frente Amplio le fue un factor (...) de terrenalidad, es decir, cuidado es posible ganar y llegar al gobierno y gobernar. Se puede.

Y más adelante agrega, el triunfo de Allende,

no lo vivíamos como la noticia internacional, vos te dabas cuenta, que nos estábamos jugando mucho ahí de lo que pasaba en Chile. No era lo mismo las elecciones en el 71'con Allende presidente que $\sin (. ..) \mathrm{O}$ sea, que yo creo que eso fue un factor, fue un factor como de estimulo de que era posible proponerse un objetivo de esa forma ${ }^{397}$.

Carlos Pérez ${ }^{398}$, visualiza en el triunfo de Allende, un elemento que

influyó incluso, para el propio cambio del Partido (...). Dijimos bueno, si Allende puede ganar, si una organización de izquierda puede utilizar determinados resquicios que nos da la democracia capitalista, burguesa, o como quieran llamarle, para ganar el gobierno, se puede utilizar. Y eso fue lo que de alguna manera, fue llevando también a la conformación del Frente Amplio. Para decir, bueno igual que en Chile ganemos acá las elecciones. (...) sin duda la experiencia de Chile favoreció eso, fue un aliento para que los socialistas y los comunistas se juntaran en el Frente Amplio ${ }^{399}$.

Tres días después de la asunción de Allende, el 6 de noviembre de 1970, el Partido Socialista señalaba un cambio en el clima del país, "la preocupación por los temas de unidad, los frentes amplios, las elecciones, etc., están en el orden del día de la masa, de sus dirigentes, de los revolucionarios y de los oportunistas". Este cambio estaría dado no solamente por la proximidad de las elecciones en Uruguay y el movimiento interno de los partidos, por la elección de candidatos, etc., sino también por los acontecimientos internacionales de Bolivia, Perú y Chile. La participación electoral, estaría sustentada entonces en que "las elecciones han sido y siguen siendo un hecho importante para las masas." Y eso los lleva a definirse "claramente en cuanto a que las vanguardias deben estar inmersas en el proceso electoral. Estar para que el hecho se transforme no en un crédito al parlamentarismo sino en una experiencia útil para la masa”. En esta estrategia, definen las alianzas entre circunstanciales y consolidadas. Las consolidadas, serían las alianzas de clase, que en Uruguay se daría con los sectores más combativos de la CNT y que integrarían en un futuro el Frente Revolucionario a

\footnotetext{
${ }^{397}$ Luis Senatore se vincula al PS a fines de la década del $60^{\prime}$, en el movimiento estudiantil. Participa de la fundación del Frente Amplio y poco tiempo antes del golpe de Estado, en mayo de 1973 -junto con un importante grupo de la Juventud Socialista- se afilia al PCU.

${ }^{398}$ Carlos Pérez, llega a mediados de los años $60^{\prime}$ desde el departamento de Rivera a estudiar Derecho a Montevideo. Allí se vincula periféricamente al Movimiento de Liberación Nacional- Tupamaros. En 1968, estudiando Psicología en la entonces Facultad de Humanidades y Ciencias, se vincula a las Brigadas Universitarias Socialistas y comienza a militar directamente en el PS.

${ }^{399} \mathrm{El}$ Sol. Carlos Pérez. "El resultado de las elecciones en Chile". 09.10.1964.
} 
desarrollar. Los "frentes amplios", afirman, son procesos unitarios circunstanciales y pasajeros. "Si bien es cierto que pueden responder a ya conocidos planteos reformistas, cabe también la posibilidad de que sea una necesidad objetiva, para el avance de la masa". Este frente estaría integrado, por el PCU creando un "polo reformista", el PDC sumado al desgajamiento de los partidos tradicionales que formarían un "polo centrista", y de allí la importancia de la inclusión del PS, encargado de formar el "polo revolucionario" 400.

De hecho, en los meses previos a la constitución del Frente Amplio, el PS realiza un llamado a organizaciones políticas y militantes independientes con el fin de constituir una alianza, a la que denominan "Frente Socialista".

Para los democratacristianos, el recibimiento del triunfo de la Unidad Popular, tuvo claramente otras implicancias. Esperanzados en una posible victoria de Tomic, luego de realizadas las elecciones, y hasta la proclamación de Allende en el Congreso Nacional, comenzaron a llegar a Uruguay las evaluaciones sobre la derrota y el camino a seguir. En medio de estas discusiones, el 21 de setiembre, Flecha publica una nota en la que deja en claro, que el objetivo principal era la derrota de la derecha,

la UP obtuvo la mayoría relativa de los sufragios, triunfo que saludamos, a pesar de que sintamos que no haya sido para Tomic, porque significa por encima de todo la derrota de la derecha, la continuación del proceso revolucionario (...). Mal que le pese a la derecha, Allende será el nuevo Presidente de Chile, y puede estar muy seguro desde ya, en Chile, en el Uruguay y en toda América por los votos del PDC en el Congreso Pleno no le serán dados jamás a su candidato Alessandri. No porque lo impida la tradición, sino por la valla insalvable de la historia y del pueblo chileno que se han puesto en camino de hacer su revolución dándole la mayoría absoluta de los votos (64\%) al conjunto de las izquierdas constituido por la UP y el PDC ${ }^{401}$.

Es interesante señalar, este camino conjunto -más allá de las desavenencias electorales chilenas- que los democratacristianos uruguayos realizan de lo acontecido. Su clara integración a al colectivo de izquierda, marca la pauta de lo que sucederá en Uruguay poco tiempo después. El primer objetivo, claro -en Uruguay y en Chile- era la derrota de la derecha.

El 13 de octubre de 1970, ya en medio de las discusiones sobre la conformación del Frente Amplio, el PDC organiza una mesa para intercambiar sobre las enseñanzas del proceso político chileno luego del triunfo de Allende y también en medio de las conversaciones en el vecino país entre la UP y el PDC para el apoyo en la votación en el Congreso Nacional.

\footnotetext{
${ }^{400}$ El Oriental. "La Unidad y el Frente Amplio". 06.11.1970.

${ }^{401}$ Flecha. "Chile: la oligarquía otra vez derrotada" 21.09.1970.
} 
Dicha mesa, estuvo integrada por Carlos Monteagudo y Omar Cuadrado (Juventudes Socialistas), Ricardo Figueroa (Movimiento Poder Joven. Partido Nacional), León Lev (Unión de la Juventud Comunista), Eduardo Durquet (Lista 99), Jorge Zas (Lista 315), Abel Facal (Agrupación Pregón) y José Luis Veiga (Juventud Demócrata Cristiana). Desde Flecha, se dio cuenta de las principales intervenciones volcadas allí. José Luis Veiga, analizaba el triunfo de la UP como un camino hacia la izquierda que había iniciado Eduardo Frei en 1964:

el triunfo de la Unión Popular (sic) debe ser rastreado muy atrás, hasta 1964. Desde la asunción del poder de Frei, quien (...) preparó el terreno para la realidad de hoy, para esa unión de pueblo chileno. (...) Tanto es así que las elecciones pese a los juegos de la prensa grande, fueron entre dos fuerzas populares (PDC y Unión Popular) contra la derecha. En nuestro país, la represión ha logrado una unión de las fuerzas populares (...). La sola presencia de todos los sectores invitados esta noche, indica que desde 1967, hemos empezado a recorrer caminos de unidad $^{402}$.

Héctor Lescano afirma que,

alguna gente (...) tuvo mucho que ver con el impulso que el PDC uruguayo le dio al camino de formación del Frente Amplio, justamente a su regreso de Chile. Y advirtiendo una realidad, que no era de todos, pero compartida por muchos, de avanzar en alianzas, de no recorrer el camino solos como se planteaba en aquel momento, sino un camino de conformar alianzas poderosas, electorales, que convocaran a la realidad popular.

Igualmente, al igual que en Santiago, los jóvenes democratacristianos se unieron a los festejos por el triunfo de Allende. José Luis Veiga, recuerda que "podríamos querer que ganara Tomic, pero festejamos el triunfo de Allende. (...). Cuando la cuestión quedó entre Alessandri y Allende, quería que ganara Allende (...)”

${ }^{402}$ Flecha. "Chile: un programa revolucionario". 13.10.1970. 


\title{
5.3. Hermano no te vayas, ha nacido una esperanza ${ }^{403}$ : la fundación del Frente Amplio
}

\author{
Vamos subiendo la cuesta \\ que el tren que fue a Chile \\ va a parar en ésta ${ }^{404}$
}

El 3 y 4 de octubre, la Comisión Nacional del PDC, autoriza a la dirección del Partido ha mantener los contactos con los dirigentes de la Lista 99, y otros grupos políticos, para establecer un primer agrupamiento, con el fin de seguir las negociaciones hacia un frente más amplio. Este será el origen de lo que finalmente se concretará el 8 de enero de 1971, como Frente del Pueblo.

Tres días después, el 7 de octubre, un grupo de ciudadanos independientes ${ }^{405}$ realiza una declaración pública llamando a constituir un "acuerdo sin exclusiones", de todas las fuerzas opositoras al gobierno, "en vistas a establecer un programa destinado a superar la crisis estructural del país, restituirle su destino de nación independiente y reintegrar al pueblo la plenitud del ejercicio de las libertades individuales y sindicales". (Aguirre Bayley, 2005, p. 32). Lo interesante, de esta declaración -firmada un poco más de un mes del triunfo electoral de Salvador Allende- es la realización de importantes actividades, mesas redondas, etc., por el interior del país. Tal como señala, Carlos Zubillaga,

el llamamiento que el Comité hizo público el 7 de octubre y la prédica de sus integrantes a lo largo del país, constituyeron el catalizador de las inquietudes frentistas y concurrieron a viabilizar los movimientos políticos que diversos partidos y grupos venían desarrollando con el mismo fin. (1991, p. 78).

Como hemos señalado, estos primeros puntos de contacto, comienzan a realizarse en Uruguay simultáneamente que en Chile la UP y la DC, realizan conversaciones con el fin de lograr el apoyo de ésta en el Congreso Nacional para la proclamación de Salvador Allende. Esas negociaciones, fueron seguidas de cerca por el comunismo uruguayo ${ }^{406}$. Incluso en la separata de la UJC que se publicaba los viernes con El Popular, se difunde en este contexto,

\footnotetext{
${ }^{403}$ Uno de los slogans de campaña para las elecciones de 1971, como respuesta a los miles de uruguayos que ya desde este momento comenzaban a salir del país.

${ }^{404}$ Tomado de la obra presentada en el Teatro El Galpón Libertad, Libertad en el marco de la campaña electoral del Frente Amplio en 1971.

${ }^{405}$ Entre los firmantes estaban el Gral. Artuño Baliñas, Óscar Bruschera, Luis A. Viera, Héctor Rodríguez, Germán D’Elía, Julio Castro, Carlos Quijano, Eugenio Petit Muñoz, Reina Reyes, entre otros.

${ }^{406}$ Desde las páginas de El Popular, se da cuenta de ello: "Respuesta de Allende a la Democracia Cristiana" 01.10.1970; "Chile: numerosas consultas realizan dirigentes del PDC" 02.10.1970; "Corvalán: es inminente el acuerdo con el PDC" 03.10.1970; "Unidad Popular y PDC estudiarán estatuto jurídico constitucional" 03.10.1970; "Allende: el Consejo del PDC por sí" 04.10.1970; "Nombrarán comisión mixta U. Popular-PDC" 08.10.1970; "Chile: la DC votará por Allende". 09.10.1970.
} 
una entrevista al Presidente de la JDC de Chile, Luis Badilla ${ }^{407}$ y un saludo de la JDC uruguaya con motivo del aniversario del PCU, en el que éstos afirman "estamos seguros que nos encontramos en el camino de la unidad y la revolución, defendiendo los intereses del pueblo en contra de la oligarquía y el imperialismo" ${ }^{\text {408 }}$.

El 12 de noviembre de 1970, El Popular publica una larga entrevista a Aniceto Rodríguez, Secretario General del Partido Socialista de Chile, donde también se reafirma el papel determinante de la unidad de las fuerzas populares para el triunfo de Allende,

nosotros no pretendemos exportar la experiencia política chilena. Creemos que ninguna experiencia política o revolucionaria, se puede copiar mecánicamente. Cada país tiene sus caminos propios para llegar al socialismo. Sentada esa premisa pienso que es estimulante la experiencia chilena- para todas las corrientes revolucionarias, como lo fue la revolución cubana, en su caso y en su tiempo ${ }^{409}$.

Parecería que esta entrevista, podría haber funcionado de factor de convencimiento hacia el PS uruguayo, que si bien apoyaba al gobierno popular chileno, aún no había tomado una posición oficial sobre su integración al Frente Amplio.

El 24 de noviembre de 1970, Eduardo Cisternas, Encargado de Negocios de la Embajada de Chile en Uruguay, informa a su Canciller, que

se viene advirtiendo desde un tiempo a esta parte el surgimiento de un nuevo conglomerado político, con preponderancia izquierdista, que estaría alcanzando suficiente cuerpo en la opinión pública como para preocupar a los dos grandes partidos tradicionales (...). La cuestión da lugar a especulaciones, por momentos esperanzadas, de posibles combinaciones electorales y ello ha cobrado mayor consistencia luego del triunfo de la Unidad Popular en Chile ${ }^{410}$.

En los meses subsiguientes, hasta el 5 de febrero de 1971, la embajada seguirá de cerca los movimientos de cada uno de los sectores que finalmente conformarán el Frente Amplio, y de reuniones que el Encargado de Negocios mantiene con varios de los dirigentes involucrados, como Zelmar Michelini, Ariel Collazo o José Díaz ${ }^{411}$.

\footnotetext{
${ }^{407}$ El Popular. Separata de la UJC. "Reportaje al Presidente de la JDC de Chile". 09.10.1970.

${ }^{408}$ El Popular. Separata de la UJC "Saludo de la Juventud Demócrata Cristiana". 09.10.1970.

${ }^{409}$ El Popular. "Aniceto: recogemos el fruto de lo sembrado durante muchos años". 12.11.970.

${ }^{410}$ Ministerio de Relaciones Exteriores de Chile. Archivo General Histórico. Embajada de Chile en Uruguay. Fondo Países. Año 1970. Embajada. Oficios Confidenciales. Confidencial RIA 819/92.

${ }^{411}$ Puede verse Ministerio de Relaciones Exteriores de Chile. Archivo General Histórico. Embajada de Chile en Uruguay. Fondo Países. Año 1970. Embajada. Oficios Confidenciales. Confidencial RIA 861/100 y Confidencial RIA $877 / 102$.
} 
El 30 de noviembre, Juan Pablo Terra dejaba en claro que no se "trata de una unidad popular a la chilena ni de un frente de izquierda. Es un frente amplio en función de los objetivos primarios: derrotar a la dictadura y la oligarquía, concretar un nuevo camino de salida para el país." (Ilha López, 2014, p. 17)

El 14 de diciembre, el gobierno le restituye la legalidad de funcionamiento a los partidos que había ilegalizado en 1967. El histórico local del PS, "Casa del Pueblo" es reabierto los primeros días de enero de 1971, y en el acto se destacó la presencia del Gral. Arturo Baliñas y del Dr. Óscar Bruschera, ambos firmantes de la Declaración del 7 de octubre, así como de Claudio Vidal representante del PS chileno.

Al día siguiente, el PDC, el Movimiento Blanco Popular y Progresista y la lista 99, suscribieron la declaración conjunta "Por un frente sin exclusiones", en la que expresan

su deseo de constituir un frente político amplio sin exclusiones, integrado por todas aquellas fuerzas que actúen en función de un programa nacionalista, progresista, antioligárquico, antiimperialista y popular, así como su absoluta convicción de que tal frente debe tener un carácter esencialmente político y que por lo tanto las soluciones electorales sólo serán una consecuencia de esa fuerza política. (Zubillaga, 1991, p. 78).

El 18 de diciembre, se realiza el II Pleno Nacional del PS, que ya legal, había determinado "realizar todos los esfuerzos para la formación del Frente Amplio de Unidad Popular (en proceso de gestación)”. (Caetano y Neves, 2016, p. 142). Uno de los elementos claves, según su concepción, será el quiebre de los sectores provenientes de los partidos tradicionales e incluso del PDC, lo que brinda a la alianza uruguaya una amplitud inédita.

Afirmamos que nuestra participación en el F. Amplio, la concretamos movilizados y sin tregua, pues el desarrollo de la lucha de masas y la radicalización de los enfrentamientos a la dictadura en todos los planos, es una necesidad del proceso e insoslayable deber revolucionario. (...). Hoy, con más fuerza y dimensión debemos reafirmar la consigna socialista uruguaya de: Unidad y Lucha. Venceremos ${ }^{412}$.

Recordemos, que la estrategia de horadar el poder de los partidos tradicionales, apoyando el quiebre de sus sectores más progresistas y de esta manera lograr el apoyo obrero que en su mayoría veían como vinculados a estos partidos, era una estrategia de larga data en el PS uruguayo. José Díaz, recuerda que fue el PDC y particularmente Juan Pablo Terra, quienes se contactaron con el PS aún ilegal, con el fin de mantenerlos informados de cómo iban las conversaciones.

${ }^{412}$ El Oriental. "En el Frente Amplio: movilizados”, por José Díaz. 29.12.1970. 
Para el PDC era una condición de que en la unidad que se quería forjar estuvieran también los socialistas, porque evidentemente no querían formar una unidad en la que pudieran quedar enfrentados con el Partido Comunista; querían que la unidad fuera lo más amplia posible. (Ilha López, 2014, p. 26)

En este mismo momento, el PDC realiza un importante acto en el Estadio Platense, como culminación de su Convención Nacional, en la que participa Radomiro Tomic. El 22 de diciembre, Eduardo Cisternas informa de su visita a Uruguay, respondiendo a una "invitación de la Democracia Cristiana uruguaya al Congreso de ese partido, que en esa oportunidad decidía su incorporación al Frente Amplio. (...)"413

Flecha, señala al respecto que

Tomic es un entrañable amigo del Uruguay, (...) Cuando en mayo de 1969, en el seno de su Partido se planteó la discusión sobre la forma de encarar la cuestión presidencial, Tomic defendió la idea de la unión de todas las fuerzas populares como medio de que fuera todo el pueblo el que venciera la resistencia de la derecha y todo el pueblo el que realizara la labor creadora de una nueva sociedad. En otras palabras, una concepción similar a la del Frente Amplio. ${ }^{414}$

Carlos Baráibar, recuerda que a Tomic "se le invitó en el marco de venir a explicar, digamos, el proceso (...) y a defender la tesis de la unidad popular” En ese contexto, la Junta Nacional del PDC emite una carta dirigida a sus militantes, en el que detallan las distintas instancias desarrolladas tendientes a la formación del Frente Amplio. Allí, explicitan esta necesidad de crear un eje no marxista, clave en el camino de ese frente más amplio. (Citado por Ilha López, 2014, p. 54)

Héctor Lescano, afirma que para el PDC

se trataba de hacer algo muy distinto de la Unidad Popular, porque la Unidad Popular era (...) un gran bloque marxista (...), que no era posible en el Uruguay. (...). Esa idea de amplitud de la nueva alianza, esa idea de ampliar cierta predominancia de partidos marxistas o exclusividad como en el caso de Chile, era un elemento absolutamente fundamental.

José Luis Veiga, también desde la JDC, ratificará esta visión,

Frente Amplio fue la exigencia, y que nos costó mucho del Partido Demócrata Cristiano. (...) Esto era si había sectores importantes, sectores significativos de los partidos

\footnotetext{
${ }^{413}$ Ministerio de Relaciones Exteriores de Chile. Archivo General Histórico. Embajada de Chile en Uruguay. Fondo Países. Año 1970. Embajada. Oficios Confidenciales y aerogramas. Confidencial RIA 874/550.

${ }^{414}$ Flecha. "El PDC chileno hermanado con el uruguayo. Tomic presente". 17.12.1970.
} 
tradicionales que también ingresaban al proyecto y además si los sectores marxistas con los cuales nosotros no teníamos ningún problema en hacer la coalición (...), tuvieran un papel pero no fuera el papel determinante. No jugáramos todos para el crecimiento del Partido Comunista, no.

\section{Jorge Rodríguez, afirma que explícitamente Juan Pablo Terra}

y con el acuerdo claro de Seregni, claramente se opuso a ponerle Unidad Popular al Frente (...). Se opuso y sentó la tesis de que el Frente Amplio en Uruguay podía ser si no se constituía en frente de izquierda, sino que era un Frente Amplio, por eso le puso amplio, donde podía haber blancos, colorados, la Democracia Cristiana, progresistas en general, es un concepto distinto (...). Esa creo que es la gran diferencia, el Frente Amplio tenía esa amplitud que no tenía la Unidad Popular.

El Partido Comunista, realiza también en diciembre de 1970 su XX Congreso, en el que reafirma un camino que -como vimos- venía promoviendo desde mediados de la década del 50'. Para este Congreso, también contarán con participación chilena, será Volodia Teitelboim, quien reafirme la importancia del ingreso a una amplia alianza ${ }^{415}$. En el Informe de balance del Comité Central, pronunciado por Arismendi, se afirma "no estamos ante un simple frente electoral, sino a un agrupamiento del pueblo con vistas a transformaciones radicales". (Arismendi, 1999, p. 93).

El 23 de diciembre de 1970, el MLN-T emite un comunicado en el que afirma:

mantenemos nuestras diferencias de métodos con las organizaciones que forman el Frente y con la valoración táctica del evidente objetivo inmediato del mismo: las elecciones. Sin embargo, consideramos conveniente plantear nuestro apoyo al Frente Amplio (...) en el entendido de que su principal tarea debe ser la movilización de las masas trabajadoras, y que su labor dentro de las mismas no empieza, no termina con las elecciones. (Aguirre Bayley, 2005, p. 36).

Como vimos, una actitud bastante similar había resuelto el MIR, que si bien no apoyaron públicamente la candidatura de Allende, ni la apuesta por las elecciones como camino, también paralizaron durante la campaña las acciones armadas e invitaron a sus militantes a votar por la Unidad Popular. En el caso del MLN-T, el 6 de abril de 1971 -ya fundado el Frente Amplio-, crean el "Movimiento de Independientes 26 de Marzo"- con la cara visible de Mario Benedetti y Daniel Vidart, entre otros-, que aunque no presentó

\footnotetext{
415 Ministerio de Relaciones Exteriores de Chile. Archivo General Histórico. Embajada de Chile en Uruguay. Fondo Países. Año 1970. Embajada. Oficios Confidenciales y aerogramas. Confidencial RIA 882/556.
} 
candidatos electorales para los comicios de 1971, era una columna "legal" del MLN-T, que tampoco quería en definitiva quedarse por fuera de la alianza.

Tal como señalamos anteriormente, el 8 de enero de 1971, se formó el Frente del Pueblo, una primera alianza entre la Lista 99 de Michelini y el Partido Demócrata Cristiano, que finalmente convocó a todas las fuerzas políticas a la construcción de un Frente Amplio, que fuera algo más que un simple acuerdo electoral, y en el cuál cada sector integrante mantuviera su identidad. Para esa conformación, llamaban a una reunión a celebrarse el 5 de febrero siguiente, de la que nació la Declaración Constitutiva del Frente Amplio, aprobada por los dos grupos que hicieron el llamamiento, más el Movimiento Popular, Blanco y Progresista, el Frente Izquierda de Liberación, el Partido Comunista, el Partido Socialista, el Movimiento Socialista, el Movimiento Herrerista Lista 58 (escindido también del Partido Nacional), los Grupos de Acción Unificadora, el Partido Obrero Revolucionario (de orientación trotskista), el Movimiento Revolucionario Oriental y el grupo de independientes del llamado del 7 de octubre. El 17 de febrero, se aprobaron las Bases programáticas de la Unidad, el 16 de marzo el Reglamento de Organización, y el 25 de agosto las 30 Primeras Medidas de Gobierno.

El 10 de febrero, se sumó la Unión Popular de Enrique Erro, así como otros pequeños grupos provenientes de los partidos tradicionales. La Antesala del Senado del Palacio Legislativo ofició de salón de honor para la realización del acto fundador, cuya sesión fue presidida por el entonces Senador, Zelmar Michelini en nombre del Frente del Pueblo. Ese mismo día, por la tarde, se reunió por primera vez el Plenario Nacional del FA, en la sede del PDC, en donde se designó una Mesa Ejecutiva provisoria, integrada por diez miembros y cuya presidencia sería rotativa ${ }^{416}$. En marzo, se sumarían la Agrupación Batllista "Pregón" (liderada por la Dra. Alba Roballo ${ }^{417}$ ) y el Partido Revolucionario de los Trabajadores.

La candidatura a la Presidencia, estuvo a cargo del Gral. Líber Seregni (propuesta directamente por Zelmar Michelini), acompañado del Dr. Juan José Crottogini, ambas

\footnotetext{
${ }^{416}$ La Mesa la integraban: Zelmar Michelini (Lista 99), Francisco Rodríguez Camusso (Movimiento Blanco, Popular y Progresista), Luis Pedro Bonavita (FIdeL), Rodney Arismendi (PCU), Juan Pablo Terra (PDC), José Pedro Cardoso (PS), Eduardo Jaurena (Movimiento Socialista), Héctor Rodríguez (GAU), Jorge Durán Matos (Movimiento Herrerista- Lista 58), Gral. Arturo Baliñas alternándose con Oscar Bruschera (grupo de los independientes)

${ }^{417}$ Carlos Demasi, plantea que la incorporación de Alba Roballo fue decisiva, ya si permanecía dentro del Partido Colorado, podía nuclear a su alrededor a todas aquellas fuerzas batllistas que estaban potencialmente en posibilidad de incorporarse al Frente Amplio, pero de repente, dentro del Partido Colorado un referente tan fuerte como era la Dra. Roballo podía frustrar toda la operación. (Demasi, 2007, p. 7)
} 
propuestas unitarias y aprobadas por unanimidad. Los candidatos serían proclamados en el multitudinario acto del 26 de marzo de 1971. Allí, Seregni afirmó que el Frente Amplio es

el último y definitivo intento del Uruguay de buscar salidas legales, democráticas, pacíficas. Somos el Frente Amplio una afirmación pacífica, pero no nos dejaremos trampear nuestro destino. No queremos la violencia. (...) Nosotros sí queremos cambios radicales en la vida económica y social del país. Son los que no quieren cambiar las cosas, los agentes de la violencia y el desorden. (1971, p. 15).

Arismendi, realiza un interesante paralelismo entre este discurso de Seregni, y el realizado por Allende en su Primer Mensaje al Congreso en mayo de 1971. Tal como el mismo afirma,

pensamos que los planteamientos acerca de la violencia o no violencia en el proceso de la revolución, están señalados - con palabras parecidas a las de Allende (...)- en la formulación del Gral. Seregni (...), queremos el desarrollo pacífico del país, somos una fuerza de paz, pero no nos dejaremos trampear nuestro destino. (1999, p. 119).

El programa de gobierno, estaba encaminado a la reforma de la estructura social y económica, pero que no implicaban claramente una definición hacia el socialismo. Las treinta primeras medidas de gobierno, incluían: la redistribución de la riqueza en base al control de precios y salarios, una no muy definida reforma agraria, la nacionalización de la banca y sectores exportadores, una industrialización dirigida por el Estado, una mayor cobertura de beneficios sociales y una política exterior independiente. De la misma manera, se aseguraba el restablecimiento de derechos, libertades y garantías individuales, destacando el normal desarrollo de la democracia, en pluralidad de partidos políticos. Hay incluso, algunas coincidencias, o punto de encuentro entre el Programa de la Unidad Popular, que como vimos, había sido aprobado el 17 de diciembre de 1969 y las Primeras 30 medidas de gobierno, aprobadas por el Frente Amplio el 25 de agosto de 1971. Algunos de esos tópicos, son reivindicaciones claras de la izquierda de la época, como: el rechazo a las imposiciones del FMI, la reforma agraria, la nacionalización de la banca, entre otras.

Sin embargo, María Elena Martínez, militante del PDC reivindica que

el documento de formación del Frente Amplio, es un documento no ideológico, es un documento de plantear el país con la visión de que todos tienen derechos, que lo que hay que hacer es que todos puedan vivir bien, que puedan tener educación, que puedan tener salud, (...) no nada de eliminar la propiedad privada, todo eso acá no se habló nunca. Si en Chile (...). El Frente nuestro como más amplio. Tenía gente que nunca en la vida hubiera admitido la expropiación de tierras, la expropiación de inmuebles para vivir, no se les ocurrió cortar con los organismos internacionales, ni las relaciones con ningún país. 


\subsection{La campaña electoral de 1971 y los puntos de encuentro}

Es imposible reseñar aquí las numerosas actividades que se realizaron para la campaña electoral de 1971. Sí es interesante señalar, que tal como señala Gerardo Leibner,

el surgimiento del Frente Amplio en 1971, sus movilizaciones y campañas son muchas veces descritas como una verdadera sucesión entusiasta de actos multitudinarios, fiestas y éxitos. Así han quedado marcadas en la memoria de muchos de sus protagonistas y sin duda reflejan las esperanzas del surgimiento de una fuerza política que por primera vez unía electoralmente a quienes ya se habían unido en la lucha callejera. (2011, p. 591)

Sin embargo, la campaña electoral de 1971, fue también quizás una de las más violentas del siglo XX. Varios militantes de base del FA fueron detenidos y golpeados por la policía mientras realizaban tareas de propaganda de un partido absolutamente legal, varios locales fueron allanados con el pretexto de la lucha contra la subversión o buscando militantes tupamaros, allanamientos que en varios casos incluían destrucción del local o de los materiales que allí se encontraban. La campaña se realizó además, bajo el régimen de Medidas Prontas de Seguridad, y con la prensa de izquierda censurada y clausurada por largos períodos.

Nos centraremos en este apartado, a reseñar brevemente los contactos con militantes chilenos, o la toma de ciertos símbolos tomados de la campaña trasandina. Como hemos señalado ya, la participación de dirigentes chilenos en las diversas actividades de la misma, fue continua y en algunos casos clave, así como pudimos relevar algunas características propagandísticas de la campaña misma con vinculación a la campaña realizada por la UP chilena.

En abril de 1971, la JDC realiza su VI Congreso, en el que participa Pedro Felipe Ramírez, diputado y presidente de la JUDCA. En ese contexto, da su opinión sobre el proceso de unificación de la izquierda uruguaya, en la que afirma

me parece que el grave problema que tenía Uruguay era la existencia de una estructura política muy rígida, que ubicaba a los orientales exclusivamente ante la alternativa de tener que elegir entre dos partidos controlados por la burguesía. (...) ahora se produce en Uruguay una agrupación de las fuerzas sociales en un nuevo cuadro político, respondiendo mucho más a los intereses de clase, y en consecuencia con una posibilidad de dinamismo mucho mayor que el esquema anterior ${ }^{418}$.

\footnotetext{
${ }^{418}$ Flecha. "Ramírez: la libertad la defienden los pueblos" 23.04.1971.
} 
El 21 de mayo, el PDC chileno envía a su hermano uruguayo,

un voto de saludo y respaldo a la lucha que sostiene (...). Ella ha hecho posible la unificación de todos los sectores populares y progresistas en la organización del Frente Amplio, a través del cual el pueblo oriental lucha hoy para ganar el gobierno e iniciar desde allí las urgentes transformaciones económicas y sociales, que el país requiere para conquistar la libertad, la justicia, el bienestar y la independencia económica ${ }^{419}$.

En agosto nuevas declaraciones de Tomic en Flecha, siguen marcando el camino de su necesidad de vinculación con la izquierda y la tesis de la Unidad del Pueblo, "la respuesta adecuada para la DC no era entenderse con la Derecha para enfrentar a la Unidad Popular, en todos los sectores de la vida nacional, sino persistir en la búsqueda de la Unidad del Pueblo" ${ }^{420}$. Un mes después insistía que,

el pueblo y la juventud chilenos están a la izquierda. El cristianismo, sobre todo en América Latina, se desplaza más y más hacia la izquierda. No hay destino para la DC sino en la izquierda, en estrecha comunión con la realidad nacional, los intereses de nuestro pueblo y la sensibilidad de la juventud chilena ${ }^{421}$.

El Partido Comunista, organiza la Brigada Liber Arce, que intentaba emular los murales de la Brigada Ramona Parra del comunismo chileno. El 6 de febrero de 1971, en la Separata de la UJC publicada junto a El Popular, se da cuenta de una breve nota sobre las actividades de esta brigada. El periodista, pregunta explícitamente cuál es el común denominador entre ambas brigadas, a lo que los jóvenes uruguayos miembros de la misma responden: "si es necesario pintar en diez horas varias veces un mismo muro, lo haremos. Ese espíritu es el común denominador" ${ }^{422}$. Moriana Hernández, recuerda que "los chilenos tenían unas brigadas de propaganda extraordinarias, la Ramona Parra era impresionante. Y nosotros la copiamos al pie de la letra (...) hicimos una brigada de propaganda copiando la de los chilenos". Jorge Mazzarovich, sostiene que "la brigada Líber Arce se formó rumbo al 71', fue a Chile, no me acuerdo con motivo de que y ellos hicieron también unos muros con especial significado en pleno gobierno de Allende"

En mayo de 1971, al cumplirse el $15^{\circ}$ aniversario de la Revista Estudios, Arismendi pronunciará un discurso que será luego publicado bajo el título, La revolución uruguaya en la hora del Frente Amplio. Allí, se considera a la nueva coalición como el fruto de casi veinte

\footnotetext{
${ }^{419}$ Flecha. "Saludo del PDC de Chile al de Uruguay" 21.05.1971.

${ }^{420}$ Flecha. "Chile: la actitud de Tomic ante la actual situación del PDC". 27.08.1971.

${ }^{421}$ Flecha. "Habla Tomic: el cristianismo se desplaza más y más hacia la izquierda". 26.09.1971.

${ }^{422}$ El Popular. Separata de la UJC. "Brigada Líber Arce”. 06.02.1971.
} 
años de acumulación de fuerzas, que estaría claramente antecedida por la Convención Nacional de Trabajadores, pero también por el FIdeL. "Porque el Frente Amplio es, en sí mismo, no sólo un frente de partidos sino el caudal inmenso del pueblo puesto en movimiento". Y más adelante, agrega

el nacimiento y las perspectivas del Frente, colocan entre nosotros en primer plano, (...) los problemas de forjar y desarrollar la unidad. Ser unitarios y mil veces unitarios. Unitarios, los primeros o los que más, porque queremos ampliar y extender el Frente, consolidarlo. Y no dejaremos que se introduzca la cizaña, la división y el menudo sectarismo (Arismendi, 1999, p. 118-124)

El caso del PS uruguayo, es aún más claro. Apenas comenzado el gobierno popular en Chile, el militante socialista uruguayo, Jorge Irisity $^{423}$ es invitado a integrarse al equipo económico del gobierno de Salvador Allende. Allí permanecerá hasta el golpe de Estado de 1973, aunque mantenga un permanente contacto con Uruguay ${ }^{424}$.

Además, una importante delegación del PS uruguayo, participa en el tenso congreso del PS chileno en La Serena, a fines de enero de 1971. José Díaz, afirmó allí que

sin duda, un largo empeño unitario ha dado el fruto de la conquista del gobierno y será instrumento de la efectiva conquista del poder y la construcción del socialismo (...). Y este avance del pueblo uruguayo está estrechamente unido con la victoria de la UP en Chile, con la lucha del Perú y Bolivia por su destino independiente, con la construcción del socialismo en $\mathrm{Cuba}^{425}$.

En abril, José Pedro Cardoso concurre al $38^{\circ}$ aniversario del PS chileno, donde además visita industrias nacionalizadas, asentamientos campesinos y poblaciones. Se reunirá con el Presidente Allende, y con la dirección del Partido Comunista y del MAPU. El 30 de abril, el PS chileno le realiza un homenaje en el Teatro Caupolicán, recibido personalmente por Allende es el único extranjero invitado.

En mayo de 1971, Vivían Trías realiza un larga visita a Chile, donde se reúne con el embajador de Cuba en dicho país, al cual entregó un informe sobre la situación uruguaya; con el Ministro de Relaciones Exteriores, Clodomiro Almeyda; y dictó una charla sobre Uruguay organizada por el Departamento de Relaciones Internacionales del PS chileno; también se reunió con numerosos uruguayos residentes en Santiago, así como con asesores del gobierno

\footnotetext{
423 Economista, ex funcionario de la OPP y funcionario de CEPAL. Sus contactos con Chile, fueron permanentes, en setiembre de 1968, por ejemplo fue detenido en el Aeropuerto Internacional de Carrasco, a su regreso de la ciudad de Santiago, por tener en su valija ejemplares de la Revista Punto Final, en la cual apareció "30 preguntas a un tupamaro".

${ }^{424}$ El Oriental. "Irisity a Chile" 22.01.1971.

${ }^{425}$ El Oriental. “Avanzando hacia el poder. $23^{\circ}$ Congreso del Partido Socialista chileno”. 05.02.1971.
} 
de Allende ${ }^{426}$. En junio es entrevistado largamente por el diario chileno Última Hora, y reproducido íntegramente por el semanario socialista uruguayo. En dicha entrevista, explicita que "gran importancia le atribuimos a la conformación de este frente, al triunfo en Chile de la Unidad Popular, que demostró en los hechos que se podía llegar al gobierno a través de la vía electoral" 427

Incluso, durante 1971, El Oriental publica en exclusiva y por partes, la larga entrevista que Regis Debray le realiza a Allende.

El Partido Socialista, realiza un importante acto de masas en julio de 1971, al que invitan a participar a Carlos Altamirano. Por dificultades personales, este no puede viajar pero envía en su directa representación a Edmundo Seriani. Varias son las actividades, además, que realiza el dirigente chileno, entre ellas su participación en diversos intercambios en el interior del país sobre el proceso de la UP y su llegada al gobierno. Preguntado sobre las similitudes entre la UP y el FA, el dirigente chileno responde:

pues yo creo que existe una similitud. Las dos fuerzas aglutinan a los sectores revolucionarios y progresistas que mantienen una posición, antimperialista, anticapitalista y antioligárquica. Pero entendemos también que el Frente Amplio no es una copia de la Unidad Popular, sino que es producto de razones propias de la situación uruguaya. Sobre este punto, quiero destacar además una creencia. Los revolucionarios no deben ceñirse a un solo método de lucha. Las diversas tácticas aplicadas deben estar de acuerdo con las particularidades de la época en que se vive. $(\ldots)^{428}$

A fines de octubre, Manuel Rodríguez -Secretario Gral. de las Juventudes Socialistas de Chile- llega a Montevideo, invitado por las Brigadas Juveniles Socialistas, con el fin de intercambiar sobre el acceso al gobierno de la UP y los primeros pasos del gobierno popular $^{429}$.

Dos días antes de las elecciones, Adonis Sepúlveda -Subsecretario Gral. del PS de Chile- envía una carta a José Díaz -Secretario Gral. del PS uruguayo-, manifestando

al partido hermano nuestros sinceros deseos de éxito en esta batalla, una más y de trascendental importancia, en el largo historial de lucha del pueblo oriental. (...) sea cual sea el resultado electoral, que anhelamos de todo corazón sea coronado por el triunfo, el pueblo uruguayo ya ha obtenido éxito de valor histórico: ha logrado unirse combatiendo y ha logrado también destruir la falsa omnipotencia de las fuerzas oligárquicas que pensaban seguir explotando al pueblo sin oposición (...). Cuenten como siempre con nuestra solidaridad militante, de la misma forma, en que hemos recibido de los socialistas

\footnotetext{
${ }^{426}$ El Oriental. "Vivian Trías en Chile" 14.05.1971.

${ }^{427}$ El Oriental. "El Frente Amplio vencerá a la derecha”, por Vivián Trías. 11.06.1971.

${ }^{428}$ El Oriental. "Edmundo Serani: no ceñirse a un solo método de lucha". 16.07.1971.

${ }^{429}$ El Oriental. "Manuel Rodríguez: paso a paso hacia el poder". 29.10.1971.
} 
uruguayos el apoyo decidido en nuestra común lucha contra el imperialismo y por la conquista del poder para construir el socialismo. (...). ¡Patria, revolución, socialismo! $(\ldots)^{430}$.

Guaraní Pereda, vivía en Chile y ya se había nacionalizado chileno, pero recuerda que pocos días antes de las elecciones "Jorge Irisity me dijo: vamos a Uruguay, y yo quería ir, así que fui y vote siendo chileno, porque tenía todavía la credencial cívica"

En este clima, de claro avance autoritario, el domingo 28 de noviembre se realizaron las elecciones nacionales. Al contexto de profunda tensión política interna, se le sumaban las versiones en torno a la "Operación 30 horas", una "eventual invasión brasileña en caso de triunfar la izquierda" ${ }^{431}$. (Nahum y otros, 1990, p. 75). Vania Markarián, afirma que

la embajada de Estados Unidos en Montevideo realizó varias recomendaciones para "disminuir la amenaza de que el Frente tome el poder político" y proporcionó al gobierno asistencia económica, policial y militar, así como estrategias para debilitar el movimiento obrero, hacer propaganda y lanzar campañas psicológicas ${ }^{432}$. $(2006$, p. 27)

Junto a la elección de las autoridades nacionales y departamentales, se consultaba sobre la reforma del artículo 125 de la Constitución, que implicaba la posibilidad de reelección inmediata del Presidente de la República. Finalmente la fórmula triunfante es la del Partido Colorado (que obtiene en total el $41 \%$ del electorado), y en su interior la dupla formada por Juan María Bordaberry- Jorge Sapelli, que obtiene el 22,8\% sobre el total de votantes $^{433}$. Le sigue el Partido Nacional (que obtiene el 40,2\%), y en su interior la fórmula encabezada por Wilson Ferreira Alduante (que obtiene el 26,5\% sobre el total de votantes) ${ }^{434}$.

\footnotetext{
${ }^{430}$ El Oriental. "Del PS chileno". 26.11.1971.

${ }^{431}$ Por más información ver: LEICHT, Federico (2013). Orden y progreso: el influjo de Brasil en el camino al golpe de Estado, Montevideo, Ediciones de La Plaza.

${ }^{432}$ Esto provocó a su vez, el trabajo conjunto entre los tupamaros y el FA, con el fin de realizar un plan militar con el fin de resistir un posible golpe destinado a impedir el acceso al gobierno de la nueva coalición en caso de ganar las elecciones. Como hemos señalado en capítulos anteriores, tanto los comunistas, como los socialistas y el MRO, contaban con aparatos armados, aunque con distintos grados de desarrollo. Miembros de estos grupos junto a algunos militares retirados y militantes tupamaros, unieron sus esfuerzos, para la planificación del denominado "plan contragolpe". (Aldrighi, 2001, p. 103)

${ }^{433}$ El Partido Colorado, había llevado cinco formulas presidenciales, encabezadas por Bordaberry (obtiene el $22,8 \%$ ), Jorge Batlle (14,6\%), Amilcar Vasconcellos (2,9\%) y dos más (Pintos y Ribas) que no llegan al $0.1 \%$ del total. La suma de todas las candidaturas bajo el lema Partido Colorado, lo define a este como ganador con el $41 \%$ del total de votantes.

${ }^{434}$ El Partido Nacional, denunció en los días siguientes, incluso antes de conocerse los resultados definitivos una serie de irregularidades que confirmarían un posible fraude electoral: sustracción de sobres y hojas de votación, puertas sin lacrar en los recintos donde se cuidaban las urnas, entre otras. El 2 de enero de 1972, Wilson Ferreira, denunció que existían más votos que votantes, y el Directorio del Partido Nacional pidió la anulación de los comicios. Finalmente, en febrero, la Corte Electoral proclamó oficialmente el triunfo de Bordaberry, a pesar de la gravedad de las denuncias.
} 
Y luego el Frente Amplio, con el 18,3\% del total ${ }^{435}$. La reforma que habilitaba la reelección de Jorge Pacheco, no obtuvo el mínimo exigido para su aprobación.

La izquierda entonces, lograba superar el histórico techo del 10\% ahora unida, lo que le permitió contar con cinco senadores y dieciocho diputados, representación parlamentaria inédita. Su electorado, fue mayormente urbano, superando el 30\% en Montevideo, siendo la segunda fuerza política de la capital, aunque no le alcanzó para cubrir las expectativas de poder acceder al gobierno departamental.

"Las reacciones de los dirigentes, militantes y partidarios del FA fueron ambiguas, principalmente porque la mayoría había sido optimista sobre el resultado electoral de la nueva coalición, con el ejemplo chileno en mente.” (Markarián, 2006, p. 31).

\subsubsection{El primer comité de base del Frente Amplio en el exterior}

Desde el punto de vista organizativo, el Frente Amplio se presentará electoralmente como una alianza de partidos, cuyos núcleos de base son los denominados "comité de base" integrados zonalmente por todas aquellas personas integrantes de la coalición. Su característica principal es que son unitarios y frenteamplistas, sin importar el sector político interno al que pertenezcan los integrantes. Es difícil registrar cuál fue el primer comité de base que se creó en este contexto. Los estudios existentes, dan cuenta de su nacimiento, en plena discusión sobre la fundación del Frente Amplio, incluso antes del 5 de febrero de 1971.

El primer comité de base instalado en el exterior, se organizó en la ciudad de Santiago de Chile, luego de realizadas las elecciones de 1971. Se fundó el 6 de julio de 1972, y si bien su nacimiento excede los límites temporales de esta tesis, no quisimos dejar de nombrar aunque sea en forma breve su existencia, ya que la misma es parte también del profundo vínculo que los uruguayos tenían con el país vecino ${ }^{436}$.

Estuvo integrado por representantes de casi todas las organizaciones que lo integraban en Uruguay, tanto el PDC, como el PCU (Carlos Wuhl y Eduardo Sanseviero), el PS (Jorge

\footnotetext{
${ }^{435}$ Los votos se subdividieron: $6 \%$ para el PCU, 4,3\% para Erro, 3,7\% para el PDC, $2,2 \%$ para el PS, y el 1,9\% para el sector de Michelini.

${ }^{436}$ Incluso desde antes del triunfo de Allende, la salida de militantes uruguayos (fundamentalmente tupamaros, pero no exclusivamente) hacia Chile fue masiva. Varios de ellos, salieron legalmente haciendo uso del Inciso 17, del art. 168 de la Constitución uruguaya que determina que los detenidos por MPS pueden cumplir su pena saliendo del país. Muchos otros salieron clandestinamente y encontrarán en Chile un lugar de refugio durante el avance del autoritarismo en Uruguay. Es una parte interesante del exilio uruguayo, que comienza varios años antes de la disolución de las cámaras y la instalación de la dictadura cívico-militar. Por más información, se puede ver: Aldrighi y Waksman (2015) y Alonso (2016).
} 
Irisity), la Lista 99 (Mario Jaurena), la Unión Popular (José Vera), el Movimiento de Independientes 26 de Marzo, los Grupos de Acción Unificadora (Ruben Svirsky) e incluso los frenteamplistas independientes (Guillermo Waksman), tuvieron representación en dicho comité.

La historiadora Clara Aldrighi, señala que si bien, varias de estas organizaciones no tenían casi militantes en Chile que el mismo representante en el comité, quienes participaron debieron acreditar su representación consultando a las autoridades de cada partido en Uruguay. Entre sus objetivos principales, estuvo la atención de los cientos de uruguayos que iban llegando producto del agravamiento de la política represiva en Uruguay, y la denuncia de lo que estaba sucediendo con las violaciones a los derechos humanos, pero también fue el punto de contacto con el gobierno de la Unidad Popular. De la misma manera, hasta setiembre de 1973, fue el nexo con los dirigentes de la izquierda uruguaya que visitaron la experiencia del gobierno de Allende. Por ejemplo: Zelmar Michelini visita Chile en enero 1973 y Líber Seregni en abril de ese mismo año, reuniéndose con Allende, pero también con Tomic y Bernando Leighton. Es interesante señalar, que desde la Embajada de Uruguay, "se hizo notar a la Cancillería, que Seregni (...) no había sido recibido por Eduardo Frei Montalva ni por el comité ejecutivo de la Democracia Cristiana”. (Aldrighi y Waksman, 2015, p. 106)

\subsection{Algunas apreciaciones finales}

La historiografía nacional, ha dedicado escasas investigaciones a la fundación del Frente Amplio. Incluso, la mayoría de las investigaciones, explican este nacimiento como producto exclusivamente de causas nacionales, es decir, únicamente como respuesta a la política autoritaria del gobierno de Pacheco.

Analizando cada uno de los partidos por separado, y su recorrido hacia el Frente Amplio, podemos ver que además de esas causas locales -que sería un despropósito desconocer- existieron también transformaciones a la interna de cada uno de los sectores, producto de la recepción en este caso del proceso chileno.

El caso más claro, es nuevamente el del Partido Comunista. Teóricos ambos -el uruguayo y el chileno- del camino electoral y de la necesidad de la alianza amplia de varios sectores, vieron en la consumación del Frente Amplio el punto de llegada de una larga tradición. Quizás, en este contexto, fue el sector menos conflictivo en su discursividad, mostrando su acuerdo en aliarse con otros sectores desde un comienzo. Su práctica sí, quizás pecó de cierto sectarismo. Varios de los militantes entrevistados de otras contiendas, 
denunciaban prácticas autoritarias de sus pares comunistas en la militancia sindical, gremial, incluso en tareas de propaganda (tapadas de muros, etc.,), que mostraban en el accionar una política que no alentaba el acercamiento de otros sectores. Incluso la insistencia previa, a la fundación del Frente Amplio, de que el FIdeL ya podría ser el amplio paraguas que los nucleara a todos. Igualmente, es claro, que el triunfo de Allende, la asunción de un gobierno popular por el triunfo electoral, era la confirmación de que ese camino era posible, camino que venían promoviendo desde mediados de la década del 50'.

El Partido Socialista, como señalábamos, transitó durante este período, por un camino complejo. En primer lugar, había perdido su lugar en el Parlamento, por lo que su actuación política pública, se había visto obstaculizada severamente. Por otro lado, hasta 1971, transitaron por un período de ilegalidad, que si bien no les implicó pasar a la clandestinidad, y pudieron fundar otros medios de prensa luego de la clausura de El Sol, lo cierto es que su actividad se vio disminuida por ambos acontecimientos.

Esto profundizó de cierta manera, una línea política por la que venían transitando, que desconfiaba en primer lugar, de que la izquierda pudiera acceder al gobierno por la vía electora, y en segundo lugar, que la derecha le permitiera acceder al mismo en caso de ganar las elecciones. Estos argumentos, fueron los que provocaron que hasta noviembre de 1970, el socialismo uruguayo viera con cierto recelo los acontecimientos chilenos, y se cuestionaran sobre el que hacer para que se pudiera consumar la victoria. Luego del 3 de noviembre, cuando Salvador Allende, asume el cargo, tal como ellos mismos señalan, los socialistas chilenos habian roto las reglas de juego, y lo que se necesitaba ahora, era apoyar al gobierno y prepararse para defender las conquistas. La unidad para la revolución, y la necesidad de crear un polo revolucionario en la interna del Frente Amplio, será el motor que los impulsará a integrarlo, ahora que el camino era posible.

El viraje del Partido Socialista, quizás es el ejemplo que mejor muestra, el giro que la izquierda revolucionaria -que tenía a Cuba como referente-, comienza a dar luego del triunfo de Allende. La opción de creación de frentes electorales, también como camino revolucionario, comienza a ser claro a partir de esta experiencia. No es casualidad, que durante todo el año 1971 desde El Oriental, se reproduzca íntegramente la larga entrevista que Debray le realiza a Allende.

Por otro lado, a medida que la alianza se iba concretando, fue clave el apoyo de los sectores progresistas de los partidos tradicionales -estrategia que el socialismo uruguayo venía postulando por lo menos desde 1962- cumplió un rol definitorio también para lograr el acuerdo socialista. Tal como señala José Díaz, finalmente "las dos posiciones, la de los 
comunistas unidad sin exclusiones y la nuestra unidad con los sectores progresistas de los partidos tradicionales se convirtió en el Frente Amplio. O sea, unimos las dos perspectivas. $(\ldots) "$

Viendo la amplitud de la alianza, y de la cantidad de sectores que se iban sumando, es cierto, que la posibilidad de aislarse políticamente también fue un argumento aglutinador.

En el PDC el recorrido, fue quizás un poco más complejo. Si bien, no transitaron por rupturas internas -salvo el pequeño grupo que rompe justamente por la fundación del Frente Amplio-, la posibilidad de aliarse con el comunismo, fue un precio alto a pagar a nivel internacional.

Héctor Lescano, recuerda que a ellos

\begin{abstract}
les costó mucho explicar el Frente Amplio, en plena Guerra Fría, formábamos parte de la Internacional Democratacristiana y de la regional, de manera que explicar que en Uruguay nos juntábamos con los comunistas especialmente, en lo que fue un Frente Amplio sin exclusiones, como definición de una de las convenciones del PDC, era algo fuerte. Y también no fue nada fácil en Chile, frente a líderes que no compartían para nada esa posición. Radomiro Tomic nos comprendió y nos apoyó mucho.
\end{abstract}

Carlos Baráibar, en una argumentación similar señala que

uno de los componentes ideológicos y políticos que explican este paso que era inédito para la Democracia Cristiana se explica por la experiencia de Chile, que fue una experiencia muy intensa, muy frecuente y de un enorme valor en cuánto a antecedentes para impulsar después el Frente Amplio en Uruguay.

Jorge Rodríguez, afirma que a Juan Pablo Terra, "en la Internacional Demócrata Cristiana lo aislaron, cuando el Frente Amplio, pero si tuvo la comprensión y la alianza de la Democracia Cristiana chilena por Tomic que lo apoyó". Tal como señalamos, un reducido núcleo de dirigentes del PDC, se fueron del Partido cuándo este resuelve integrar el Frente Amplio, justamente sosteniendo la tesis freista del camino propio ${ }^{437}$. Sin embargo, el apoyo chileno, y el acuerdo con la estrategia tomicista, provocó en primer lugar, que el PDC no se fracturara -tal como sucedió con su par chileno- y que además pudiera jugar un rol clave en la unificación de las izquierdas.

En diciembre de 1970, en plena discusión sobre las características de la alianza, los tres partidos analizados, contaron con el apoyo chileno para argumentar su estrategia. Tal

\footnotetext{
${ }^{437}$ Eduardo J. Corso, afirmaba en 1971 en su documento El cristiano y el Frente Amplio, que quienes apoyan al PDC en "su versión de Frente Amplio, vota con el marxismo, vota por el marxismo, vota al marxismo y vota para el marxismo". (Ilha López, 2014, p. 26)
} 
como señalamos: Volodia Teitelboim participa del Congreso del PCU, Radomiro Tomic de la Convención Nacional del PDC y Claudio Vidal del Pleno del PS. Tal como señala, Aguirre Bayley,

la victoria de la Unidad Popular que llevó al doctor Salvador Allende a la presidencia en Chile en 1970, ratificada por el Congreso Nacional el 23 de octubre de ese año con el respaldo de la Democracia Cristiana, se convirtió en otro argumento capitalizador de voluntades para la unidad de la izquierda y las fuerzas progresistas. $(2005$, p. 34). 


\section{Conclusiones}

El objetivo de la presente tesis, se centró en analizar el camino recorrido por comunistas, socialistas y democratacristianos uruguayos que finalmente desembocó en la fundación del Frente Amplio, el 5 de febrero de 1971, pero que sin desconocer las variables nacionales iluminara en la recepción que estos sectores habían realizado sobre el proceso de unificación de la izquierda chilena y fundamentalmente del triunfo de Salvador Allende el 4 de setiembre de 1970 .

De esta manera, dimos cuenta de los vínculos que estos tres sectores mantuvieron con su par chileno.

En el caso del Partido Comunista, si bien ambos -el uruguayo y el chilenomantuvieron exactamente la misma estrategia a lo largo de todo el período, fue dónde se me dificultó más ver la influencia del proceso chileno. No porque esta fuera más débil, sino por la relevancia radical que en ambos produjo el PCUS. Lo más claro de esta importancia, se ve en el hecho de que el comunismo latinoamericano no creó un ámbito de coordinación regional que como vimos sí constituyeron tanto socialistas como democratacristianos- sino que las directivas provenían del Movimiento Comunista Internacional. Esto provocó de cierta manera, que ambos partidos promovieran una misma estrategia política en contextos nacionales bastante diferentes.

Igualmente, ha quedado demostrado como la unidad de la izquierda, fue una constante del comunismo en ambos países durante todo el período. No sólo la unidad a nivel político partidario, sino también a nivel obrero. Unidad del pueblo -en sentido amplio-, alianza con la burguesía nacional -pero manteniendo la vanguardia del proceso en la clase obrera-, lucha de masas y vía pacífica, fue la línea política constante del comunismo durante estos quince años.

Los comunistas uruguayos miraron con atención los sucesos chilenos, en primer lugar apreciaban su raigambre obrera y la temprana posibilidad de haber logrado la alianza con el socialismo. No es menor, resaltar como vimos, que pocos meses después de constituido el FRAP, Arismendi envía la primera invitación de alianza al PS. Claro está, en el mismo momento, el XX Congreso del PCUS habilitaba e incentivaba estos caminos. La importante votación electoral del FRAP en 1958, también fue analizada por el comunismo uruguayo como reafirmación del camino. En varias notas de prensa, se exalta la idea de formar una alianza similar en Uruguay. 
Luego de 1970, esta estrategia va a ser mucho más evidente. Las referencias a imitar lo sucedido en Chile son numerosas. Con la conformación del Frente Amplio, entonces, el comunismo uruguayo cumplía entonces con un objetivo anhelado desde mucho tiempo atrás.

En el caso del Partido Socialista, fueron mucho más evidentes los vínculos entre ambas colectividades. En el primer período, hasta la ilegalización en 1967, el PS transitó una transformación que lo llevó de ser un partido que apostaba completamente a la legalidad institucional -encabezada por su entonces Secretario General Emilio Frugoni- a proponer una estrategia política que oscilaba entre el camino legal y el armado. El nacimiento en su seno de corrientes rupturistas, que se mantuvieron incluso dentro del PS por algunos años, con claras muestras de ello.

Los contactos entre ambos sectores, comenzaron en primer lugar con el PSP, siendo en este sentido considerados referentes para el socialismo uruguayos los escritos teóricos de Ampuero, por citar un ejemplo. Pudimos dar cuenta, en este sentido, de lecturas comunes, del seguimiento en Uruguay de los caminos recorridos por su par chileno, así como movimientos de militantes entre uno y otro país, asistencia a Congresos, etc. Los intercambios producidos en la experiencia del Secretariado Latinoamericano de la IS, fueron claves en este sentido.

El levantamiento de 1956 en Chile, fue seguido con detenimiento en Uruguay, que incluso como vimos logra enviar algunos militantes para mirar de cerca los acontecimientos. Esa experiencia demostraba, que la coordinación de clase y la movilización obrera en la calle, eran las claves de la estrategia del socialismo en esta primera etapa.

Desde el punto de vista ideológico, compartían en primer lugar la caracterización de la revolución sin etapas. Establecida ésta en dos fases: la nacional (que cumpliría con los objetivos no llevados a cabo por las burguesías) y la propiamente socialista. La diferencia fundamental, radicaba en la negativa a aliarse con los comunistas, tal como hemos señalado y que en Chile era una alianza consolidada.

Varias de las consignas teorizadas por el socialismo chileno serán tomadas directamente en Uruguay. Ejemplo de ello son: "revolución o miseria" adaptada en Uruguay como "socialismo o miseria"; la idea del Frente de Trabajadores y más adelante, la necesidad de crear un Frente revolucionario. Frente al avance de las ideas de crear frentes electorales que compitieran en las elecciones, el socialismo de ambos países, no tuvo una actitud fuerte en su apoyo, sino más bien dubitativa. Esto provocó que -fundamentalmente luego de la derrota chilena en las elecciones de 1964- el socialismo se inclinara en pensar que el camino electoral estaba cerrado y que era necesario por ende, prepararse para un posible escenario de 
violencia. Recordemos, que tanto en 1962 como en 1966, el socialismo no accede a su representación parlamentaria, por lo que aunque sin quererlo, quedó por fuera de los canales institucionales de discusión política. La ilegalización de diciembre de 1967 del socialismo uruguayo, es el punto culminante del proceso de radicalización. De alguna manera, vendría a confirmar que el camino institucional no era una opción viable.

La misma actitud oscilante, se mantendrá incluso hasta el 1970, con la convicción de que aunque la UP triunfara en las elecciones, los sectores dominantes iban a impedir que ésta se hiciera del gobierno e incluso pudiera llevar adelante sus propuestas. Lo interesante, es que ninguno de los dos partidos socialistas, más allá de estas teorizaciones abandona el camino electoral.

Luego de la asunción de Allende, el 3 de noviembre de 1970, la actitud del socialismo dará un giro y pasará a defender al gobierno popular. Lo mismo sucederá en Uruguay, la posibilidad de que una alianza de izquierda acceda al gobierno por la vía electoral, en definitiva terminará de convencer al PS de unirse al Frente Amplio. Igualmente, no debemos dejar de señalar, que la explicitación de que el modelo chileno no podía copiarse en Uruguay, sobre todo por los diferentes contextos políticos de ambos países, será manifestado por el socialismo de forma insistente. La clave en Uruguay, entonces, estuvo no en la alianza con el comunismo, sino en los desgajamientos de los sectores progresistas de los partidos tradicionales, política que el socialismo venía promoviendo de una década atrás. Esta estrategia, sumada a la concreción del ejemplo chileno, fueron el impulso final para que el socialismo aceptara integrarse a la alianza.

De los tres casos, el PDC fue en el que más claramente puede verse la influencia de la DC chilena en su recorrido. Además de los vínculos personales -que venían incluso desde antes de transformados los partidos en democracias cristianas- los uruguayos veían en su par chileno, efectivamente un modelo a seguir.

El temprano triunfo de Eduardo Frei en 1964, logrando un importante apoyo electoral que lo ubicó como el primer presidente electo por un solo partido, mostró que la DC era capaz de hacerse con el gobierno. Este camino sin alianzas, reforzó la posibilidad de triunfo, manteniéndose equidistantes del "marxismo" y del capitalismo. Esto provocará que en Uruguay, el PDC también vaya sin alianzas políticas tanto en 1962, como en 1966, y que no integren la Mesa por la Unidad del Pueblo. En plena Guerra Fría, el anticomunismo era claro en los democratacristianos, en estos primeros años. La campaña del terror, realizada contra Allende en 1964, también fue utilizada en Uruguay, denunciando el "peligro comunista". El 
apoyo en financiamiento, formación política e incluso logística para las elecciones, fundamentalmente de 1996, quedó claramente establecido.

Sin embargo, a medida que el gobierno de Frei avanzaba, las tensiones internas también tuvieron eco en Uruguay. El intercambio en este caso fue directo. Como vimos, varios jóvenes de la Democracia Cristiana uruguaya, se radican directamente en Santiago de Chile, por lo que viven las tensiones de primera mano, fundamentalmente entre los sectores de la Juventud. Esto permitirá que el PDC uruguayo, tenga un claro alineamiento con Tomic e incluso, con los sectores disidentes chilenos. Figuras como Rodrigo Ambrosio o Pedro Felipe Ramírez, fueron referentes claves para los jóvenes uruguayos.

La participación de Tomic, en los últimos acontecimientos públicos, antes de la Fundación del Frente Amplio fue una muestra explicita del apoyo uruguayo a la tesis de la Unidad social del Pueblo, y un hecho político también para la DC chilena, de que su último candidato a las elecciones, participara de un mitin que promovía la acción conjunta con la izquierda.

El liderazgo de los jóvenes del Partido, sumado a la acción de Juan Pablo Terra, será decisiva, no solamente para que el PDC promueva una alianza amplia con todos los sectores de la izquierda, sino para que en su interna no sufra fracturas importantes. La clave, estará además, justamente en lo amplio de la alianza, y en la conformación de lo que ellos denominaron el eje no marxista.

A nivel general, tanto en Chile como en Uruguay, aunque en momentos históricos diferentes el camino de unificación de la izquierda, fue en el marco de procesos o políticas autoritarias: Carlos Ibañez para el caso del FRAP, el giro autoritario del gobierno de Frei que provocó el quiebre de la DC, y la fundación de la Unidad Popular a partir de una ampliación del FRAP; y el avance del autoritarismo en Uruguay bajo el gobierno de Pacheco Areco.

En Uruguay, podríamos afirmar que lo conflictivo de la alianza -antes de 1970- estaba en la negativa de todos los sectores a formar un frente común con el PCU. No es solamente de los socialistas la negativa; Juan Pablo Terra sostendrá lo mismo en 1969, y lo mismo hará Michelini poco tiempo después. Justificada o no esta negativa, lo cierto es que la unión con el comunismo, hasta el triunfo de Allende, les provocaba más dudas y problemas que aciertos.

Justamente, lo que hemos querido mostrar, es que más allá del autoritarismo desplegado por el gobierno de Jorge Pacheco Areco y de la acción común que se venía 
desarrollando en varios terrenos -entre ellos el parlamentario- el triunfo de Salvador Allende fue la concreción material de que ese camino era viable y que para eso era necesario aliarse.

Los giros y las negociaciones que se producen en Uruguay entre setiembre y diciembre de 1970 son muestra de ello. Raúl Legnani, lo dice muy claramente "la discusión salió del plano de la teoría y de los deseos a la concreta. Señor mío, en Chile, acá al lado ganaron, vamos a dejarnos de joder. (...) Lo de Allende concreta."

Otro dato que me llamó la atención, es que de las 23 entrevistas realizadas, ante la pregunta de si los sucesos de Chile habían confirmado el camino, y dado este impulso a la unificación en Uruguay, uno sólo -el militante socialista Carlos Riverós- descartó esta conexión. Lo que me sorprendió, fue que para el resto de los militantes fuera un elemento bastante claro (tal como aparece en los extractos citados), incluso para algunos evidente, pero que a la vez no haya sido hasta ahora, un elemento a considerar por parte de la historiografía. Carlos Riverós, establece como antecedente único del Frente Amplio los giros que se dieron tanto en el PCU y el PS en la segunda mitad de los 50', y la unidad sindical, "más que la influencia de ningún lugar del extranjero al Uruguay”.

Esto no quiere decir de ninguna manera, que el Frente Amplio es copia de lo sucedido en Chile. Ya quedaron demostradas también las diferencias. Ni tampoco que sea necesario preponderar si importaron más las causas nacionales que lo ocurrido a nivel regional. Lo que quisimos, fue ampliar la mirada y analizar que las discusiones que venían transitándose en la izquierda uruguaya por más de una década, tiene su impulso final a partir de lo sucedido en Chile.

La posibilidad de acceder al gobierno a través de un frente electoral, mostraba a América Latina, que la revolución podía tener otro camino, diferente al ejemplo cubano de 1959. Toda la izquierda entonces, estuvo atravesada por la discusión de cómo hacer la revolución, por definir su carácter, sus vías y con quién aliarse para lograr dicho objetivo. Y quienes permanecieron en el medio, como el Partido Radical o la DC chilena, terminaron de hecho fracturados, dividiéndose entre quienes acompañaban un camino revolucionario y quienes no. Incluso el ala conservadora de la DC, accedió al gobierno en 1964, con un lema también vinculado a este tema, la "Revolución en Libertad" se proponía un cambio radical de las estructuras pero dentro de la institucionalidad. Tal como señala, Julio Pinto, "lo “políticamente correcto" era ser partidario de la revolución”. (2005, p. 10)

No sólo la izquierda visualizó esta posibilidad, sino también la derecha. Hemos referido a documentos, que señalan del peligro de que el ejemplo chileno se repita en la 
región. La denominada Operación 30 horas, es decir, la posibilidad de que Brasil invadiera a Uruguay en caso del triunfo del Frente Amplio en 1971, es también muestra de esa preocupación.

Varias líneas de análisis quedan pendientes. Como señalamos anteriormente, queda abierta para futuras investigaciones, ver con detalle las implicancias que este triunfo tuvo para las derechas latinoamericanas, entre ellas la uruguaya. Siguiendo a Arismendi, "la reacción, el imperialismo, las fuerzas del gobierno y los sectores que organizan el terrorismo detrás del cual hay agentes policiales y espías, tratan de aprender la lección chilena, como antes aprendiera el imperialismo la lección cubana”. (Arismendi, 1999, p. 121).

En segundo lugar, las viscitudes atravesadas por el gobierno de la Unidad Popular y finalmente su derrota luego del golpe de Estado del 11 de setiembre de 1973, han sido analizadas en sus dimensiones nacionales, es decir, que implicancias tuvo ésta para la historia chilena.

En el caso uruguayo, en el período 1970-1973, producto del aumento represivo varios son los militantes de diversas tiendas políticas que encuentran en Chile lugar de refugio. Hemos referido al comienzo, al trabajo de Clara Aldrighi y Guillermo Waksman sobre el exilio Tupamaro durante el gobierno de Allende. Sin embargo, queda pendiente dar cuenta desde el punto de vista político, de cómo la izquierda uruguaya (estando en Chile o no) recepcionó lo ocurrido en dicho país, las medidas tomadas por el gobierno, los ritmos de las mismas y las tensiones ocurridas a la interna de la Unidad Popular. Podríamos pensar, que así como el triunfo de 1970 constituyó un impulso para la vía electoral, el derrocamiento de Allende, confirmaba una vez que las clases dominantes no iban a permitir pacíficamente el desarrollo de un gobierno popular. La evaluación de este proceso en la izquierda uruguaya con buena parte ya en el exilio o presa- es un debe que sigue pendiente.

Lo mismo podríamos plantear, ampliando el período hacia la transición democrática. Las diferencias a simple vista, son enormes, pero no dejan de ser parte del mismo debate. El Frente Amplio, se reconstruyó en los $80^{\prime}$ casi con la misma integración y se mantiene de esa manera hasta nuestros días ${ }^{438}$. La Unidad Popular, sin embargo, se destruye y al retorno a la democracia, la alianza es del PS con la DC y sin los comunistas. Poder mirar globalmente,

\footnotetext{
${ }^{438}$ Poco tiempo después del golpe de Estado, el PDC uruguayo propone que dadas las circunstancias el FA debería quedar en receso y de hecho, rompen con la alianza. En 1984, se reincorporan hasta 1989, que luego de duras discusiones producto del ingreso del MLN rompen nuevamente y fundan junto a la Lista 99 y la Unión Cívica lo que se denominó "Nuevo Espacio". En 1994, forman un nuevo acuerdo entre el Nuevo Espacio y el Frente Amplio, denominado Encuentro Progresista y en 1999 vuelven al FA.
} 
como ambos colectivos de izquierda procesaron su reconstrucción, también es una línea a seguir en el futuro.

Para el mismo período de esta tesis, queda pendiente mirar también a nivel transnacional el rol desempeñado por la revolución cubana. Ya desde 1958, se formaron en Uruguay los comités de apoyo a la revolución cubana, siendo la puerta de ingreso para muchos jóvenes militantes. Y luego del triunfo, es evidente decir que se constituyó el camino de la revolución latinoamericana y que varios colectivos de la izquierda intentaron imitar su recorrido. Podríamos decir entonces, que en 1958 mientras en Cuba se desarrollaba intensamente la guerrilla, en Chile el FRAP casi alcanza el gobierno mediante elecciones. La manera en que el modelo cubano, es recepcionado en Uruguay por la izquierda y las transformaciones concretas que produce en su interior, es un camino aún por recorrer.

Desde el punto de vista metodológico, varios son los sucesos de la política uruguaya que podrían analizarse con una perspectiva que amplíe fronteras. Es imposible dar cuenta de todas aquí. Siguiendo a los historiadores Purcell y Riquelme, "en vez de construir murallas, los historiadores debiéramos abrir puertas y ventanas que nos permitan observar más allá de lo nacional (...)". (2009, p. 9) 


\section{Bibliografía}

Abbattista, Lucía y Starcenbaum, Marcelo. (2013) Sobre la perspectiva transnacional. En: Aletheia, volumen 3, número 6, julio 2013

Aguirre Bayley, Miguel. (1985) El Frente Amplio: historia y documentos, Montevideo, Ediciones de Banda Oriental.

Aguirre Bayley, Miguel (2005). Frente Amplio: la admirable alarma de 1971, Montevideo, Ediciones Cauce.

Aguirre Bayley, Miguel (2012). Frente Izquierda de Liberación (FIdeL), 50 años de historia, Montevideo, Tradinco.

Aldrighi, Clara (2001). La izquierda armada. Ideología, ética e identidad en el MLNTupamaros, Montevideo, Editorial Trilce.

Aldrighi, Clara (2014). El Movimiento de Liberación Nacional- Tupamaros (1965-1975). Estructura interna, fases de desarrollo y política de alianzas. En: Pozzi, Pablo y Pérez, Claudio. "Historia oral e historia política. Izquierda y lucha armada en América Latina, 19601990”, Chile, Ed. LOM.

Aldrighi, Clara y Waksman, Guillermo (2015), Tupamaros en el Chile de Allende, Montevideo, Ed. Fin de Siglo.

Alfaro, Hugo. (1984) Navegar es necesario. Quijano y el Semanario "Marcha”, Uruguay, Ediciones de la Banda Oriental.

Alonso, Jimena (2016). Uruguayos en Chile: de la solidaridad al exilio (1970-1973). En: Horvitz, María Eugenia y Peñaloza, Carla. "Exiliados y desterrados en el Conosur de América", Santiago, Universidad de Chile.

Álvarez, Rolando (2007). ¿Reforma o revolución?: Lucha de masas y la vía no armada al socialismo. El Partido Comunista chileno 1965-1973. En: Modonesi, Massimo y otros. "El comunismo: otras miradas desde América Latina", México, UNAM.

Álvarez, Rolando (2014). Arriba los pobres del mundo. Cultura e identidad politica del Partido Comunista de Chile entre la democracia y la dictadura (1965-1990), Chile, Ed. LOM.

Amorós, Mario (2013). Allende, la biografía, Barcelona, Ediciones B.

Amorós, Mario (2015). Miguel Enríquez. Un nombre en las estrellas”, Chile, Ediciones B.

Angel, Allan (2001). Chile 1958-1990. En: Bethell, Leslie. "Historia de América Latina", Barcelona, Ed. Crítica. Vol. 15 "El Conosur desde 1930".

Armony, Ariel C (2004). Transnacionalizando la guerra sucia: Argentina en Centroamérica". En: Spenser, Daniela (Coord.) "Espejos de la guerra fría: México, América Central y el Caribe", México, CIESAS.

Arrate, Jorge y Rojas, Eduardo. (2003) Memoria de la izquierda chilena, Tomo I y Tomo II, Chile, Ed. Grupo Zeta.

Bachetta, Víctor (2010). El asesinato de Arbelio Ramírez. La República a la deriva, Montevideo, Doble clic editoras. 
Barr Melej, Patrick (2009). Hippismo a la chilena: juventud y heterodoxia en un contexto transnacional (1970-1973). En: Purcell, Fernando y Riquelme, Alfredo, “Ampliando miradas. Chile y su historia en un tiempo global", Santiago, RIL Editores

Blixen, Samuel. (1997) Seregni. La mañana siguiente, Montevideo, Ed. Brecha.

Buchelli, Gabriel y Yaffé, Jaime (2007). Sobre el aparato militar del Partido Comunista. Un ejército sin comandante en jefe conocido, En: Cuadernos de la Historia Reciente, Nro. 2, Montevideo, Ediciones de la Banda Oriental.

Butazzoni, Fernando. (2002) Seregni-Rosencof: mano a mano, Montevideo, Ed. Aguilar

Caetano, Gerardo y Rilla, José (1995) Izquierda y tradición: un problema y su versión en Uruguay. En: Caetano, Gerardo y otros. "La izquierda uruguaya. Tradición, innovación y política”. Montevideo, Ediciones Trilce.

Caetano, Gerardo y Neves, Salvador (2016). Seregni. Un artiguista del siglo XX, Montevideo, Ediciones de la Banda Oriental.

Cardemil, Alberto (1997) El camino de la utopía. Alessandri, Frei, Allende. Pensamiento y obra, Santiago de Chile, Ed. Andrés Bello.

Casals Araya, Marcelo (2010). El alba de una revolución. La izquierda y el proceso de construcción estratégica de la "vía chilena al socialismo", Chile, Ed. LOM.

Cayota, Mario (2014). Las raices de la democracia cristiana uruguaya, Montevideo, Instituto Humanista Cristiano- Juan Pablo Terra.

Coelho Prado, María Ligia (2012). América Latina: historia comparada, historias conectadas, historia transnacional, Rosario, Anuario $\mathrm{N}^{\circ} 24$, Escuela de Historia, Revista Digital $N^{\circ}$ 3, Facultad de Humanidades y Artes, UNR.

Costa Bonino, Luis. (1995) La crisis del sistema político uruguayo. Partidos políticos y democracia hasta 1973, Montevideo, Fundación de Cultura Universitaria.

Daire, Alonso (1988) La política del Partido Comunista desde la post-guerra a la Unidad Popular. En: Varas, Augusto (Comp.) "El Partido Comunista en Chile", Santiago de Chile, FLACSO.

De Giorgi, Ana Laura (2011). Las tribus de la izquierda. Bolches, latas y tupas en los 60', Montevideo, Ed. Fin de Siglo.

De la Guardia, Carmen y Pan Montojo, Juan (1998). Reflexiones sobre una historia transnacional, Revista Estudios de Historia Contemporánea, $\mathrm{N}^{\circ} 16$, Ediciones de la Universidad de Salamanca.

Demasi, Carlos (2006). Blancos y colorados en la creación del Frente Amplio, Montevideo, Fundación Vivían Trías, Cuaderno Nro. 33.

Drake, Paul (2001). Chile 1930-1958. En: Bethell, Leslie. "Historia de América Latina", Barcelona, Ed. Crítica. Vol. 15 "El Conosur desde 1930".

Duffau, Nicolás (2008). El Coordinador. La participación de los militantes del Partido Socialista en los inicios de la violencia revolucionaria en el Uruguay, Montevideo, Facultad de Humanidades y Ciencias de la Educación, Colección Estudiantes No 30.

Failache, César (2014). Dos décadas de propuestas programáticas del PDC para Uruguay, Montevideo, Instituto Humanista Cristiano- Juan Pablo Terra. 
Fernández Huidobro, Eleuterio (1986). Historia de los Tupamaros, Montevideo, Ed. Tae, Vol. 1

Fernández, Joaquín (2015). Allende, el allendismo y los partidos: El Frente de Acción Popular en las elecciones presidenciales de 1958. En: Revista Izquierdas, Santiago de Chile, Nro. 23.

Fundación Salvador Allende (2008). Salvador Allende, fragmentos para una historia, Chile, Ed. Fundación Salvador Allende.

Gallardo, Javier (1995). La parábola de los “zorros" y los “leones”. En: Caetano, Gerardo y otros. "La izquierda uruguaya. Tradición, innovación y política”. Montevideo, Ediciones Trilce.

Garcé, Adolfo (2014). El Partido Comunista del Uruguay y la vía armada. En: Revista Izquierdas, $\mathrm{N}^{\mathrm{o}} 19$, Santiago de Chile.

Gazmuri, Cristian (2000). Eduardo Frei Montalva y su época, Santiago de Chile, Ed. Aguilar. 2 Tomos.

Goicovic, Igor (2014). El Movimiento de Izquierda Revolucionaria (MIR) y la irrupción de la lucha armada en Chile (1965-1990). En: Pozzi, Pablo y Pérez, Claudio. "Historia oral e historia política. Izquierda y lucha armada en América Latina, 1960-1990”, Chile, Ed. LOM.

Ilha López, Julio (2014). El PDC protagonista en la creación del Frente Amplio, Montevideo, Instituto Humanista Cristiano- Juan Pablo Terra.

Ilha López, Julio (2016). La construcción ideológica de una izquierda cristiana en Uruguay, Montevideo, Instituto Humanista Cristiano- Juan Pablo Terra.

Jobet, Julio César (1971). El Partido Socialista de Chile, Santiago, Ed. Prensa Latina. 2 Volúmenes.

Jobet, Julio César (1987). Historia del Partido Socialista de Chile, Santiago de Chile, Ediciones Documentas.

Lanzaro, Jorge Luis (Coord.) (2004) La izquierda uruguaya entre la oposición y el gobierno, Montevideo, Ed. Fin de Siglo.

Leibner, Gerardo (2011) Camaradas y compañeros. Una historia política y social de los comunistas del Uruguay, Montevideo, Ed. Trilce.

Leicht, Federico (2013). Orden y progreso: el influjo de Brasil en el camino al golpe de Estado, Montevideo, Ediciones de La Plaza.

López D’Alessandro, Fernando (1988). Historia de la izquierda uruguaya, Montevideo, Ediciones del Nuevo Mundo. Volumen 1 (1838-1910) y Volumen 2 (1911-1918)

Loyola, Manuel y Rojas, Jorge (2000). Por un rojo amanecer. Hacia una historia de los comunistas chilenos, Vaulus, Santiago de Chile.

Marchesi, Aldo. (2009). Geografias de la protesta armada: nueva izquierda y latinoamericanismo en el Cono Sur. El ejemplo de la Junta Coordinadora Revolucionaria, Revista Sociohistórica $\mathrm{N}^{\circ} 25$, Universidad Nacional de La Plata.

Marchesi, Aldo y Yaffé, Jaime. (2010) La violencia bajo la lupa: una revisión de la literatura sobre violencia y política en los sesenta, Uruguay, Revista Uruguaya de Ciencia Política, Vol. 19, $\mathrm{N}^{\circ} 1$. 
Marchesi, Aldo. (2012) La partida decisiva de la revolución en América Latina: militantes bolivianos, chilenos y uruguayos en la Argentina peronista. Buenos Aires 1973-1976, Revista PolHis, Año 5, $\mathrm{N}^{\mathrm{o}} 10$

Markarián, Vania (2006). Idos y recién llegados. La izquierda uruguaya en el exilio y las redes transnacionales de derechos humanos, Montevideo, Ed. La vasija.

Markarián, Vania (2012). El 68 uruguayo. El movimiento estudiantil entre molotovs y música beat, Buenos Aires, Ed. Universidad Nacional de Quilmes.

Molt, Peter (1971). La Democracia Cristiana en América Latina, Roma, Centro Internacional Demócrata Cristiano de Información y Documentación, Cuaderno Nro. 7.

Moulián, Tomás. (1998) Conversación interrumpida con Allende, Santiago de Chile, Ed. LOM.

Moulián, Tomás (2005). La vía chilena al socialismo: itinerario de los discursos estratégicos de la Unidad Popular. En: PINTO, Julio (Coord). "Cuando hicimos historia. La experiencia de la Unidad Popular", Santiago de Chile, Ed. LOM.

Moulián, Tomás (2006). Fracturas: de Pedro Aguirre Cerda a Salvador Allende (1938-1973), Chile, Ed. LOM.

Moulián, Tomás (2009) Contradicciones del desarrollo político chileno (1920-1990), Chile, Ed. LOM.

Moyano, Cristina (2009). MAPU o la seducción del poder y la juventud: los años fundacionales del partido mito de nuestra transición (1969-1973), Santiago de Chile, Universidad Alberto Hurtado.

Nahum, Benjamín y otros (1990). El fin del Uruguay liberal, Montevideo, Ediciones de la Banda Oriental, Colección Historia Uruguaya, Tomo 8.

Nercesián, Inés (2016). Las coaliciones electorales de la izquierda chilena. Un análisis de larga duración. En: Revista Sociohistórica. Centro de Investigaciones Sociohistóricas. Universidad Nacional de La Plata. No 38, e013.

Nocera, Raffaele (2009). Italia y América Latina: una relación de bajo perfil, 1945-1965. El caso Chile. En: Purcell, Fernando y Riquelme, Alfredo, "Ampliando miradas. Chile y su historia en un tiempo global", Santiago, RIL Editores.

Novoa, Eneida (1972). El reformismo: teoría de la contrarrevolución. En: Real de Azúa, Carlos. "Disyuntivas de la democracia cristiana”, Montevideo, Ed. Sandino.

Ortega, Luis (2003). Del Frente de Trabajadores al Congreso de Chillán. Los Socialistas de Chile entre 1956 y 1967. En: Revista Palimpsesto, Departamento de Historia Universidad de Santiago de Chile, Nro. 1, Año 1.

Palieraki, Eugenia (2014). ¡La revolución ya viene! El MIR chileno en los años sesenta, Chile, Ed. LOM

Paysée González, Eduardo (1972). Confesionalismo, ideología y revolución. En: Real de Azúa, Carlos. "Disyuntivas de la democracia cristiana”, Montevideo, Ed. Sandino.

Pedroza, Fernando (2011). La otra izquierda. Las estrategias de la socialdemocracia europea en América Latina 1951-1971. En: Revista Contemporánea. Historia y Problemas del siglo XX, Volumen 2, Año 2, Montevideo

Pedroza, Fernando (2013). Redes trasnacionales y partidos políticos. La Internacional Socialista en América Latina (1951-1991). En: Revista Iberoamericana, Vol. XIII 
Pérez, Romeo (1984). Partidos de ideas, Montevideo, Ed. CLAEH.

Pérez, Romeo (1987). Los cristianos y la política en el Uruguay, Montevideo, Ediciones del Nuevo Mundo.

Pinto, Julio (2005). Hacer la revolución en Chile. En: Pinto, Julio (Coord.) "Cuando hicimos historia. La experiencia de la Unidad Popular", Santiago, Ed. LOM.

Pittaluga, Roberto (2015) Soviets en Buenos Aires: la izquierda de la Argentina ante la revolución en Rusia, Buenos Aires, Ed. Prometeo.

Politzer, Patricia (2013). Altamirano, Santiago de Chile, Ed. Debate.

Purcell, Fernando y Riquelme, Alfredo (2009) Ampliando miradas. Chile y su historia en un tiempo global, Santiago, RIL Editores.

Rampoldi, Rodrigo (2014). La Democracia Cristiana y su lucha contra el autoritarismo predictatorial, Montevideo, Instituto Humanista Cristiano Juan Pablo Terra.

Ratto, María Celeste. (2006) El surgimiento de una alternativa de izquierda viable: análisis del caso Frente Amplio, En: Abal Medina, Juan. (Comp.). "Los senderos de la nueva izquierda partidaria", Buenos Aires, Ed. Prometeo.

Rey Tristán, Eduardo. (2005) A la vuelta de la esquina. La izquierda revolucionaria uruguaya, 1955- 1973, Montevideo, Ediciones Fin de Siglo.

Riquelme, Alfredo (2009). Rojo atardecer. El comunismo chileno entre dictadura y democracia, Santiago de Chile, Centro de Investigaciones Diego Barros Arana.

Rodríguez, Mauricio (2016). La voz de todos. Biografía de Zelmar Michelini, Montevideo, Ed. Fin de Siglo.

Salinas, Maximiliano (2013). Salvador Allende: una vía pacífica al socialismo, Santiago de Chile, Editorial USACH. Colección Grandes de Chile.

Santoni, Alessandro (2011). El comunismo italiano y la vía chilena, Santiago, RIL editores.

Sessa, Leandro (2013). Aprismo y apristas en Argentina. Derivas de una experiencia antiimperialista en la "encrucijada" ideológica y política de los años treinta. Tesis de Doctorado. Universidad Nacional de La Plata. Disponible en: http://www.memoria.fahce.unlp.edu.ar/tesis/te.824/te.824.pdf

Silva, Alberto. (2004) Profesor Juan José Crottogini: una vida alumbrando vida, Montevideo, Editorial La rueda de amargueando.

Silva, Marisa (2009) Aquellos comunistas (1955-1973), Montevideo, Ed. Taurus.

Teo Valenzuela, Esteban (2014). Dios, Marx... y el MAPU, Santiago, Ed. LOM.

Trullen, Gustavo (2014) Una historia de la izquierda: de los cambios en el Partido Socialista a la Unión Popular.

Disponible en:

https://www.colibri.udelar.edu.uy/bitstream/123456789/4955/1/TCP_TrullenGustavo.pdf

Ulianova, Olga; Álvarez, Rolando y Loyola, Manuel (2012). El siglo de los comunistas chilenos 1912-2012, Santiago de Chile, Ediciones USACH.

Valenzuela, Arturo. (1989) El quiebre de la democracia en Chile, Chile, Ed. FLACSO.

Varas, Augusto (Comp.) (1988). El Partido Comunista en Chile, Santiago de Chile, FLACSO. 
Venegas, Hernán (2003). El Partido Comunista de Chile: antecedentes ideológicos de su estrategia hacia la Unidad Popular (1961-1970). En: Revista de Historia Social y de las Mentalidades. Departamento de Historia. Universidad de Santiago de Chile. No 7, Vol. 2.

Walker, Ignacio (1990). Democracia, populismo y leninismo: el Partido Socialista de Chile (1933-1973). En: Walker, Ignacio. "Socialismo y democracia: Chile y Europa en perspectiva comparada", Santiago, Ed. Hachette.

Weinstein, Bárbara. (2013) Pensando la historia más allá de la nación: la historiografía en América Latina y la perspectiva transnacional. En: Aletheia, volumen 3, número 6, julio 2013. Traducción de Lucía Abbattista y Marcelo Starcenbaum

Winn, Peter (2013). La revolución chilena, Santiago de Chile, Ed. LOM.

Yaffé, Jaime. (2004) Del Frente Amplio a la Nueva Mayoría: la izquierda uruguaya (19712004), Montevideo, Secuencia, número 60.

Yaffé, Jaime (2016) Izquierda y democracia en el Uruguay. Un estudio sobre lealtad democrática en tiempos de la Guerra Fría latinoamericana. Tesis presentada para aspirar al título de Doctor en Ciencia Política, Montevideo, Universidad de la República. Inédita. .

Yaffé, Jaime y Garcé, Adolfo. (2006) La izquierda uruguaya (1971-2004): Ideología, estrategia y programa. En: América Latina Hoy, $\mathrm{N}^{\circ}$ 44, Ediciones de la Universidad de Salamanca, España.

Yerushalmi, Yosef (1989). Reflexiones sobre el olvido. En: Yershalmi, Loraux, Mommsen, Milner y Vattimo . "Usos del olvido", Buenos Aires, Nueva Visión.

Zubillaga, Carlos (1991). Los partidos políticos ante la crisis (1958-1983). En: Caetano, Gerardo y otros "De la tradición a la crisis: pasado y presente de nuestro sistema de partidos", Montevideo, CLAEH.

\section{Fuentes}

\section{Fuentes éditas}

AAVV (1962). La polémica socialista-comunista, Santiago, Ed. Prensa Latina.

Almeyda, Clodomiro (1967). Dejar a un lado el ilusionismo electoral, Punto Final, Santiago, Chile, 22 de noviembre de 1967.

Altamirano, Carlos (1968). El Parlamento. Tigre de papel, Punto Final, Santiago, Chile, 21 de mayo de 1968, Documentos.

Allende, Salvador (1973). La revolución chilena, Buenos Aires, Ed. Eudeba.

Ampuero, Raúl (1964) 1964, año de prueba para la revolución chilena. Visto en: http://www.blest.eu/biblio/ps/

Ampuero, Raúl (1969). La izquierda en punto muerto, Santiago, Ed. Orbe.

Arismendi, Rodney (1971). La revolución uruguaya en la hora del Frente Amplio, Montevideo, Ed. Pueblos Unidos.

Arismendi, Rodney (1999) La construcción de la Unidad de la Izquierda, Montevideo, Ediciones Fundación Rodney Arismendi. 
Arismendi, Rodney (2013) Lenin, la revolución y América Latina, Montevideo, Ediciones Fundación Rodney Arismendi.

Barros-Lemez, Àlvaro (1987) Arismendi: forjar el viento, Montevideo, Ed. Monte Sexto.

Barros-Lemez, Álvaro. (1989) Seregni, Montevideo, Ed. Monte Sexto.

Corvalán, Luis (1965). Chile hoy: la lucha de los comunistas chilenos en las condiciones del gobierno de Frei, Buenos Aires, Ed. Anteo.

Corvalán, Luis (1971). Camino de victoria, Santiago de Chile, s/d.

Corvalán, Luis (2010) De lo vivido y lo peleado, Chile, Ed. LOM.

Corvalán, Luis (2013). El gobierno de Salvador Allende, Chile, Ed. LOM.

Chelen, Alejandro (1960) La revolución cubana y sus proyecciones en América Latina, Santiago, Ed. Prensa Latinoamericana.

Debray, Regis (1973). Conversación con Allende, México, Ed. Siglo XXI.

Díaz, José y otros (1995). La izquierda en los 50 y los caminos de unidad, Montevideo, Fundación Vivían Trías, Cuaderno Nro. 2.

Frei, Eduardo (1993). Obras escogidas (1931-1982), Chile, Ediciones del Centro de Estudios Políticos Latinoamericanos Simón Bolívar.

Gazmuri, Jaime y Martínez, Jesús Manuel (2000). El sol y la bruma, Santiago de Chile, Ed. B.

Gumucio, Rafael; Silva Solar, Julio; Jerez, Alberto (1966). Planteamiento político. Análisis y proposiciones para cumplir el Programa Revolucionario. $2^{\circ}$ Congreso Nacional, Santiago de Chile.

Información Documental de América Latina (1972) Partido Comunista del Uruguay y la formación del Frente de Izquierda, Venezuela, $\mathrm{N}^{\mathrm{o}} 2$

Información Documental de América Latina (1973). Democracia cristiana del Uruguayy formación del Frente Amplio, Venezuela, № 3.

Información Documental de América Latina (1973). El Frente Amplio del Uruguay y las elecciones de 1971, Venezuela, $\mathrm{N}^{\circ} 4$.

Ljubetic, Iván y otros (2014). Corvalán: páginas escogidas 1916-2010, Santiago de Chile, Editorial USACH, Colección Testimonios.

Marambio, Max (2009). Las armas de ayer, Buenos Aires, Ed. Debate.

Marín, Gladys (2002). La vida es hoy, Santiago de Chile, Ed. Don Bosco.

Neruda, Pablo (2013) Confieso que he vivido, Santiago de Chile, Ed. Pehuén.

Pérez, Jaime (1996). El ocaso y la esperanza. Memorias políticas de medio siglo, Montevideo, Ed. Fin de Siglo.

Plá Rodríguez, Américo (1959). Principios de la Democracia Cristiana, Montevideo, Imp. Don Orione.

Rodríguez, Aniceto (1995) Entre el miedo y la esperanza, Santiago de Chile, Ed. Andrés Bello.

Seregni, Líber (1971). Discursos, Montevideo, Ed. Arca.

Seregni, Liber. (1985) El ABC del F.A., Montevideo, Libros para la Patria Nueva. 
Suárez Bastidas, Jaime (2008) Allende. Visión de un militante, Santiago de Chile, Ed. Ocho libros.

Terra, Juan Pablo (1971). Del pachequismo al Frente Amplio, Montevideo, Ediciones del Nuevo Mundo.

Terra, Juan Pablo (1971). El PDC y las raices del Frente. Marxistas y cristianos. Montevideo, Cuadernos de Marcha, No 47.

Terra, Juan Pablo (2014) Mística, desarrollo y revolución, Montevideo, Instituto Humanista Cristiano- Juan Pablo Terra.

Trías, Vivián (1965) Por un socialismo nacional, Montevideo, Ediciones El Sol.

Waiss, Oscar (1961). Vía pacífica o revolución. Ni dogmatismo, ni revisionismo: leninismo, Santiago, Ediciones Socialismo.

Waiss, Oscar (1962) El espejismo del 64, Santiago, Imprenta Victoria.

Waiss, Oscar (1986). Chile vivo: memorias de un socialista 1928-1970, Madrid, Centros de Estudios Salvador Allende.

\section{Documentos}

\section{Archivo del Congreso Nacional de Chile}

\section{Fondo Folletos Políticos}

Informe de Luis Corvalán al Pleno Nacional del Partido Comunista de Chile. Derrotemos al imperialismo y sus gerentes. 1961.

PCCh. Documentos del XIII Congreso del Partido Comunista de Chile. 1965.

\section{Fondo Alejandro Hales}

FRAP. Un camino nuevo para Chile: el programa del gobierno popular. 1958.

\section{Fondo Partidos Políticos}

PCCh. Informe del Comité Central al XII Congreso del PCCh. Hacia la conquista de un gobierno popular. 1962.

PCCh. Esta y no otra es la política de los comunistas. Discurso de Luis Corvalán. 04.08.1964.

PCCh. Curso elemental sobre el Partido. 1965.

PCCh. Unidad socialista comunista cimiento del movimiento popular. 1965.

PCCh. La clase obrera centro de la unidad y motor de los cambios revolucionarios. 1965.

PCCh. La juventud chilena junto a la clase obrera por la revolución. 1965.

PCCh. El Partido Comunista reafirma la línea de su XIII Congreso Nacional. 1966.

PCCh. Respuesta del Partido Comunista al Partido Socialista: nuestros caminos conducen al socialismo. 1966.

PCCh. Informa de Luis Corvalán. Unión de las fuerzas revolucionarias y antiimperialistas de América Latina. 1967. 
PCCh. Informe de Luis Corvalán. Lo internacional en la línea del PC. 1973.

\section{Instituto Humanista Cristiano Juan Pablo Terra}

PDC (1960). Documentos de la Primera Convención Nacional. Santiago de Chile.

PDC (1962). El a, b, c de la Democracia Cristiana. Cuadernos de divulgación doctrinaria, Concepción, Cuadernos de divulgación doctrinaria, Instituto de Estudios Políticos del PDC en Concepción

PDC (1963). La Revolución, la Democracia y el Movimiento Popular. Respuesta a los Partidos Comunista y Socialista, Santiago de Chile, Editorial del Pacífico.

PDC (1963). II Congreso de la Juventud Demócrata Cristiana, Santiago, Ed. El diario ilustrado.

JDC (1965). Ayer una marcha, hoy una revolución, Santiago, Ediciones Rebeldía, Publicación del Departamento de Relaciones Públicas.

PDC (1966). Segundo Congreso Nacional. Informe: El programa de la Revolución en Libertad y su cumplimiento. Santiago de Chile.

PDC (1967). El pueblo responde!, Santiago de Chile, Editorial del Pacífico.

PDC (s/f). El abc de la Democracia Cristiana, Uruguay.

PDC (1970). ¿Por qué el Frente Amplio?, Montevideo, Secretaría Nacional de Propaganda del PDC.

PDC (1971). Por qué impulsamos el Frente, Montevideo, Secretaría Nacional de Propaganda del PDC.

JDC (1969). Bases para una opción revolucionaria, Montevideo, JDC.

JDC (1970). Frente Amplio para unir al pueblo, Montevideo, JDC.

Frente del Pueblo (1971). Manifiesto del Frente del Pueblo, Montevideo, Secretaría Nacional de Propaganda del PDC, 8 de enero de 1971.

Frente del Pueblo (1971). Por un frente sin exclusiones, Montevideo, Cuadernos de Marcha Nro. 46, febrero de 1971.

Frente Amplio (1971). Declaración constitutiva del Frente Amplio, Montevideo, Cuadernos de Marcha Nro. 46, febrero de 1971.

Frente Amplio (1971). Bases programáticas de la Unidad, Montevideo, Cuadernos de Marcha Nro. 46, febrero de 1971.

Frente Amplio (1971). 30 primeras medidas de Gobierno, Montevideo, Cuadernos de Marcha Nro. 53, setiembre de 1971.

PDC (1973). El pensamiento de la Democracia Cristiana. Dimensiones del socialismo comunitario, Santiago de Chile, Dirección nacional de capacitación doctrinaria.

\section{Centro de Documentación e Investigación de la Cultura de Izquierdas (CeDInCI)}

Boletines del Secretariado Latinoamericano de la Internacional Socialista (1956-1967) 


\section{Ministerio de Relaciones Exteriores de Chile. Archivo General Histórico. Embajada de Chile en Uruguay. 1958-1969.}

Ministerio de Relaciones Exteriores de Uruguay. Archivo Histórico- Diplomático. Embajada de Uruguay en Chile. 1958-1960.

\section{Prensa}

Revista "Estudios”. PCU. 1956-1970

Revista “Principios”. PCCh. 1956-1970

“E1 Popular”. PCU. 1956-1970

"El Siglo". PCCh. 1956-1970

"El Sol” 1956-1967

“Arauco" 1959- 1967

El ciudadano (1962-1964)

De Frente (1965-1967)

Encuentro (1971)

\section{Entrevistas}

Carlos Baráibar, realizada por la autora en Montevideo. Fecha: 26.07.2016.

Carlos Pérez, realizada por la autora en Montevideo. Fecha: 12.05.2016.

Carlos Riverós, realizada por la autora en Montevideo. Fecha: 23.09.2016.

Eduardo Aparicio, realizada por la autora en Montevideo. Fecha: 25.07.2016.

Guaraní Pereda, realizada por la autora en Santiago. Fecha: 10.04.2015 (Primera parte) y 15.04.2015 (Segunda parte).

Héctor Lescano, realizada por la autora en Buenos Aires. Fecha: 15.10.2016.

Jorge Mazzarovich, realizada por la autora en Montevideo. Fecha: 12.09.2016.

Jorge Rodríguez, realizada por la autora en Montevideo. Fecha: 17.05.2016.

José Díaz, realizada por la autora en Montevideo. Fecha: 12.09.2016.

José Luis Veiga, realizada por la autora en Montevideo. Fecha: 13.09.2016.

José Pereira, realizada por la autora en Montevideo. Fecha: 19.09.2016.

Juan Trímboli, realizada por la autora en Santiago. Fecha: 28.04.2015.

Julio Louis, realizada por la autora en Montevideo. Fecha: 14.09.2016.

María Elena Martínez, realizada por la autora en Montevideo. Fecha: 13.09.2016. 
Mauricio Langón, realizada por la autora en Montevideo. Fecha: 20.09.2016. Miguel Millán, realizada por la autora en Montevideo. Fecha: 20.05.2016. Miguel Vasallo, realizada por la autora en Montevideo. Fecha: 22.09.2016. Moriana Hernández, realizada por la autora en Montevideo. Fecha: 28.07.2016 Luis Senatore, realizada por la autora en Montevideo. Fecha: 13.09.2016 Raúl Legnani, realizada por la autora en Montevideo. Fecha: 16.05.2016. Roberto Markarián, realizada por la autora en Montevideo. Fecha: 19.05.2016. 